\title{
THEORY OF PULSE FORMING NETWORK DESIGN FOR ACCELERATION WAVEFORM TIME DOMAIN REPLICATION
}

\author{
A DISSERTATION IN \\ Electrical Engineering \\ Presented to the Faculty of the University \\ of Missouri-Columbia in partial fulfillment of \\ the requirements for the degree \\ DOCTORATE OF PHILOSOPHY
}

by

ERIK JOSEPH TIMPSON, P.E.

B.S.E.E., University of Missouri-Rolla, 2004

M.S.E.E., University of Missouri-Kansas City, 2011

Columbia, Missouri

May 2014 
The undersigned, appointed by the dean of the Graduate School, have examined the dissertation entitled

\section{THEORY OF PULSE FORMING NETWORK DESIGN FOR ACCELERATION WAVEFORM TIME DOMAIN REPLICATION}

Presented by Erik J. Timpson, a candidate for the degree of doctor of philosophy, and hereby certify that, in their opinion, it is worthy of acceptance.

Dr. Thomas G. Engel (Advisor)

Dr. John Farmer

Dr. Naz Islam

Dr. Stephen Montgomery-Smith 


\section{ACKNOWLEDGEMENTS}

Where did I begin? This question, one of the most fundamental and profound questions that philosophers have dealt with and even died for is just the first question and not to the point. Who was there helping me? Who continued to be there throughout? Who will never leave me? These questions are to the point. Truly, the list of names is not only expansive but also expanding, as I believe in everlasting life - with Jesus, I will not end. I consider this belief and my ability to express it quite a privilege. That said I generally categorize my gratification to three groups of people.

To God, family, and friends, I love you. This dissertation would not have been created if it were not for you. Your never-ending love, your tireless patience, your forgiveness, your hugs, your handshakes, your exciting fun filled laughter, every moment we share is a gift so great. Just reflecting on this gift drives a hot smile stretching across my face cooled only by my tears of joy.

To my advisors, colleges, and engineers who had a hand in the work. The greatest of these is Dr. Engel. He is the giant I stand on. He taught me so much in the way of freedom, engineering, economics, fabrication techniques, the list goes on, the debt cannot be repaid, but rather I'll do my best to pass it on. To the rest of this category, your contributions have been numerous and this work would not be complete without you - Thank You.

To the readers and appliers of the work and ideas presented here. With you, the work can

continue to live. I hope you have as much fun as I did in exploring this new world. Enjoy, and if questions arise, please find a way to contact me - I am here to help you. 


\section{CONTENTS}

ACKNOWLEDGEMENTS ................................................................................... ii

LIST OF ILLUSTRATIONS ........................................................................................ vii

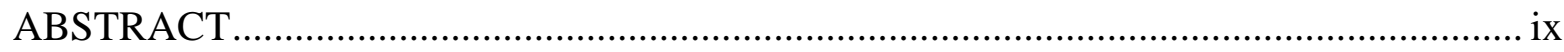

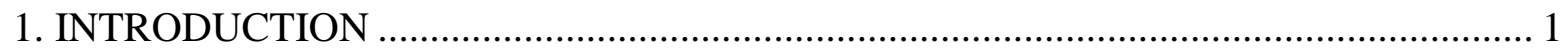

1.1 Why one should read this dissertation ........................................................ 1

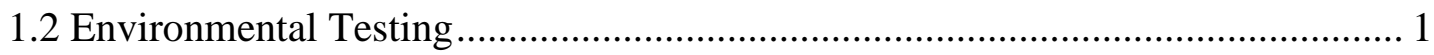

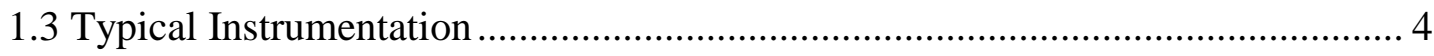

1.4 Problems Associated with Typical Instrumentation ......................................... 10

1.5 Creative Proposal to Solve the Problems......................................................... 10

1.6 Previous Work Supporting the Proposal ..................................................... 11

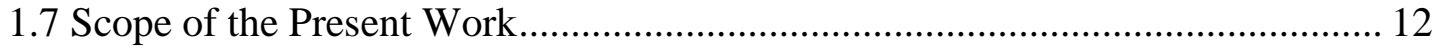

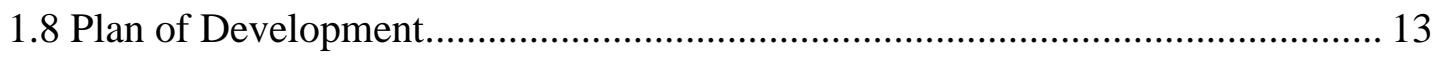

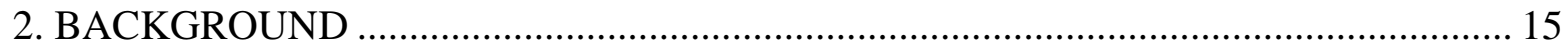

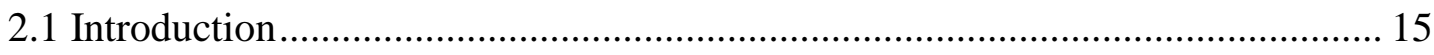

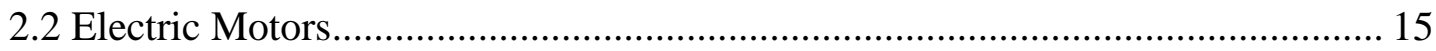

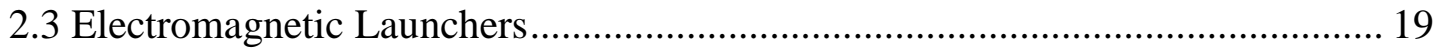

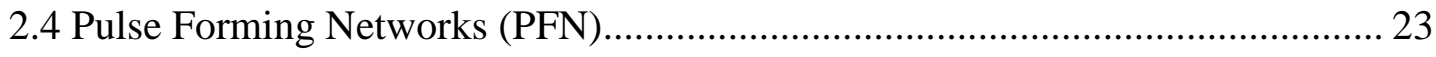

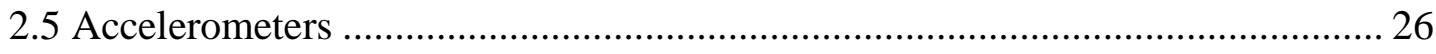

2.6 Engineer’s Expectations and the Uncertainty target ..................................... 28

3. THE PROPOSED THEORY AND ALGORITHM ….............................................. 31 
3.1 Pulse Shapes and Solution Approaches ................................................................. 31

3.2 Time and Frequency Domain Contribution ........................................................... 33

3.3 Modeling an Electric Launcher........................................................................... 37

3.4 Energy Domain Contribution................................................................................. 41

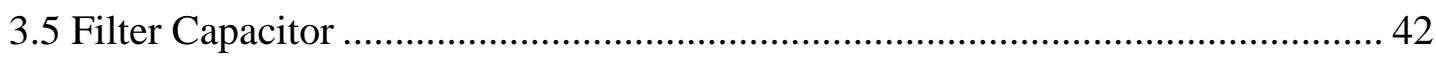

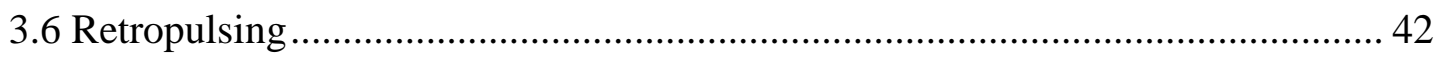

3.7 The Algorithm............................................................................................... 43

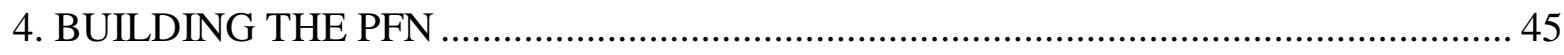

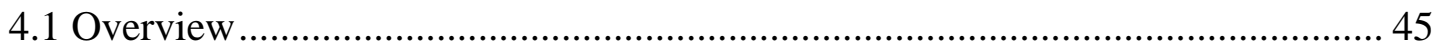

4.2 Safety Systems and Power Distribution............................................................... 50

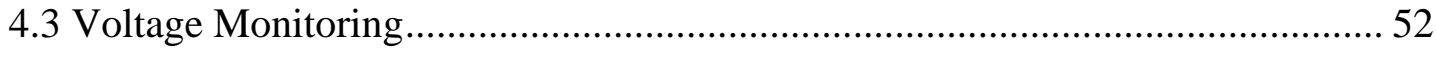

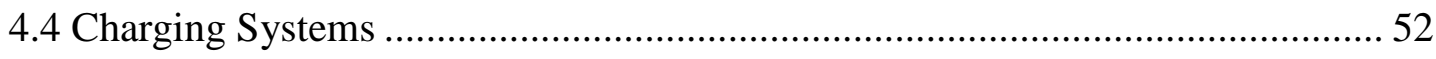

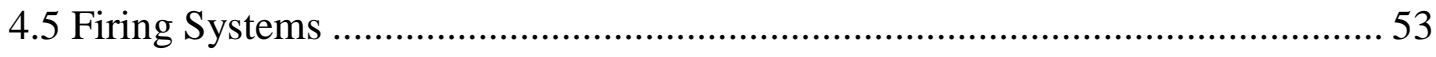

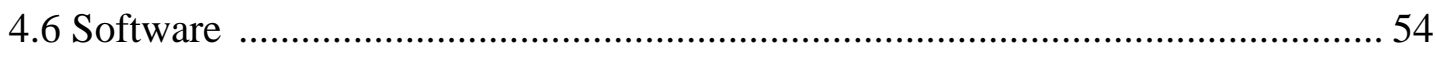

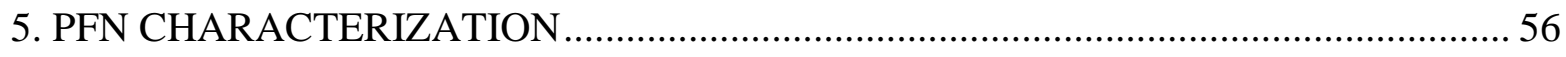

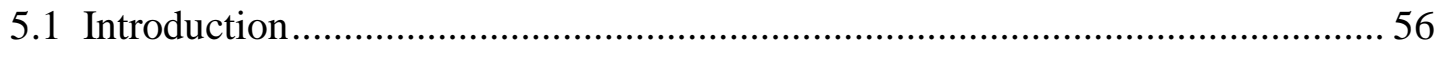

5.2 Peak Current Pulse and Inductive Gradient Distribution........................................ 56

5.3 Initial L \& C Assumption verification Diode effect .............................................. 58

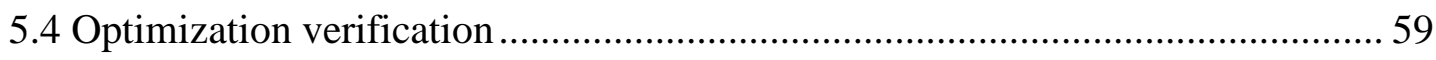

5.5 Synchronous Firing Verification........................................................................... 61

5.6 Simultaneous Firing Verification....................................................................... 61

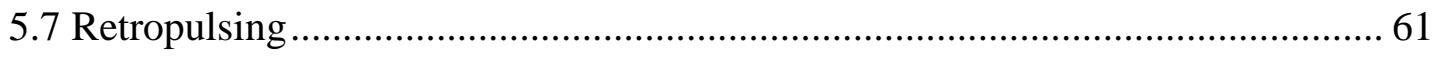




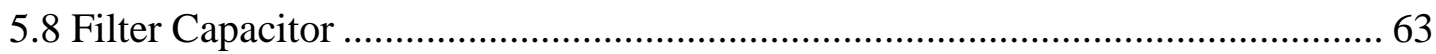

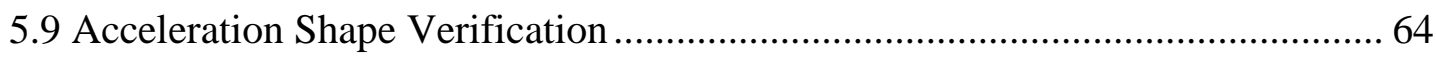

5.10 Considering Repeatability and Maintenance ………………................................ 68

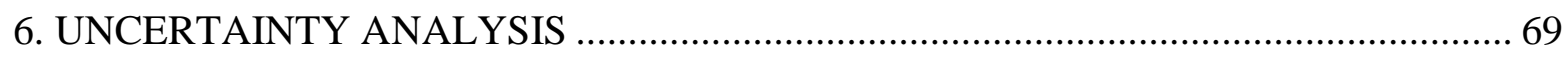

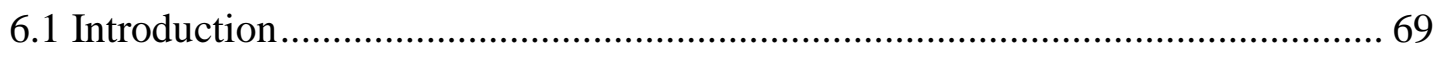

6.2 The Acceleration Measurement .......................................................................... 70

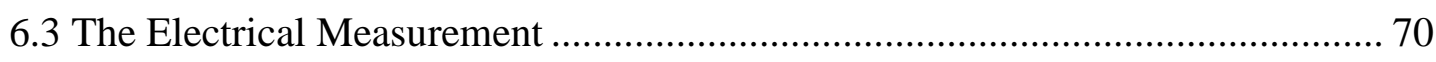

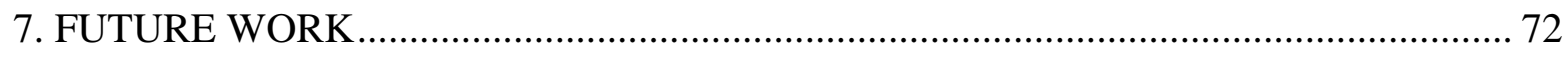

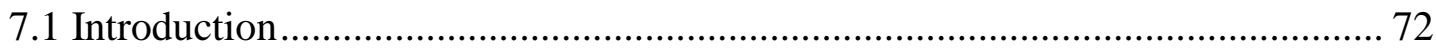

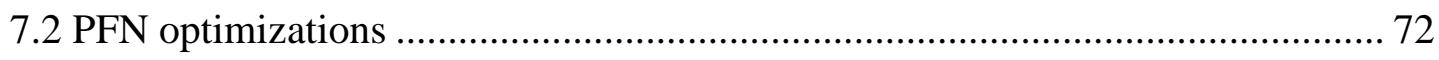

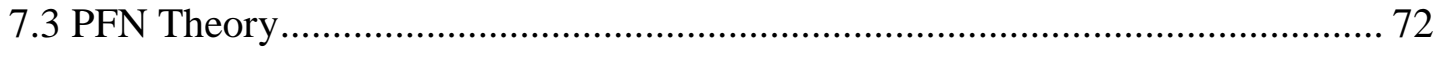

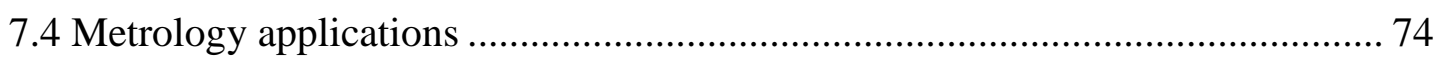

7.5 Reversible HEML …………………………………................................... 74

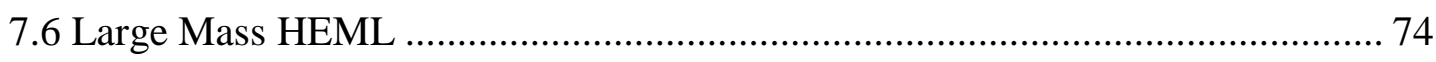

7.7 Micro/Nano HEML..................................................................................... 75

8. SUMMARY AND CONCLUDING MARKS................................................................. 76

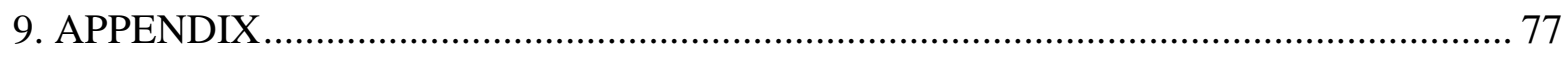

9.1 WHAT A SHOT LOOKS LIKE ........................................................................ 78

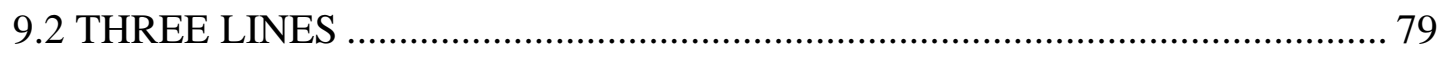

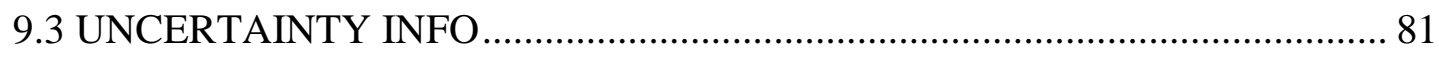

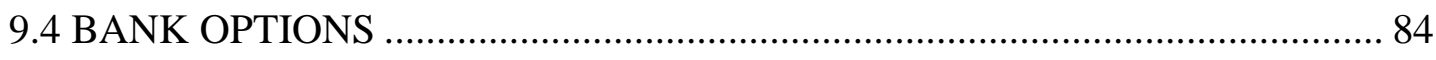

9.5 DIODE CONFIGURATIONS ....................................................................... 87 
9.6 SIMPLE RLC CIRCUIT ……………………………................................. 90

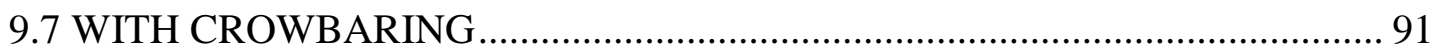

9.8 WITH FILTER CAP ................................................................................... 92

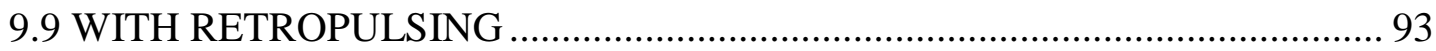

9.10 WITH RETROPULSING FOR SAWTOOTH ................................................. 94

9.11 WITH RETROPULSING FOR TRIANGLE .................................................. 95

9.12 CIRCUITE BOARD PICTURES AND SCHEMATICS ..................................... 96

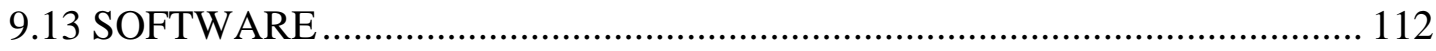

9.14 PICTURES OF PULSES 1-62 ................................................................... 127

9.15 THE PFN COMPARED TO PIANO AND OTHER INSTRUMENTS........... 189

9.16 UNITED STATES GOVERNMENT CLAIM ................................................... 191

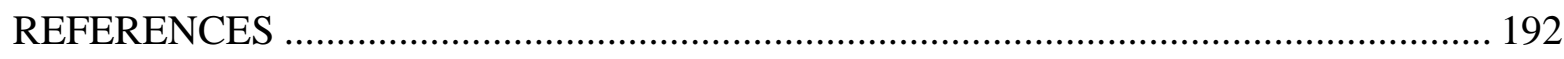

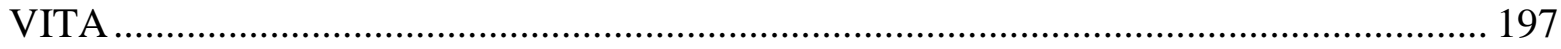




\section{ILLUSTRATIONS}

Figure Page

$1.1 \quad$ Typical Chambers, right picture [3].................................................................... 5

1.2 Inside the chambers in Figure 1.1, right picture [3].................................................. 5

1.3 (a) Pneumatic, (b) Drop, and (c) Bungee assisted mechanical shock testers [4]......... 6

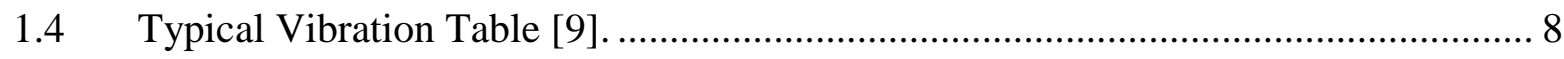

1.5 Temperature, Vibration and Humidly in one instrument [10] .................................... 9

1.6 Multi-Axis Table left [11], right [12] ……………............................................... 9

$1.7 \quad$ The Pulse Forming Network ……………….............................................................. 13

2.1 Example of a DC Electric Motor, (a) as seen, (b) simplified side views and table of unit vectors.......................................................................................... 17

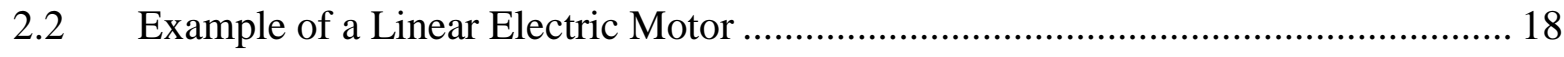

2.3 Working principle of Coil Gun as compared to Magnets …...................................... 20

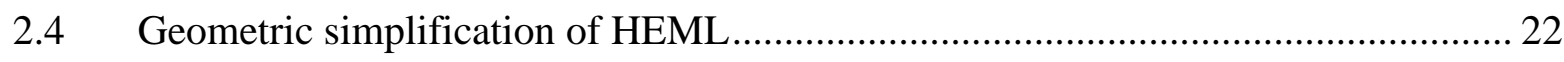

2.5 Mountable Electric Launchers Design Concepts ......................................................... 23

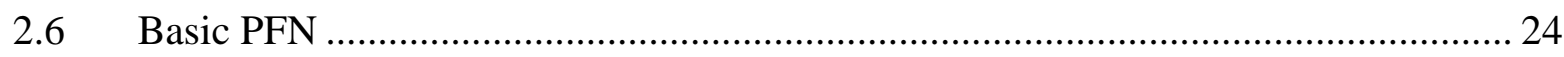

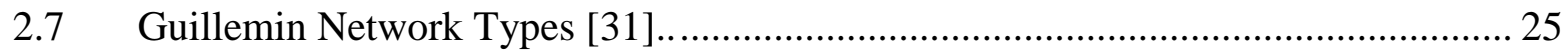

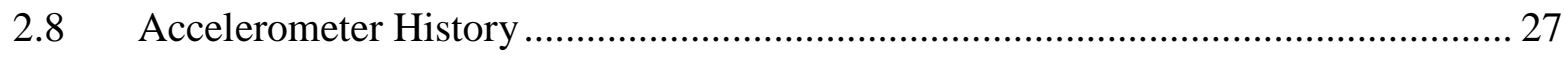

2.9 Typical Verified Range for an Accelerometer......................................................... 28

$2.10 \quad$ Target Amplitude and Duration ................................................................................ 29

3.1 Wavelet Decomposition of Pulse shapes ................................................................... 33 


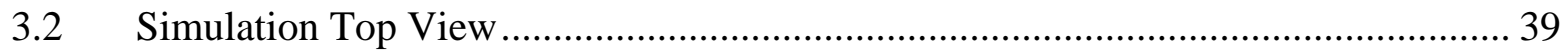

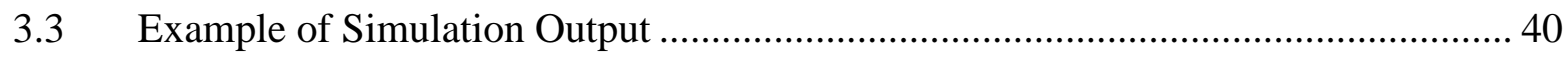

3.4 The Timpson Algorithm for selecting PFN Components and Conditions.................. 44

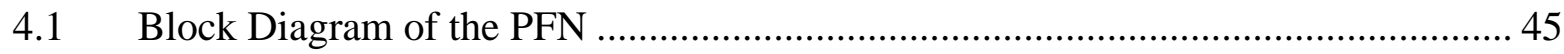

4.2 Block Diagram of Every Component ………………............................................. 46

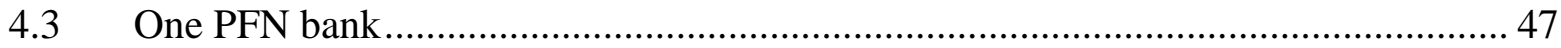

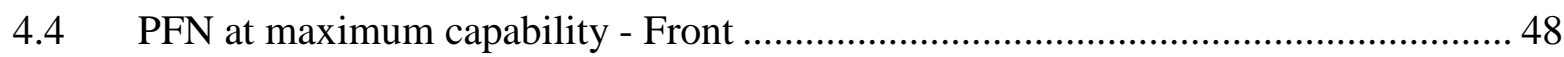

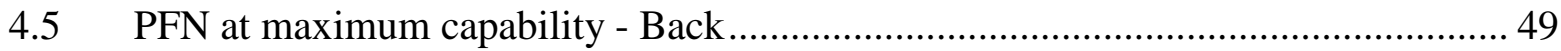

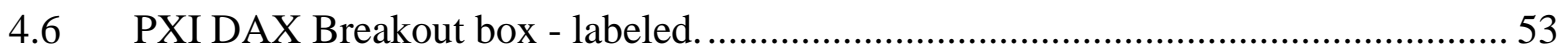

4.7 Front Panel of PFN Software ................................................................................... 55

$5.1 \quad$ Electrical Measures of the PFN shots …………..................................................... 57

$5.2 \quad$ Histogram and Normality Test of Calculated $\mathrm{M}^{\prime}$..................................................... 58

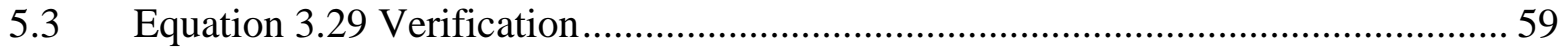

5.4 The Three lines on a Map of the Acceleration world ................................................... 60

5.5 Retropulsing verification Shot 43 (red) vs. Shot 44 (blue) ......................................... 62

5.6 Filter Cap Verification, Shot 50 (red) vs. Shot 49 (blue)........................................... 63

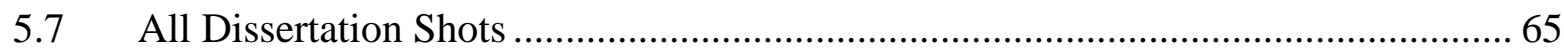

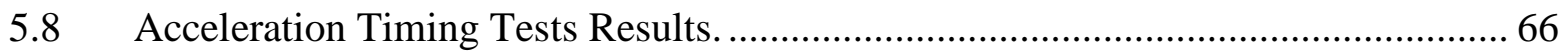

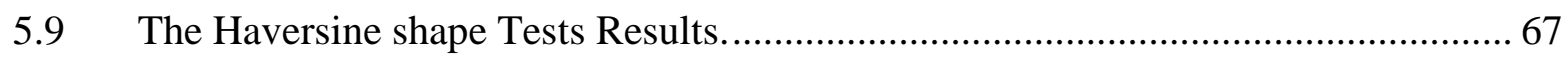

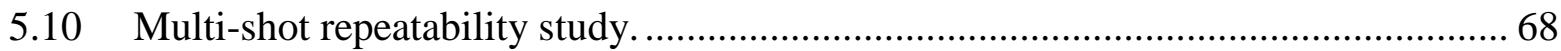

7.1 Algorithm with indication of experimental verification. ............................................. 73 


\title{
THEORY OF PULSE FORMING NETWORK DESIGN FOR ACCELERATION WAVEFORM TIME DOMAIN REPLICATION
}

\author{
Erik Joseph Timpson, Candidate for the Doctor of Philosophy Degree
}

University of Missouri-Columbia, May 2014

\begin{abstract}
A Pulse Forming Network (PFN) was built and optimized using an Algorithm based on theory and experimental data. The target load for the PFN was a Helical Electromagnetic Launcher. The target application of the launcher is Environmental Testing - mechanical shock time domain replication. The new Algorithm that was used combines time, frequency, and energy domain methods to restrict the solution space before optimization. As in many other applications, the final optimization was done though experimental trial and error. The PFN ultimately met the repeatability and uncertainty targets specified by environmental engineers.
\end{abstract}




\section{CHAPTER 1}

\section{INTRODUCTION}

\subsection{Why one should read this dissertation}

This dissertation is a deep dive in electrical engineering and mechanical engineering, tunneling from the depths of one to another, liberating one side to another for the benefit of mankind. Beyond that simplification, there are three good reasons to read this dissertation. First, to give perspective not just on the sheer number of engineered devices around you, helping you, protecting you, but that they all have to be soundly tested for their respective environments. Second, because this document clearly shows the second industrial application for electromagnetic launchers - Shock Testing. Third, because this research shows the promise of Electromagnetic Launchers to not just revolutionize Shock Testing as a part of environmental testing but also in many other Industrial areas.

\subsection{Environmental testing}

In 2013, there were 6.8 billion mobile-cellular subscriptions compared to a population of 7.1 billion people [1]. This does not include radios, portable computers, global positioning systems and many other devices. Someone influences these devices by considering possible environments. After consideration, in the development cycle, these devices undergo environmental testing to ensure that the expectations for performance are well founded.

Environmental testing can vary wildly from a detailed scientific cocktail of organic compounds to a simple drop on a concrete floor. A long but not exhaustive list includes: 
temperature cycling, temperature shock, mechanical shock, vibration, salt fog, dust, chemical resistance, humidity, submersion, solar radiation, and extreme pressures. When environmental testing becomes useful is not just when each of these environments are tested alone but when they are combined. For example, Highly Accelerate Life Testing (HALT) or a Highly Accelerated Stress Screen (HASS), accomplishes this by combining different testing into a single harsh test. Using important conclusions from environmental testing, with a carefully constructed prescription of sequencing environmental testing combinations, one can predict future outcome.

This dissertation will focus on mechanical shock, and some vibration, but ultimately not lose sight of the other environmental testing areas listed above. By considering the typical instrumentation used to produce the environmental tests listed above, one can gain understanding as to the desired visibility. Said differently, by considering the size of instrumentation alone one can understand, for example, if vibration instrumentation will fit into a dust chamber. Obviously, size alone is not the only consideration as most vibration equipment cannot itself survive in harsh dust environments; and so, one should consider many factors.

The cost of environmental testing is another important consideration. Obviously, for a product with total cost less than a few dollars one can keep durability in mind when designing it, but rarely would add additional cost to ensure its longevity. The additional cost of environmental testing can be thought of in terms of time, material, and equipment. Time, of the engineer to determine what test should be run, of the technician to setup and run said tests, of the engineer to report on any findings. Examples of material include fluorinert for temperature shock, or delrin for mechanical shock. The equipment or instrumentation alone is a significant capital investment. 
All that said, when considering mechanical shock and vibration, the most important reason to be less than satisfied with existing environmental testing equipment is the inability to do true Time Domain Waveform Replication (TDWR). One can, using mechanical programmers, excite a test article to varying acceleration pulses typically haversine in shape only one pulse at a time. One can also consider a complicated sequence of events in the time domain - say a car moving down a road and then hitting a pothole, truing sharply to the right, and slamming on its breaks. Then take the acceleration data from that sequence, analyze it's frequency content, and perform a vibration test that should have the appropriate amount of acceleration for each frequency - but all the while have to rig the test so as to have a zero displacement so as not to break the shaker. It goes without saying the obvious from a Digital Signal Processing perspective - the frequency to time conversion is not mathematically One-toone and Onto. Said differently, there are multiple frequency domain solutions for a single time domain solution.

What would be more idea for the same car example is to specifically replicate the acceleration phenomena in the time domain - TDWR. Rather than needing to do this for every acceleration event (say the total displacement here could be a mile), one could cut off low acceleration events and replicate with some vibration, the pothole and slamming on the breaks (total displacement would be about a meter, multiple shock pulses). Before the research documented in this thesis, there would have been no way to replicate this acceleration waveform in the time domain - without a considerable investment. But wait, before we get into new instrumentation let's review typical instrumentation. On the order of this complexity consider the VITS machine developed by Lansmont [2]. 


\subsection{Typical Instrumentation}

For the sake of brevity, I will not talk about salt fog, dust, chemical resistance, humidity, submersion, solar radiation, and extreme pressures instrumentation. The most one must understand from all these examples are that there is a region in which that test article must fit. The test much fit into a 'small' controlled environment. This is most easily understood with Temperature cycling. Here, an adiabatic chamber is desired with a heating or cooling element to

precisely control the temperature. For temperature shock, two chambers must be located next to one another in order to quickly shift the sample from one to another. Note that temperature shock can be done a number of ways not just with two chambers. But to close the thought with a simple example, think of a freezer next to an oven. One could take a test article out of the freezer and put it into the oven, or vice versa. The point is again that the oven and freezer are a confined size. Meaning, if one wanted to test something larger than the smaller of the two, oven or freezer, they would be out of luck. Typical maximum size to consider is a 4 foot square box Figures 1.1 and 1.2. 


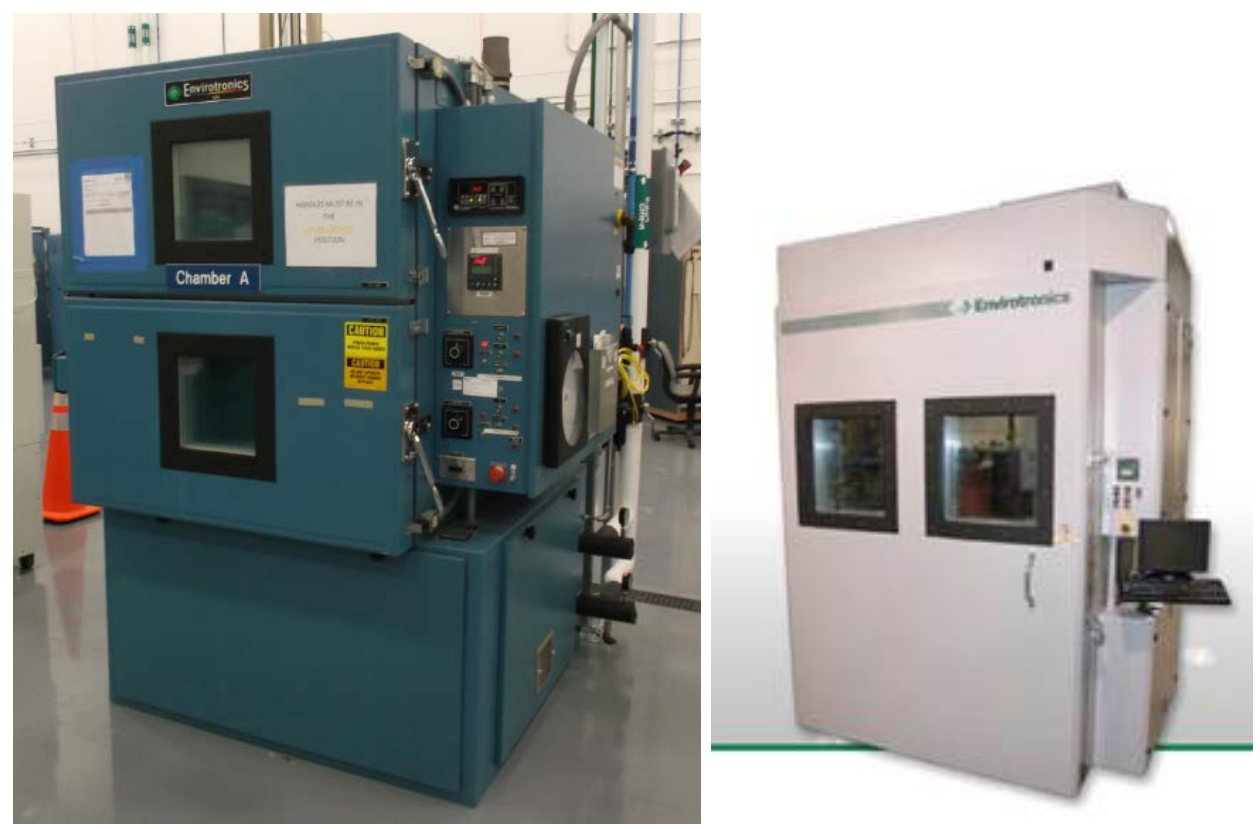

Figure 1.1: Typical Chambers, right picture [3].
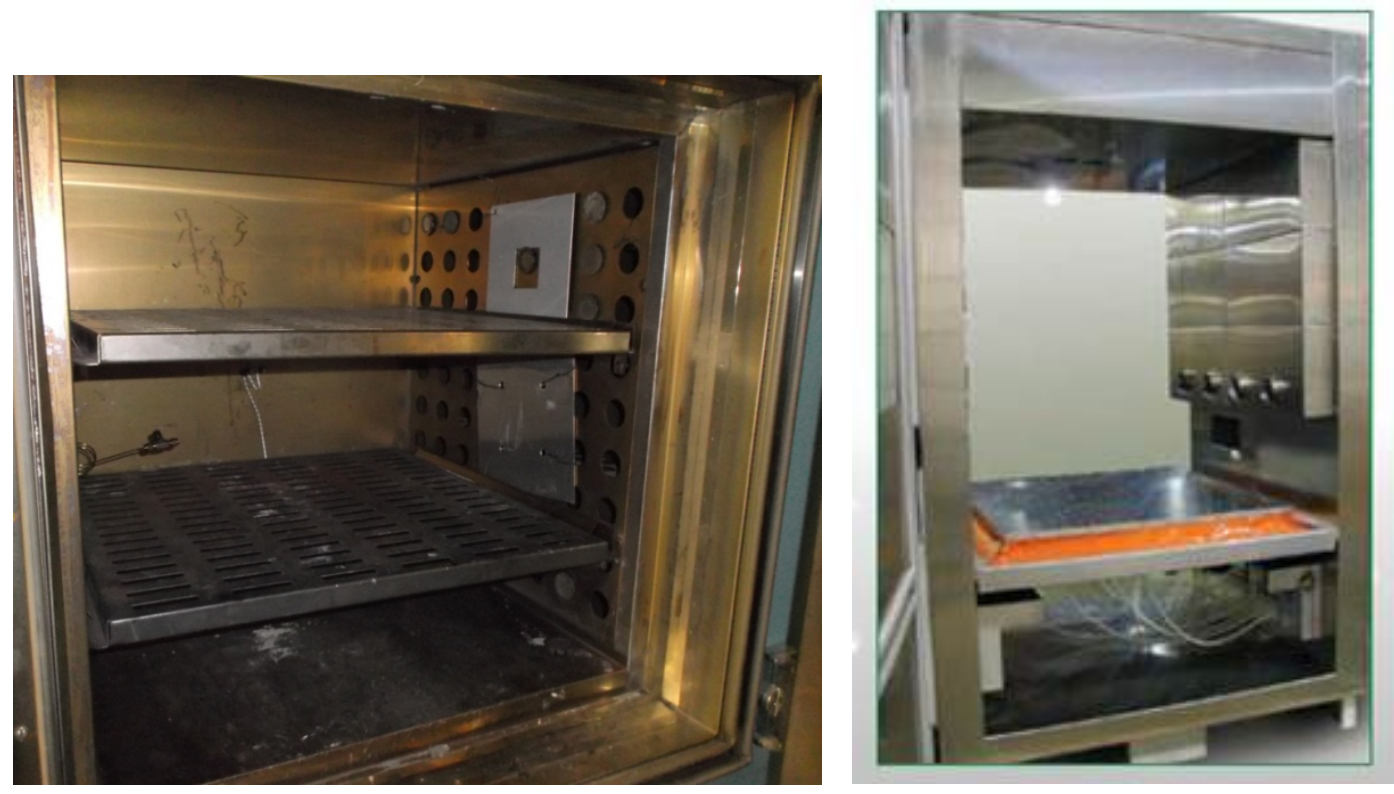

Figure 1.2: Inside the chambers in Figure 1.1, right picture [3]. 


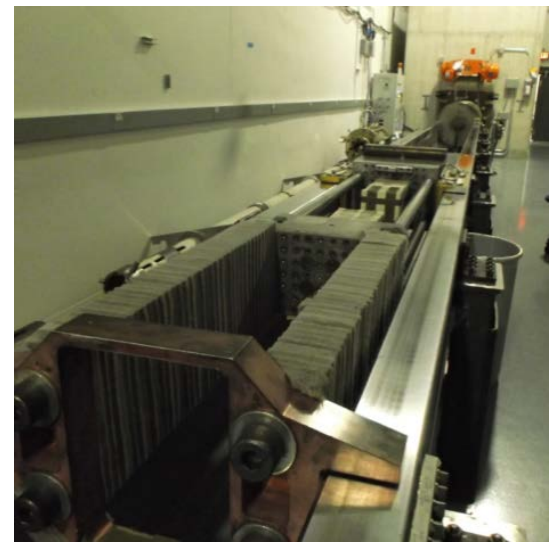

(a)

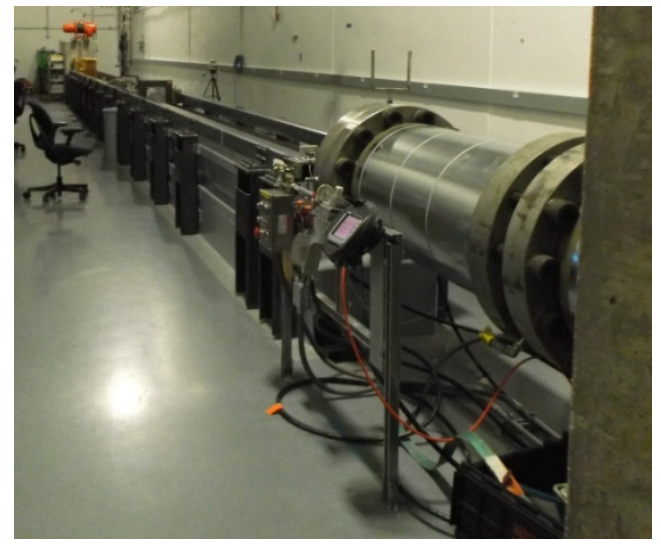

(a)

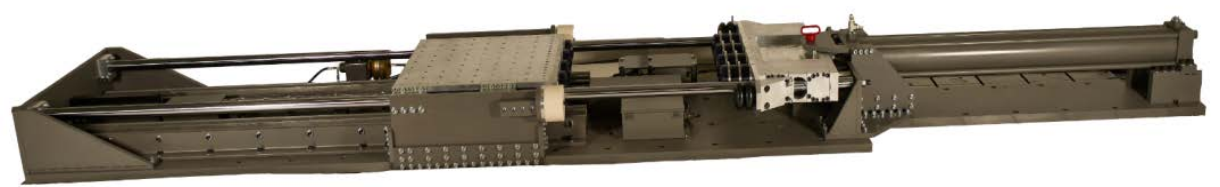

(a)

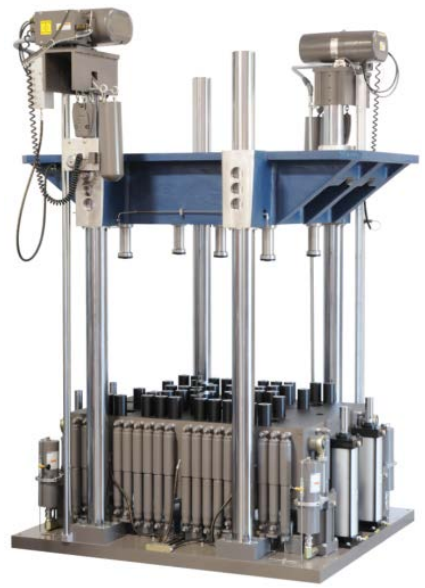

(b)

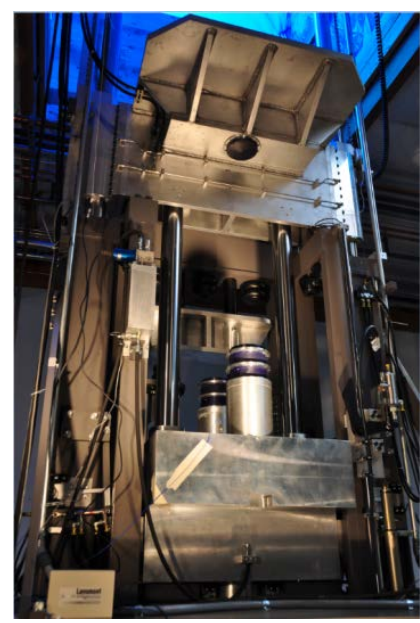

(b)

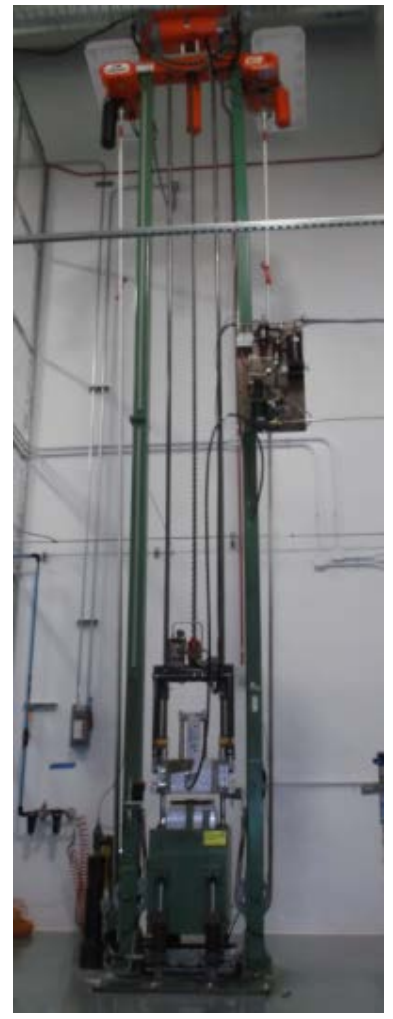

(c)

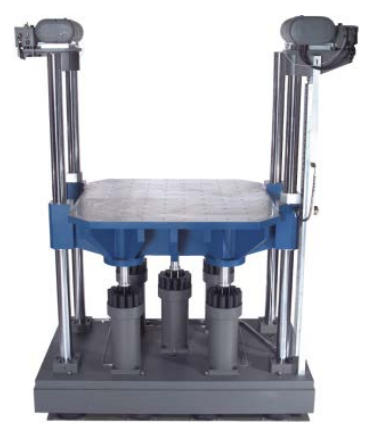

(b)

Figure 1.3: (a) Pneumatic, (b) Drop, and (c) Bungee assisted mechanical shock testers [4].

Now let us turn to Mechanical shock. Most of the instrumentation used to produce a mechanical shock is large and uses pneumatics or bungee cords to produce the force - Figure 
1.3. Tall towers and loud compressors are behind the largest acceleration pulses and great velocity changes in laboratories these days [5,6]. In the 2005 and 2007 handbooks, no electromagnetic solutions were documented for mechanical shock $[7,8]$.

This instrumentation takes up a lot of space and, in my opinion, could gain much from the technological advances that have been made in the last decade. Simply because of the fact that if one wanted to combine mechanical shock and any other test as listed above, for example an extreme temperature, one is left with the notion they have to build a very large oven or freezer. Alternatively, transfer the test article from an oven or freezer as fast as possible into the ambient temperature room where the shock tester sits. Because of how unlikely testing like that is, and because of the close link between vibration and shock, people have turned to testing systems like HALT or HASS. A much deeper discussion as to why a transducer like an accelerometer, and further, a test article, is in need of both vibration and shock is in section 2.5. For now, we shall say that it is important for not just vibration, but also that shock must be evaluated.

Vibration instrumentation is a very fun topic to discuss. If at all possible, learn about vibration and shock testing from Mr. Wayne Tustin. With vibration instrumentation, we have seen, as in the transfer from steam trains to electric trains, an adoption of technology. Specifically electrical technology had given rise to the complex and necessary world of vibration testing. We shall start with the shaker. If one does not understand how these work they should review a simple speaker construction and be assured that this has exactly the same workings. They work by creating two opposing or attracting magnetic fields where one of the fields producers is held fixed and the other is allowed to move carrying a diaphragm or test article table 
with it, resulting in a prescribed motion dictated by the electrical field that was used to create the magnetic fields to begin with. Now there are many types of shakers, but most work off the principle just described - Figure 1.4. Some have made the bottom of a climatic chamber the shaker - Figure 1.5. To model the most realistic vibration setups use three shakers, one for each $\mathrm{x}, \mathrm{y}$, and $\mathrm{z}$ - Figure 1.6. Counting yah, pitch, and roll, this equates to 16 degrees of freedom. Yet this complicity is sometimes necessary for accurately simulating the environment or it can reduce time by allowing one test to be run, rather than three tests.

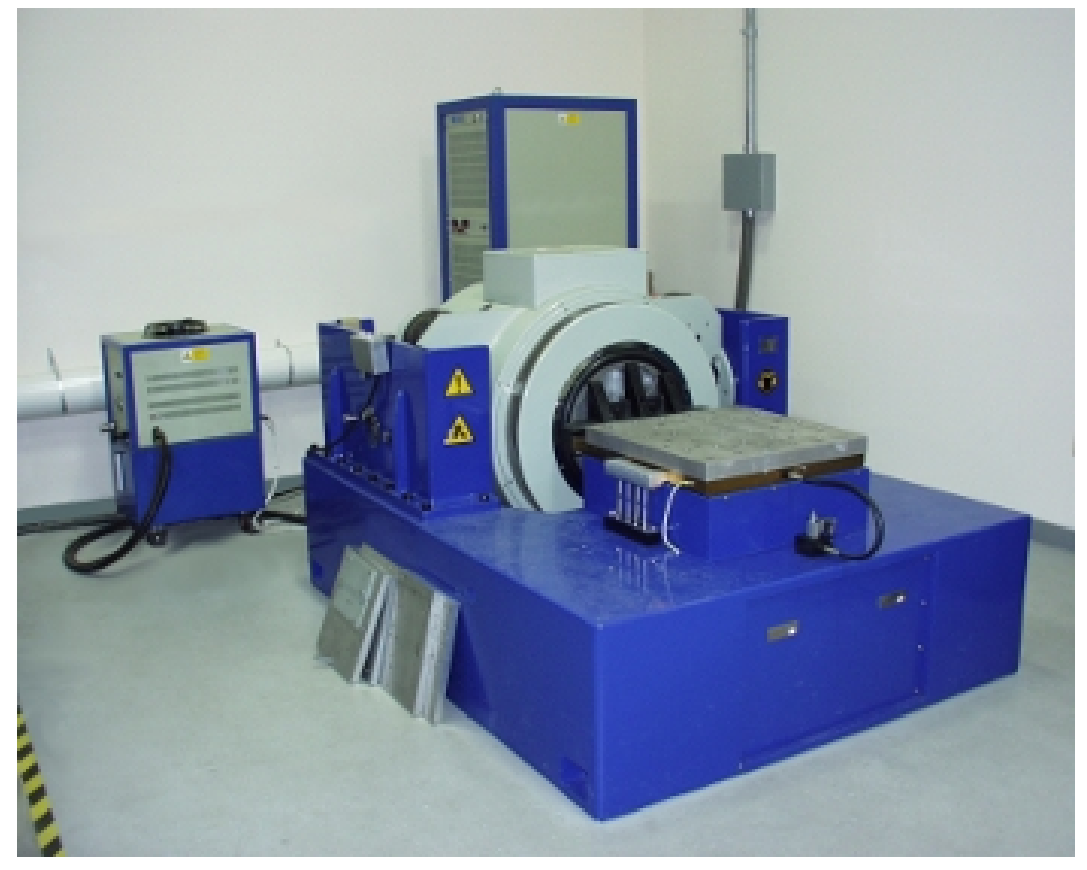

Figure 1.4: Typical Vibration Table [9]. 


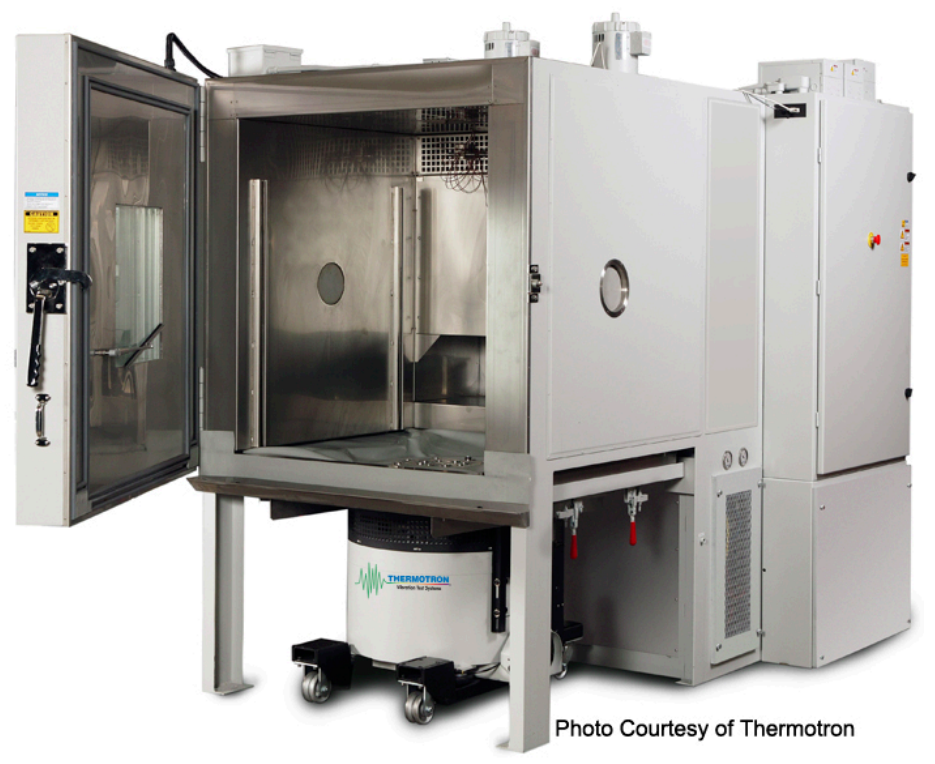

Figure 1.5: Temperature, Vibration and Humidly in one instrument [10].
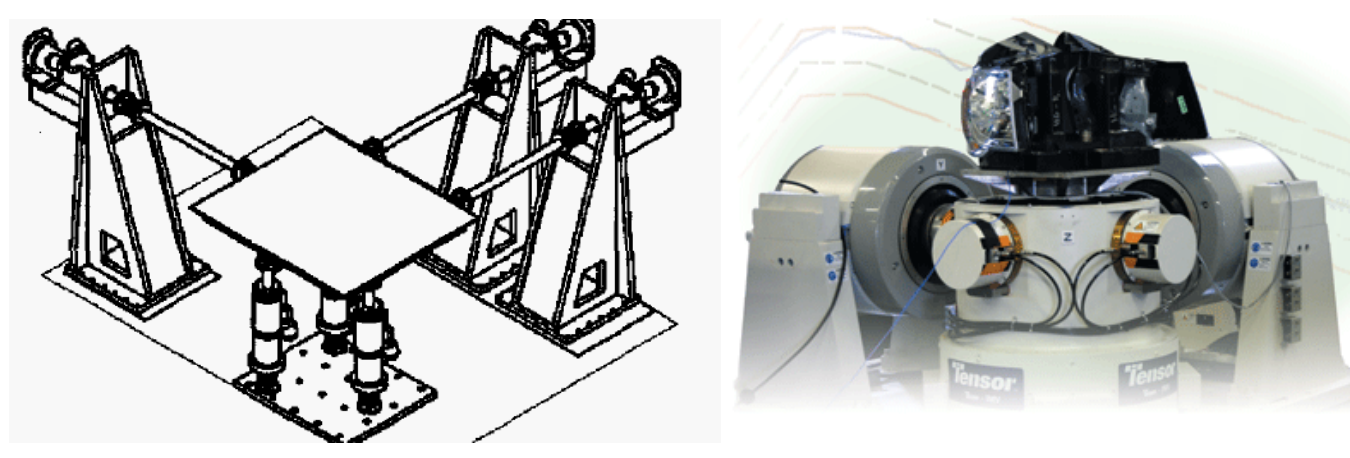

Figure 1.6: Multi-Axis Table left [11], right [12].

Next, we move to the control system of the shaker. Here much work has been done to ensure that the electrical signal and in turn the mechanical signal is exactly what it needs to be. To determine "what it needs to be” means one has a good understanding the shock event and specifically the Shock Response Spectrum (SRS). SRS is a graph of how a single degree of freedom system responds to the shock event input. In other words, it is what peak shock 
amplitudes are at what frequencies. Tom Irvine has a wonderful course devoted to this topic. For the control system it is not only important to know what the shock should be but the feedback of what the shock is currently. If this information is available, then there are clever algorithms to deal with the multi-shaker control [13].

\subsection{Problems Associated with Typical Instrumentation}

To the point of this section, we have highlighted that the problem of large instrumentation is the inability to be easily incorporated simultaneously with another instrument. This does not mention the cost of a facility square footage, which is not negligible. Not previously mentioned is the inability of mechanical programmers to deliver repeatable long duration large amplitude shock events. Also not mentioned is the long setup time for mechanical programmers. Mentioned is the cost of mechanical programs, but further developing reality is the fact that they degrade and are hard to characterize. For this reason, using mechanical programmers it is very difficult to automate the setup process. Further when using the actuation energy as gravity, bungee, or pneumatics one is left with tall towers and noisy compressors.

\subsection{Creative Proposal to Solve the Problem}

The proposal is to begin incorporating electromagnetic launchers into environmental testing, specifically for inducing mechanical shock pulses. By doing this, the first advantage is the ability to obtain higher velocities due to the intrinsic limitation of the speed of light not the speed of sound as with pneumatics. What follows also is not only the ability to create as long of an acceleration pulse as desired; but because of these higher amplitude longer duration pulses, a 
smaller over all footprint is required. This smaller footprint means that inducing a mechanical shock can be done in a small chamber or on a shaker. This means one does not need to rely on SRS accurately describing the event, as there are many time waves that could be represented by the same SRS. A pulse forming network (PFN) is the power supply for electromagnetic launchers. PFNs are quiet, unlike compressors. The PFN is also electronically adjustable, meaning it conforms nicely to the ideas one may have for automation. With an electromagnetic launcher, one now has a mechanism to transform from the current domain into the acceleration domain. This ability means that TDWR is possible so long as one can make the desired current pulse in the current domain.

\subsection{Previous Work Supporting the Proposal}

The most relevant papers to this dissertation were written in the 60's by a Sandia Engineer, Meagher [14,15]. It seems as though he had the very same idea. Unfortunately, he was using an inductivity coupled coil launcher and in turn was limited to shorter duration pulses. Perhaps this is one reason why more papers were not published on the subject. Or, more likely, perhaps funds were just no longer allocated to his project, as some other project took priority over it. The point is simply that the research seemed to stop. Luckily in the last decade electromagnetic launchers have had a considerable amount of research devoted to them. More information as to exactly what is meant by this can be found in Section 2.3.

A paper on calibrating accelerometers with electromagnetic launchers was written before this dissertation was conceived [16]. This paper marked the first industrial application of an electromagnetic launcher. In using the instrument clearly outlined in said paper, mechanical 
programs still made the processes more challenging. The launcher was the actuation device and it hit an anvil with the mechanical programmer. When using the instrument and being frustrated by the non-repeatability of mechanical programmers an epiphany struck the engineer. The epiphany - the launcher could program the shock pulses electrically.

The idea was then experimentally verified, [17] and documented in the paper titled "Experimental Evaluation of Helical Electromagnetic Launchers for Electronically Programmable Shock Pulses.” This paper sets up the dissertation nicely in that it shows the advantages of using an electromagnetic launcher to electronically program shock pulses. It should be noted that the advantages, without hard numbers, to justify the claims, need only for the technology to mature. At the time of writing this dissertation, the author considers the technology to be a Technology Readiness Level (TRL) to be less than three.

\subsection{Scope of the Present Work}

The scope of this work will be first to develop further the theory of pulse forming networks, specifically for TDWR (Chapter 3), next in describing the construction of a cutting edge Pulse Forming Network PFN (Figure 1.7, Chapter 4) and last to characterize this PFN in terms of current and acceleration given a certain type of launcher (Chapter 5). There will also be the necessary chapter for all experimental work (Chapter 6) - Uncertainty analysis. 


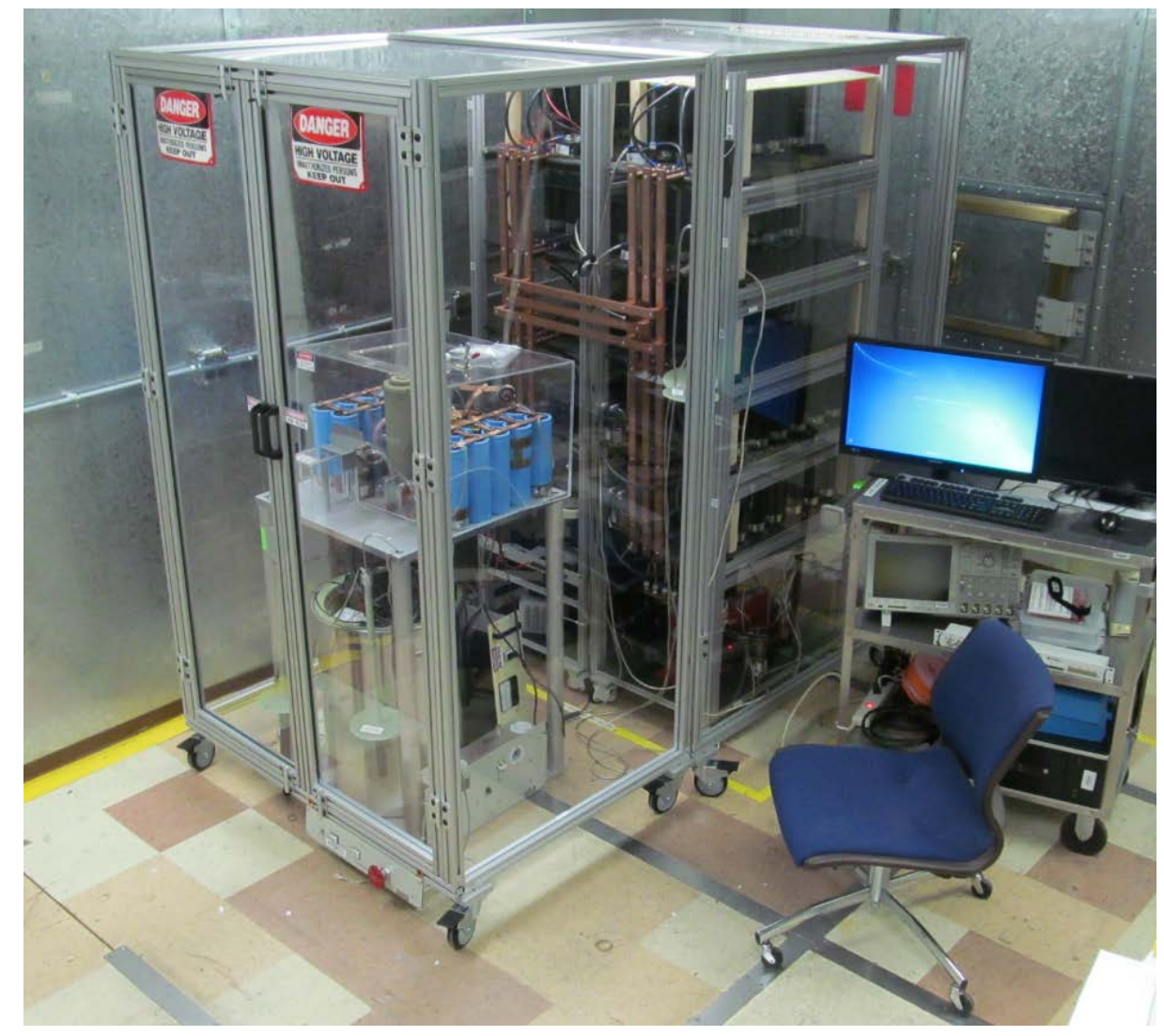

Figure 1.7: The Pulse Forming Network.

\subsection{Plan of Development}

After considering the application, proposed solutions and existing theory there is one very clear question that comes after considering the proposal. What is the best way to shape acceleration pulses? More specifically, what is the solution space of possible acceleration pulses given a PFN and Electro Magnetic Launcher (EML) with known characteristics? This question, as all well posed questions do, lead to many more: What shapes and sizes of acceleration pulses are most needed? What characteristics of the acceleration pulses are most important? How do these characteristics dictate PFN and EML characteristics? 
The plan starts with establishing a well-researched background on theory (Chapter 2). Next, consulting a seasoned group of industry experts with regard to the first of the derived questions (Section 2.5) - What shapes and sizes of acceleration pulses are most needed? Then, one can apply existing theory and adapt and create more theory in order to influence the construction process. The construction process was also influenced by the design of experiments. Meaning, after construction, the last step of the plan on development is to characterize what was created in terms of theory - confirm that the new theory developed has at least some experimental verification. Last, one can use that theory to propose new construction projects to ultimately meet the needs identified by the industry experts. 


\section{CHAPTER 2}

\section{BACKGOUND}

\subsection{Introduction}

This chapter focuses on introducing the reader to electric motors, electric launchers, pulse forming networks, accelerometers, and last gives an engineer's expectation to the acceleration TDWR uncertainties. Introduction to all of these areas is critical in understanding design rational behind the new proposed environmental testing apparatus. Each topic serves a different purpose that will be identified below.

\subsection{Electric Motors}

The purpose of introducing electric motors is that electric motors are common, easy to understand, and similar to electric launchers. Electric motors are made of copper, steel laminations, and sometimes magnets. There are many types of electric motors and much literature on them [18-21]. They come in all shapes and sizes and use various methods for their working principles. Delineation categories often include DC motors, induction motors, synchronous machines, brushless permanent magnet machines, and stepper motors. Because our purpose is only to set up the introduction of launchers, we will only cover a conventional DC motor then discuss linear electric motors.

The physics behind a conventional DC motor is primarily the Lorentz force - a charged particle moving in a magnetic field experiences a force - equation 2.0. One can use this equation 
to derive an equation for the torque of a current carrying loop but let us just remain here and look to Figure 2.1. The other equation to make sense of Figure 2.1 is that a Torque or Moment are defined as r cross F - Equation 2.1.

$$
\begin{aligned}
& F=q(E+v \times B) \\
& M=r x F
\end{aligned}
$$

If one wanted to use this physics for a utilitarian purpose then we can look at positions 19 and understand. Position one, the amount of current is multiplied by the number of turns in the $\mathrm{y}$-direction and under the influence of the magnetic field in the z-direction experiences a force in the $\mathrm{x}$-direction. That force cross a radius in the negative z-direction results in a Moment in the negative y-direction. The loop moves to position 2. What may not be obvious, the magnetic field magnitude decreases quite significantly as the test point moves farther away. This is important in that position 2 will have a decreased force and resulting decreased moment. When the loop reaches position three will be little force and assuming the magnetic is perfectly centered then the two forces cancel. Let's assume one gave a good flick in the beginning or the force was really that large to begin with then the loop has momentum - angular momentum, to be precise, will keep the loop moving around to position 4. In position 4-6, the force and moment will be in the opposite direction, but if one intentionally insulates the wire where the side indicator does not allow current to pass or if it simply has enough angular momentum then the loop will carry through until it makes it to position 8 and 9 . Position 9 is the same as position 1 thus the cycle continues just so long as there is current and no other un-mentioned forces, like friction, stop the motion. 


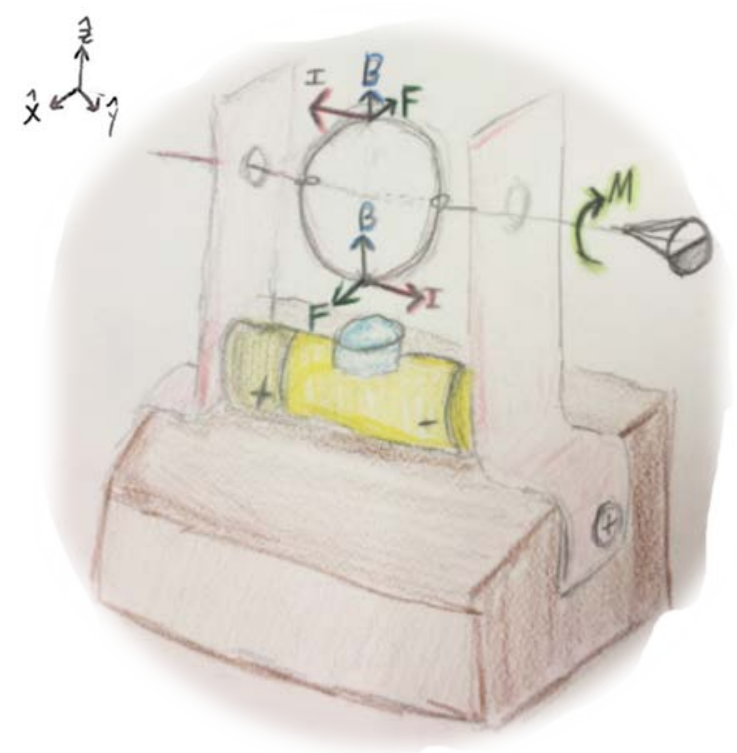

(a)

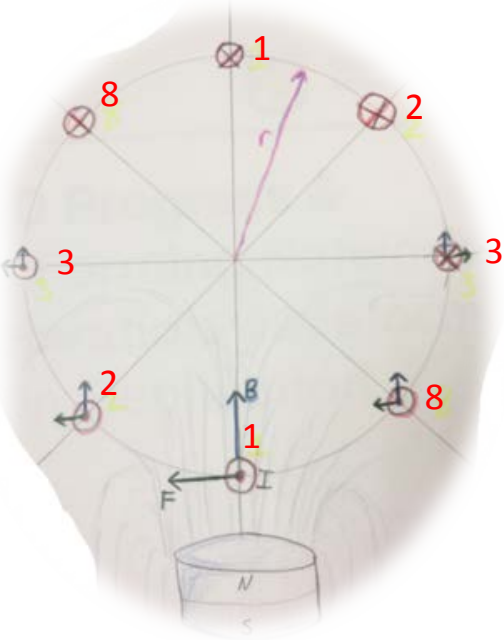

(b)

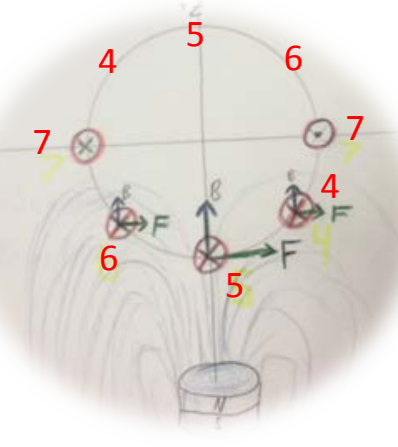

(b)

\begin{tabular}{|c|c|c|c|c|c|c|c|}
\hline Position & Position & Side Indicator & I & B & $F$ & $r$ & $\mathbf{M}$ \\
\hline 1 & $\frac{x}{+}$ & & $\hat{y}$ & $\hat{Z}$ & $\hat{x}$ & $-\hat{Z}$ & $-\hat{y}$ \\
\hline 2 & \begin{tabular}{l|l} 
& $x$ \\
$\odot$ &
\end{tabular} & & $\hat{y}$ & $\hat{Z}$ & $\hat{x}$ & $-\hat{Z}$ & $-\hat{y}$ \\
\hline 3 & $\cdot-x$ & & \multicolumn{5}{|c|}{ Balanced } \\
\hline 4 & $\stackrel{-}{-}{ }_{-}^{-}$ & & $-\hat{y}$ & $\hat{z}$ & $-\hat{x}$ & $-\hat{Z}$ & $\hat{y}$ \\
\hline 5 & $\frac{\ominus}{\dot{1}}$ & & $-\hat{y}$ & $\hat{z}$ & $-\hat{x}$ & $-\hat{Z}$ & $\hat{y}$ \\
\hline 6 & \begin{tabular}{l|l} 
& 0 \\
$x$ &
\end{tabular} & & $-\hat{y}$ & $\hat{Z}$ & $-\hat{x}$ & $-\hat{Z}$ & $\hat{y}$ \\
\hline 7 & $x-0$ & & \multicolumn{5}{|c|}{ Balanced } \\
\hline 8 & \begin{tabular}{l|l}
$x$ & \\
& 0
\end{tabular} & & $\hat{y}$ & $\hat{Z}$ & $\hat{x}$ & $-\hat{Z}$ & $-\hat{y}$ \\
\hline 9 & $\frac{x}{+}$ & & $\hat{y}$ & $\hat{Z}$ & $\hat{x}$ & $-\hat{Z}$ & $-\hat{y}$ \\
\hline
\end{tabular}

Figure 2.1: Example of a DC Electric Motor, (a) as seen, (b) simplified side views and table of unit vectors. 
Now, we will talk about a linear electric motor. First, line up multiple magnets, install two rails with a battery with a moveable conductor and admire the fact that the physics, equation 2.0, still works. Consider now the line of current moving from position 1 to position 2 . The line will then move from position 2 to position 3 and so on down the line. Compared to the rotational motor, this is a simpler example. An electromagnetic launcher (EML) works in the very same manner with some exceptions.
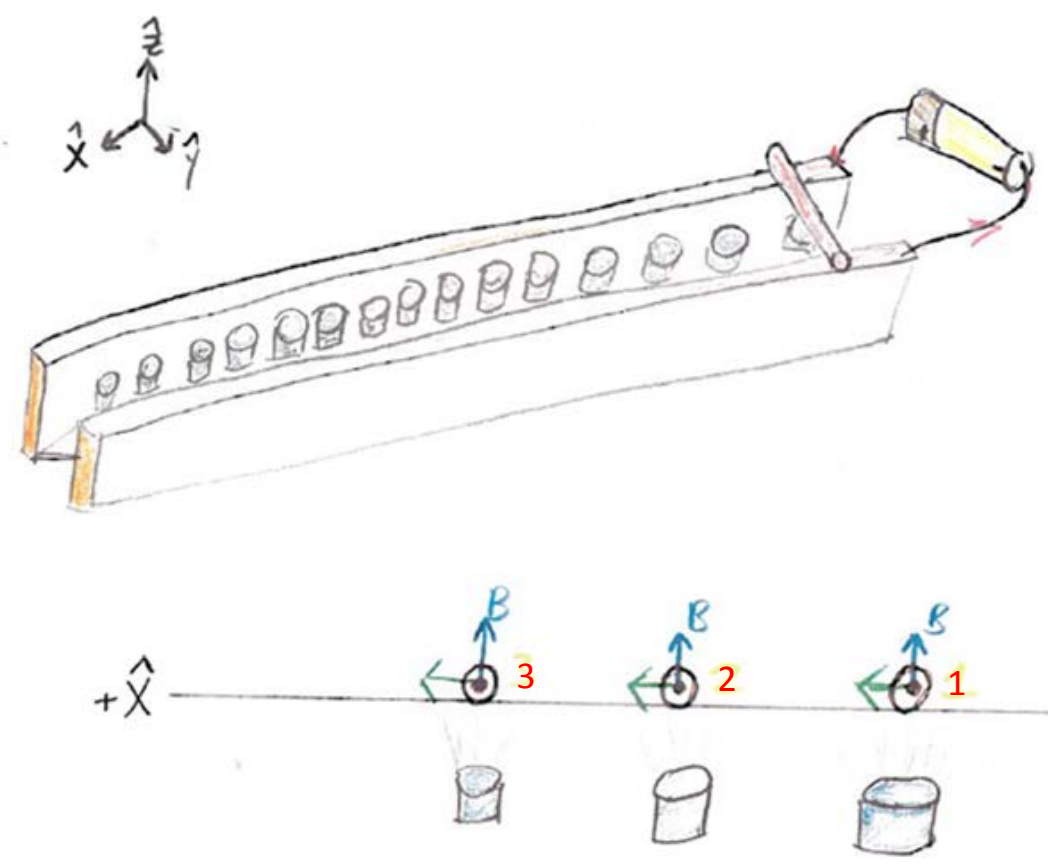

\begin{tabular}{c|c|c|c|} 
Position & $I$ & $B$ & $F$ \\
\hline $1 \square$ & $\hat{y}$ & $\hat{z}$ & $\hat{x}$ \\
\hline \multirow{2}{O}{} & $\hat{y}$ & $\hat{z}$ & $\hat{x}$ \\
\hline 0 & $\hat{y}$ & $\hat{z}$ & $\hat{x}$ \\
\hline
\end{tabular}

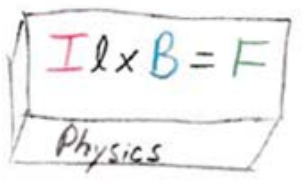

Figure 2.2: Example of a Linear Electric Motor. 


\subsection{Electromagnetic Launchers}

The purpose of introducing electromagnetic launchers (EMLs) is they are the mechanism of choice, powered by the Pulse Forming Network, to replicate acceleration waveforms in the time domain. There have been many proposed applications for electromagnetic launchers [22,23]. There has also been much literature on EMLs $[24,25]$. To be simple, there are three primary types of electric launchers: Rail gun, coil gun, and the Helical Electromagnetic Launcher (HEML). The first two have unique physics of operation and the third combines both into one working model. Because of this, it is no wonder that much evidence has been collected showing that the HEMLs are the most efficient of the three launcher types.

The rail gun uses the Lorentz force to operate as previously introduced. The difference now is that the magnetic field is not something created externally but rather created by the incredibly large currents rushing though the rails and projectile together. The primary disadvantage here is that there is effectively only one loop of current that generates all the magnetic field and in turn the force required, leading to the realization that the magnitude of current necessary is quite astronomical. Researchers have tried to augment the rail gun by adding more current loops with some success.

Coil guns are much like solenoids, which are inside some door bells, and have unique physics in that now it is easier to think of the force that is generated coming from two opposing electromagnets. Meaning, as displayed in Figure 2.3, the two magnets that are created repel one another. One coil is fixed or static and the other is allowed to move and is called the projectile. Here, for the same amount of current, you get a larger force but for short time. The short time, or 
primary disadvantage, is that the stator and projectile decouple (move away from) each other quickly thus minimizing the amount of total force that can be generated.
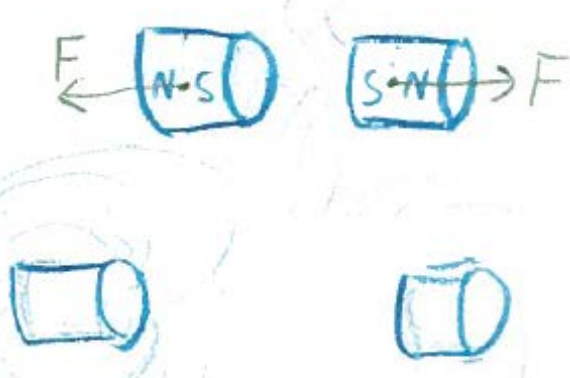
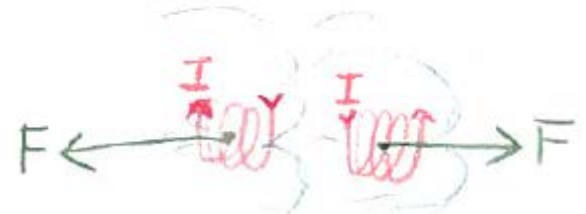

$=$
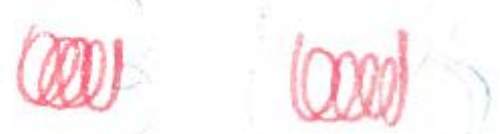

Figure 2.3: Working principle of Coil Gun as compared to Magnets.

Last, we consider the HEML. Now that the other two types have been introduced, it is easy to think of the HEML as the elegant combination of the two prior - a coil gun inside a rail gun. In this way, both disadvantages are negated. The large current requirement is addressed by the addition of more current carrying loops. The decoupling is addressed by constructing the coils in such a way the stator coil can move along with the projectile. The best way to consider the true advantage is by looking at efficiency. HEMLs are more efficient that the other types [26-30].

HEML launchers can be built with both an external or internal projectile. Meaning, of the two coils inside the rails the internal coil may be static and the projectile would look like a donut. Or the converse is also true, the stator could look like a typical gun barrel and the projectile a bullet. For laboratory applications, such as environmental testing, it is easy to see 
why an external projectile is preferred - visibility. The second reason why external projectiles are preferred is the ability to instrument the projectile (section 2.5). In fact, the instrumentation of the projectile was a necessary precursor to the idea of using the launchers projectile as a test platform. The most necessary precursor of all is the clear understanding of the working principle, or analytical solution, and so we will spend time on this before concluding with comments how it will work as an instrument.

There are many ways to approach an analytical solution. One could review the theory of Electromagnetic Launchers [26]. Here, for the case of a HEML, we find an equation for Force in terms of current and the Mutual Inductance gradient.

$$
F=\frac{1}{2} \frac{d L}{d x} I^{2}=M^{\prime} I^{2}
$$

The process to calculate the mutual inductance gradient is a complicated task. One can make many simplifying assumptions that can reduce the geometry to two current carrying loops (Figure 2.4). The force per length is found to be eq. 2.3, then simplified further to give the total force experienced due to current traveling through the structure eq. 2.4. 

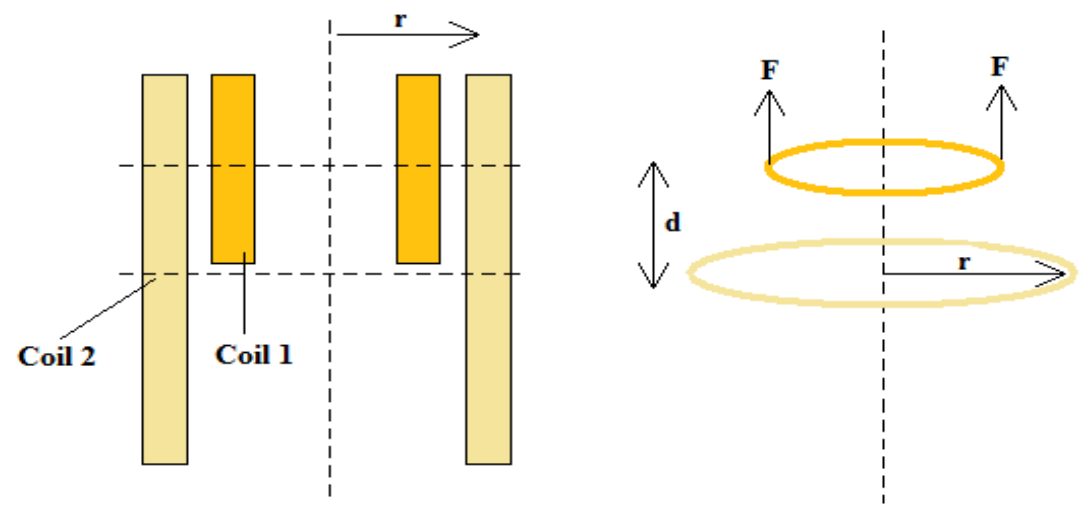

Figure 2.4: Geometric simplification of HEML.

$$
\begin{gathered}
\frac{\text { force }}{\text { length }}=\mu_{0} \frac{I_{1} I_{2}}{2 \pi d} \\
F_{\text {mag }}=(2 \pi r) \frac{\text { force }}{\text { length }}=\mu_{0} \frac{n_{1} n_{2} I^{2} r}{d}
\end{gathered}
$$

Another way to approach an analytical solution is though magnetic field equations. The field inside a solenoid was found using Amperes law and given by eq. 2.5, where $N$ is the number of turns, $I$ the current, and $l$ the coil length. One could assume that the repulsive force between the two coils is given by eq. 2.6 where $R$ is the radius, $x$ the distance the coils are apart, and $h$ the coil height.

$$
\begin{gathered}
B=\mu_{0} \frac{N I}{l} \\
F(x)=\frac{\pi \mu_{0}}{4} M^{2} R^{4}\left[\frac{1}{x^{2}}+\frac{1}{(x+2 h)^{2}}+\frac{2}{(x+h)^{2}}\right] \\
B_{0}=\left(\frac{\mu_{0}}{2}\right) * M
\end{gathered}
$$


When a HEML will be used for environmental, testing one could consider the Figure 2.5. This shows how easy it is to create a mountable platform. Here it is easy to see how a test article (e.g. circuit board) could be mounted and tested. In this way, we are considering the future of environmental testing machinery. Now let us consider how to power and control such a machine. The name for this power supply is a Pulse Forming Network (PFN).

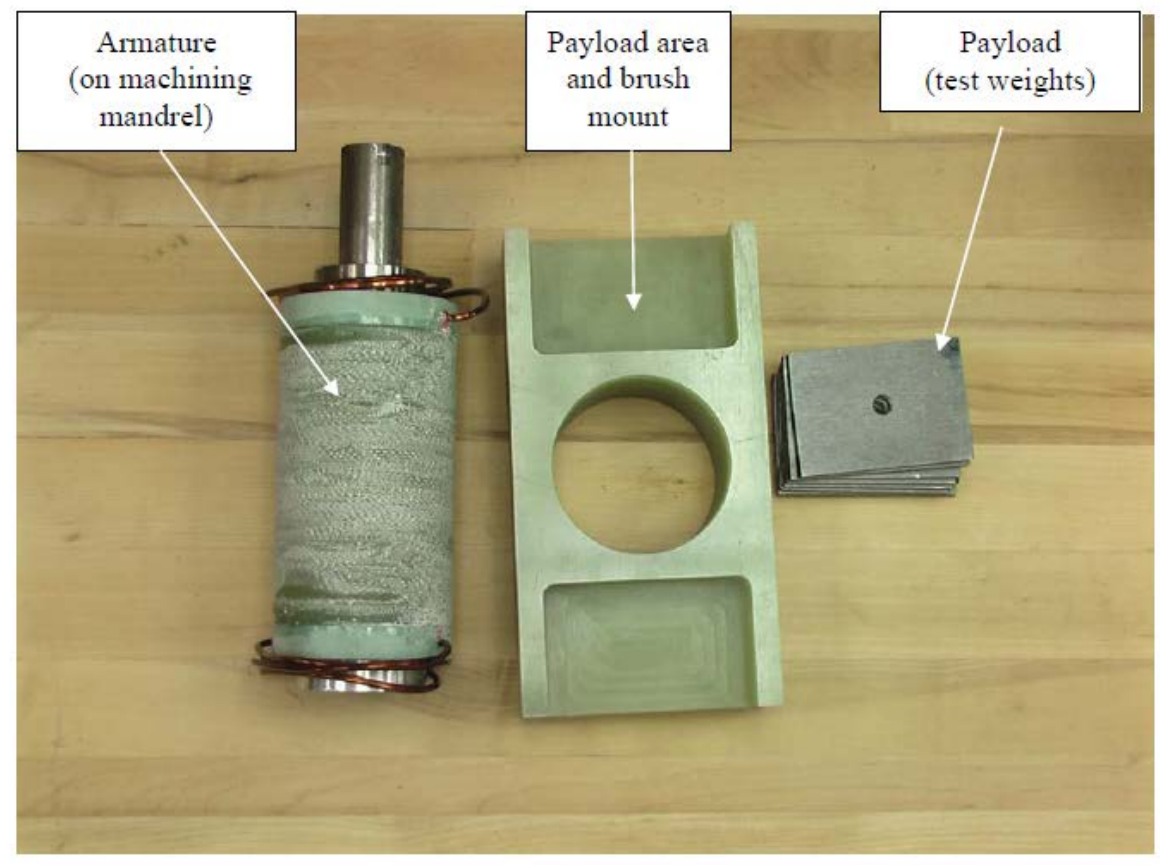

Figure 2.5: Mountable Electric Launchers Design Concepts.

\subsection{Pulse Forming Networks (PFN)}

The purpose of reviewing Pulse Forming Networks is first to give context as to what exactly was built and documented and then to specifically introduce some techniques and theories that were already documented. The terminology Pulse Forming Network (PFN) was defined in 1949 by Glasoe and Lebacoz [31]. "The pulse-forming network serves the dual 
purpose of storing exactly the amount of energy required for a single pulse and of discharging this energy into the load in the form of a specified shape.” At this time, the shape most desired was square. Because of this, over the next few decades, there was little emphasis on how one would make other shapes.

There are many types of Pulse forming networks. They all have three main parts: The Energy Storage Device, The Switch, and the Load - Figure 2.6. Most use Capacitors and Inductors for the Energy Storage. For this Dissertation Capacitors were used for the energy storage, several Silicon Controlled Rectifiers (SCRs) were used as the switch and the Load for this dissertation is an Electromagnetic Launcher.

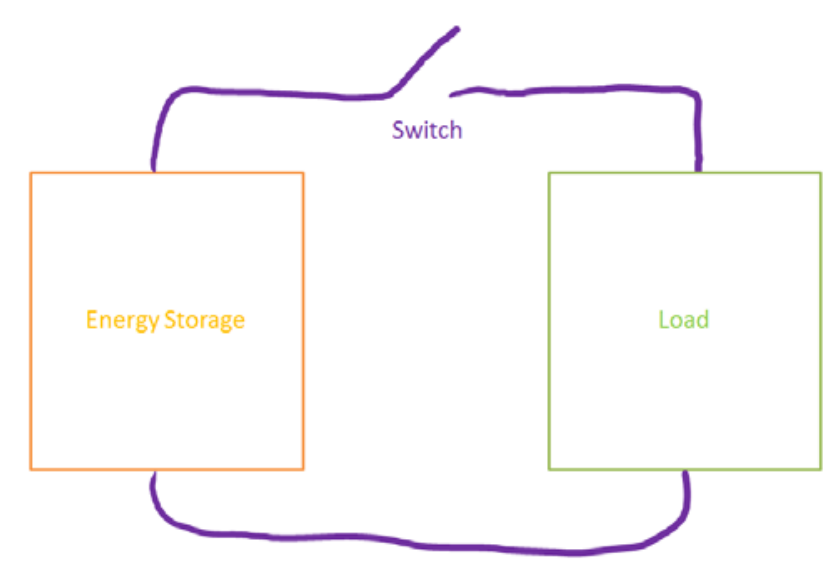

Figure 2.6: Basic PFN.

The Glasoe and Lebacoz book goes on to talk about building a network to perform a specific pulse - Figure 2.7. This works beautifully if you want to construct a PFN for only one pulse shape, peak, and duration. The problem comes when one wants one PFN to be able to perform many pulse shapes, peaks, and durations. Another problem is described on page 9, "The 
consideration of impedance matching is extremely important...if the load is nonlinear...the shape can only approximate...and...ultimately depends on experimental testing with subsequent modifications to obtain the desired pulse shape.”

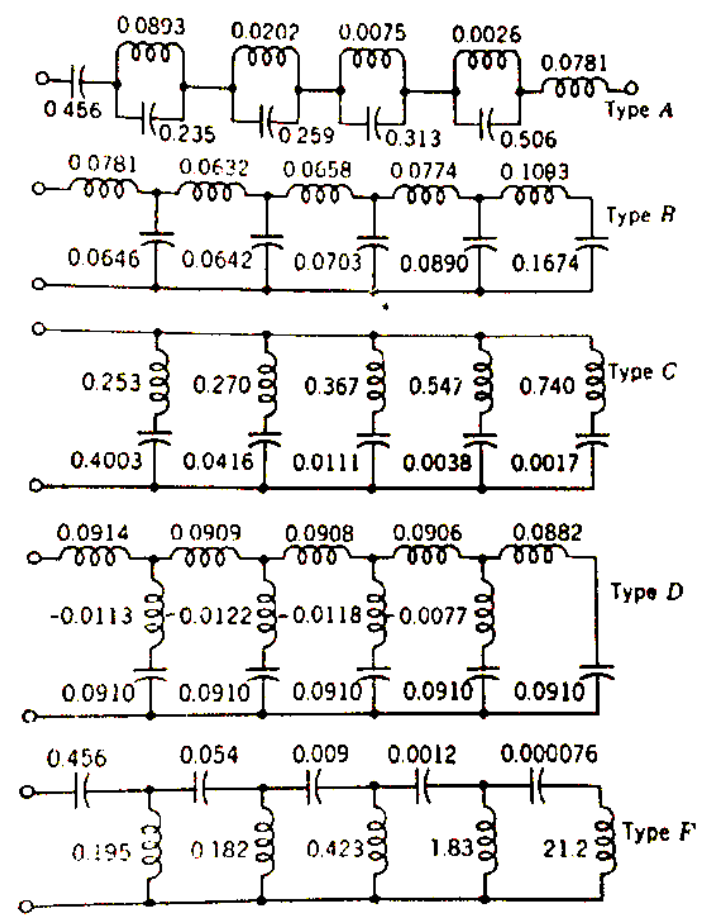

Figure 2.7: Guillemin Network Types [31].

It is important to review the Network Analysis and Synthesis including the work of Guillemin [32]. In this book chapter five covers the mathematics of Network Synthesis. It is important because as the PFNs become more complex than what is proposed in this dissertation, embracing the mathematics will help make analyzing the networks possible as he says, "without becoming lost in a maze of detail.” 


\subsection{Accelerometers}

The purpose for introducing accelerometers is as Hertz said in his address to the Imperial Palace, Berlin, August, 1891:

Outside our consciousness there lies the cold and alien world of actual things. Between the two stretches the narrow borderland of the senses. No communication between the two worlds is possible excepting across the narrow strip. For a proper understanding of ourselves and of the world, it is of the highest importance that this borderland should be thoroughly explored.

Further, as stated in the title, we are discussing theory for designing a PFN yes; but moreover, for Acceleration Time Domain Waveform Replication (ATDWR). Just TDWR, as mention in the last section, for current waveforms has been done. The acceleration waveforms in this dissertation are taken by an accelerometer and will be judged by this data. Therefore, an appropriate introduction to accelerometers is necessary.

Transducers to measure acceleration come in all shapes and sizes. Accelerometers were first developed fully in 1923 and were a resistive bridge type. Over the next 80 years, the size and complexity changed dramatically - Figure 2.8. Now, most people carry transducers measuring acceleration in their phones, tablets, and even inside them - pacemakers. All of which need some form of calibration to be useful. 


\begin{tabular}{|c|c|c|c|c|c|c|c|c|}
\hline $\begin{array}{c}\text { First resistance- } \\
\text { bridge-type } \\
\text { accelerometer }\end{array}$ & $\begin{array}{c}\text { Bruel \& Kjaer } \\
\text { develops first } \\
\text { PE accel }\end{array}$ & $\begin{array}{c}\text { Endveco } \\
\text { manufactures } \\
\text { 1st Accel }\end{array}$ & $\begin{array}{l}\text { Kistler granted } \\
\text { US patent for } \\
\text { charge Amp }\end{array}$ & $\begin{array}{c}\text { Bruce Wilner of } \\
\text { Endevco } \\
\text { designs and } \\
\text { patents the } \\
\text { world's first and } \\
\text { only } 200,000 \mathrm{~g} \\
\text { PR accel }\end{array}$ & $\begin{array}{c}\text { B\&K develop } \\
\text { first shear type } \\
\text { PE Accel }\end{array}$ & $\begin{array}{c}\text { An } \\
\text { accelerometer } \\
\text { history session } \\
\text { is held at the } \\
\text { Shock and } \\
\text { Vibration } \\
\text { Symposium } \\
\text { with Endevco, } \\
\text { Kistler, PCB etc. } \\
\end{array}$ & $\begin{array}{c}\text { The Modal } \\
\text { Shop's } \\
\text { commercial } \\
\text { accel cal system } \\
\text { included air } \\
\text { bearing shaker } \\
\text { and pneumatic } \\
\text { shock exciter }\end{array}$ & $\begin{array}{c}\text { Electromagnetic } \\
\text { launchers were } \\
\text { used for } \\
\text { accelerometer } \\
\text { calibration }\end{array}$ \\
\hline 1923 & 1943 & 1951 & 1960 & 1971 & 1972 & 1996 & 2005 & 2011 \\
\hline
\end{tabular}

Figure 2.8: Accelerometer History.

Jon Wilson offers a thorough accelerometer calibration course. The calibration method for an accelerometer typically includes a verification of frequency linearity and then of amplitude linearity. Frequency linearity is verified on a shaker. The Ball Drop calibration method for shock was first documented in 1979 [33]. This method is used to verify amplitude linearity, but has a peek amplitude limitation. To calibrate the highest amplitudes of shock one must use a Hopkinson bar [34,35]. Imagine now the total operational space of an accelerometer - Figure 2.9. Only the blue dots are actually verified in a test. The red area performance is assumed based of the performance of the accelerometer at the blue dots. The primary reason for having to make this assumption is the inability to produce an acceleration in this region with reasonable traceability. To be fair, the 79 ' text did say "there is reason to assume the accelerometer is linear." Still, high velocity change is what causes failure of brittle materials. Therefore, this dissertation proposes the verification of this red area, and a method to do the verification - use an electromagnetic launcher, the theory derived here, and necessary persistence in construction to chart this territory in the world map of acceleration. 


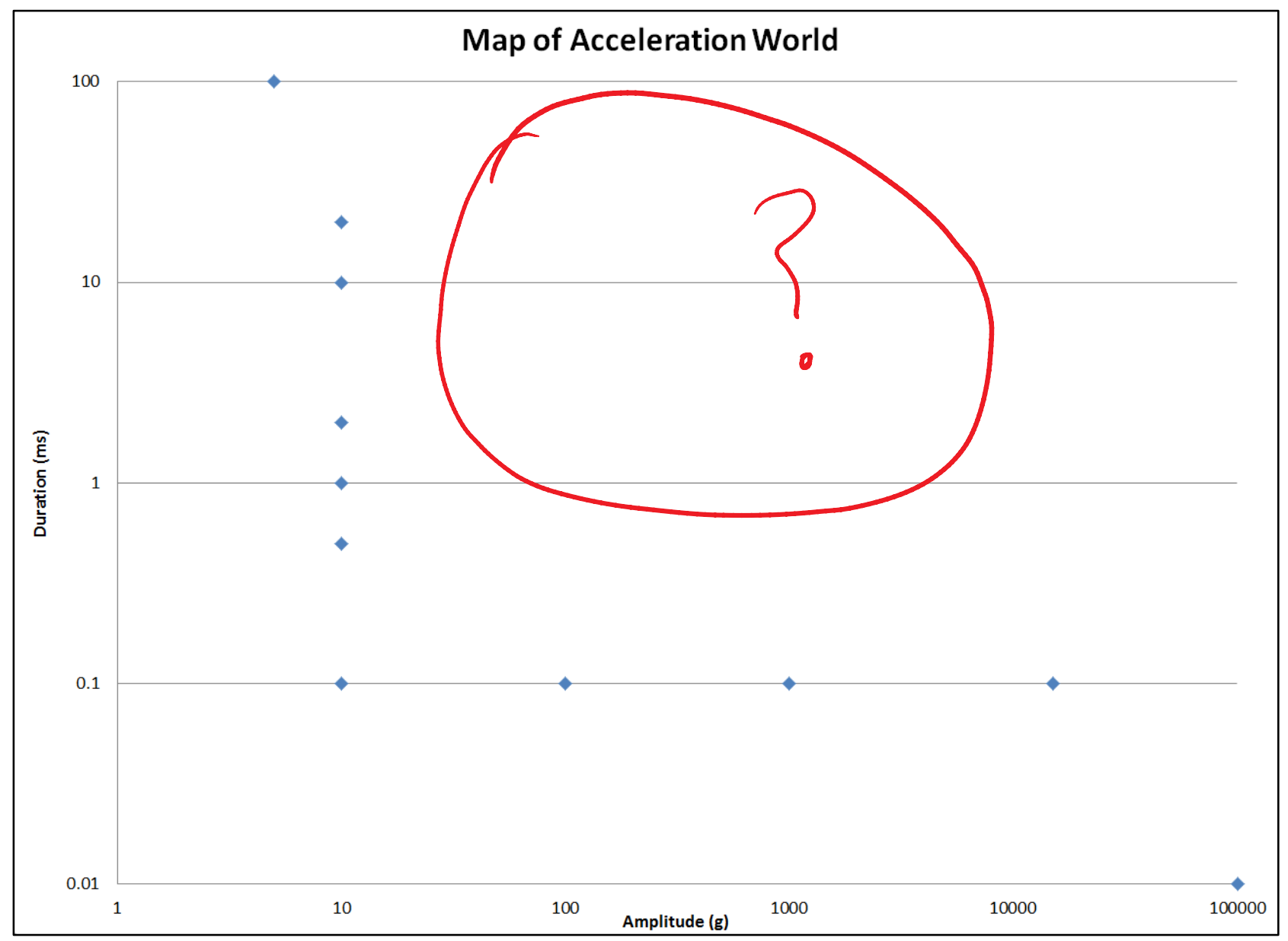

Figure 2.9: Typical Verified Range for an Accelerometer.

\subsection{Engineer's Expectations and the Uncertainty target}

Before embarking on any quest or trying to define success, it is always essential that a good goal be set. The goal set here is to be able to produce the correct Time Domain Acceleration Waveform in terms of pulse shape, amplitude, duration and uncertainty. Rather than picking a target out of the air, the author asked many engineers as to what would be 
expected of this proposed machine. First, the repeatability would have to be 4 times better than the accelerometer uncertainty. Most accelerometers are calibrated to about 3-4\% so a target of $12 \%$ was set. In terms of amplitude and duration, Figure 2.8 now shows the map of the acceleration world but with typical shock test instrumentation points. The goal will be to cover as much of this map as possible.

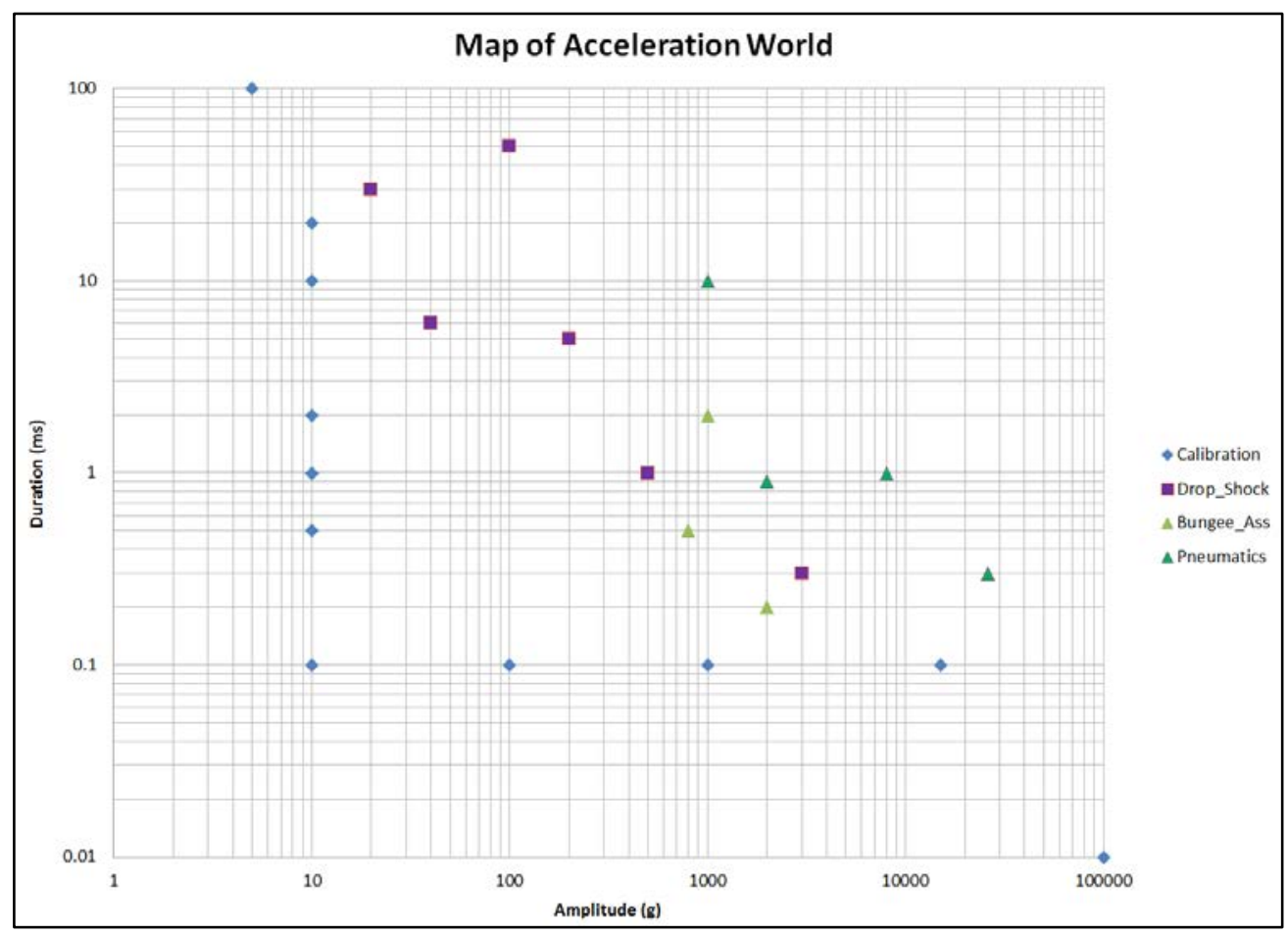

Figure 2.10: Target Amplitude and Duration.

The question of shape was also answered by discussing with a group of seasoned professional at the 2012 SAVE Conference. It was determined that any shape may be needed: Saw tooth, Triangle, Square, Trapezoid, Half-sine, and Haversine. This dissertation will focus on the Haversine shape but comment on the others in the algorithm. Rather than relying only on subjective criteria to judge the pulses, the following criteria are proposed. 
The easiest way to think about the criteria is the pulse must be symmetric and produce an expected velocity. This is done by first measuring peak filtered amplitude $\mathrm{a}_{\mathrm{m}}$. Then the time it takes to get from $10 \%$ of that value to $90 \%$ of that value is $\mathrm{t}_{\mathrm{r}}$. The time it takes to get from $90 \%$ on one side to the other will be $\mathrm{t}_{\mathrm{d} 90 \%}$, this will be used in later sections. Further the time it takes to get from $90 \%$ of that value to $10 \%$ is $\mathrm{t}_{\mathrm{f}}$. Last, the duration is the time it takes to get from $10 \%$ back to $10 \%$ of the peak value and named $t_{d}$. Comparing the values to one another will be done with the three following tests.

$$
\begin{aligned}
& \text { Rise Test }=\frac{t_{r}}{t_{d}}=0.373 \pm 15 \% \\
& \text { Fall Test }=\frac{t_{f}}{t_{d}}=0.373 \pm 15 \%
\end{aligned}
$$

$$
\text { Third Test }=\frac{V}{a_{m} * t_{d}}=0.628 \pm 5 \%
$$




\section{CHAPTER 3}

\section{THE PROPOSED THEORY AND ALGORITHM}

\subsection{Pulse Shapes and Solution Approaches}

When considering the design of a Pulse Forming Network many options exist. This dissertation proposes the use of known theoretical approaches and other pulse shaping techniques to make the desired acceleration pulses. It does so by way of Algorithm for selecting network components given the answers to important questions regarding the specifics of the requested pulse. The solution will ultimately depend on experimental evaluation as the electromagnetic launcher is non-linear; in as much, the possible outcomes can be estimated with careful consideration. Below, find a group of tested general propositions that together guide a decision as to what the resistance, capacitance, inductance, number of banks, initial voltage, and timing of when to fire with respect to one another that will in the end build the desired acceleration pulse.

There are two paths one can travel to find the desired pulse shape. The first path is selecting the desired circuit components so that when a single switch is closed, the resulting pulse is acceptable with no other intervention. This path is desirable in terms of simplicity, however it lacks flexibility - it only produces a single pulse type (one capacitor bank will typically only have one set of $\mathrm{R}, \mathrm{L}$ and $\mathrm{C}$ ). One would have to get creative for this path to be flexible. For instance, build a PFN with 10 different banks to produce the 10 most desirable pulses. Given enough time, space, and resources one could not stop at 10, make the network 
more like Bösendorfers piano with 97 keys. Or one could make their network like a more traditional 88 key piano, but with 242 banks, one for each string. Yet, with the first path, one is only allowed to play one key at a time.

The second path is more complicated but gives the desired flexibility. On this path more than one switch (multiple capacitor banks) gives the ability to construct a piecewise linear function with basis functions. The resulting pulse is the superposition of the basis pulses, where by applying Wavelet Theory to Pulse Forming Network Theory [36]. Now one can play several keys on the hypothetical piano proposed in path one taking full advantage of the harmony, constructive and deconstructive interference, to produce the desired acceleration waveform.

Upon further inspection of the desired pulse shapes presented in chapter two (i.e. Saw Tooth, Triangle, Square, Trapezoid, Half-sine, and Haversine) there are two categories that emerge. The first is 'flat top' and the second is not. The flat top pulse category naturally fit the first path (single switch, but may have multiple components inside) and one can see the work Guillemin documented [31]. The pulses without a flat top can be broken down further into continuous functions or discontinuous functions. Again, the continuous functions lend themselves to a single bank path. The discontinuous pulses lend themselves into wavelet basis functions. Starting with the Sawtooth (rise time), adding triangle (falltime), and some level width (square) can be visualized in Figure 3.1 as moving from black to blue then to red. Last, the green shows that even the imposed limit to test haversign criteria is evident.

If we were to continue with the Wavelet decomposition method the discussion is twofold. One, how can one create or express rise time, fall time, and level time in terms of known 
parameters. Two, how can one create the continuous pulses. The first question's answer is documented below in Section 3.2. The second question is answered with the remaining sections ultimately culminating in an Algorithm - Section 3.7.

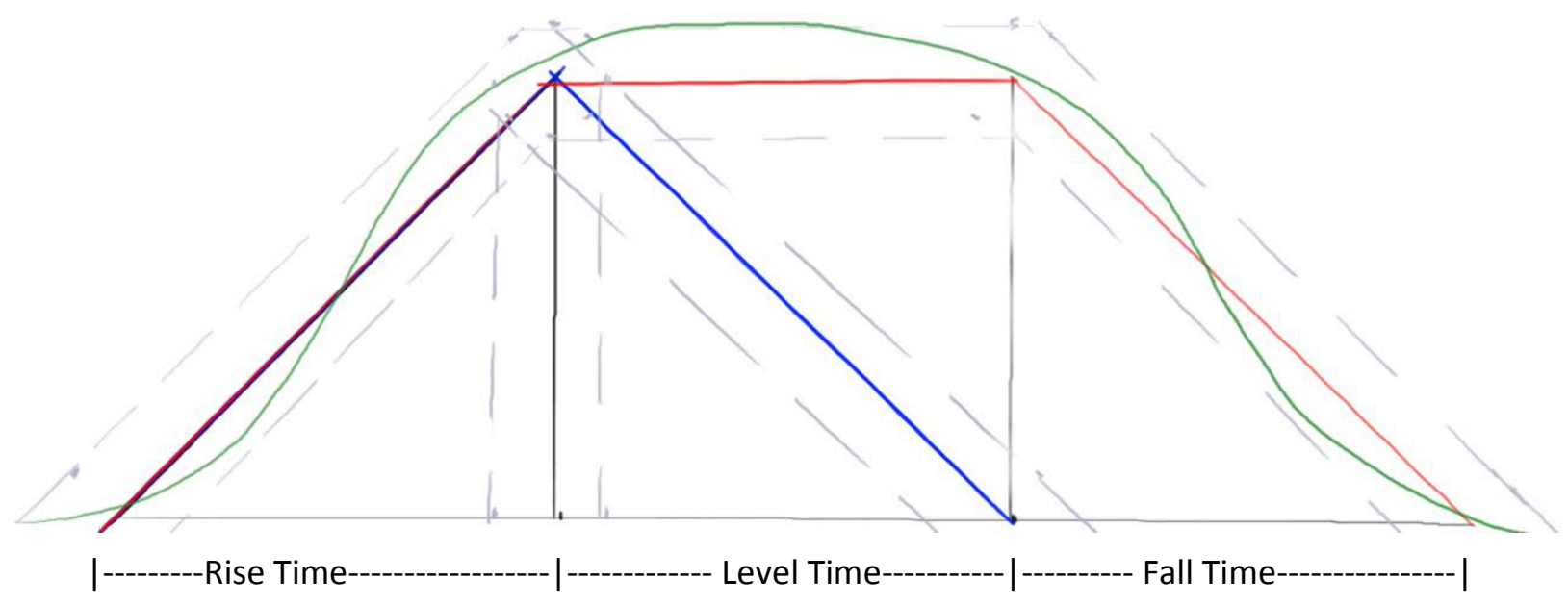

Figure 3.1: Wavelet Decomposition of Pulse shapes.

\subsection{Time and Frequency Doman Contribution}

The Simple Circuit we will consider is a series RLC, where the C is initially charged and allowed to discharge through the Inductor and Resistor. This circuit is in the appendix (p. 90), and in many books and references [37]. For simplicity let us assume that the Inductor contains the inductance from the electromagnetic launcher, assuming converting the electromagnetic energy into mechanical motion with no side effects. In Chapter 4.5, we will find this not to be 
the case when we get a more accurate Launcher Model; but for now, think of current being synonymous with acceleration.

An equation is found by using Kurchofs Voltage Law - equation 3.1. Mathematically, equation 3.1 can be expressed as the differential equation 3.2. When this equation is solved the three presented curves in the appendix now have mathematical form equations 3.3-3.5.

$$
\begin{gathered}
L \frac{f_{i}(t)}{d t}+R_{i}(t)+\frac{1}{C} \int_{0}^{t} i(T) d \tau+v_{C}(0)=0 \\
\frac{d^{2} i(t)}{d t^{2}}+\frac{R}{L} \frac{d i(t)}{d t}+\frac{1}{L C} i(t)=0 \\
i(t)=\frac{v_{0}}{\omega_{0} L} e^{\frac{-R}{2 L} t} \sin \omega_{0} t \\
i(t)=\frac{v_{0} t}{L} e^{\frac{-R}{2 L} t} \\
i(t)=\frac{v_{0}}{\widetilde{\omega_{0} L}} e^{\frac{-R}{2 L} t} \sinh \widetilde{\omega_{0} t}
\end{gathered}
$$

Now let us define parts of these equations as to allow for more simple discussion. Equation 3.6 will be alpha or in physical terms how much the system is damped. Equation 3.7 is the fundamental angular frequency, and is the natural frequency of the system with no dampening. Equation 3.8 and 3.9 are what the frequency actually is depending on which quantity, omega or alpha, is larger.

$$
\alpha=\frac{R}{2 L}
$$




$$
\begin{gathered}
\omega_{f 0}=\frac{1}{\sqrt{L C}} \\
\omega_{0}=\sqrt{\frac{1}{L C}-\left(\frac{R}{2 L}\right)^{2}} \\
\widetilde{\omega_{0}}=\sqrt{\left(\frac{R}{2 L}\right)^{2}-\frac{1}{L C}}
\end{gathered}
$$

Because we have seen this exercise through, we are rewarded with the ability to express rise time and fall time mathematically in terms of known parameters. Rise time equations 3.10, 3.11, 3.12 are derived. These are not perfect linear rise times, but in truth, a perfect linear rise time does not exist. For now, the 'rise time' is the time at which the function is maximized. Moreover, this is the current rise time which is different from the acceleration rise time; inasmuch, launcher properties will alter the form of the rise as well - but it is a first approximation. The same goes for fall time.

$$
\begin{aligned}
& R T_{\text {under_damped }}=\frac{\pi}{2 \omega_{0}} \\
& R T_{\text {criticaly_damped }}=\frac{2 L}{R} \\
& R T_{\text {over_damped }}=\frac{\ln \left(\frac{R+2 L \widetilde{\omega}_{0}}{R-2 L \widetilde{\omega}_{0}}\right)}{2 \widetilde{\omega}_{0}}
\end{aligned}
$$

While rise time does not seem to change drastically depending on the dampening, fall time is directly affected. In the case of a severely under damped system, up to the first zero crossing the pulse is symmetric; meaning, rise time is the same as fall time. For the damped 
case, the rise time can be less than $1 \%$ of the total time with no zero crossing. For the critical case, rise time is about $25 \%$ of the total time, also with no zero crossing. Pulse duration is best defined as the time it takes to travel from $10 \%$ of the peak, back to $10 \%$ of the peak.

Now we come to the initial assumption in the Algorithm from this time and frequency path. We will minimize the total resistance; strive to make the value of Capacitance and Inductance the same, only looking at the first unimodal halfsine, thus creating an underdamped circuit. Now if one knows the desired pulse duration, one knows how to choose the capacitance and inductance - Equation 3.13.

$$
C \sim L=\frac{\mathrm{PW}}{\pi}
$$

Up to this point, we have shown that if one knows their desired rise time, fall time or pulse duration then one can determine what resistance inductance and capacitance they need. If one knows how much level time is desired, one simply has to use the equations above and calculate the approximant level time of one bank then compare this to the desired level time. A simple example follows. If one wanted a $10 \mathrm{~ms}$ pulse, and each bank had an approximate level time of $1 \mathrm{~ms}$, than one would need 10 banks to reach the desired level time. This is shaping a pulse with synchronous firing. Remember, that if one only wanted one square pulse with one network, not synchronous firing of many, there has been much research done in the way of Network Synthesis [32, 38-45]. 
Initial voltage, and its relation to peak acceleration, is also dependent on the damping of the circuit. Equations 3.16 through 3.18 will help in estimating the maximum acceleration from known parameters. Note that these equations, while correct, have resistance in them. When one is trying to minimize resistance it becomes a challenging measurement to perform with reasonable uncertainty.

$$
\begin{aligned}
& A_{-} M_{\text {underdamped }}=\left(\frac{v_{0}}{\omega_{0} L} e^{\frac{-R}{\omega_{0} L}}\right)^{2} L^{\prime} / m \\
& A_{-} M a x_{\text {criticaly damped }}=\left(\frac{2 v_{0}}{e R}\right)^{2} L^{\prime} / m \\
& A_{-} \text {Max }_{\text {over damped }}=\left(\frac{v_{0}}{{\widetilde{\omega_{0} L}}_{0}} e^{\left(\frac{-R}{4 L \widetilde{\omega}_{0}} \ln \left(\frac{R+2 L \widetilde{\omega}_{0}}{R-2 L \widetilde{\omega}_{0}}\right)\right)} \sinh \left(\frac{1}{2} \ln \left(\frac{R+2 L \widetilde{\omega}_{0}}{R-2 L \widetilde{\omega}_{0}}\right)\right)\right)^{2} L^{\prime} / m
\end{aligned}
$$

\subsection{Modeling an Electric Launcher}

Remember now the theory of electromagnetic launchers from section 2.3. The only thing not presented in section 2.3 was back voltage. The simplest way to think of back voltage is the electrical consequence of generating mechanical motion. One can start with the complete definition of inductance - equation 3.16. From there, the first step is differentiate, understanding that the inductance will change over time. This portion is oftentimes assumed to be zero in circuit parameters. Current multiplied by the change of inductance divided by the change in time together represent the amount if mechanical work done in the system. The electrical work is the inductance multiplied by the change in current divided by the change in time. The net voltage is 
the electrical work plus the mechanical work - equation 3.21. If we focus on the mechanical work and separate the inductive gradient from the velocity we can see an equation for the back voltage - equation 3.23.

$$
\begin{gathered}
V(t)=\frac{d}{d t}(L i) \\
V(t)=L \frac{d i}{d t}+i \frac{d L}{d t} \\
V(t)=\text { Electrical Work }+ \text { Mechanical Work } \\
i \frac{d L}{d t}=i \frac{d L}{d x} \frac{d x}{d t} \\
i \frac{d L}{d t}=i \frac{d L}{d x} \frac{d x}{d t} \\
i \frac{d L}{d t}=i L^{\prime} v
\end{gathered}
$$

Now, we are ready to build our model. First, we incorporate a current dependent voltage source to allow us to calculate Force and acceleration in a voltage domain. Then, with integrator functions we can obtain voltage nodes that represent velocity and position. We can multiply the velocity voltage node with the inductive gradient and current to get the back voltage in terms of voltage. The voltage value can be fed back into the system with a voltage controlled voltage source. All that remains to model is the PFN. This can be done by simple RLC circuits allowed to switch in at a prescribed time. Figure 3.2 contains the Top View of the simulation used. Notice that the parameters are in a table form so as to allow for easy manipulation and experimentation. 


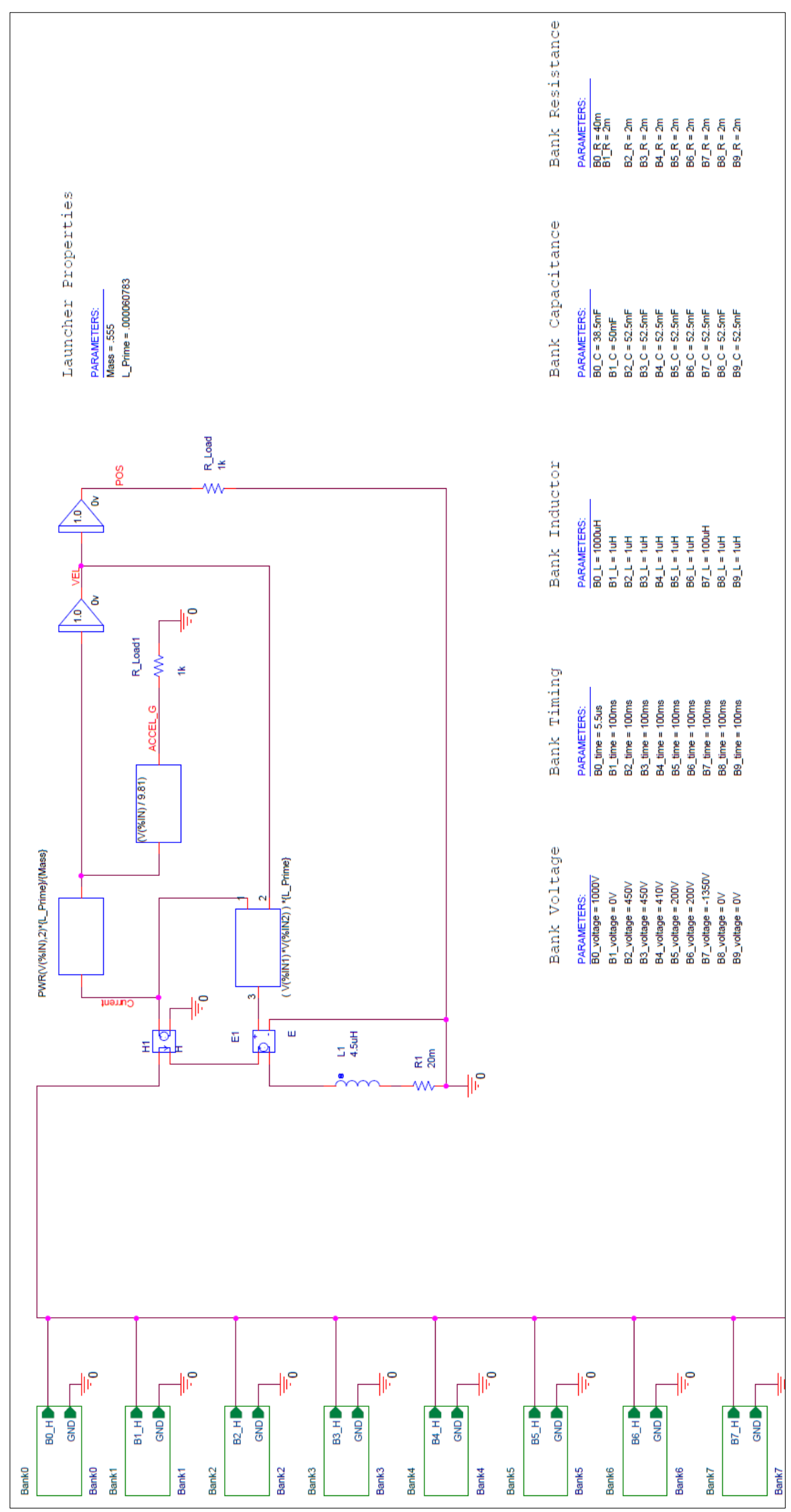

Figure 3.2: Simulation Top View. 
After modeling the launcher the theory developed in section 3.2 can be modified to incorporate the added contributions of the back voltage feedback. By modeling the launcher three significant notes follow. The first is that given an underdamped PFN, a Haversine is created - Figure 3.3. This can be very beneficial for someone looking to obtain this pulse shape. The second is that the solution space can now be limited in terms of the physical size of the electromagnetic launcher. Said differently, one can check to see if the max position is larger than the launcher. The third, the initial voltage can be estimated given the desired peak acceleration.

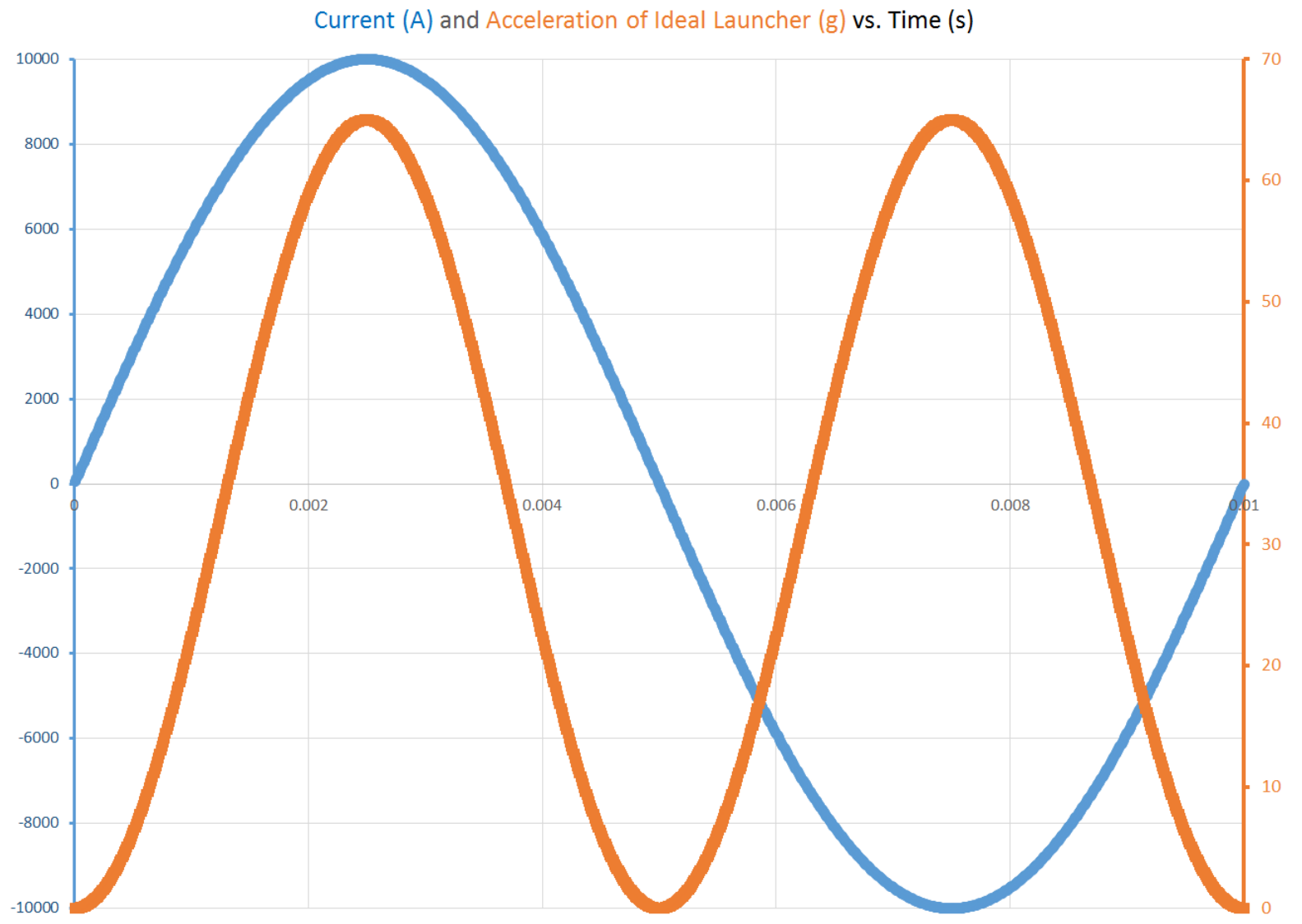

Figure 3.3: Example of Simulation Output. 


\subsection{Energy Domain Contribution}

In an elementary physics course, after learning about energy, problems that were challenging suddenly become easy. By considering energy, we can limit the solution space further. Simply, the energy in the bank goes to joule heating and motion. To determine how much energy is transferred in motion, it is most helpful to review the efficiency and scaling of electromagnetic launchers [26].

Using energy methods, approximating efficiency values, one can determine what a good starting voltage is for a given desired peak acceleration and duration. First, assume all of the energy is in the capacitor. This energy is then stored in the Inductor in the form of current and some of it is consumed by the resistance. In order to move quickly to an estimate of what the peak value of current is relative to voltage one can assume the amount consumed by the resistor is negligible. We remember Newton’s Second Law and the Specific Force parameter of the Launcher, we derive equation 3.27. Substitute 3.26 into 3.27 and find equation 3.28 - the second starting condition of the Algorithm.

$$
\begin{aligned}
& \frac{1}{2} C V^{2}=\frac{1}{2} L I^{2}+R I^{2} \\
& I_{\text {peak }}=\sqrt{\frac{C}{L}} V_{o} \\
& A_{\text {peak }}=\frac{M \prime}{m} I^{2} \\
& A_{\text {peak }}=\frac{M \prime}{m} \frac{C}{L} V_{o}^{2}
\end{aligned}
$$




$$
\mathrm{V}_{o}=\sqrt{\frac{A_{p e a k} m L}{M^{\prime} C}}
$$

\subsection{Filter Capacitor}

The purpose of talking about a Filter Capacitor is to introduce a method for changing rise time. A low pass filter allows a low frequency signal to pass and attenuates high frequencies. The sharp rise time of a half sine function can be turned into a smother more haversine like function is a low pass filter is used. The simplest form of a low pass filter is a capacitor, which can take the power requirements, connected in parallel with the EML load. Simulations in the appendix show that this can be an effective technique for smoothing the sharp rise time. This filter capacitor could also smoother events like Retropulsing.

\subsection{Retropulsing}

There are three other ways to influence the fall time. First, one can switch in a smaller resistance to divert current. This technique is called crowbarring and is well documented [4648]. The second approach to this is to switch in a negatively charged bank with respect to the bank that just fired. This method will be known as Retropulsing. Retropulse is a term used to describe pulse that will result in retropulsion, as opposed to propulsion, or a pulse used to retard, arrest, or reverse the motion originally created. A Retropulse will force a reduction in current through the launcher. The third way to influence a fall time in the acceleration time domain is with a reversible electromagnetic launcher documented in Chapter 7 - Future work. 


\subsection{The Algorithm}

Now that we have seen where 3.13 and 3.29 have been derived, let us use them in the Algorithm for selecting PFN components given a desired Shape, Amplitude and Duration Figure 3.4. The simplest form of this Algorithm is three steps: Start, Test, and Optimize. First one picks the shape they are targeting. Then one picks the capacitance with equation 3.13, ensuring that the voltage rating and intern energy storage is sufficient. Then test with a launcher by judging the acceleration created. Most likely some form of the pulse will be unacceptable. It is important to get the pulse width correct first. One can do this most easily by altering the

inductance - Add or subtract turns. For a given RLC circuit, over short ranges, voltage has a linear relationship to amplitude and inductance has a linear relationship with pulse duration. 


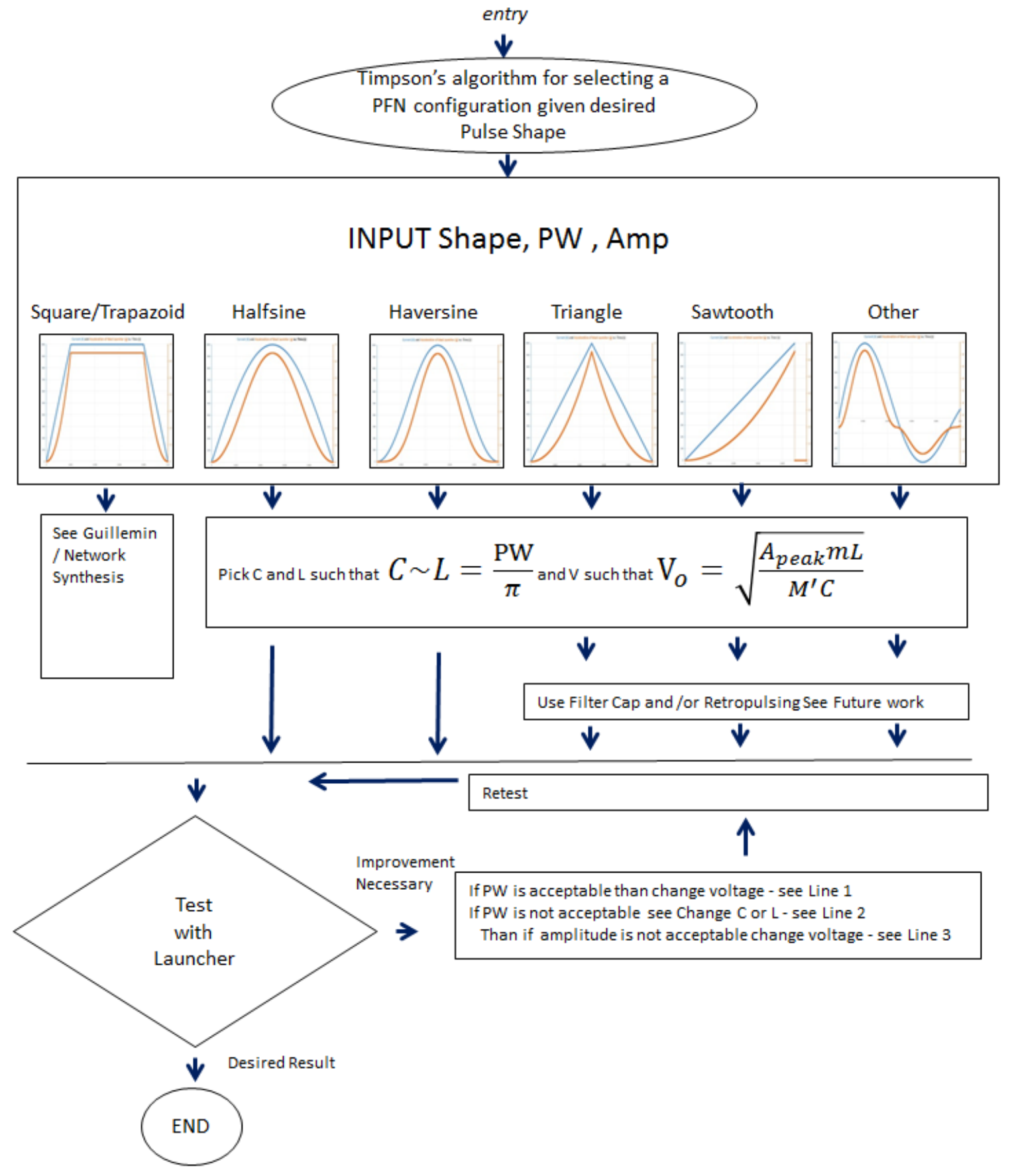

Figure 3.4: The Timpson Algorithm for selecting PFN Components and Conditions. 


\section{CHAPTER 4}

\section{BUILDING THE PFN}

\subsection{Overview}

Section 2.4 gave background on the many forms of Pulse Forming Networks (PFN) that are in existence. In 2006, a thesis documented the construction of a sequentially-fired PFN [49]. This was a good starting point. To progress, Chapter 3 gave the theory used to make the critical design decisions for parameters with shaping the pulse in mind. This chapter is devoted to the practical aspects of building a proof-of-concept PFN. From the most important safety systems to the most exciting firing system, this chapter provides a clear detailed 'user manual' to the PFN.

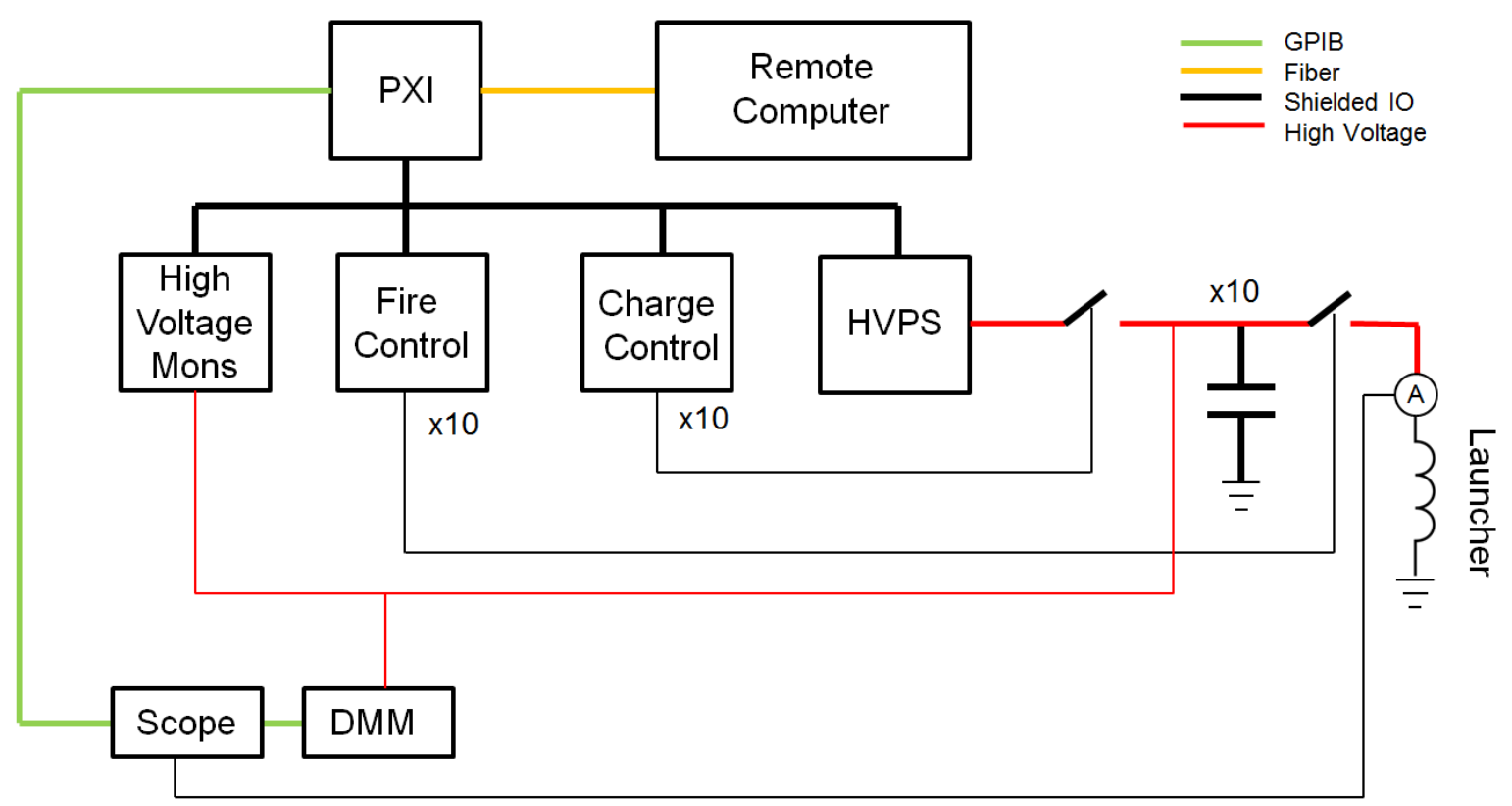

Figure 4.1: Block Diagram of the PFN. 
We begin with a block diagram of the Pulse Forming Network - Figure 4.1. Let your eyes start with the remote computer, flowing counter clockwise to see how with complete optical isolation a user can safely charge 10 large capacitors with high voltage and discharge them into a launcher all the while collecting the Acceleration and Current information on an oscilloscope. A different, more complicated, yet complete, way to look at the total system is in terms every major component - Figure 4.2.

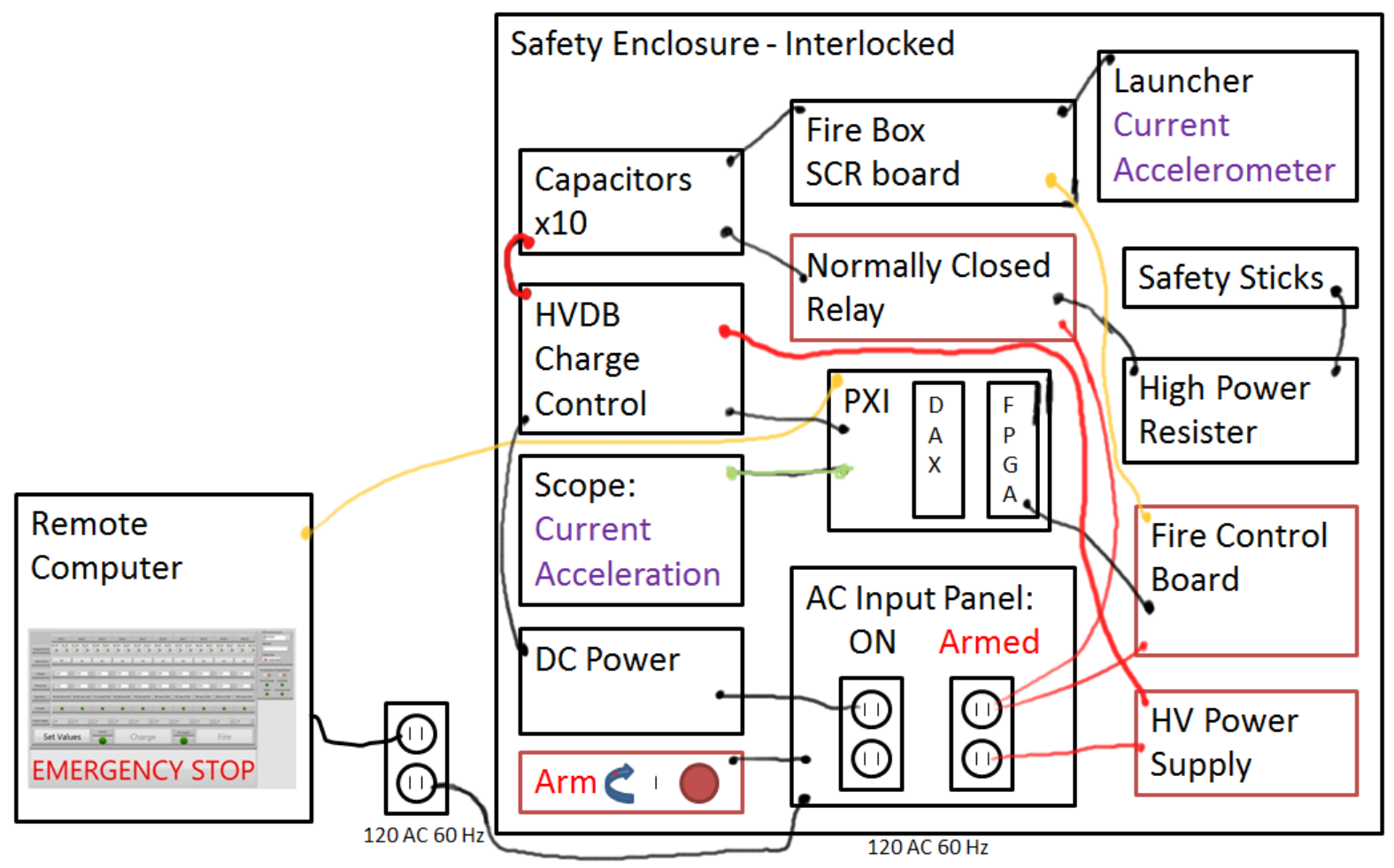

Figure 4.2: Block Diagram of Every Component. 
Notice that the PFN will have 10 banks of capacitors monitored with High Voltage Divider Boards (HVDB), charged with a high voltage power supply using H-Bridge boards, fired with an optical signal using SCR Boards, remotely discharged with the AC Interlock Panel, that server as building blocks. Before we detail each system, let us first turn our attention to these blocks. One bank, depending on it capacitance and inductance value can look very different from another. Nevertheless, there is much commonality between all the Banks. Figure 4.3 shows what one bank could look like.

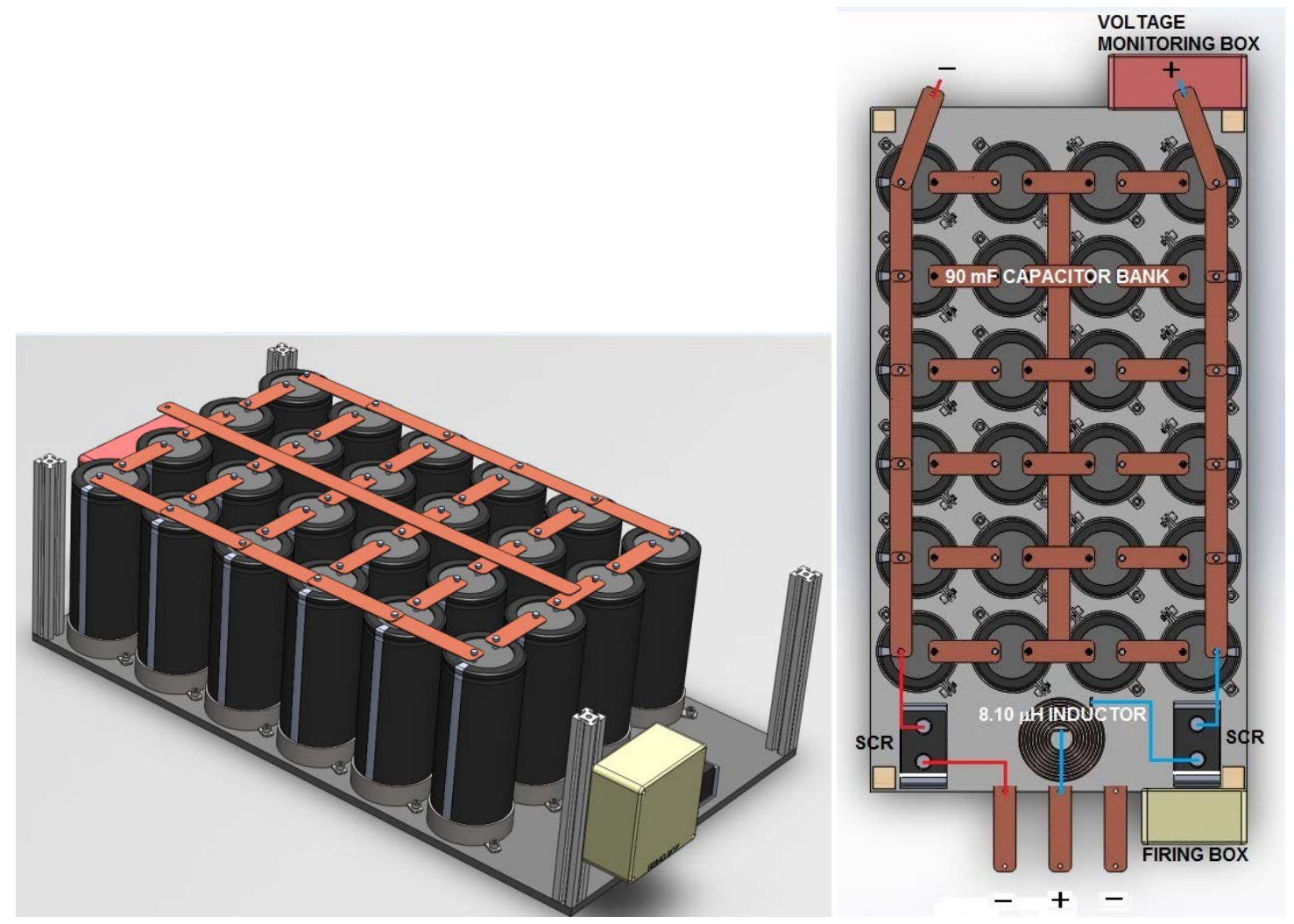

Figure 4.3: One PFN bank. 
These banks will be placed in a standard 16 inch rack. Five banks on one side and five on another. It should be noted that because this system was designed with modular architecture at the very foundation. Meaning, one bank does not have to fit into a server rack one bank could be a server rack or larger or smaller. On this thought, remember from section 2.4 that one could build a Type C Guillemin Network by simply loading each of the five shelves with one capacitor and one inductor and treating the entire rack as one bank.

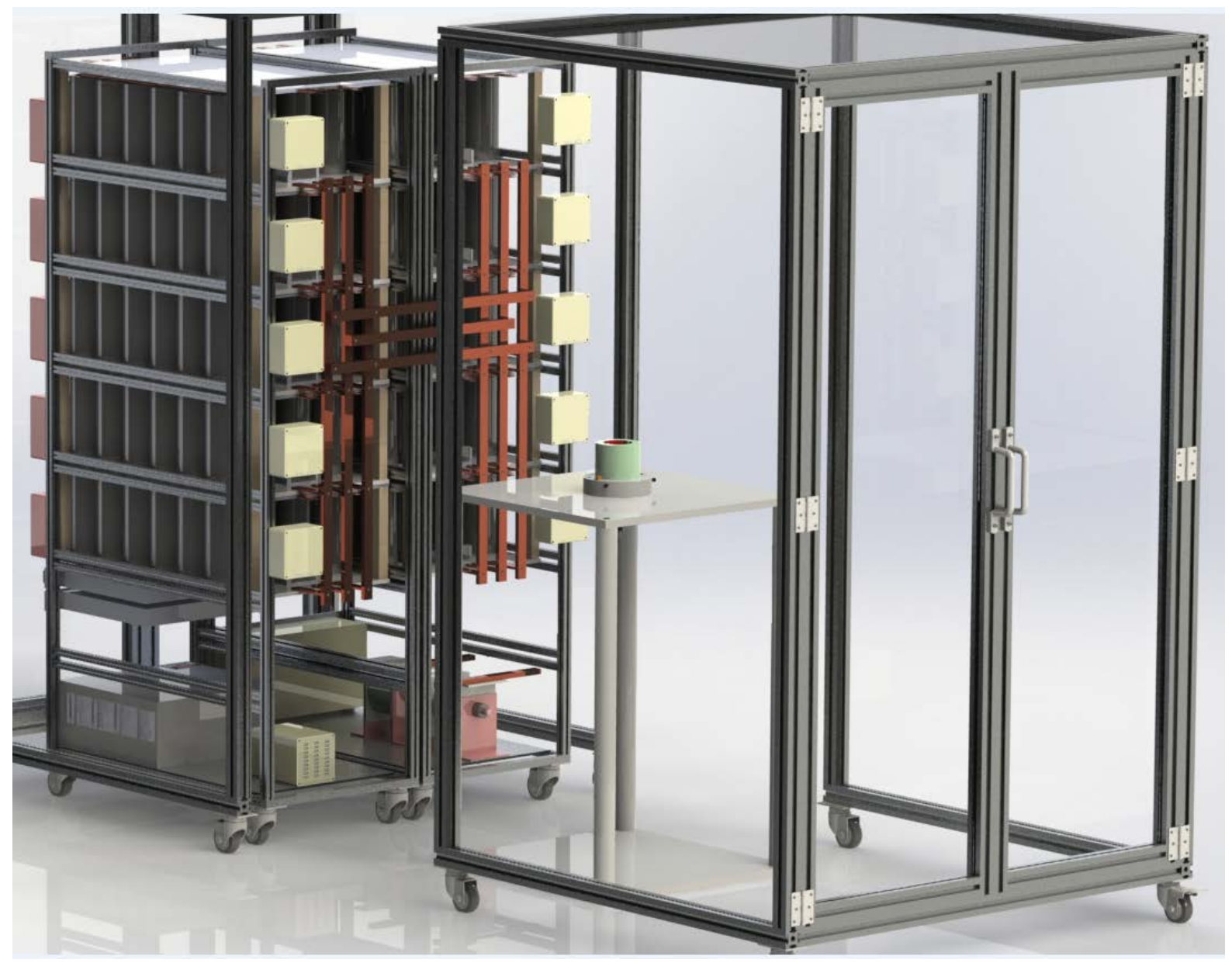

Figure 4.4: PFN at maximum capability - Front. 


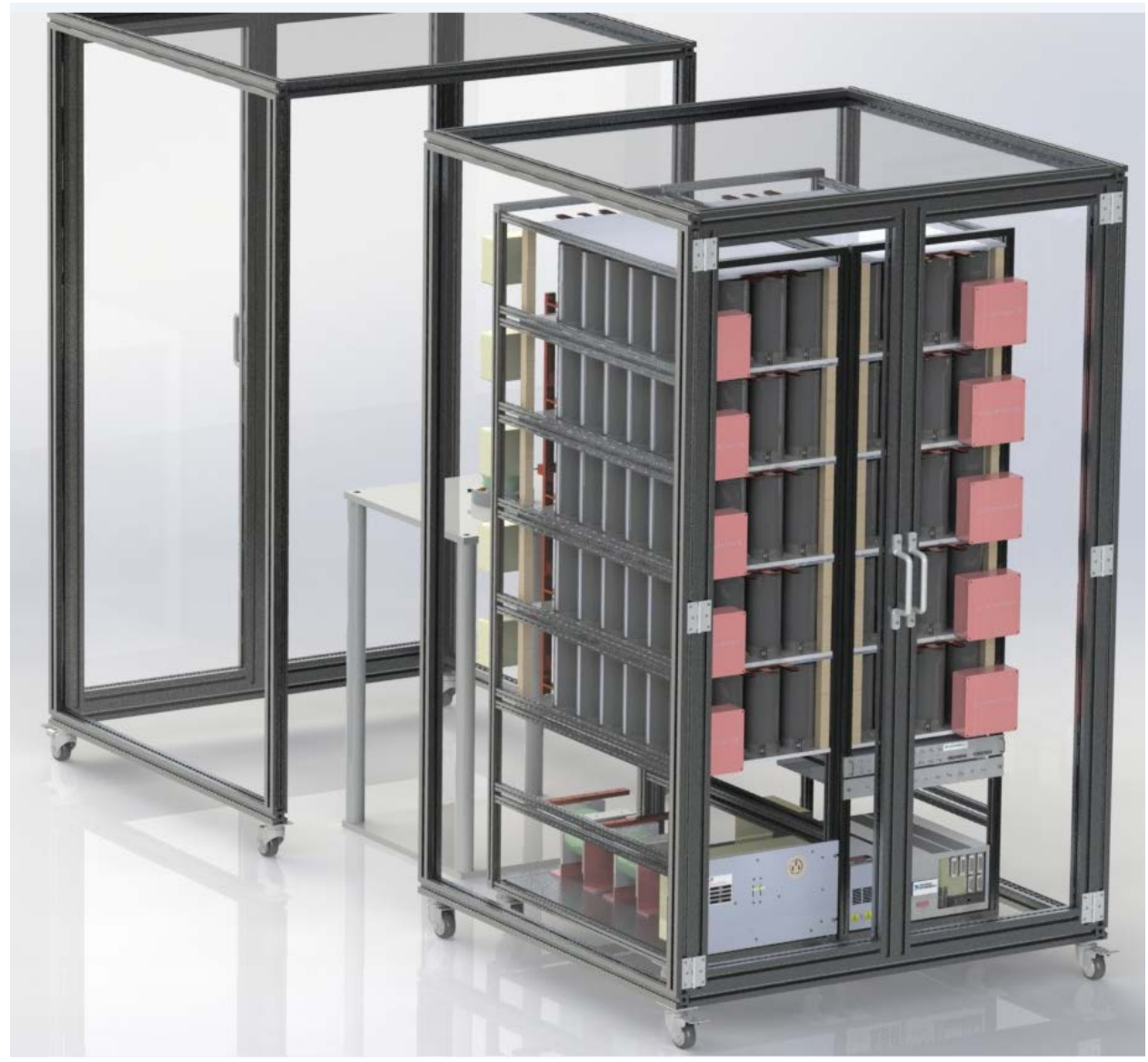

Figure 4.5: PFN at maximum capability - Back.

Figures 4.4 and 4.5 show the PFN at full capacity, ten banks of 24 capacitors each for a total stored energy of $450 \mathrm{~kJ}$. Impressive as a total stored energy of the magnitude is, flexibility of pulse shape is the desire of this work - not stored energy. For maximum flexibility, no more than two banks will have the same capacitance and inductance. Further reducing the total amount of energy stored is the simple fact that electrolytic capacitors were used in this investigation and they cannot be reverse biased so the maximum amount of energy stored is half.

If there was one key lesson, I took from my undergraduate studies in terms of electromagnetic compatibility, it is that the geometric centroid of the 'to path' must be the 
geometric centroid of the 'return path.' This single principle guided the design of the 'lid' of each bank, and the firing transmission line. Figure 4.5 shows the 'lid' of the bank. Notice that the 'to path' is nestled in between 'return paths.' Take a closer look at Figure 4.4 and the primary 1 "x 0.5 ” copper conductors maintain the same principle.

\subsection{Safety Systems and Power Distribution}

Any high-energy experiment must be conducted with safety as the number one highestranking consideration of paramount importance. Important safety considerations include personnel training, isolation, and national standards for electrical safety. With regard to the first, it is very important that untrained individuals should not try to read this chapter and build a high energy PFN without considering death or dismemberment. Isolation, as used in this chapter is in two forms - human and equipment. The National Electric Code is the best place to find the standards for electrical safety and was the supreme decision maker with regard to many things like wire or insulation rating choices.

The primary requirement for a high energy system is that there are multiple safe methods to dissipate the energy. This is why we introduce the power system first. In the event of a power outage, or accident, or unauthorized human entry into the experiment the system must dissipate any stored energy safely. Enter the AC Input Panel and arm switch. Together, they create the basis of automatically ensuring energy is dissipated. When the PFN is not armed, a normally closed relay is shorting out the capacitor with a high power resister, only the communication systems, the scope, and low voltage DC power is operational. As soon as the PFN is armed, the relay will open and power will be supplied to the high voltage power supply and the Fire Control 
Board. With safety in mind, the entire experiment is enclosed with interlocks so that if the two shells or doors are opened or if there is a loss of power the PFN will become unarmed and the relay in combination with the high power resistor will safely dissipate the energy. In the event the relay does not work, use safety sticks manually to dissipate the stored energy.

The first safety sticks are resistive and the second are dead shorts. The resistive sticks are for use on energized equipment to dissipate the energy form unforeseen circumstances. Only after energy has been dissipated from the system should the dead short safety sticks be used. There primary purpose is to keep the capacitors at ground when work is being performed on the network.

Power distribution has to be the most boring yet important jobs of an electrical engineer save paperwork. AC power distribution has already been discussed, as it is key to the overall safety plan. DC power distribution was done in a cost effective and creative way by using a USB cable. Because each box as labeled in Figure 4.3 requires no more than $100 \mathrm{~mA}$ a USB cable can handle the current. Special care in a cable management strategy will be the only concern to ensure that they go nowhere near the high voltage. The benefit is that both the cables and ports are readily available and at a very low cost point.

The last item to mention with regard to the safety system is a large and loud light. The light's purpose is to warn people in the area that a shot is about to take place. The light also shows when the bank is armed. The light is controlled by the PXI via Break out box (Figure 4.6). The light can be used more in the future for such things as signaling when there was a error or 
signaling the area is safe. See the Labview code (p. 112) for just how the Light was used and for the data collected in this dissertation.

\subsection{Voltage Monitoring}

The voltage of a single capacitor bank is measured with the HVDB board located in the Voltage Monitoring Box. This board, detailed in the appendix, was designed taking special care to ensure that neither terminal of the capacitor is connected to ground and is appropriately fused. The primary purpose of the board is to divide $\pm 1500 \mathrm{~V}$ down to \pm 10 Volts. The output of the board is sent through BNC cable to the rack mounted BNC breakout board connected to the PXI.

\subsection{Charging System}

The power supply selected is the XXX. It is a 1000 watt, 1500 Volt supply. This supply is powered from the AC input panel armed plug and controlled by the PXI via breakout box Figure 4.6. Because there is only one power supply, but then banks, there is a need for Charge control boards. Before the power supply is turned on a signal is sent to the charge control board allowing a path to the Capacitors. Because there exists a need to retro pulse and the power supply is only a positive power supply an additional board was built - the H-Bridge Board. This board allows a bank to be charge to a negative potential relative to the other banks. 


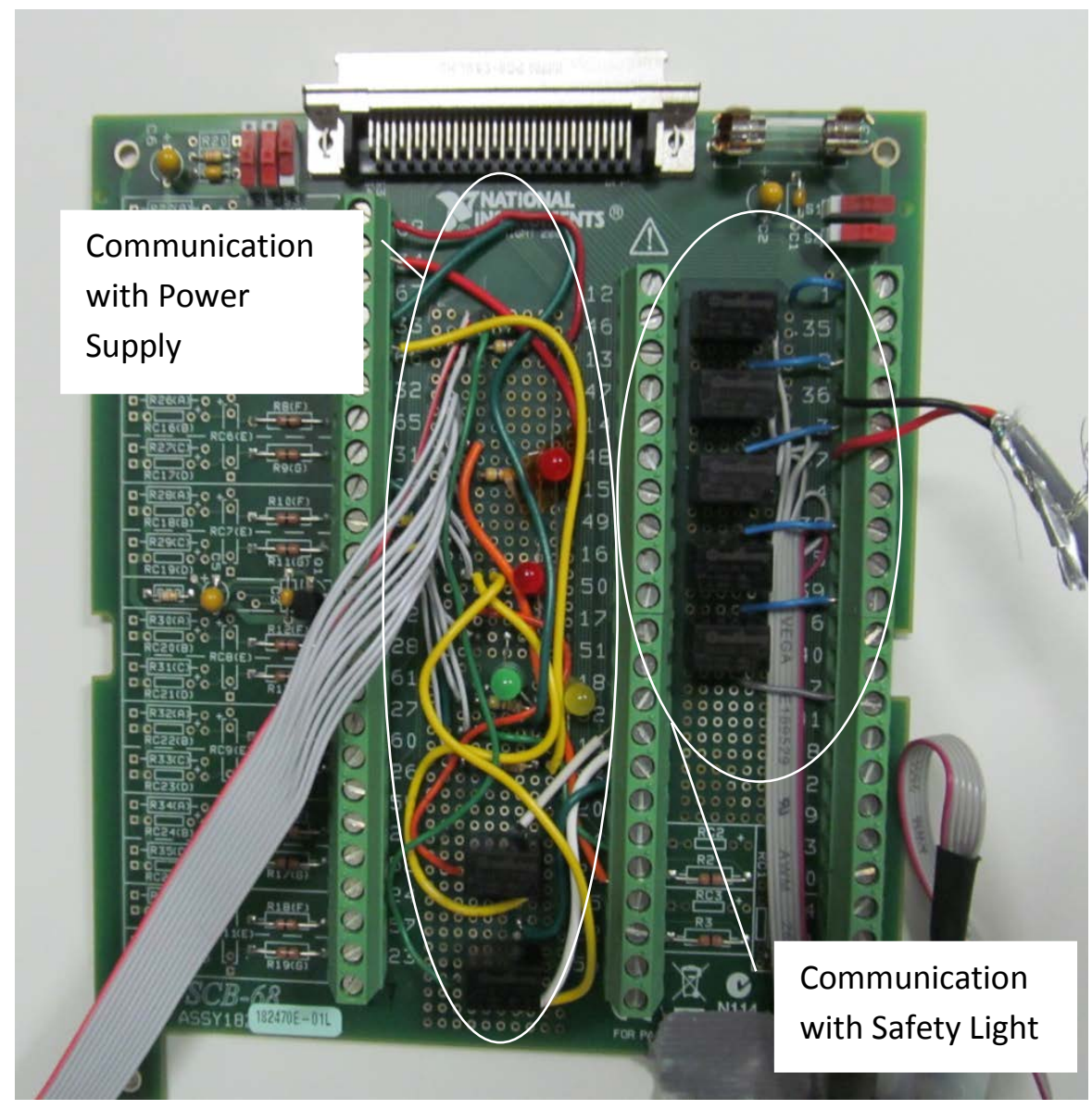

Figure 4.6: PXI DAX Breakout box - labeled.

In the Software section there will be more detail as to how the charging system was used manually to charge different banks. With regard to future optimizations, one can easily see how to control the charging of all the banks in a way that is both safe and effective.

\subsection{Firing Systems}

Up to this point isolation has been used for human protection. In this section, we will see that isolation is used for equipment protection. The best place to start for the firing system is 
with the requirements from the Theory section - very accurate timing. For this to work well we will use a Field Programmable Gate Array (FPGA). The user uses the software to program in when each bank should fire relative to one another. When the Fire button is clicked the FPGA takes over and sends the signals to the Fire Control Board (FCB). The fire control board converts the electrical signals into optical signals for equipment isolation.

The Optical signals are received by the SCR board. On the SCR board there is more layer of isolation - the transformer. This transformer then allows a pulse to be sent to the gate of the SCRs which in turn allows the large amount of energy stored in the capacitor to be released in the form of current traveling to the Launcher and causing the projectile to accelerate. Just how much current and acceleration will be detailed in Chapter 5 .

\subsection{Software}

The language selected for the software was National Instruments - Labview. To survive in this visual environment, it is critical that many Virtual Instruments (VIs) were created. All of the code is in the Appendix we will only detail the primary situation and state sequence of the main operating procedure. A user first sees the Front Panel - Figure 4.7. The user selects what banks they will use, what voltage they will be charged to, and when they will fire relative to one another. Then the Set Values button is pressed. 


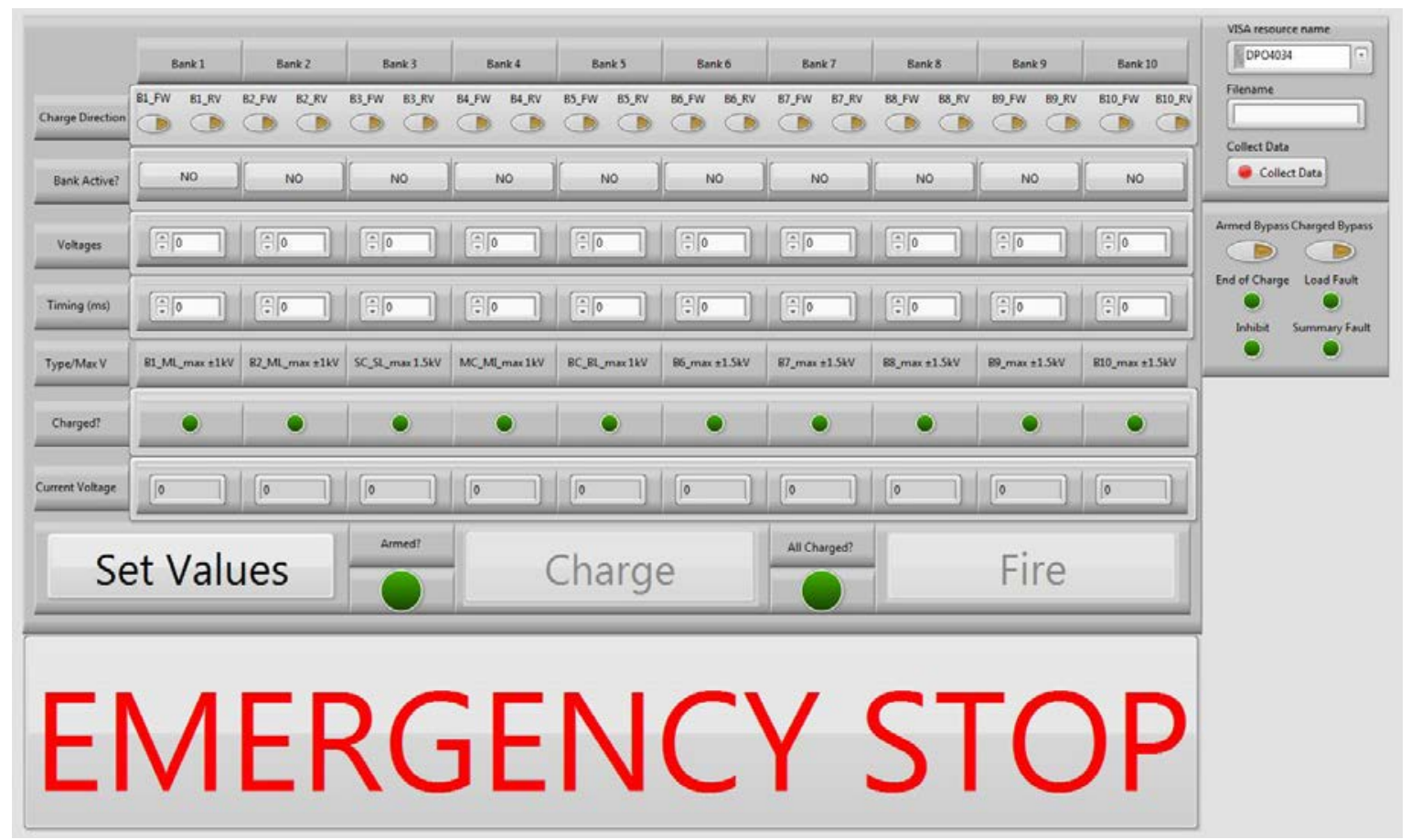

Figure 4.7: Front Panel of PFN Software.

When the Set Values button is pressed the Charge button becomes available. Now it is the users responsibility to manually click the forward (FW) or reverse (RW) Charge Disconnect buttons and then press the Charge button. When the charging is complete it is the users reasonability to stop charging and disconnect the power supply with the Charge Disconnect buttons.

After all the banks have been charged, the Fire button is activated. When the Fire button is pressed, as discussed in the fire section, the banks are allowed to discharge into the launcher. Assuming there was a successful shot; the Collect Data button is pressed after naming what shot was just preformed. In the Future work section, it will be shown the entire operation described can be a sub VI with a new Font panel that asks the user for the shape, duration and peak amplitude. 


\section{CHAPTER 5}

\section{PFN CHARACTERIZATION}

\subsection{Introduction}

During the last three years, we have taken hundreds of shots with a several different HEMLs. Several years before, Dr. Engel was experimenting with and perfecting these Launchers. The HEML currently connected to the PFN is on shot number 253 and in great condition. This Chapter will focus on the last fifty shots from the PFN perspective. It will also include, in section 5.4, the Optimization verification, and repeatability study previously presented at the $83^{\text {rd }}$ SAVE conference [17]. In the appendix are all 124 pictures, two each, of the 62 shots described in this section. For the simple purpose of motivation and encouragement to do well in this section, my two favorite Lord Kelvin quotes:

"To Measure is to Know"

"If you cannot measure it, you cannot improve it."

\subsection{Peak Current Pulses and Inductive Gradient Distribution}

For each shot, Figure 5.1 contains the electrical parameters of interest. Each parameter is a different color and the bars are directly proportional to the magnitude of the value. The first assumed 'known' quantity is the capacitance. A capacitance meter with the ability to measure these values was not accessible so we have to take the manufacture's word on the values - why it is 'known'. 


\begin{tabular}{|c|c|c|c|c|c|c|c|}
\hline & MAX & 0.09 & 0.00262885 & 1500 & 14160 & 0.424 & 0.221 \\
\hline & MIN & 0.005 & 8.1049E-06 & 200 & 2320 & 0.017 & 0.015 \\
\hline Shot\# & Name & Capacatance (F) & Inductance (H) & Voltage (V) & Peek Current (A) & $\begin{array}{c}R(\Omega) \text { if } \\
\text { underdamped }\end{array}$ & $\begin{array}{c}R(\Omega) \text { if } \\
\text { overdamped }\end{array}$ \\
\hline 1 & 1_BC_BI_1000V & 0.0900 & $2.63 \mathrm{E}-03$ & 1000 & 2940 & 0.233 & \\
\hline 2 & 2_BC_MI_300V & 0.0900 & $1.08 \mathrm{E}-04$ & 300 & $\square \quad 3940$ & 0.041 & \\
\hline 3 & 3_BC_MI_500V & 0.0900 & $1.08 \mathrm{E}-04$ & 500 & 6420 & 0.039 & \\
\hline 4 & 4_MC_MI_1000V & 0.0375 & $1.08 \mathrm{E}-04$ & 1000 & 9600 & 0.075 & \\
\hline 5 & 5_MC_MI_500V & 0.0375 & $1.08 \mathrm{E}-04$ & 500 & 4820 & 0.075 & \\
\hline 6 & 6_MC_MI_300V & 0.0375 & $1.08 \mathrm{E}-04$ & 300 & 2940 & 0.076 & \\
\hline 7 & 7_SC_MI_500V & 0.0050 & $1.08 \mathrm{E}-04$ & 500 & 2380 & 0.250 & \\
\hline 8 & 8_SC_MI_1000V & 0.0050 & $1.08 \mathrm{E}-04$ & 1000 & 4860 & 0.251 & \\
\hline 9 & 9_SC_MI_1500V & 0.0050 & $1.08 \mathrm{E}-04$ & 1500 & 7180 & 0.250 & \\
\hline 10 & 10_MC_MI_500V & 0.0375 & $1.08 \mathrm{E}-04$ & 500 & 4810 & 0.075 & \\
\hline 11 & 11_SC_SI_300V & 0.0050 & $8.10 \mathrm{E}-06$ & 300 & 2980 & 0.032 & \\
\hline 12 & 12_SC_SI_500V & 0.0050 & $8.10 \mathrm{E}-06$ & 500 & 4740 & 0.021 & \\
\hline 13 & 13_SC_SI_1000V & 0.0050 & $8.10 \mathrm{E}-06$ & 1000 & 9640 & 0.026 & \\
\hline 14 & 14_SC_SI_1500V & 0.0050 & $8.10 \mathrm{E}-06$ & 1500 & 13000 & & 0.027 \\
\hline 15 & 15_MC_BI_1000V & 0.0375 & $2.63 \mathrm{E}-03$ & 1000 & 2320 & 0.424 & \\
\hline 16 & 16_MC_SI_300V & 0.0375 & $8.10 \mathrm{E}-06$ & 300 & 6200 & & 0.020 \\
\hline 17 & 17_MC_SI_500V & 0.0375 & $8.10 \mathrm{E}-06$ & 500 & 9640 & & 0.024 \\
\hline 18 & 18_BC_SI_300V_withdiode & 0.0900 & $8.10 \mathrm{E}-06$ & 300 & 7560 & & 0.022 \\
\hline 19 & 19_BC_SI_300V_withoutdiode & 0.0900 & $8.10 \mathrm{E}-06$ & 300 & $74 \$ 0$ & & 0.023 \\
\hline 20 & 20_SC_SI_300V_withoutdiode & 0.0050 & $8.10 \mathrm{E}-06$ & 300 & 3320 & 0.045 & \\
\hline 21 & 21_SC_SI_500V_withoutdiode & 0.0050 & $8.10 \mathrm{E}-06$ & 500 & 5160 & 0.037 & \\
\hline 22 & 22_SC_SI_1000V_withoutdiode & 0.0050 & $8.10 \mathrm{E}-06$ & 1000 & 9400 & 0.019 & \\
\hline 23 & 23_SC_SI_1500V_withoutdiode & 0.0050 & $8.10 \mathrm{E}-06$ & 1500 & 14160 & 0.020 & \\
\hline 24 & 24_SC_MI_1000V_withoutdiode_1 & 0.0050 & $1.08 \mathrm{E}-04$ & 1000 & 5080 & 0.255 & \\
\hline 25 & 25_SC_MI_1000V_withoutdiode_2 & 0.0050 & $1.08 \mathrm{E}-04$ & 1000 & 5240 & 0.258 & \\
\hline 26 & 26_BC_MI_300V_withoutdiode_1 & 0.0900 & $1.08 \mathrm{E}-04$ & 300 & 4120 & 0.044 & \\
\hline 27 & 27_BC_MI_300V_withoutdiode_2 & 0.0900 & $1.08 \mathrm{E}-04$ & 300 & 4280 & 0.046 & \\
\hline 28 & 28_SC_MI_300V_withoutdiode & 0.0050 & $1.08 \mathrm{E}-04$ & 300 & 2840 & 0.283 & \\
\hline 29 & 29_BC_MI_300V_withoutdiode_3 & 0.0900 & $1.08 \mathrm{E}-04$ & 300 & 4200 & 0.045 & \\
\hline 30 & 30_BC_MI_300V_withoutdiode_4 & 0.0900 & $1.08 \mathrm{E}-04$ & 300 & 4200 & 0.045 & \\
\hline 31 & 31_SC_MI_500V_1 & 0.0050 & $1.08 \mathrm{E}-04$ & 500 & 2600 & 0.257 & \\
\hline 32 & 32_SC_MI_500V_2 & 0.0050 & $1.08 \mathrm{E}-04$ & 500 & 2970 & 0.266 & \\
\hline 33 & 33_B1_MI_300V_1 & 0.0300 & $1.08 \mathrm{E}-04$ & 300 & 3040 & 0.095 & \\
\hline 34 & 34_B1_B2_4 mslater_MI_300V_1 & 0.0300 & $1.08 \mathrm{E}-04$ & 300 & 2960 & 0.094 & \\
\hline 35 & 35_B1_B2_4 mslater_MI_300V_2 & 0.0300 & $1.08 \mathrm{E}-04$ & 300 & 3520 & 0.102 & \\
\hline 36 & 36_B1_B2_2mslater_300V & 0.0300 & $1.08 \mathrm{E}-04$ & 300 & 3760 & 0.104 & \\
\hline 37 & 37_B1_B2_symo_MI_300V & 0.0300 & $1.08 \mathrm{E}-04$ & 300 & 3760 & 0.104 & \\
\hline 38 & 38_B1_MI_300V_2 & 0.0300 & $1.08 \mathrm{E}-04$ & 300 & 3040 & 0.095 & \\
\hline 39 & 39_B1_MI_300V_3 & 0.0300 & $1.08 \mathrm{E}-04$ & 300 & 3040 & 0.095 & \\
\hline 40 & 40_B1_MI_300V_crowbarat1ms & 0.0300 & $1.08 \mathrm{E}-04$ & 300 & 2560 & 0.083 & \\
\hline 41 & 41_BC_MI_200V_B2_1ms & 0.0900 & $1.08 \mathrm{E}-04$ & 200 & 2800 & 0.045 & \\
\hline 42 & 42_BC_MI_200V_B2_2ms & 0.0900 & $1.08 \mathrm{E}-04$ & 300 & 2800 & & 0.038 \\
\hline 43 & 43_B1_MI_300V_4 & 0.0300 & $1.08 \mathrm{E}-04$ & 300 & 3040 & 0.095 & \\
\hline 44 & 44_B1_300V_B2_-200V_1mslater & 0.0300 & $1.08 \mathrm{E}-04$ & 300 & 3120 & 0.097 & \\
\hline 45 & 45_B1_300V_zoomedin & 0.0300 & $1.08 \mathrm{E}-04$ & 500 & 3040 & & 0.017 \\
\hline 46 & 46_B1_MI_500V_1 & 0.0150 & $1.08 \mathrm{E}-04$ & 500 & 2800 & 0.107 & \\
\hline 47 & 47_B1_MI_500V_2 & 0.0150 & $1.08 \mathrm{E}-04$ & 500 & 3120 & 0.122 & \\
\hline 48 & 48_B1_MI_500V_3 & 0.0150 & $1.08 \mathrm{E}-04$ & 1000 & 2640 & & 0.221 \\
\hline 49 & 49_B1_MI_1000V_nofilter & 0.0150 & $1.08 \mathrm{E}-04$ & 1000 & 5440 & 0.102 & \\
\hline 50 & 50_B1_MI_1000V_filtercap & 0.0150 & $1.08 \mathrm{E}-04$ & 1000 & 3600 & & 0.114 \\
\hline 51 & $10-S 3 A$ & 0,0385 & $9.00 \mathrm{E}-06$ & 300 & 5760 & & 0.023 \\
\hline 52 & $12-S 4 A$ & 0,0385 & $9.00 \mathrm{E}-06$ & 500 & 9280 & & 0.025 \\
\hline 53 & 14-S5A & 0,0385 & $9.70 \mathrm{E}-05$ & 500 & 5280 & 0.072 & \\
\hline 54 & 16-S6A & 0,0385 & $7.00 \mathrm{E}-05$ & 500 & 6400 & 0.063 & \\
\hline 55 & 18-S7A & 0.0385 & $4.40 \mathrm{E}-05$ & 500 & 6480 & 0.037 & \\
\hline 56 & 20-S8A & 0,0385 & $2.20 \mathrm{E}-05$ & 500 & 8240 & 0.017 & \\
\hline 57 & 22-S9A & 0.0385 & $9.00 \mathrm{E}-06$ & 400 & 8240 & & 0.018 \\
\hline 58 & 24-S10A & 0,0385 & $9.00 \mathrm{E}-06$ & 200 & 4320 & & 0.015 \\
\hline 59 & 1-S11A & 0,0385 & $9.70 \mathrm{E}-05$ & 300 & 3200 & 0.073 & \\
\hline 60 & 2-S12A & 0,0385 & $9.70 \mathrm{E}-05$ & 400 & 4240 & 0.073 & \\
\hline 61 & 3-S13A & 0,0385 & $9.70 \mathrm{E}-05$ & 500 & 4880 & 0.066 & \\
\hline \multirow[t]{2}{*}{62} & 4-S14A & 0,0385 & $9.70 \mathrm{E}-05$ & 600 & 5600 & 0.062 & \\
\hline & & & & & & $R(\Omega)$ average & 0.095 \\
\hline
\end{tabular}

Figure 5.1: Electrical Measures of the PFN shots. 
The second parameter is the inductance, measurements were taken on a Agilent 4284A precision LCR Meter at $1 \mathrm{kHz}$ to find these values. These voltage values were 'as set' and measured with an Agilent 3458 digital multimeter (DMM).

The peak current values were taken with a Rogowski coil logged on a scope. The Resistance values were calculated with equations 3.8 and 3.9 simply for the purpose of confirming a reasonable low resistance and for indicating whether each shot was underdamped or over damped. As can be seen, the peak current values range from 2.3 to $14.1 \mathrm{kA}$.
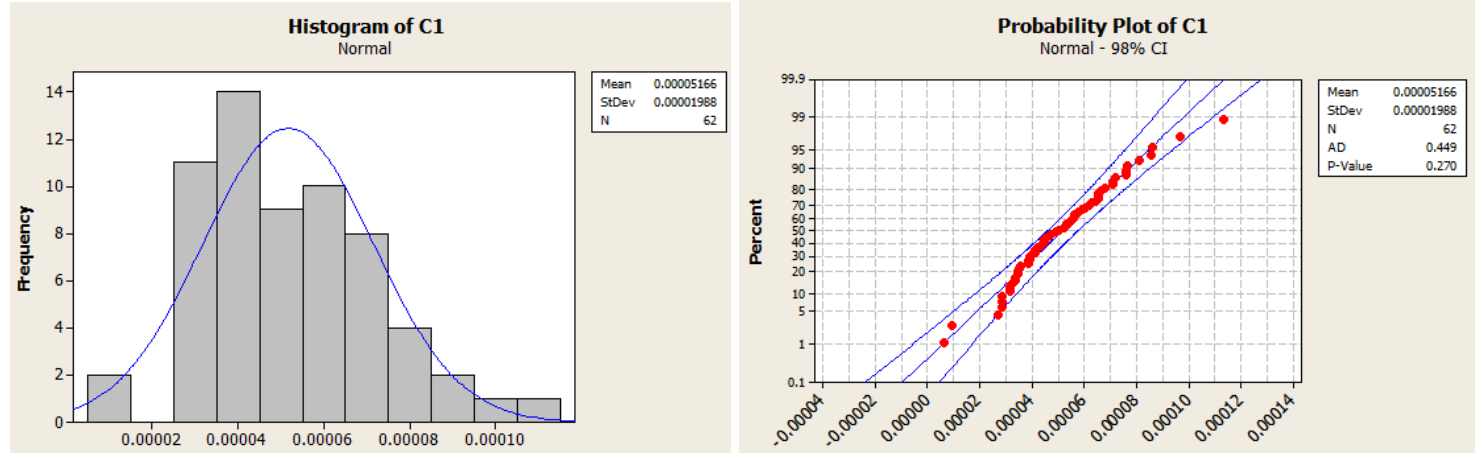

Figure 5.2: Histogram and Normality Test of Calculated M’.

With peak current values, a known mass and equation 3.27 we can calculate the Mutual Inductive Gradient of the launcher. After calculating for each of the 62 shots we can look at the distribution and test for normality. The normality test passed, meaning the $\mathrm{P}$ value is greater than 0.05 .

\subsection{Initial L \&C Assumption Verification}

The initial assumption in the algorithm is based on equation 3.13 and 3.29. As far as equation 3.13 is concerned the introduction of a free wheel diode elongates the pulse width. In the appendix (p. 87), there are diode configuration simulations that will help with the 
understanding of this statement. That said, when the diode is removed one can see what one should - the bigger the capacitance and inductance, the bigger the pulse width and vice versa.

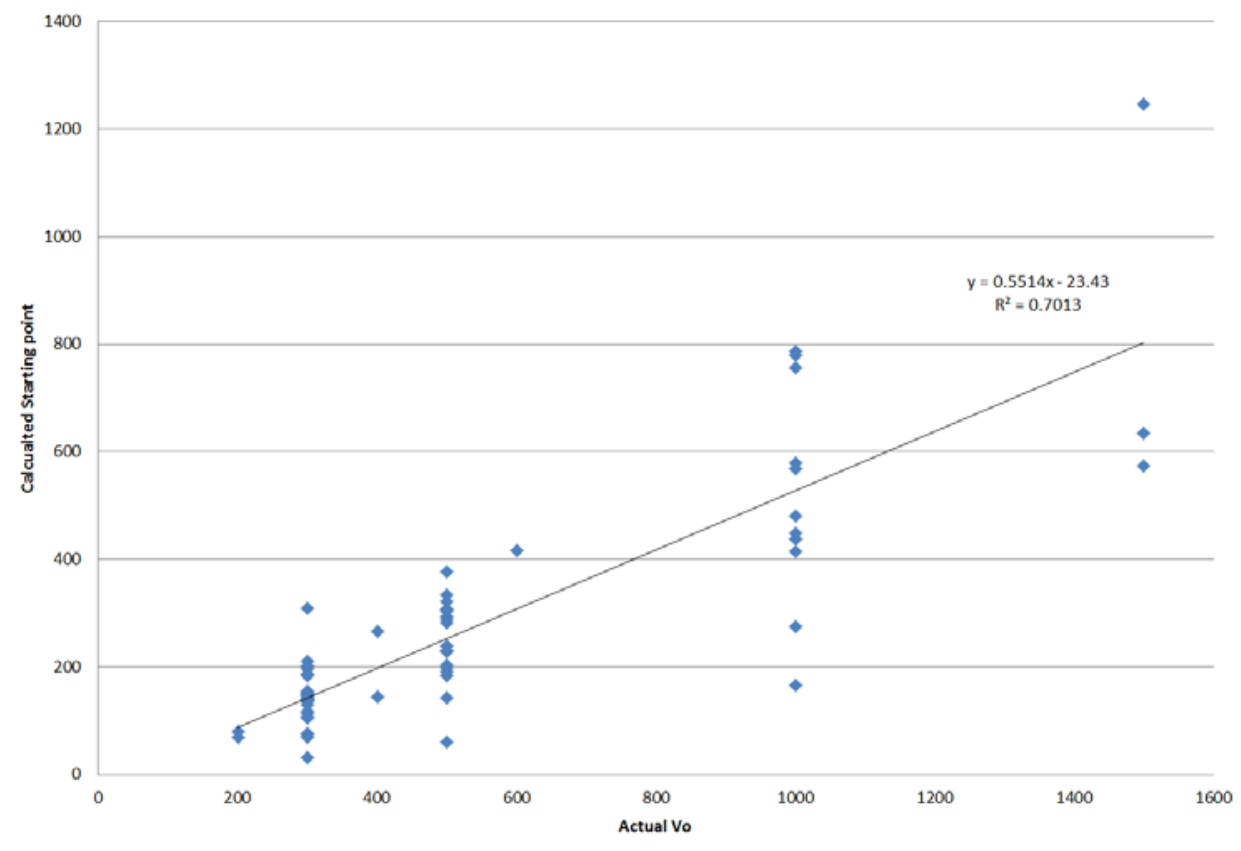

Figure 5.3: Equation 3.29 Verification.

Now that we have a good estimate of the mutual inductive gradient, from section 5.2, we can calculate what would have been the initial voltages. We may now know if the proposed is a good starting point. Figure 5.3 shows that our starting point has some to be desired, but will not over shock the part if it is used.

\subsection{Optimization Verification}

In light of the fact that getting the correct shock the first time with no previous experience is challenging, optimization is not. In fact, the three lines referred to in the algorithm will be defined now and can be seen in Figure 5.4 - Compare this to Figure 2.9 and 2.10. The 
lines are also documented in the appendix. The first line is found by changing nothing but the voltage and measure the peak acceleration amplitude. The second line, give a voltage change the inductance until the desired pulse width is found. The third line, same as the first, change the voltage until the desired peak amplitude, or velocity change is found. In this way the algorithm, and in turn the PFN, will converge on the desired solution. Also, note in Figure 5.4 the many different points one can start with depending on the initial assumption of pulse width. For example, Big Capacitor Big Inductor (BC_BI) starts the pulse width at 20 milliseconds, while Small Capacitor Small Inductor (SC_SI) has a starting pulse width of 720 microseconds.

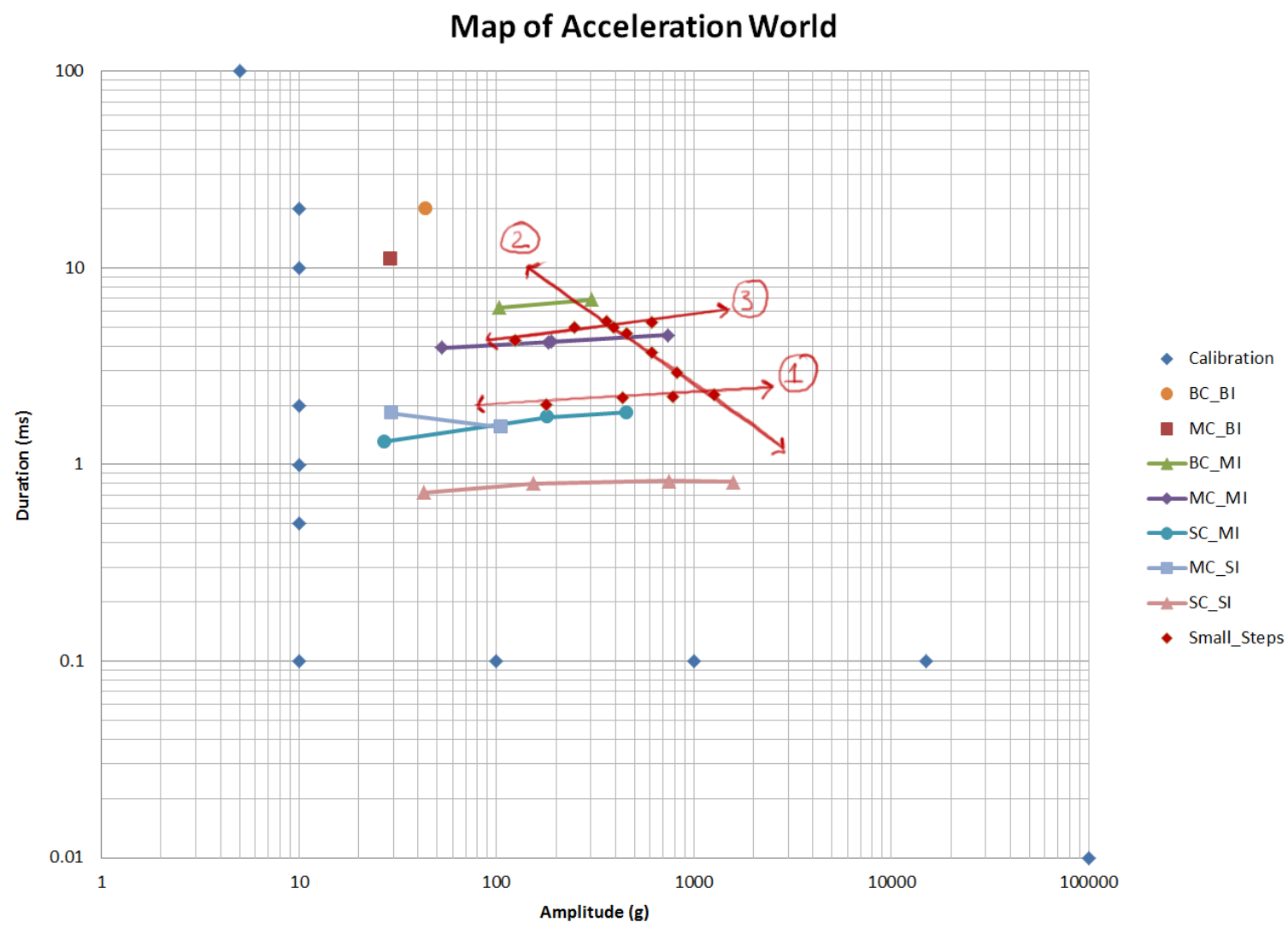

Figure 5.4: The Three lines on a Map of the Acceleration world. 


\subsection{Synchronous Firing Verification}

Shots 34-36 show that the PFN has the capability to fire shots in sequence. What was a surprise was the fact that one can stack the acceleration on one another - shot 36. Meaning, not only does the duration increase, from $3.2 \mathrm{~ms}$ to $4.13 \mathrm{~ms}$ as proposed in section 3.2 , but that amplitude can as well from $39.9 \mathrm{~g}$ to $77.6 \mathrm{~g}$. Shot 35 shows the unique ability of an EML for shock pulsing, namely multiple shock scenarios.

\subsection{Simultaneous Firing Verification}

The simultaneous shot number was 37. Here it is best to compare with shot 36 from above. The amplitude decreased from $77.5 \mathrm{~g}$ to $71.1 \mathrm{~g}$ but the duration increased from $4.1 \mathrm{~ms}$ to $5.1 \mathrm{~ms}$. When the values of capacitance and initial voltage are not matched, as they were for shot number 37, this trend will be influenced. Future work should be done to more fully understand the possibility of pulse shaping in this way.

\subsection{Retropulsing}

As a reminder, Retropulsing is a technique to increase the negative Jerk - shorten the fall time. Comparing Shot 43 and 44 we see that this technique is effective decreasing the fall time from $1.396 \mathrm{~ms}$ to $0.721 \mathrm{~ms}$ - Figure 5.5. Remember, that Retropulsing gives the ability to vary the change on the fall time with the value of the negative voltage of the second capacitor; whereas crowbarring does not allow variability of fall time. Note that the moment there is a 
discontinuity in the induced acceleration mechanical resonances are excited. An entire thesis was devoted to studying this phenomenon [50]. Harris and Crede said, "The Design of equipment to withstand dynamic loads is one of the more difficult and less developed aspects of shock and vibration [51]." They go on to say, "One of the more troublesome problems in the design...is the proper balance between flexibility and rigidity of structures [51].” Keeping this in mind, not only investigating the launcher design but the PFN design can lead to less resonance. More work should be done to completely verify Retropulsing experimentally and give a degree to the variability that can be obtained.

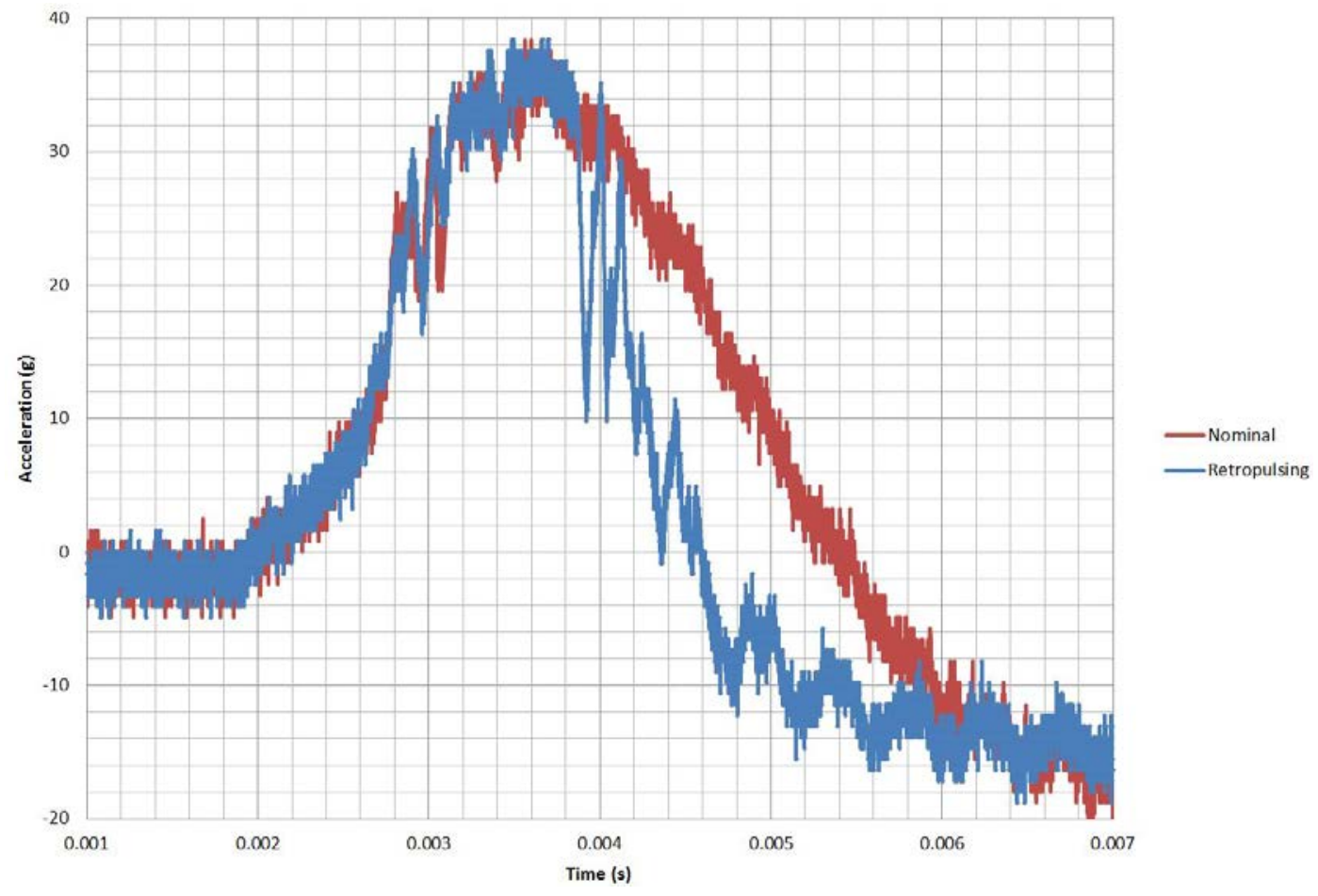

Figure 5.5: Retropulsing verification Shot 43 (red) vs. Shot 44 (blue). 


\subsection{Filter Capacitor}

As a reminder, using a filter capacitor is a technique to decrease the positive Jerk lengthen the rise time. Comparing Shots 49 and 50, we see that this technique is effective increasing the rise time from $0.559 \mathrm{~ms}$ to $0.677 \mathrm{~ms}$ - Figure 5.6. This technique gives the ability to vary the change on the rise time with the value of the second capacitor. More work should be done to completely verify this experimentally and give a degree to the variability.

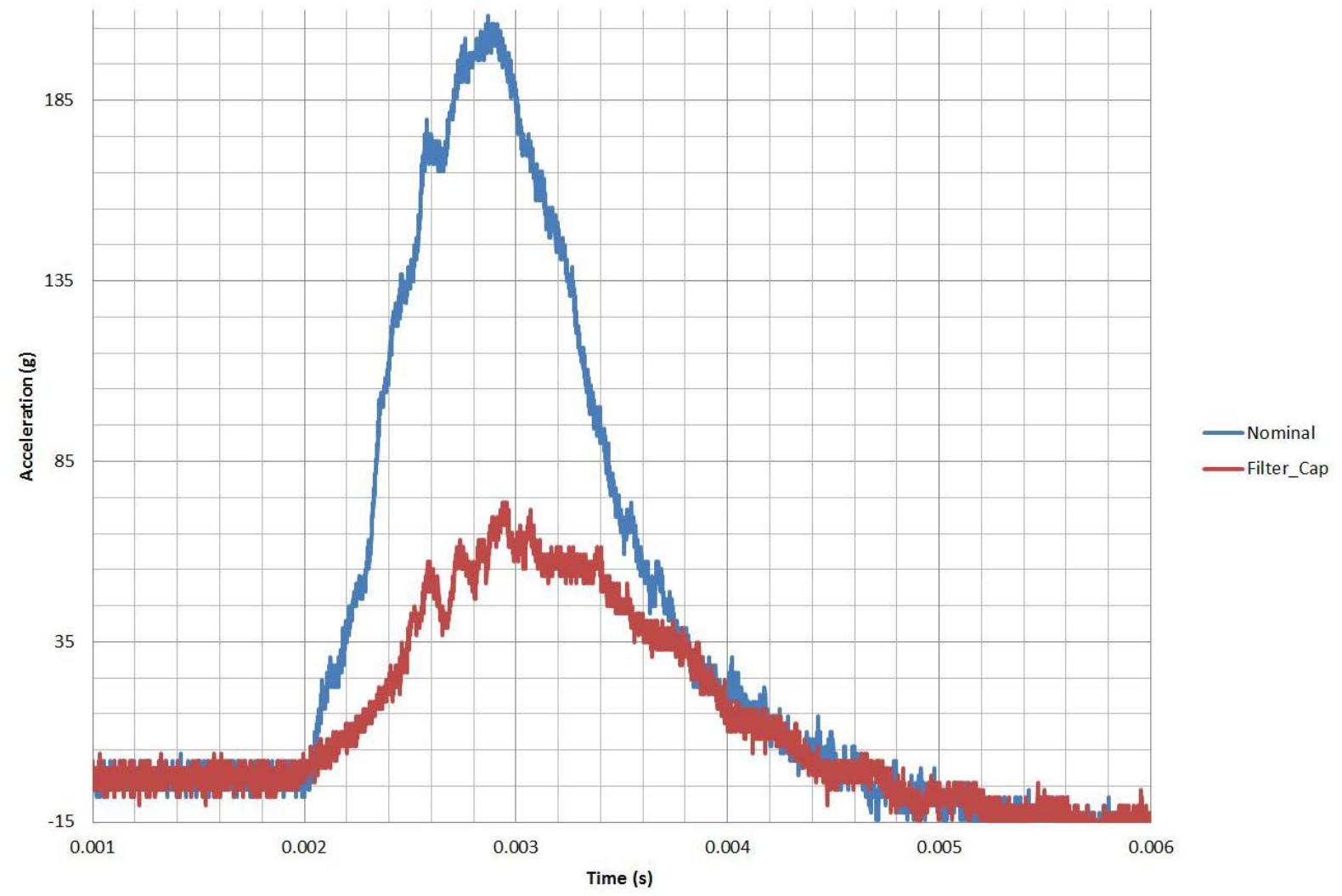

Figure 5.6: Filter Cap Verification, Shot 50 (red) vs. Shot 49 (blue). 


\subsection{Acceleration Size and Shape Verification}

Considering all 62 shots a wide range of amplitudes, durations and resulting velocity changes were obtained. Figure 5.7 shows the results of these tests on the map of the acceleration world. Figure 5.8 tabulates the numeric values; red denotes high values and blue denotes smaller values. The maximum velocity change was 70 feet per second, maximum duration was almost $20 \mathrm{~ms}$, maximum acceleration value was $1571 \mathrm{~g}$.

Section 2.6 gave an environmental engineer's expectations for haversine shape in the form of equation 2.8, 2.9, and 2.10. Figure 5.9 shows the results of these tests; shades of red background color denote the value is close to or out of the limit. Shades of green background color denote the value is close to being within limits. The red and green circles indicate the values are in fact within or out of the target. The last column tabulates how many of the tests are a pass. Six of the fifty shots passed all three of the tests. Notice that the ones that passed did not have the free wheel diode installed. This non-linear component, while great for protection had a negative effect on the acceleration shape. There are many other ways to achieve the desired protection without the use of a free wheel diode. 


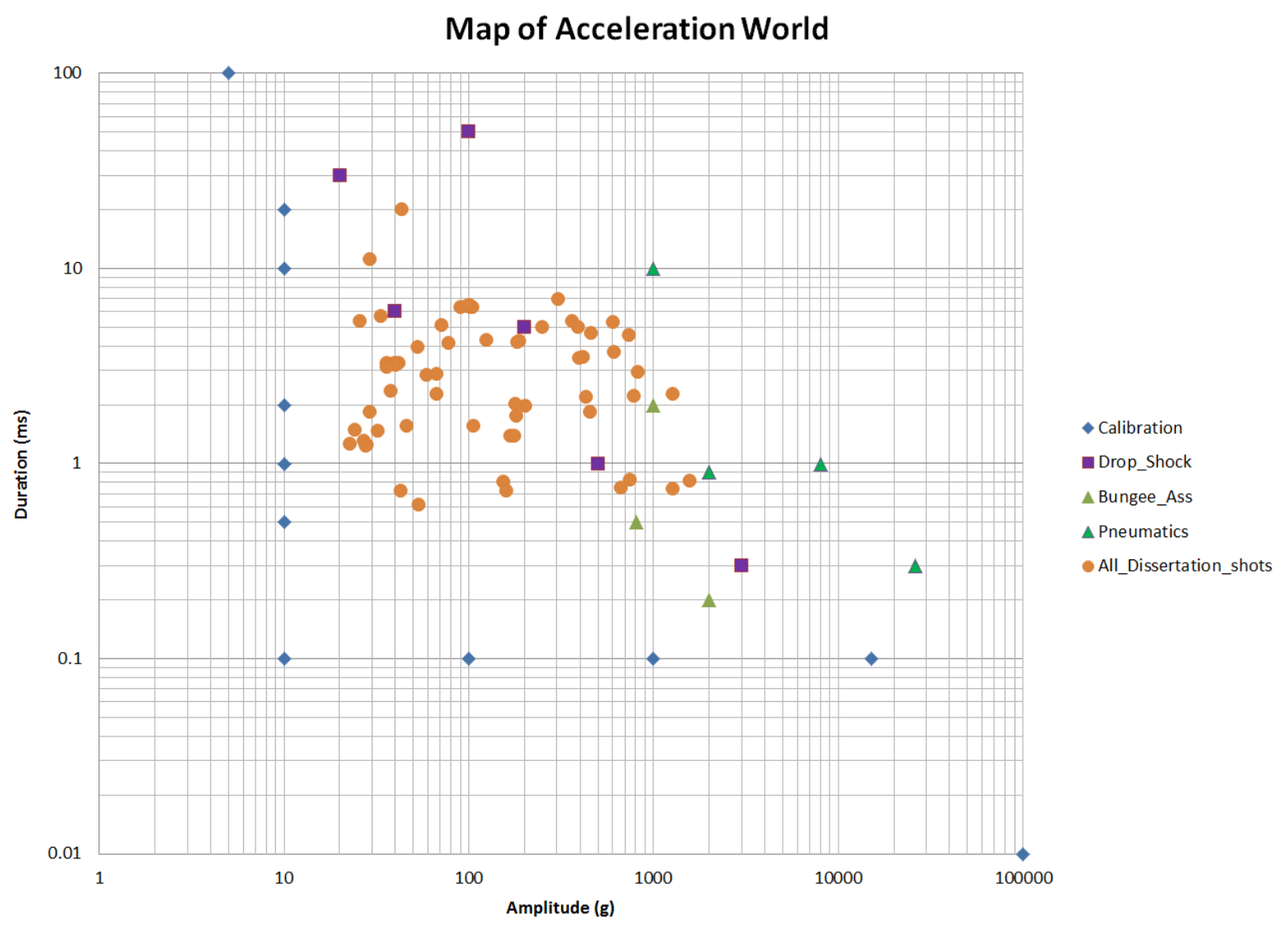

Figure 5.7: All Dissertation Shots. 


\begin{tabular}{|c|c|c|c|c|c|c|c|c|}
\hline & MAX & 1571.63 & 19.92 & 5.56 & 4.74 & 9.62 & 70.61 & 21.52 \\
\hline & MIN & 22.79 & 0.62 & 0.07 & 0.13 & 0.17 & 0.43 & 0.13 \\
\hline Shot\# & Name & Peakg & $10 \%$ Dur (ms) & $90 \%$ Dur (ms) & Rise (ms) & Fall (ms) & DeltaV (fps) & DeltaV (mps) \\
\hline 1 & 1_BC_BI_1000V & 43.649 & 19.920 & 5.560 & 4.740 & 9.620 & 17.528 & 5.342614185 \\
\hline 2 & 2_BC_MI_300V & 102.789 & 6.292 & 1.568 & 1.560 & 3.164 & 13.156 & 4.009820387 \\
\hline 3 & 3_BC_MI_500V & 303.723 & 6.932 & 1.696 & 1.820 & 3.416 & 41.966 & 12.79114841 \\
\hline 4 & 4_MC_MI_1000V & 737.564 & 4.548 & 1.508 & 1.028 & 2.012 & 70.613 & 21.52291452 \\
\hline 5 & 5_MC_MI_500V & 188.700 & 4.224 & 1.008 & 1.120 & 2.096 & 15.989 & 4.873515658 \\
\hline 6 & 6_MC_MI_300V & 52.915 & 3.920 & 0.992 & 1.196 & 1.732 & 4.183 & 1.274873232 \\
\hline 7 & 7_SC_MI_500V & 27.140 & 1.306 & 0.328 & 0.536 & 0.442 & 0.655 & 0.199650844 \\
\hline 8 & 8_SC_MI_1000V & 181.526 & 1.744 & 0.328 & 0.480 & 0.936 & 5.621 & 1.713133369 \\
\hline 9 & 9_SC_MI_1500V & 455.309 & 1.844 & 0.380 & 0.452 & 1.012 & 15.258 & 4.65070497 \\
\hline 10 & 10_MC_MI_500V & 182.532 & 4.192 & 0.928 & 1.136 & 2.128 & 15.372 & 4.685510562 \\
\hline 11 & 11_SC_SI_300V & 42.749 & 0.720 & 0.316 & 0.168 & 0.236 & 0.720 & 0.219431463 \\
\hline 12 & 12 SC_SI_500V & 153.405 & 0.804 & 0.136 & 0.240 & 0.428 & 2.519 & 0.767693826 \\
\hline 13 & 13_SC_SI_1000V & 746.264 & 0.828 & 0.070 & 0.181 & 0.578 & 11.338 & 3.455955381 \\
\hline 14 & 14_SC_SI_1500V & 1571.627 & 0.816 & 0.160 & 0.144 & 0.512 & 26.026 & 7.932639031 \\
\hline 15 & 15_MC_BI_1000V & 29.134 & 11.070 & 2.750 & 3.040 & 5.280 & 6.789 & 2.069212026 \\
\hline 16 & $16 \_M C \_S I+300 \mathrm{~V}$ & 29.319 & 1.824 & 0.376 & 0.584 & 0.864 & 1.088 & 0.33172908 \\
\hline 17 & 17_MC_SI_500V & 105.821 & 1.552 & 0.460 & 0.372 & 0.720 & 2.732 & 0.832625617 \\
\hline 18 & 18_BC_SI_300V_withdiode & 415.145 & 3.512 & 0.740 & 0.760 & 2.012 & 27.412 & 8.35525419 \\
\hline 19 & 19_BC_SI_300V_withoutdiode & 394.775 & 3.450 & 0.834 & 0.671 & 1.945 & 25.968 & 7.915033748 \\
\hline 20 & 20_SC_SI_300V_withoutdiode & 53.940 & 0.615 & 0.139 & 0.306 & 0.170 & 0.667 & 0.203309443 \\
\hline 21 & 21_SC_SI_500V_withoutdiode & 160.683 & 0.721 & 0.153 & 0.226 & 0.342 & 2.224 & 0.677768131 \\
\hline 22 & 22_SC_SI_1000V_withoutdiode & 668.836 & 0.748 & 0.189 & 0.180 & 0.379 & 9.655 & 2.942698988 \\
\hline 23 & 23_SC_SI_1500V_withoutdiode & 1279.314 & 0.742 & 0.421 & 0.129 & 0.192 & 21.356 & 6.509293714 \\
\hline 24 & 24_SC_MI_1000V_withoutdiode_1 & 167.508 & 1.380 & 0.367 & 0.467 & 0.546 & 4.666 & 1.422214616 \\
\hline 25 & 25_SC_MI_1000V_withoutdiode_2 & 177.934 & 1.384 & 0.374 & 0.467 & 0.543 & 4.879 & 1.487218849 \\
\hline 26 & 26_BC_MI_300V_withoutdiode_1 & 90.076 & 6.336 & 1.948 & 1.526 & 2.862 & 12.036 & 3.66872107 \\
\hline 27 & 27_BC_MI_300V_withoutdiode_2 & 105.453 & 6.298 & 1.238 & 1.824 & 3.236 & 12.983 & 3.957146385 \\
\hline 28 & 28_SC_MI_300V_withoutdiode & 27.996 & 1.246 & 0.360 & 0.480 & 0.406 & 0.698 & 0.212645723 \\
\hline 29 & 29_BC_MI_300V_withoutdiode_3 & 100.516 & 6.460 & 1.520 & 1.750 & 3.190 & 12.972 & 3.954015717 \\
\hline 30 & 30_BC_MI_300V_withoutdiode_4 & 97.374 & 6.392 & 1.708 & 1.688 & 2.996 & 12.783 & 3.896158696 \\
\hline 31 & 31_SC_MI_500V_1 & 27.636 & 1.236 & 0.208 & 0.464 & 0.564 & 0.661 & 0.201545514 \\
\hline 32 & 32_SC_MI_500V_2 & 41.789 & 3.252 & 0.876 & 0.952 & 1.424 & 2.684 & 0.818217045 \\
\hline 33 & 33_B1_MI_300V_1 & 39.972 & 3.256 & 0.860 & 0.972 & 1.424 & 2.566 & 0.781975277 \\
\hline 34 & 34_B1_B2_4 mslater_MI_300V_1 & 59.184 & 2.828 & 0.732 & 0.768 & 1.328 & 3.357 & 1.023196222 \\
\hline 35 & 35_B1_B2_4 mslater_MI_300V_2 & 67.420 & 2.880 & 0.728 & 0.764 & 1.388 & 3.965 & 1.208542429 \\
\hline 36 & 36_B1_B2_2mslater_300V & 77.569 & 4.136 & 0.860 & 1.912 & 1.364 & 6.081 & 1.853594899 \\
\hline 37 & 37_B1_B2_symo_MI_300V & 71.134 & 5.104 & 1.428 & 1.412 & 2.264 & 7.482 & 2.280494979 \\
\hline 38 & 38_B1_MI_300V_2 & 40.303 & 3.176 & 0.876 & 1.024 & 1.276 & 2.591 & 0.789722487 \\
\hline 39 & 39_B1_MI_300V_3 & 39.033 & 3.220 & 0.860 & 0.968 & 1.392 & 2.495 & 0.760549591 \\
\hline 40 & 40_B1_MI_300V_crowbarat1ms & 22.791 & 1.265 & 0.122 & 0.714 & 0.429 & 0.429 & 0.13082215 \\
\hline 41 & 41_BC_MI_200V_B2_1ms & 33.317 & 5.656 & 1.520 & 1.940 & 2.196 & 3.854 & 1.174701143 \\
\hline 42 & 42_BC_MI_200V_B2_2ms & 25.848 & 5.328 & 1.732 & 1.204 & 2.392 & 2.972 & 0.905999129 \\
\hline 43 & 43_B1_MI_300V_4 & 36.187 & 3.256 & 0.872 & 0.988 & 1.396 & 2.328 & 0.709720059 \\
\hline 44 & 44_B1_300V_B2_-200V_1mslater & 37.906 & 2.345 & 0.529 & 1.095 & 0.721 & 1.646 & 0.501578442 \\
\hline 45 & 45_B1_300V_zoomedin & 35.886 & 3.102 & 0.851 & 1.009 & 1.242 & 2.231 & 0.679942021 \\
\hline 46 & 46_B1_MI_500V_1 & 32.173 & 1.472 & 0.254 & 0.697 & 0.521 & 0.888 & 0.270650906 \\
\hline 47 & 47_B1_MI_500V_2 & 46.108 & 1.547 & 0.213 & 0.735 & 0.599 & 1.324 & 0.403579456 \\
\hline 48 & 48_B1_MI_500V_3 & 24.199 & 1.477 & 0.437 & 0.596 & 0.444 & 0.674 & 0.205351066 \\
\hline 49 & 49_B1_MI_1000V_nofilter & 203.754 & 1.960 & 0.352 & 0.559 & 1.049 & 7.019 & 2.139485327 \\
\hline 50 & 50_B1_MI_1000V_filtercap & 66.851 & 2.257 & 0.436 & 0.677 & 1.144 & 2.883 & 0.878740993 \\
\hline 51 & $10-S 3 A$ & 433.8217966 & 2.1845 & 0.572 & 0.507 & 1.106 & 18.602 & 5.669796973 \\
\hline 52 & $12-S 4 A$ & 1269.132828 & 2.279 & 0.403 & 0.536 & 1.341 & 53.683 & 16.36254657 \\
\hline 53 & 14-S5A & 362.1864143 & 5.3841 & 1.287 & 1.403 & 2.694 & 37.341 & 11.38147461 \\
\hline 54 & $16-56 A$ & 457.4835754 & 4.6256 & 1.112 & 1.270 & 2.243 & 41.287 & 12.58434652 \\
\hline 55 & 18-S7A & 613.0779235 & 3.7074 & 0.928 & 1.002 & 1.777 & 44.976 & 13.70876246 \\
\hline 56 & $20-58 A$ & 821.8583628 & 2.9492 & 0.849 & 0.669 & 1.431 & 49.144 & 14.97917378 \\
\hline 57 & $22-59 A$ & 785.7721047 & 2.2101 & 0.451 & 0.534 & 1.224 & 33.129 & 10.0976488 \\
\hline 58 & 24-S10A & 178.9879885 & 2.0104 & 0.508 & 0.539 & 0.964 & 7.041 & 2.146229409 \\
\hline 59 & $1-S 11 A$ & 124.2013 & 4.274 & 0.970 & 1.300 & 2.030 & 10.709 & 3.26413368 \\
\hline 60 & $2-S 12 A$ & 249.4434 & 5.008 & 1.200 & 1.400 & 2.400 & 24.373 & 7.42898184 \\
\hline 61 & 3-S13A & 392.9754 & 5 & 1.200 & 1.400 & 2.400 & 39.009 & 11.88982128 \\
\hline 62 & 4-S14A & 608.4809 & 5.3 & 0.920 & 1.700 & 2.600 & 59.332 & 18.0842412 \\
\hline
\end{tabular}

Figure 5.8: Acceleration Timing Tests Results. 


\begin{tabular}{|c|c|c|c|c|c|c|c|c|c|c|}
\hline & MAX & 1571.627 & 19.920 & & 0.564 & & 0.698 & & 0.727 & 3 \\
\hline & MIN & 22.791 & 0.615 & & 0.174 & & 0.259 & & 0.463 & 0 \\
\hline Shot\# & Name & Peakg & $10 \%$ Dur (ms) & \multicolumn{2}{|r|}{ Rise check } & \multicolumn{2}{|r|}{ Fall check } & \multicolumn{2}{|r|}{ Third_check } & Sum \\
\hline 1 & 1_BC_BI_1000V & 43.649 & 19.920 & 0 & 0.238 & 10 & 0.483 & 0 & 0.627 & 1 \\
\hline & 2_BC_MI_300V & 102.789 & 6.292 & 0 & 0.248 & 0 & 0.503 & 0 & 0.632 & 1 \\
\hline 3 & 3_BC_MI_500V & 303.723 & 6.932 & 0 & 0.263 & 0 & 0.493 & 0 & 0.620 & 1 \\
\hline 6 & 6_MC_MI_300V & 52.915 & 3.920 & 0 & 0.305 & 0 & 0.442 & 0 & 0.627 & 1 \\
\hline 7 & 7 7_SC_MI_500V & 27.140 & 1.306 & $\mathrm{O}$ & 0.410 & 0 & 0.338 & 0 & 0.574 & 2 \\
\hline 8 & 8_SC_MI_1000V & 181.526 & 1.744 & 0 & 0.275 & 0 & 0.537 & 0 & 0.552 & 20 \\
\hline 9 & 9_SC_MI_1500V & 455.309 & 1.844 & 0 & 0.245 & 0 & 0.549 & 0 & 0.565 & $\mathrm{X} 0$ \\
\hline 10 & 10_MC_MI_500V & 182.532 & 4.192 & 0 & 0.271 & 0 & 0.508 & 0 & 0.624 & ? 1 \\
\hline 11 & 11 SC_SI_300V & 42.749 & 0.720 & 0 & 0.233 & 0 & 0.328 & 0 & 0.727 & 1 \\
\hline 16 & 16_MC_SI_300V & 29.319 & 1.824 & O & 0.320 & O & 0.474 & 0 & 0.633 & 2 \\
\hline 17 & 17_MC_SI_500V & 105.821 & 1.552 & O & 0.240 & O & 0.464 & 0 & 0.517 & 20 \\
\hline 18 & 18_BC_SI_300V_withdiode & 415.145 & 3.512 & O & 0.216 & O & 0.573 & 0 & 0.584 & 20 \\
\hline 19 & 19_BC_SI_300V_withoutdiode & 394.775 & 3.450 & 0 & 0.194 & 0 & 0.564 & 0 & 0.593 & 20 \\
\hline 20 & 20_SC_SI_300V_withoutdiode & 53.940 & 0.615 & O & 0.498 & 0 & 0.276 & O & 0.625 & ! 1 \\
\hline 21 & 21_SC_SI_500V_withoutdiode & 160.683 & 0.721 & O & 0.313 & O & 0.475 & 0 & 0.596 & 20 \\
\hline 22 & 22_SC_SI_1000V_withoutdiode & 668.836 & 0.748 & O & 0.241 & O & 0.506 & O & 0.599 & 1 \\
\hline 23 & 23_SC_SI_1500V_withoutdiode & 1279.314 & 0.742 & O & 0.174 & O & 0.259 & O & 0.699 & 20 \\
\hline 24 & 4 24_SC_MI_1000V_withoutdiode_1 & 167.508 & 1.380 & O & 0.338 & O & 0.396 & 0 & 0.627 & $\sqrt{3}$ \\
\hline 25 & 525SC_MI_1000V_withoutdiode_2 & 177.934 & 1.384 & O & 0.337 & 0 & 0.392 & 0 & 0.616 & $\sqrt{3}$ \\
\hline 26 & 66_BC_MI_300V_withoutdiode_1 & 90.076 & 6.336 & O & 0.241 & O & 0.452 & 0 & 0.655 & ! 1 \\
\hline 27 & 27_BC_MI_300V_withoutdiode_2 & 105.453 & 6.298 & 0 & 0.290 & 0 & 0.514 & 0 & 0.608 & 1 \\
\hline 36 & 66_B1_B2_2mslater_300V & 77.569 & 4.136 & O & 0.462 & O & 0.330 & O & 0.589 & 1 \\
\hline 37 & 7 37_B1_B2_symo_MI_300V & 71.134 & 5.104 & 0 & 0.277 & 0 & 0.444 & O & 0.640 & 1 \\
\hline 38 & 88 38_BMI_300V_2 & 40.303 & 3.176 & O & 0.322 & O & 0.402 & O & 0.629 & $\sqrt{3}$ \\
\hline 39 & 99_B1_MI_300V_3 & 39.033 & 3.220 & O & 0.301 & O & 0.432 & O & 0.617 & 1 \\
\hline 40 & 00_B1_MI_300V_crowbarat1ms & 22.791 & 1.265 & O & 0.564 & O & 0.339 & O & 0.463 & 1 \\
\hline 41 & 11_BC_MI_200V_B2_1ms & 33.317 & 5.656 & O & 0.343 & O & 0.388 & O & 0.636 & $\sqrt{3}$ \\
\hline 42 & 42_BC_MI_200V_B2_2ms & 25.848 & 5.328 & O & 0.226 & O & 0.449 & O & 0.671 & 20 \\
\hline 43 & 43_B1_MI_300V_4 & 36.187 & 3.256 & O & 0.303 & O & 0.429 & O & 0.614 & ! 2 \\
\hline 44 & 4 44_B1_300V_B2_-200V_1mslater & 37.906 & 2.345 & 0 & 0.467 & 0 & 0.307 & 0 & 0.575 & 20 \\
\hline 45 & 5 45_B1_300V_zoomedin & 35.886 & 3.102 & O & 0.325 & O & 0.400 & O & 0.623 & $\sqrt{3}$ \\
\hline 46 & 6 46_B1_MI_500V_1 & 32.173 & 1.472 & $\mathrm{O}$ & 0.474 & O & 0.354 & O & 0.583 & 1 \\
\hline 47 & 7]47_B1_MI_500V_2 & 46.108 & 1.547 & 0 & 0.475 & 0 & 0.387 & O & 0.577 & 1 \\
\hline 48 & 88_B1_MI_500V_3 & 24.199 & 1.477 & O & 0.404 & O & 0.301 & 0 & 0.586 & l 1 \\
\hline 49 & 49_B1_MI_1000V_nofilter & 203.754 & 1.960 & 0 & 0.285 & 0 & 0.535 & 0 & 0.546 & 20 \\
\hline 50 & 50_B1_MI_1000V_filtercap & 66.851 & 2.257 & O & 0.300 & O & 0.507 & O & 0.594 & 20 \\
\hline 51 & $10-S 3 A$ & 433.8217966 & 2.1845 & 0 & 0.232 & O & 0.506 & O & 0.610 & $? 1$ \\
\hline 52 & 12-S4A & 1269.132828 & 2.279 & $\mathrm{O}$ & 0.235 & 0 & 0.588 & O & 0.577 & 20 \\
\hline 53 & 14-S5A & 362.1864143 & 5.3841 & 0 & 0.261 & 0 & 0.500 & 0 & 0.595 & $\mathbf{2} 0$ \\
\hline 54 & $16-56 A$ & 457.4835754 & 4.6256 & 0 & 0.275 & 0 & 0.485 & 0 & 0.606 & ! 1 \\
\hline 55 & $18-S 7 A$ & 613.0779235 & 3.7074 & 0 & 0.270 & O & 0.479 & O & 0.615 & 81 \\
\hline 56 & 20-S8A & 821.8583628 & 2.9492 & 0 & 0.227 & 0 & 0.485 & 0 & 0.630 & ! 1 \\
\hline 57 & $22-59 A$ & 785.7721047 & 2.2101 & 0 & 0.242 & 0 & 0.554 & 0 & 0.593 & 20 \\
\hline 58 & 24-S10A & 178.9879885 & 2.0104 & 0 & 0.268 & 0 & 0.479 & 0 & 0.608 & 20 \\
\hline 59 & 1-S11A & 124.2013 & 4.274 & 0 & 0.304 & 0 & 0.475 & 0 & 0.627 & 1 \\
\hline
\end{tabular}

Figure 5.9: The Haversine shape Tests Results. 


\subsection{Considering Repeatability and Maintenance}

Three different operators over the span of three days attempted to repeat the same $500 \mathrm{~g}$ shot over 70 times. The resulting mean acceleration was $504 \pm 16 \mathrm{~g}$ or $3.2 \%$ repeatable. All of these shots were done with a nominal 300 volt initial charge and the same RLC value. And as we said before [17], “...this is a sharp contrast in repeatability vs. a mechanical programming situation where repeatability is much worse. Most times, mechanical programmers have a one or two shot lifetime - not many.”

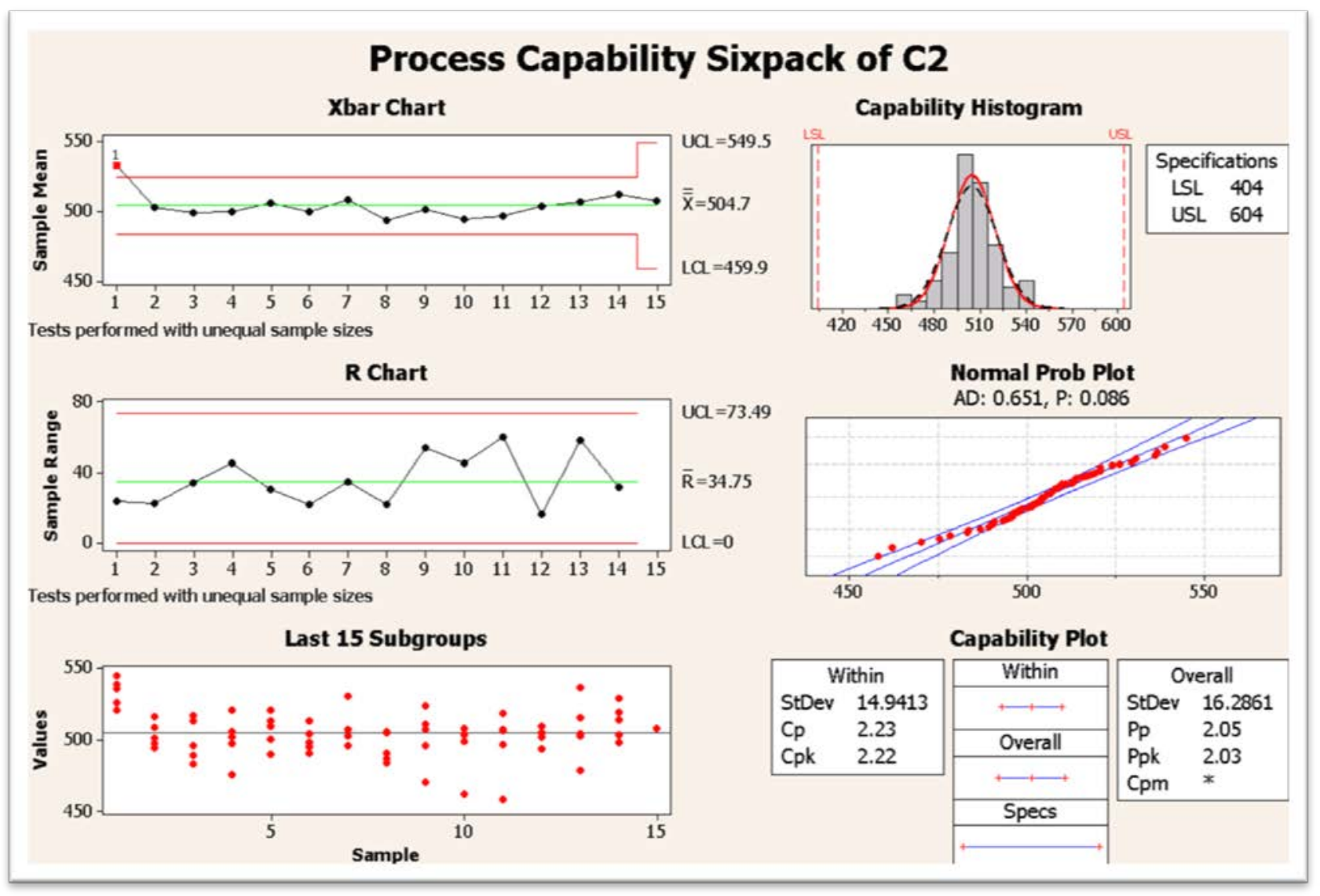

Figure 5.10: Multi-shot repeatability study. 


\section{CHAPTER 6}

\section{UNCERTAINTY ANALYSIS}

\subsection{Introduction}

Countless measurements were performed - such is the life of a metrologist. For brevity, special reflection on what measurement, and in turn what uncertainty, is included in this section; therefore, not every parameter measured is documented. For instance, friction coefficients, weights of individual banks, initial pressure of the HEML, electrical measures to ensure board operation, and many more are measurements were considered just not documented here.

The international standard for uncertainty analysis is the Guide to expression of uncertainty in measurement (GUM method) [52,53]. Uncertainties can be classified into two categories Type A and Type B. Type A uncertainties are those which are evaluated by statistical methods. Type B uncertainties are those which are evaluated by other means (e.g. manufacture specifications, data sheets, judgment, etc.). At the risk of over simplification, the guide recommends classifying the uncertainties, combining and then expanding the total uncertainty. This is the outline we will follow. All expressed uncertainties below are $k=2$, or confidence of approximately 95\%. 


\subsection{The Acceleration Measurement}

The acceleration measurements were taken with a Kistler 8044 accelerometer amplified by a Kistler type 5010 and logged on a Tektronix DPO 4034 oscilloscope. This sentence begs for three type B uncertainties to be considered. Yet for the purposes of simplification, the amplifier and accelerometer were calibrated together. This calibration was performed for frequencies from $10 \mathrm{~Hz}$ to $10 \mathrm{kHz}$ and Shock pulses as indicated on the "map of acceleration world” resulting in a total uncertainty of $\pm 5 \%$.

The next consideration is the oscilloscope used to log the acceleration data. This oscilloscope was also calibrated and its certification is in the appendix. Depending on the range and DC offset this will have an effect on the acceleration measurement result. The maximum uncertainty calculated under these conditions is $\pm 2 \%$. Assuming this uncorrelated from the accelerometer uncertainty, performing a Root Sum Square (RSS) combination, the resulting acceleration uncertainty is $\pm 5.4 \%$.

\subsection{The Electrical Measurements}

The current pulses were measured with two different Rogowski coils both of which being accurate to $\pm 1 \%$, one was $0.5 \mathrm{mV} / \mathrm{A}$, max $12 \mathrm{kA}$, and the other was, $0.05 \mathrm{mV} / \mathrm{Amp}$, max $120 \mathrm{kA}$. These millivolt signals were logged on the same scope as the acceleration was yet with a typically higher value so one can assume the worst case scope uncertainty to be $\pm 1 \%$. Assuming this uncorrelated from the coil uncertainty, performing a Root Sum Square (RSS) combination, the resulting acceleration uncertainty is $\pm 1.4 \%$. 
Voltage was measured with an Agilent 3458 DMM and its specification are in the appendix. Inductance was measured with a 4284A and their specifications are in the appendix. Resistance was measured with microohmmeters such as a Tegam 1750 or a Fluke 8508. Both of these specifications are in the appendix (p. 81). These measurements vary in uncertainties, considering these are industry standard measurements, all are acceptable. 


\section{CHAPTER 7}

FUTURE WORK

\subsection{Introduction}

This research has not only produced much fruit, but holds promise for much more harvesting. This dissertation on effectively the power supply for launchers will accommodate many new types of launchers, some of which are unimagined. Many types of new launchers are detailed below. As always, the PFN can be optimized further and new theory can be conceived.

\subsection{PFN Optimizations}

This dissertation's experimental conclusions have been derived only utilizing at a maximum $45 \mathrm{~kJ}$ stored energy, given the maximum stored energy was $450 \mathrm{~kJ}$, this equated to a utilization of only $10 \%$. In terms of number of banks fired for a given pulse shape, two were realized and with ten total banks this utilization percentage is $2 \%$. More work should be done to completely verify experimentally a degree to the variability for both using a Filter Capacitor and Retropulsing. Therefore, the PFN alone has not reached its full potential.

\subsection{PFN Theory}

Let us return to the analogy, first presented in chapter 3, of the PFN being a piano. This work has shown what one can do with two keys and how to tune the strings to make pure tones in different frequencies. Imagine now the beautiful future compositions and the equally beautiful 
mathematical theories that support their aesthetics. Therefore, Theories for Pulse Forming Network Design for Acceleration Time Domain Replication have not reached full potential.

Figure 7.1 show the Timpson algorithm and the parts of it that were verified with a green check marks. The yellow exclamation point means that experimental data still needs to be acquired. Note that it is just a yellow warning not a red $\mathrm{X}$ because simulation in the appendix shows that with Retropulsing the shapes can be obtained. Therefore, obtaining experimental data to validate the Triangle, Sawtooth, and any other functions that could be desired is future work.

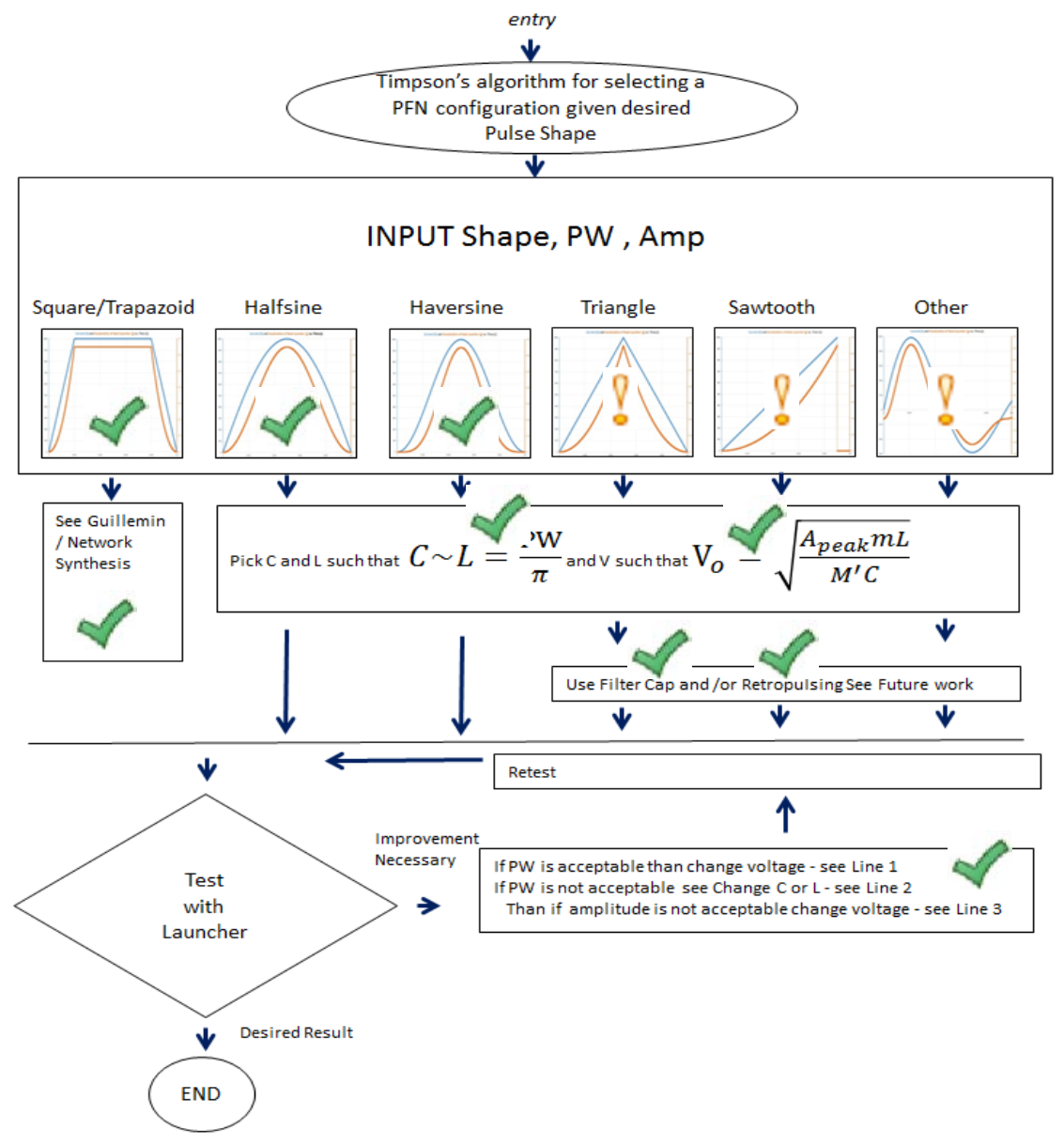

Figure 7.1: Algorithm with indication of experimental verification. 


\subsection{Metrology Applications}

Admittedly overambitious, I initially hoped to find a new traceability path for acceleration through electrical units. As the biggest news in this day and age for a metrologist is the kilogram being the last physical standard. I researched the ampere balance and the watt balance and the latter is obviously the front-runner. Early on, I saw my research going a different direction. Still, I wonder if a HEML-like architecture for the electrical to mechanical conversion would help this metrological pursuit?

\subsection{Reversible HEML}

Figure 2.5 showed the construction progress of a reversible HEML with a payload platform. Our work before this dissertation has proven another way to shape the acceleration fall time [54]. Moreover, with a reversible launcher, there is an additional coil pair and so when a pulse is provided to this pair, a Retropulse, it can actually drive motion in the opposite direction not just retard the motion originally created. Therefore, Reversible HEMLs will continue to be investigated.

\subsection{Large Mass HEML}

Throughout this dissertation, there have been "maps of the acceleration world (pp. 28,29,60,65)," none indicates the mass of the object accelerating. The maximum payload using 
in this research was 833 grams. This mass is reasonable for small circuit boards; but for this research to compete with traditional actuation methods like pneumatics, drop or bungee; work must be done to prove HEMLs can do heavy lifting. That said, the voltage and current scaling relationships for electromagnetic launchers is known [55]. Therefore, Large Mass HEMLs will continue to be investigated.

\subsection{Micro/Nano HEML}

What has been minimally investigated is the miniaturization of HEMLs [56]. As time itself proves repeatedly, the benefits of miniaturization can surpass expectations and, in particular with microelectronics, layman understanding. The new record for an electric motor is $200 \mathrm{~nm}$ [57], but even at large scales, say the size of a cell, use is obvious. Imagine again the application for a symphony at this scale. 


\section{CHAPTER 8}

\section{SUMMARY AND CONCLUDING REMARKS}

One has now been introduced to environmental testing; typical instrumentation for said testing, problems associated said instrumentation and proposed solution as scoped by the present work. The solution being intelligently designed pulse-forming networks used to power electromagnetic launchers for shaping an acceleration event in the time domain. A thorough background investigation found many solid foundations for this work. An algorithm for the intelligent design process was proposed.

This algorithm guided the construction of a Pulse Forming Network of 10 banks, each with potentially different timing, capacitance, inductance, and resistance. This PFN utilized modular architecture ensuring scalability. The PFN was characterized successfully by programming acceleration pulses. The shapes of some pulses meet the expectations of environmental engineers. HEML repeatability and wear exceeded expectations.

Uncertainty was analyzed allowing confidence in measurements. Future work was proposed in several different areas. On July $27^{\text {th }}$, 2011 accelerometers were calibrated for the first time with electromagnetic launchers. On March $6^{\text {th }}, 2011$ acceleration waveforms were first intensely controlled for said applications with electromagnetic launchers. On February $26^{\text {th }}$, 2014 materials have been characterized using electromagnetic launchers. In closing, for historic documentation purposes, two individuals, Thomas G. Engel and Erik J. Timpson, supported by a team of people in industry and academia, have pioneered the first three industrial applications of electromagnetic launchers. 
CHAPTER 9

APPENDIX

Section

Page

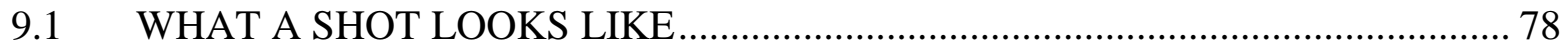

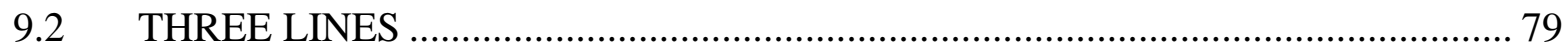

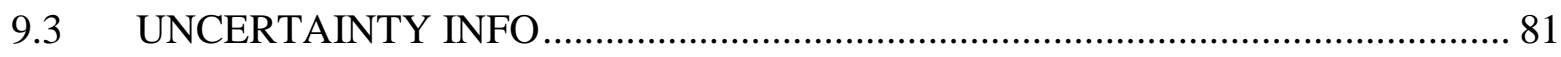

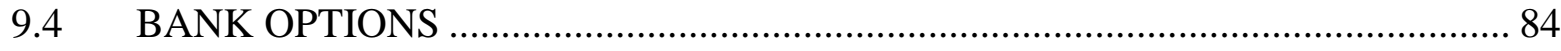

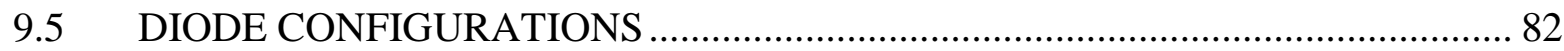

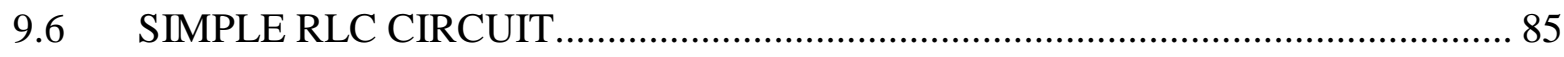

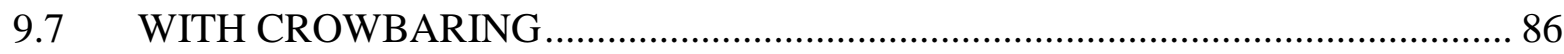

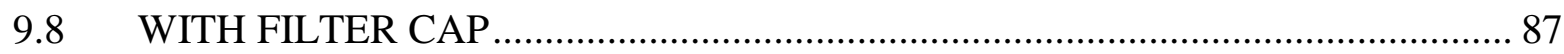

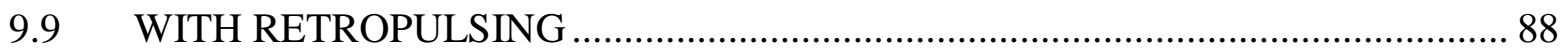

9.10 WITH RETROPULSING FOR SAWTOOTH................................................ 89

9.11 WITH RETROPULSING FOR TRIANGLE ................................................. 90

9.12 CIRCUIT BOARD PICTURES AND SCHEMATICS ........................................ 91

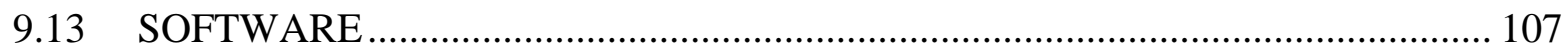

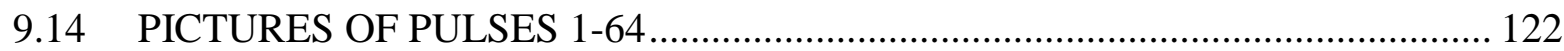

9.15 THE PFN COMPARED TO PIANO AND OTHER INSTRUMENTS................. 122

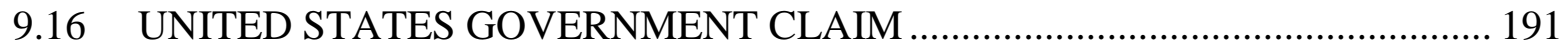


9.1 WHAT A SHOT LOOKS LIKE

- Current $=$ Yellow $(\operatorname{Max} 10,120 \mathrm{~A})$

- Acceleration = Blue $(\operatorname{Max} 1,440 \mathrm{~g})$

$a \alpha I^{2}$

- $\sim 3 \mathrm{~ms}$ PW

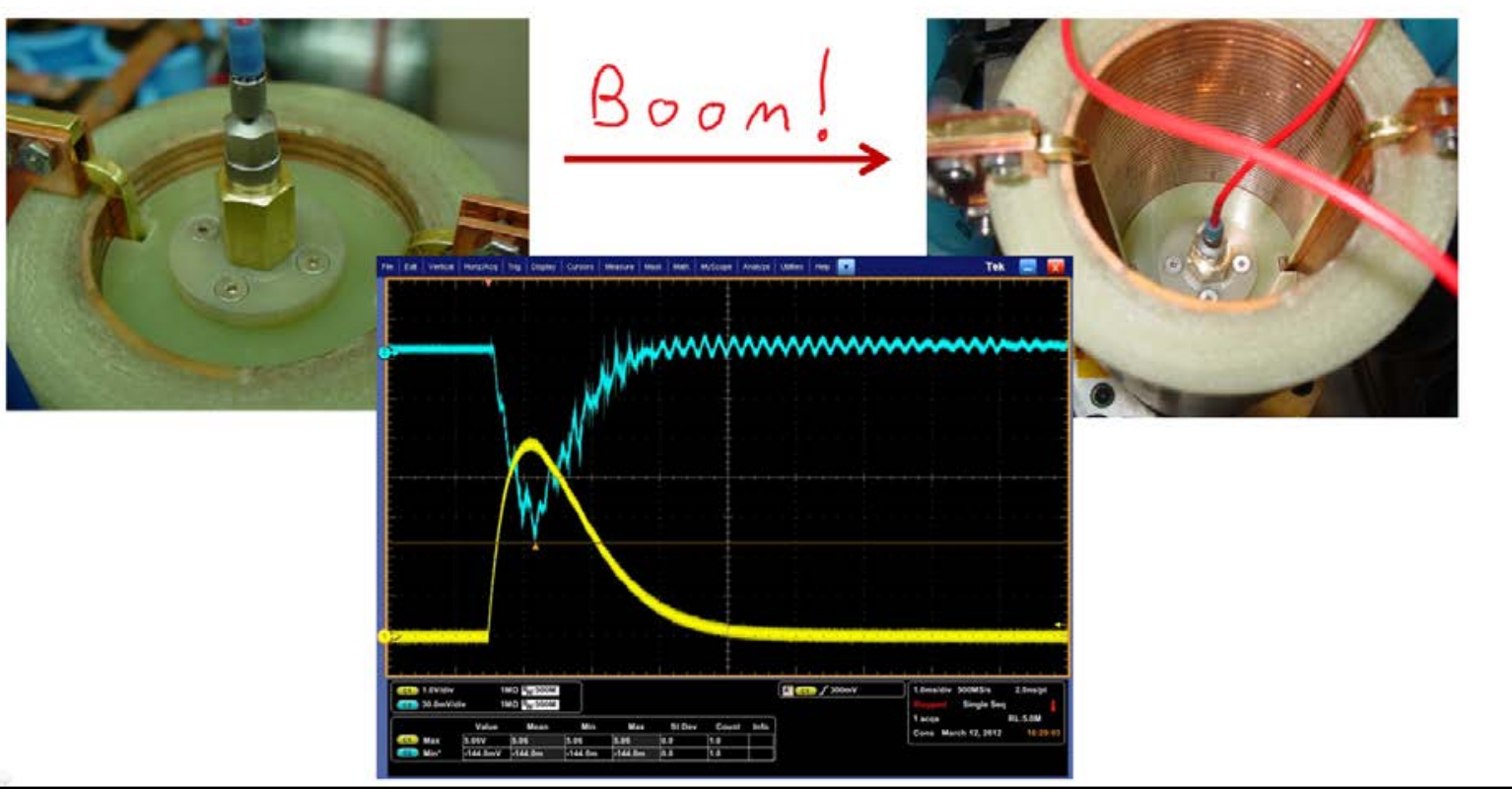




\subsection{THREE LINES}

Line One:

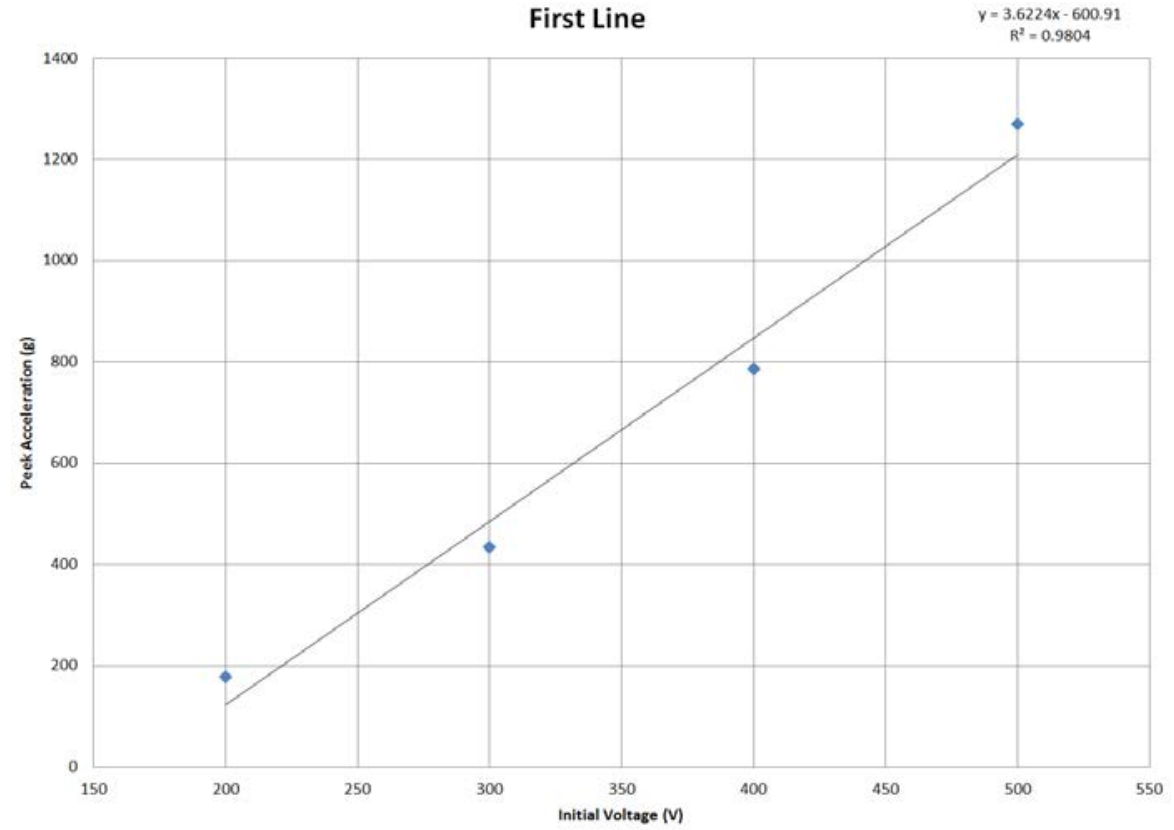

Line Two:

Second Line

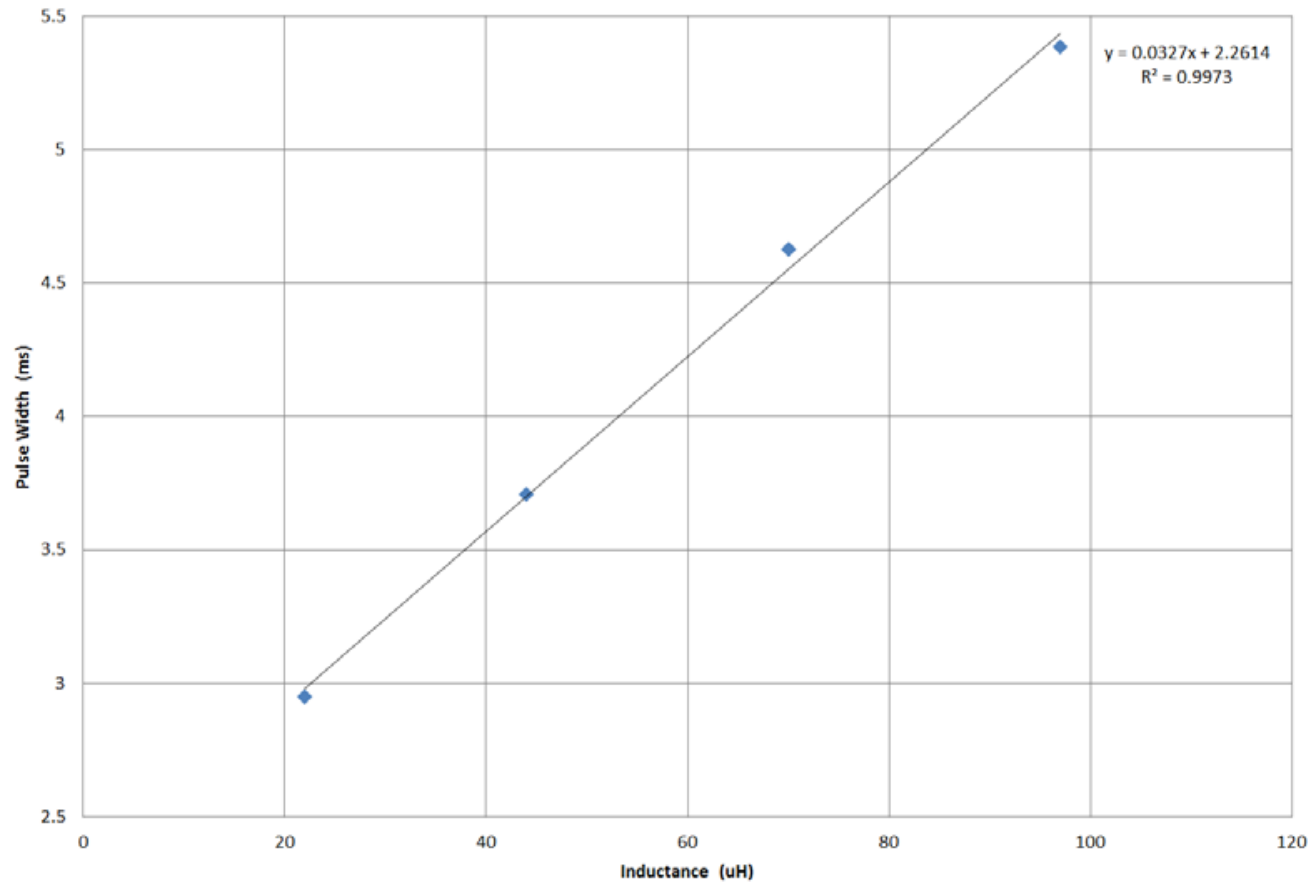


Inductor for Line Two:

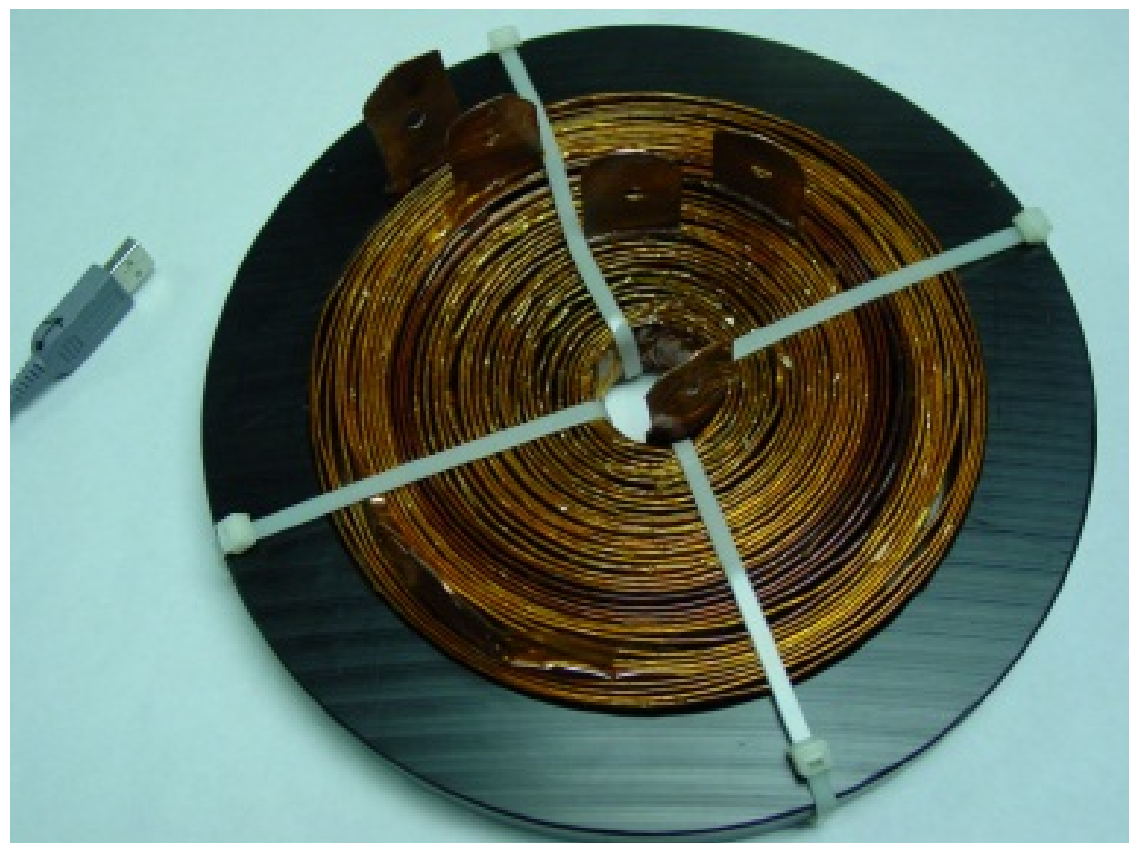

Line Three:

Third Line

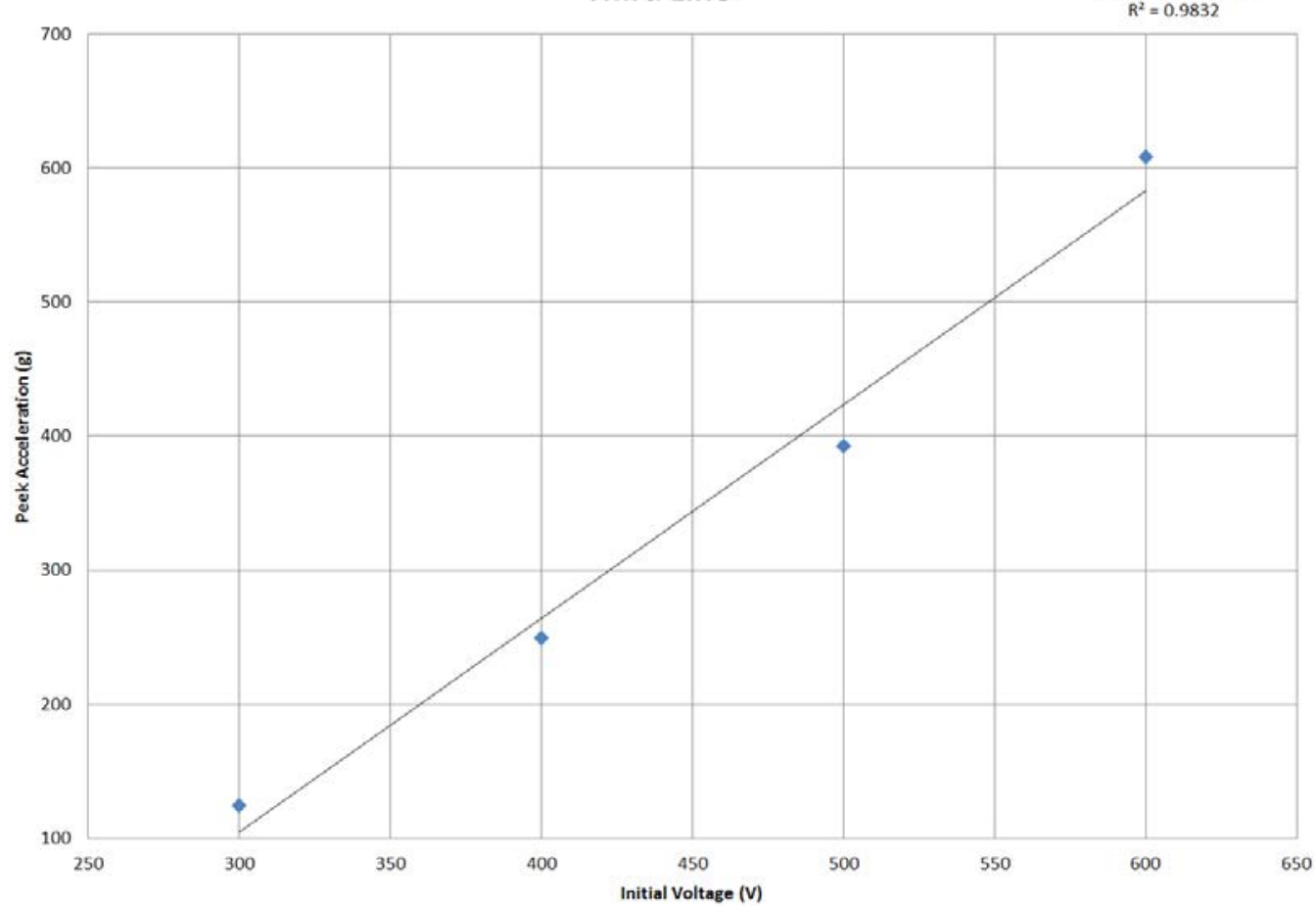




\subsection{UNCERTAINTY INFORMATION}

\begin{tabular}{|cll|}
\hline CD050A & Tektronix DPO4034 Oscilloscope & Date; $12 / 15 / 08$ \\
\hline Bandwidth: & DC to $350 \mathrm{MHz}, 2 \mathrm{mV} /$ Div to $1 \mathrm{~V} /$ Div \\
& DC to $200 \mathrm{MHz}, 1 \mathrm{mV} /$ Div and $1.99 \mathrm{~V} / \mathrm{Div}$ \\
Timebase: & $\pm 5 \mathrm{ppm}$ \\
Input Impedance: & $1 \mathrm{M} \Omega \pm 1 \%, 50 \Omega \pm 1 \%$ \\
DC Balance: & $\pm 0.2 \mathrm{div},>2 \mathrm{mV} / \mathrm{div}, \mathrm{dc}-50 \Omega$ coupled, $50 \Omega$ terminated \\
& $\pm 0.25 \mathrm{div}, 2 \mathrm{mV} / \mathrm{div}, \mathrm{dc}-50 \Omega$ coupled, $50 \Omega$ terminated \\
& $\pm 0.5 \mathrm{div}, 1 \mathrm{mV} / \mathrm{div}, \mathrm{dc}-50 \Omega$ coupled, $50 \Omega$ terminated \\
& $\pm 0.2 \mathrm{div},>1 \mathrm{mV} / \mathrm{div}, \mathrm{dc}-1 \mathrm{M} \Omega$ coupled, $50 \Omega$ terminated \\
& $\pm 0.3 \mathrm{div}, 1 \mathrm{mV} / \mathrm{div}, \mathrm{dc}-1 \mathrm{M} \Omega$ coupled, $50 \Omega$ terminated \\
DC Gain: & $\pm 1.5 \%$ \\
Offset: & $\pm[0.005 \times \mid O f f s e t$ - Position $\mid+$ DC Balance $]$ \\
Ambient temperature must be $\leq 30^{\circ} \mathrm{C}$ and the bandwidth selection to FULL. \\
\hline
\end{tabular}

\begin{tabular}{|c|c|c|c|c|c|c|}
\hline CD058E & \multicolumn{5}{|c|}{ Hewlett Packard 3458A Digital Multimeter } & Date: $1 / 31 / 11$ \\
\hline \multirow{5}{*}{ DC Voltage: } & $\mathrm{NDIG}=7, \mathrm{NPLC}=100$ & \multicolumn{5}{|c|}{$\pm(0.000914 \%$ of Reading $+0.0010 \%$ of Range $), 100 \mathrm{mV}$ Range } \\
\hline & & \multicolumn{5}{|c|}{$\pm(0.000814 \%$ of Reading $+0.0001 \%$ of Range $), 1 \mathrm{~V}$ Range } \\
\hline & & \multicolumn{5}{|c|}{$\pm(0.000814 \%$ of Reading $+0.00002 \%$ of Range $), 10 \mathrm{~V}$ Range } \\
\hline & & \multicolumn{5}{|c|}{$\pm(0.001011 \%$ of Reading $+0.00003 \%$ of Range $), 100 \mathrm{~V}$ Range } \\
\hline & & \multicolumn{5}{|c|}{$\pm(0.001012 \%$ of Reading $+0.00001 \%$ of Range $), 1000 \mathrm{~V}$ Range, Inputs $>100 \mathrm{~V}$ add $0.0012 \% \mathrm{x}(\mathrm{Vin} / 1000)^{2}$ of Reading } \\
\hline DC Current: & $\mathrm{NDIG}=8, \mathrm{NPLC}=100$ & \multicolumn{5}{|c|}{$\pm(0.003 \%$ of Reading $+0.04 \%$ of Range $), 100 \mathrm{nA}$ Range } \\
\hline & & \multicolumn{5}{|c|}{$\pm(0.002 \%$ of Reading $+0.004 \%$ of Range $), 1 \mu$ A Range } \\
\hline & & \multicolumn{5}{|c|}{$\pm(0.002 \%$ of Reading $+0.001 \%$ of Range $), 10 \mu$ A Range } \\
\hline & & \multicolumn{5}{|c|}{$\pm(0.002128 \%$ of Reading $+0.0008 \%$ of Range $), 100 \mu \mathrm{A}$ Range } \\
\hline & & \multicolumn{5}{|c|}{$\pm(0.002128 \%$ of Reading $+0.0005 \%$ of Range $), 1 \mathrm{~mA}$ and $10 \mathrm{~mA}$ Ranges } \\
\hline & & \multicolumn{5}{|c|}{$\pm(0.003575 \%$ of Reading $+0.0005 \%$ of Range $), 100 \mathrm{~mA}$ Range } \\
\hline & & \multicolumn{5}{|c|}{$\pm(0.011029 \%$ of Reading $+0.001 \%$ of Range $), 1$ A Range } \\
\hline AC Voltage: & \multicolumn{6}{|c|}{ SETACV SYNC, AC BAND $5 \mathrm{~Hz}$ to $2 \mathrm{MHz}$ for frequencies $\leq 2 \mathrm{MHz}$ and $5 \mathrm{~Hz}$ to $10 \mathrm{MHz}$ for frequencies $>2 \mathrm{MHz}$, Resolution to 0.01 , LFILTER ON for frequencies $\leq 50 \mathrm{kHz}$} \\
\hline \multirow[t]{2}{*}{ Range } & $10 \mathrm{mV}$ & $100 \mathrm{mV}$ & $1 \mathrm{~V}$ & $10 \mathrm{~V}$ & $100 \mathrm{~V}$ & 1000 V (700V MAX) \\
\hline & \multicolumn{6}{|c|}{ AC Voltage, $\pm(\%$ of Reading $+\%$ of Range $+\mu \mathrm{V})$} \\
\hline 5 to $<20 \mathrm{~Hz}$ & $0.0417+0.03+1.3$ & $0.0221+0.004+1.5$ & $0.0212+0.004+0$ & $0.0212+0.004+0$ & $0.0283+0.004+0$ & $0.0447+0.004+0$ \\
\hline 20 to $<40 \mathrm{~Hz}$ & $0.0355+0.03+1.3$ & $0.0110+0.004+1.5$ & $0.0096+0.004+0$ & $0.0097+0.004+0$ & $0.0211+0.004+0$ & $0.0412+0.004+0$ \\
\hline $40 \mathrm{~Hz}$ to $1 \mathrm{kHz}$ & $0.0228+0.011+1.3$ & $0.0080+0.002+1.5$ & $0.0074+0.002+0$ & $0.0075+0.002+0$ & $0.0202+0.002+0$ & $0.0402+0.002+0$ \\
\hline$>1$ to $20 \mathrm{kHz}$ & $0.0320+0.011+1.3$ & $0.0145+0.002+1.5$ & $0.0142+0.002+0$ & $0.0143+0.002+0$ & $0.0202+0.002+0$ & $0.0601+0.002+0$ \\
\hline$>20$ to $50 \mathrm{kHz}$ & $0.1022+0.011+2$ & $0.0308+0.002+2$ & $0.0304+0.002+0$ & $0.0304+0.002+0$ & $0.0357+0.002+0$ & $0.1207+0.002+0$ \\
\hline$>50$ to $100 \mathrm{kHz}$ & $0.5010+0.011+2.5$ & $0.0816+0.002+2.5$ & $0.0803+0.002+0$ & $0.0804+0.002+0$ & $0.1204+0.002+0$ & $0.3041+0.002+0$ \\
\hline$>100$ to $300 \mathrm{kHz}$ & $4.0008+0.02+4$ & $0.3010+0.01+4$ & $0.3004+0.01+0$ & $0.3006+0.01+0$ & $0.4006+0.01+0$ & \\
\hline$>300$ to $500 \mathrm{kHz}$ & & $1.0007+0.01+8$ & $1.0003+0.01+0$ & $1.0008+0.01+0$ & $1.5008+0.01+0$ & \\
\hline$>500 \mathrm{kHz}$ to $1 \mathrm{MHz}$ & & $1.0018+0.01+0$ & $1.0018+0.01+0$ & $1.0018+0.01+0$ & $1.5008+0.01+0$ & \\
\hline$>1$ to $2 \mathrm{MHz}$ & & $1.5033+0.01+4.5$ & $1.5033+0.01+3$ & $1.5033+0.01+3$ & & \\
\hline$>2$ to $4 \mathrm{MHz}$ & & & $4.0050+0.07+3$ & & & \\
\hline$>4$ to $8 \mathrm{MHz}$ & & & $4.0050+0.08+3$ & & & \\
\hline$>8$ to $10 \mathrm{MHz}$ & & & $15.0013+0.1+3$ & & & \\
\hline \multirow[t]{6}{*}{ Resistance: } & \multicolumn{6}{|c|}{ 4-Wire, NDIG $=8$, OHMF, OCOMP ON, NPLC $=100$, Add $0.25 \Omega$ for 2-Wire Ohms } \\
\hline & \multicolumn{3}{|c|}{$\pm(0.001515 \%$ of Reading $+0.0005 \%$ of Range $), 10 \Omega$ Range } & \multicolumn{3}{|c|}{$\pm(0.001616 \%$ of Reading $+0.0002 \%$ of Range $), 1 \mathrm{M} \Omega$ Range } \\
\hline & \multicolumn{3}{|c|}{$\pm(0.001219 \%$ of Reading $+0.0005 \%$ of Range $), 100 \Omega$ Range } & \multicolumn{3}{|c|}{$\pm(0.005142 \%$ of Reading $+0.001 \%$ of Range $), 10 \mathrm{M} \Omega$ Range } \\
\hline & \multicolumn{3}{|c|}{$\pm(0.001023 \%$ of Reading $+0.00005 \%$ of Range $), 1 \mathrm{k} \Omega$ Range } & \multicolumn{3}{|c|}{$\pm(0.050249 \%$ of Reading $+0.001 \%$ of Range $), 100 \mathrm{M} \Omega$ Range } \\
\hline & \multicolumn{3}{|c|}{$\pm(0.001022 \%$ of Reading $+0.00005 \%$ of Range $), 10 \mathrm{k} \Omega$ Range } & $\pm(0.500025 \%$ of Reading & o of Range), $1 \mathrm{G} \Omega$ Ran & \\
\hline & $\pm(0.001028 \%$ of Reading + & $00005 \%$ of Range), $100 \mathrm{k} \Omega$ & & & & \\
\hline Frequency: & NDIG = 6, LFILTER ON & $1 \mathrm{~Hz}$ to $<40 \mathrm{~Hz} \pm 0.05 \%$ o & & $40 \mathrm{~Hz}$ to $10 \mathrm{MHz} \pm 0.01 \%$ & ding & \\
\hline Period: & NDIG = 6, LFILTER ON & $>25 \mathrm{~ms}$ to $1 \mathrm{~s} \pm 0.05 \%$ of & & $0.1 \mu \mathrm{s}$ to $25 \mathrm{~ms} \pm 0.01 \%$ & & \\
\hline Ratio: & RATIO, NDIG = 6, NPLC & 00, MATH FILTER OFF, S & DEGREE $=5$ & 0.1 to $100 \pm 25 \mathrm{ppm}$ of $\mathrm{R}$ & & \\
\hline Note: & $\begin{array}{l}\text { Certification valid } \\
\text { ACAL and Zero sh }\end{array}$ & $\begin{array}{l}1 \text { hour warm up a } \\
\text { performed again }\end{array}$ & $\begin{array}{l}\text { performing } A C \\
24 \text { hours or } \pm 1^{\circ} \mathrm{C}\end{array}$ & $\begin{array}{l}\text { and Zero (CALO) pe } \\
\text { initial ACAL and Ze }\end{array}$ & $\begin{array}{l}\text { nufacturer's n } \\
\text { ithin } \pm 5^{\circ} \mathrm{C} \text { of } \mathrm{C}\end{array}$ & Temperature. \\
\hline
\end{tabular}




\begin{tabular}{|l|l|l|l|}
\hline CD097B & Certified Range & Frequency \\
\hline Function & Uncertainty & $10 \mathrm{nH}$ to $499.99 \mathrm{nH}$ & $100 \mathrm{kHz}$ to $1 \mathrm{MHz}$ \\
\hline Inductance & $\pm 8 \mathrm{nH}$ or $10 \%$ (which ever is greater) & $200 \mu \mathrm{H}$ to $<1 \mathrm{mH}$ & $1 \mathrm{kHz}$ \\
\hline Inductance & $\pm 0.3 \%$ of Reading & $1 \mathrm{mH}$ to $10 \mathrm{mH}$ & $1 \mathrm{kHz}$ \\
\hline Inductance & $\pm 0.1 \%$ of Reading & $>10 \mathrm{mH}$ to $100 \mathrm{mH}$ & $1 \mathrm{kHz}$ \\
\hline Inductance & $\pm 0.2 \%$ of Reading & $>100 \mathrm{mH}$ to $1 \mathrm{H}$ & $1 \mathrm{kHz}$ \\
\hline Inductance & $\pm 0.3 \%$ of Reading & $200 \mu \mathrm{H}$ to $100 \mathrm{mH}$ & $10 \mathrm{kHz}$ \\
\hline Inductance & $\pm 0.3 \%$ of Reading & $10 \mathrm{pF}$ to $1 \mu \mathrm{F}$ & $1 \mathrm{kHz}$ \\
\hline Capacitance & $\pm 2 \%$ of Reading & $10 \mathrm{pF}$ to $<10 \mathrm{nF}$ & $1 \mathrm{MHz}$ \\
\hline Capacitance & $\pm 0.2 \%$ of Reading & $100 \Omega$ to $1 \mathrm{k} \Omega$ & $50 \mathrm{~Hz}$ to $1 \mathrm{MHz}$ \\
\hline Resistance & $\pm 5 \%$ of Reading & $300 \mathrm{~m} \Omega$ to $<100 \Omega$ & $50 \mathrm{~Hz}$ to $1 \mathrm{MHz}$ \\
\hline Resistance & $\pm 10 \%$ of Reading & \\
\hline Frequency & $\pm 100 \mathrm{ppm}$ of Setting & $1 \mathrm{kHz}$ to $1 \mathrm{MHz}$ & \\
\hline \multicolumn{5}{|l}{$\begin{array}{l}\text { The certification above is based on the assumption that: } \\
\text { 1) Capacitance Accuracy applies when } \mathrm{D} \leq 0.1 \\
\text { 2) The Leads used for measurement have been Zero Compensated. }\end{array}$} \\
\hline
\end{tabular}

\begin{tabular}{|lccc|}
\hline CD052B & \multicolumn{2}{c}{ Tegam 1750 Mico Ohmmeter } & Date: 8/14/12 \\
\hline Resistance & $\pm(0.02 \%$ of reading $+0.0005 \mathrm{~m} \Omega)$ & $\frac{\text { Range }}{2 \mathrm{~m} \Omega}$ & $\frac{\text { Ref Current }}{1 \mathrm{~A}}$ \\
(Delayed & $\pm(0.02 \%$ of reading $+0.004 \mathrm{~m} \Omega)$ & $20 \mathrm{~m} \Omega$ & $1 \mathrm{~A}$ \\
Mode $):$ & $\pm(0.02 \%$ of reading $+0.005 \mathrm{~m} \Omega)$ & $20 \mathrm{~m} \Omega$ & $100 \mathrm{~mA}$ \\
& $\pm(0.02 \%$ of reading $+0.02 \mathrm{~m} \Omega)$ & $200 \mathrm{~m} \Omega$ & $1 \mathrm{~A}$ \\
& $\pm(0.02 \%$ of reading $+0.04 \mathrm{~m} \Omega)$ & $200 \mathrm{~m} \Omega$ & $100 \mathrm{~mA}$ \\
& & \\
& $\pm(0.02 \%$ of reading $+0.0002 \Omega)$ & $2 \Omega$ & $100 \mathrm{~mA}$ \\
& $\pm(0.02 \%$ of reading $+0.0004 \Omega)$ & $2 \Omega$ & $10 \mathrm{~mA}$ \\
& $\pm(0.02 \%$ of reading $+0.002 \Omega)$ & $20 \Omega$ & $10 \mathrm{~mA}$ \\
& $\pm(0.02 \%$ of reading $+0.004 \Omega)$ & $20 \Omega$ & $1 \mathrm{~mA}$ \\
& & \\
& $\pm(0.02 \%$ of reading $+0.02 \Omega)$ & $200 \Omega$ & $10 \mathrm{~mA}$ \\
$\pm(0.02 \%$ of reading $+0.02 \Omega)$ & $200 \Omega$ & $1 \mathrm{~mA}$ \\
& $\pm(0.02 \%$ of reading $+0.04 \Omega)$ & $200 \Omega$ & $100 \mu \mathrm{A}$ \\
& $\pm(0.02 \%$ of reading $+0.0002 \mathrm{k} \Omega)$ & $2 \mathrm{k} \Omega$ & $1 \mathrm{~mA} \& 100 \mu \mathrm{A}$ \\
& $\pm(0.02 \%$ of reading $+0.002 \mathrm{k} \Omega)$ & $20 \mathrm{k} \Omega$ & $100 \mu \mathrm{A} \& 10 \mu \mathrm{A}$ \\
& $\pm(0.02 \%$ of reading $+0.02 \mathrm{k} \Omega)$ & $200 \mathrm{k} \Omega$ & $10 \mu \mathrm{A}$ \\
& $\pm(0.04 \%$ of reading $+0.0002 \mathrm{M} \Omega)$ & $2 \mathrm{M} \Omega$ & $1 \mu \mathrm{A}$ \\
$\pm(0.04 \%$ of reading $+0.002 \mathrm{M} \Omega)$ & $20 \mathrm{M} \Omega$ & $100 \mathrm{nA}$ \\
\hline
\end{tabular}




\begin{tabular}{|c|c|c|c|c|}
\hline CD040C & & Fluke 8508A Multimeter & & DATE: $11 / 18 / 09$ \\
\hline FUNCTION & CONFIGURATION & RANGE & FREQUENCY & UNCERTAINTY \\
\hline DCVOLTS & $\begin{array}{l}7 \text { Digit Resolution } \\
\text { Filter Off \& Fast Off } \\
\text { Local Guard \& Front Input } \\
\text { Zero prior to Use }\end{array}$ & $\begin{array}{l}200 \mathrm{mV} \\
2 \mathrm{~V} \& 20 \mathrm{~V} \\
200 \mathrm{~V} \\
1000 \mathrm{~V}\end{array}$ & & $\begin{array}{l} \pm(6.5 \mathrm{ppm} \text { of Reading }+0.6 \mathrm{ppm} \text { of Range }) \\
\pm(4.5 \mathrm{ppm} \text { of Reading }+0.25 \mathrm{ppm} \text { of Range }) \\
\pm(7.0 \mathrm{ppm} \text { of Reading }+0.25 \mathrm{ppm} \text { of Range }) \\
\pm(7.0 \mathrm{ppm} \text { of Reading }+0.6 \mathrm{ppm} \text { of Range })\end{array}$ \\
\hline DC CURRENT & $\begin{array}{l}7 \text { Digit Resolution } \\
\text { Filter Off \& Fast Off } \\
\text { Local Guard \& Front Input } \\
\text { Zero prior to Use }\end{array}$ & $\begin{array}{l}200 \mu \mathrm{A} \& 2 \mathrm{~mA} \\
20 \mathrm{~mA} \\
200 \mathrm{~mA} \\
2 \mathrm{~A} \\
20 \mathrm{~A}\end{array}$ & & $\begin{array}{l} \pm(16 \mathrm{ppm} \text { of Reading }+2 \mathrm{ppm} \text { of Range }) \\
\pm(18 \mathrm{ppm} \text { of Reading }+2 \mathrm{ppm} \text { of Range }) \\
\pm(60 \mathrm{ppm} \text { of Reading }+4 \mathrm{ppm} \text { of Range }) \\
\pm(225 \mathrm{ppm} \text { of Reading }+8 \mathrm{ppm} \text { of Range }) \\
\pm(500 \mathrm{ppm} \text { of Reading }+20 \mathrm{ppm} \text { of Range })\end{array}$ \\
\hline ACVOLTS & $\begin{array}{l}6 \text { Digit Resolution } \\
\text { Transfer On } \\
\text { AC Coupled }(\mathrm{DC}<100 \mathrm{~Hz}) \\
\text { Local Guard \& Front Input } \\
\text { RMS Filter Settings: } \\
10 \mathrm{~Hz} \text { for } 20 \mathrm{~Hz} \text { and } \\
40 \mathrm{~Hz} \text { for Frequencies }>20 \mathrm{~Hz}\end{array}$ & $200 \mathrm{mV}$ & $\begin{array}{l}10 \mathrm{~Hz} \text { to }<40 \mathrm{~Hz} \\
40 \mathrm{~Hz} \text { to }<100 \mathrm{~Hz} \\
100 \mathrm{~Hz} \text { to } 2 \mathrm{kHz} \\
>2 \mathrm{kHz} \text { to } 10 \mathrm{kHz} \\
>10 \mathrm{kHz} \text { to } 30 \mathrm{kHz} \\
>30 \mathrm{kHz} \text { to } 100 \mathrm{kHz} \\
10 \mathrm{~Hz} \text { to }<40 \mathrm{~Hz} \\
40 \mathrm{~Hz} \text { to }<100 \mathrm{~Hz} \\
100 \mathrm{~Hz} \text { to } 2 \mathrm{kHz} \\
>2 \mathrm{kHz} \text { to } 10 \mathrm{kHz} \\
>10 \mathrm{kHz} \text { to } 30 \mathrm{kHz} \\
>30 \mathrm{kHz} \text { to } 100 \mathrm{kHz} \\
>100 \mathrm{kHz} \text { to } 300 \mathrm{kHz} \\
>300 \mathrm{kHz} \text { to } 1 \mathrm{MHz} \\
10 \mathrm{~Hz} \text { to }<40 \mathrm{~Hz} \\
40 \mathrm{~Hz} \text { to } 10 \mathrm{kHz} \\
>10 \mathrm{kHz} \text { to } 30 \mathrm{kHz}\end{array}$ & $\begin{array}{l} \pm(160 \mathrm{ppm} \text { of Reading }+25 \mathrm{ppm} \text { of Range }) \\
\pm(135 \mathrm{ppm} \text { of Reading }+25 \mathrm{ppm} \text { of Range }) \\
\pm(135 \mathrm{ppm} \text { of Reading }+12 \mathrm{ppm} \text { of Range }) \\
\pm(165 \mathrm{ppm} \text { of Reading }+25 \mathrm{ppm} \text { of Range }) \\
\pm(395 \mathrm{ppm} \text { of Reading }+50 \mathrm{ppm} \text { of Range }) \\
\pm(855 \mathrm{ppm} \text { of Reading }+120 \mathrm{ppm} \text { of Range }) \\
\pm(135 \mathrm{ppm} \text { of Reading }+12 \mathrm{ppm} \text { of Range }) \\
\pm(110 \mathrm{ppm} \text { of Reading }+12 \mathrm{ppm} \text { of Range }) \\
\pm(90 \mathrm{ppm} \text { of Reading }+12 \mathrm{ppm} \text { of Range }) \\
\pm(135 \mathrm{ppm} \text { of Reading }+12 \mathrm{ppm} \text { of Range }) \\
\pm(260 \mathrm{ppm} \text { of Reading }+25 \mathrm{ppm} \text { of Range }) \\
\pm(650 \mathrm{ppm} \text { of Reading }+120 \mathrm{ppm} \text { of Range }) \\
\pm(3000 \mathrm{ppm} \text { of Reading }+1200 \mathrm{ppm} \text { of Range }) \\
\pm(10000 \mathrm{ppm} \text { of Reading }+12000 \text { ppm of Range }) \\
\pm(145 \mathrm{ppm} \text { of Reading }+25 \mathrm{ppm} \text { of Range }) \\
\pm(140 \mathrm{ppm} \text { of Reading }+25 \mathrm{ppm} \text { of Range }) \\
\pm(265 \mathrm{ppm} \text { of Reading }+50 \mathrm{ppm} \text { of Range })\end{array}$ \\
\hline AC CURRENT & $\begin{array}{l}6 \text { Digit Resolution } \\
\text { AC Coupled }(\mathrm{DC}<100 \mathrm{~Hz}) \\
\text { Local Guard \& Front Input } \\
\text { RMS Filter Setting: } 40 \mathrm{~Hz}\end{array}$ & $\begin{array}{l}200 \mu \mathrm{A}, 2 \mathrm{~mA}, \& 20 \mathrm{~mA} \\
200 \mathrm{~mA} \\
2 \mathrm{~A} \\
20 \mathrm{~A}\end{array}$ & $\begin{array}{l}10 \mathrm{~Hz} \text { to } 10 \mathrm{kHz} \\
10 \mathrm{~Hz} \text { to } 10 \mathrm{kHz} \\
10 \mathrm{~Hz} \text { to } 2 \mathrm{kHz} \\
>2 \mathrm{kHz} \text { to } 10 \mathrm{kHz} \\
10 \mathrm{~Hz} \text { to } 2 \mathrm{kHz} \\
>2 \mathrm{kHz} \text { to } 10 \mathrm{kHz}\end{array}$ & $\begin{array}{l} \pm(370 \mathrm{ppm} \text { of Reading }+120 \mathrm{ppm} \text { of Range }) \\
\pm(360 \mathrm{ppm} \text { of Reading }+120 \mathrm{ppm} \text { of Range }) \\
\pm(725 \mathrm{ppm} \text { of Reading }+120 \mathrm{ppm} \text { of Range }) \\
\pm(860 \mathrm{ppm} \text { of Reading }+120 \mathrm{ppm} \text { of Range }) \\
\pm(920 \mathrm{ppm} \text { of Reading }+120 \mathrm{ppm} \text { of Range }) \\
\pm(2500 \mathrm{ppm} \text { of Reading }+120 \mathrm{ppm} \text { of Range })\end{array}$ \\
\hline FREQUENCY & $\begin{array}{l}\text { AC Voltage, } 2 V \text { Range, } 40 \mathrm{~Hz} \text { Filter, } \\
6 \text { Digit Resolution, Front Input, } \\
\text { Local Guard, Fast Gate Off }\end{array}$ & $10 \mathrm{~Hz}$ to $1 \mathrm{MHz}$ & & $\pm(10 \mathrm{ppm}$ of Reading +2 counts $)$ \\
\hline RESISTANCE & $\begin{array}{l}7 \text { Digit Resolution } \\
\text { Filter Off \& Fast Off } \\
\text { Local Guard \& Front Input } \\
\text { Zero prior to Use }\end{array}$ & $\begin{array}{l}2 \Omega \\
20 \Omega \\
200 \Omega \text { to } 20 \mathrm{k} \Omega \\
200 \Omega \text { to } 20 \mathrm{k} \Omega \\
200 \mathrm{k} \Omega \\
2 \mathrm{M} \Omega \\
20 \mathrm{M} \Omega \\
200 \mathrm{M} \Omega \\
2 \mathrm{G} \Omega \\
200 \mathrm{k} \Omega \\
2 \mathrm{M} \Omega \\
20 \mathrm{M} \Omega \\
200 \mathrm{M} \Omega \\
2 \mathrm{G} \Omega \\
20 \mathrm{M} \Omega \\
200 \mathrm{M} \Omega \\
2 \mathrm{G} \Omega \\
20 \mathrm{G} \Omega\end{array}$ & $\begin{array}{l}\text { MODE } \\
\text { Tru } \Omega \text {, Normal, Lo Current } \\
\text { Tru } \Omega \text {, Normal, Lo Current } \\
\text { Tru } \Omega \text {, Normal } \\
\text { Tru } \Omega \text {, Lo Current } \\
\text { Normal } \\
\text { Normal } \\
\text { Normal } \\
\text { Normal } \\
\text { Normal } \\
\text { Lo Current } \\
\text { Lo Current } \\
\text { Lo Current } \\
\text { Lo Current } \\
\text { Lo Current } \\
\text { High Voltage } \\
\text { High Voltage } \\
\text { High Voltage } \\
\text { High Voltage }\end{array}$ & $\begin{array}{l} \pm(22 \mathrm{ppm} \text { of reading }+2.5 \mathrm{ppm} \text { of Range }) \\
\pm(12 \mathrm{ppm} \text { of reading }+0.9 \mathrm{ppm} \text { of Range }) \\
\pm(10 \mathrm{ppm} \text { of reading }+0.3 \mathrm{ppm} \text { of Range }) \\
\pm(10 \mathrm{ppm} \text { of reading }+0.9 \mathrm{ppm} \text { of Range }) \\
\pm(10 \mathrm{ppm} \text { of reading }+0.3 \mathrm{ppm} \text { of Range }) \\
\pm(12 \mathrm{ppm} \text { of reading }+0.6 \mathrm{ppm} \text { of Range }) \\
\pm(25 \mathrm{ppm} \text { of reading }+6 \mathrm{ppm} \text { of Range }) \\
\pm(150 \mathrm{ppm} \text { of reading }+60 \mathrm{ppm} \text { of Range }) \\
\pm(1810 \mathrm{ppm} \text { of reading }+600 \mathrm{ppm} \text { of Range }) \\
\pm(10 \mathrm{ppm} \text { of reading }+0.6 \mathrm{ppm} \text { of Range }) \\
\pm(17 \mathrm{ppm} \text { of reading }+0.6 \mathrm{ppm} \text { of Range }) \\
\pm(110 \mathrm{ppm} \text { of reading }+6 \mathrm{ppm} \text { of Range }) \\
\pm(1810 \mathrm{ppm} \text { of reading }+600 \mathrm{ppm} \text { of Range }) \\
\pm(1810 \mathrm{ppm} \text { of reading }+600 \mathrm{ppm} \text { of Range }) \\
\pm(20 \mathrm{ppm} \text { of reading }+0.6 \mathrm{ppm} \text { of Range }) \\
\pm(80 \mathrm{ppm} \text { of reading }+6 \mathrm{ppm} \text { of Range }) \\
\pm(230 \mathrm{ppm} \text { of reading }+60 \mathrm{ppm} \text { of Range }) \\
\pm(1810 \mathrm{ppm} \text { of reading }+600 \mathrm{ppm} \text { of Range })\end{array}$ \\
\hline $\begin{array}{l}\text { After } 4 \text { hour w } \\
\text { Input Zero or C } \\
\text { Use only at an } \\
\star>300 \mathrm{~V},<10 \\
*>300 \mathrm{~V}, 10 \mathrm{~K}\end{array}$ & $\begin{array}{l}\text { lired every } 24 \text { hours or if temperature } \\
\text { cure of } 23^{\circ} \mathrm{C} \pm 5^{\circ} \mathrm{C} \\
004 \text { * }(\text { Reading }-300)^{\wedge} 2 \mathrm{ppm} \\
\mathrm{ddd} \pm(0.0004+(\text { Frequency }-10000) \text { * }\end{array}$ & $\begin{array}{l}\text { e changes more than } \pm 1^{\circ} \mathrm{C} \\
\star 0.0000001) \text { * (Reading - } 3\end{array}$ & $\begin{array}{l}\text { the previous Zero or Offs } \\
\mathrm{ppm}\end{array}$ & temperature \\
\hline
\end{tabular}




\subsection{PFN BANK OPTIONS}

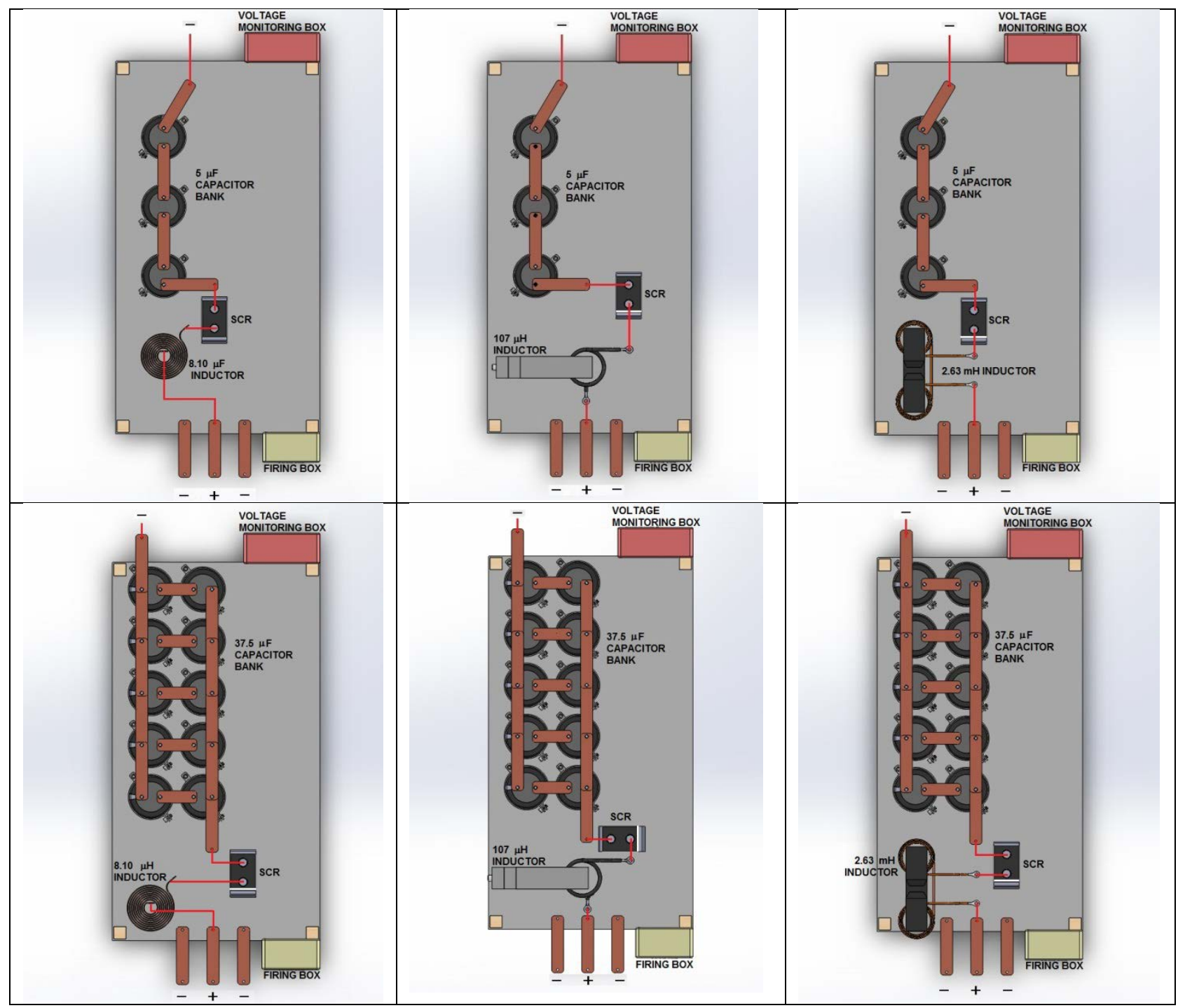




(IF)




(1)




\subsection{DIODE CONFIGURATIONS}

No Diode - Only Switch:

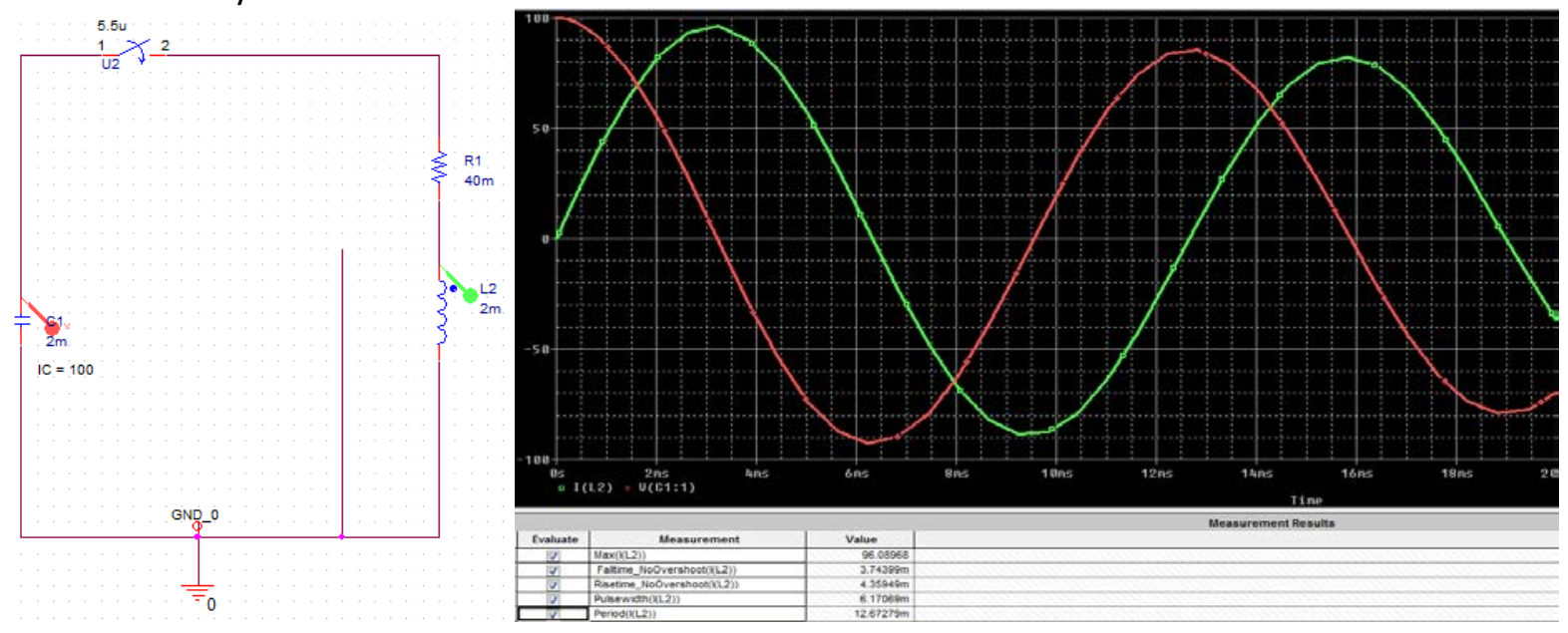

Flywheel Diode - Only Switch:

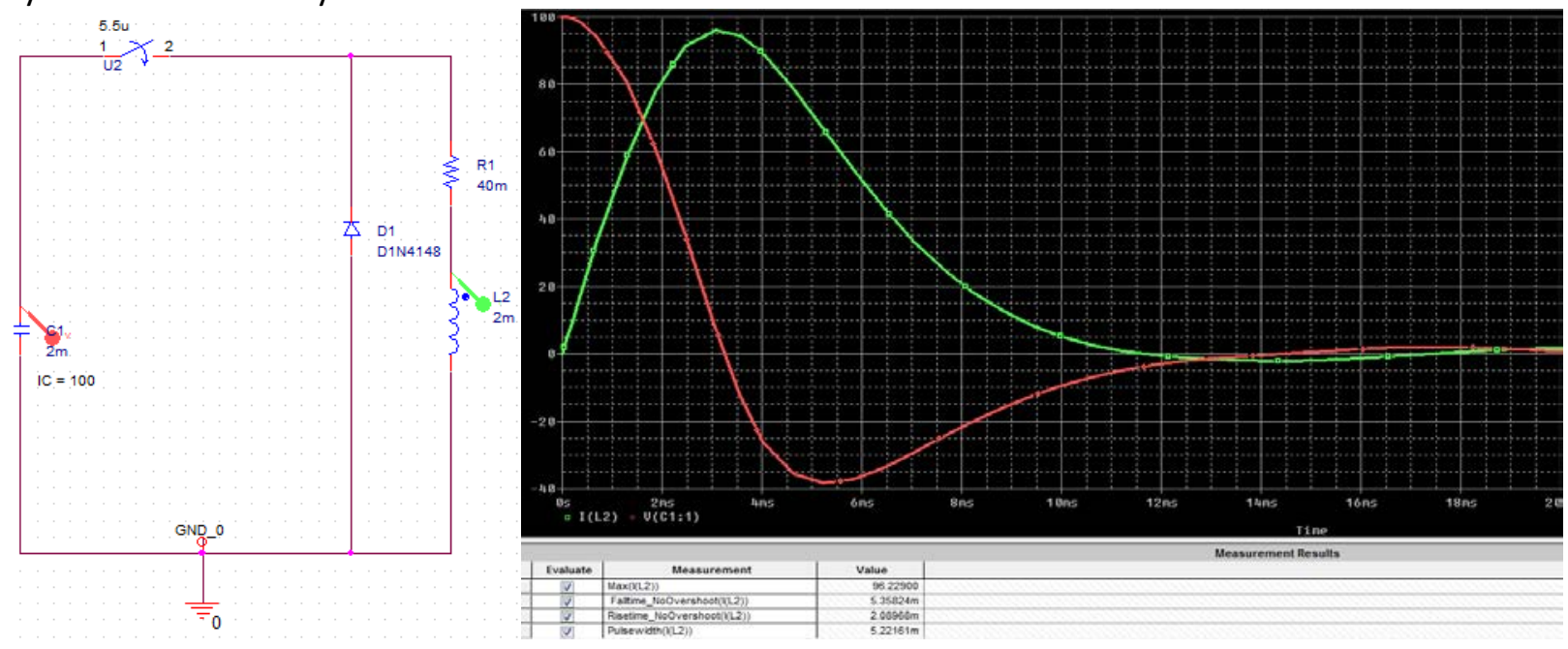


No Diode - 'SCR like' Switch:

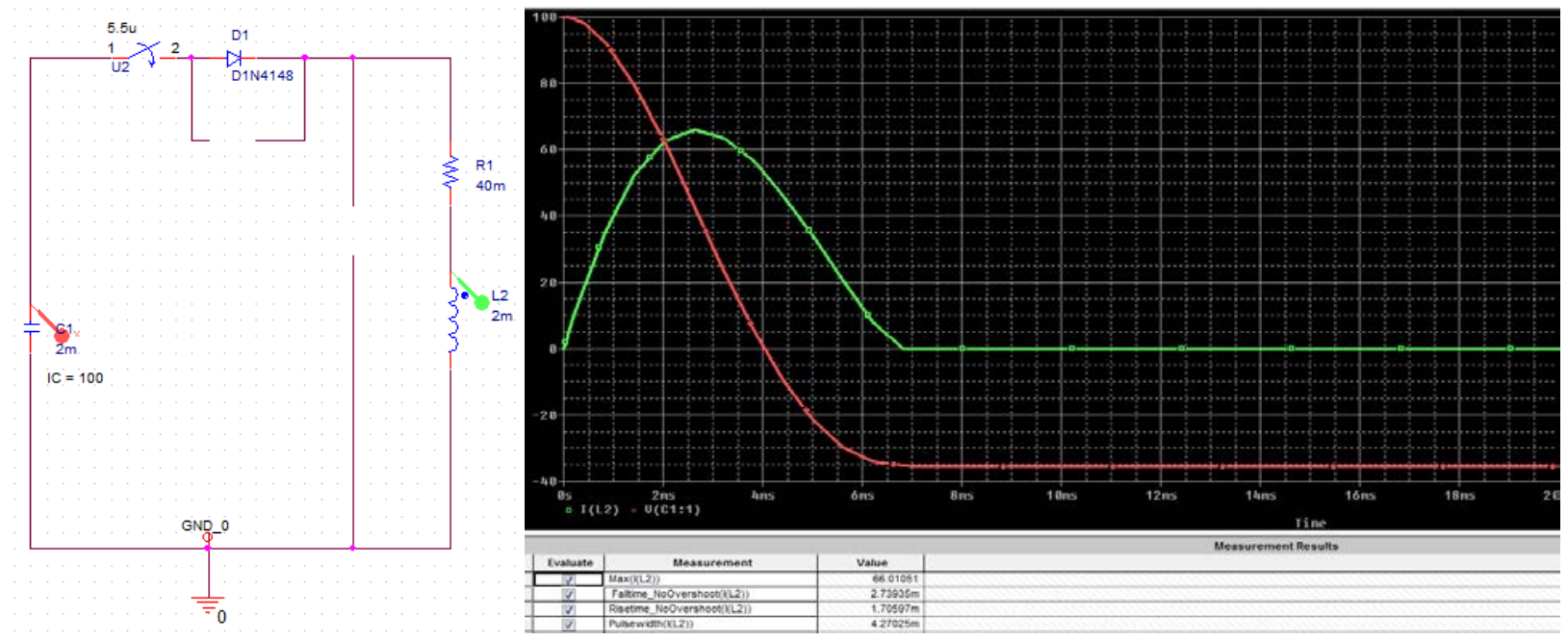

Flywheel Diode - 'SCR like' Switch:

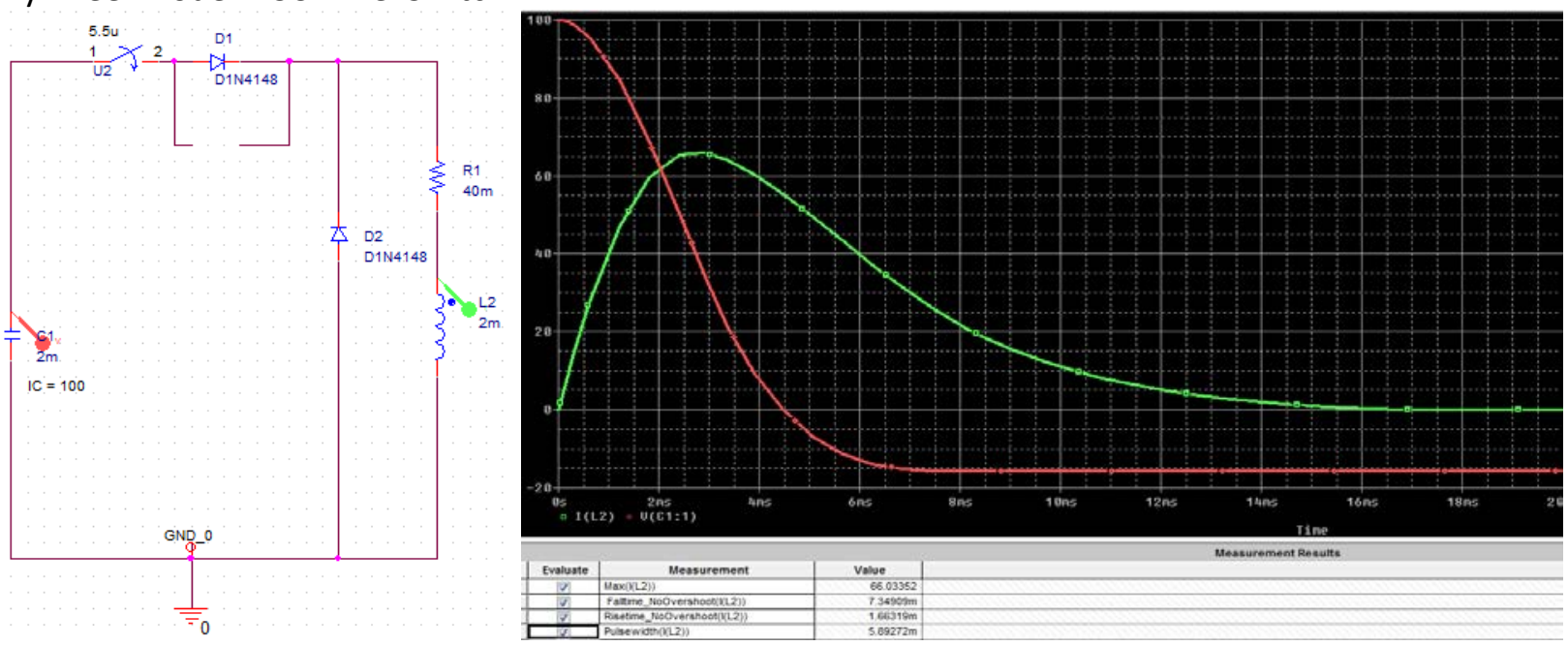


Snubber Diode - 'SCR like' Switch:

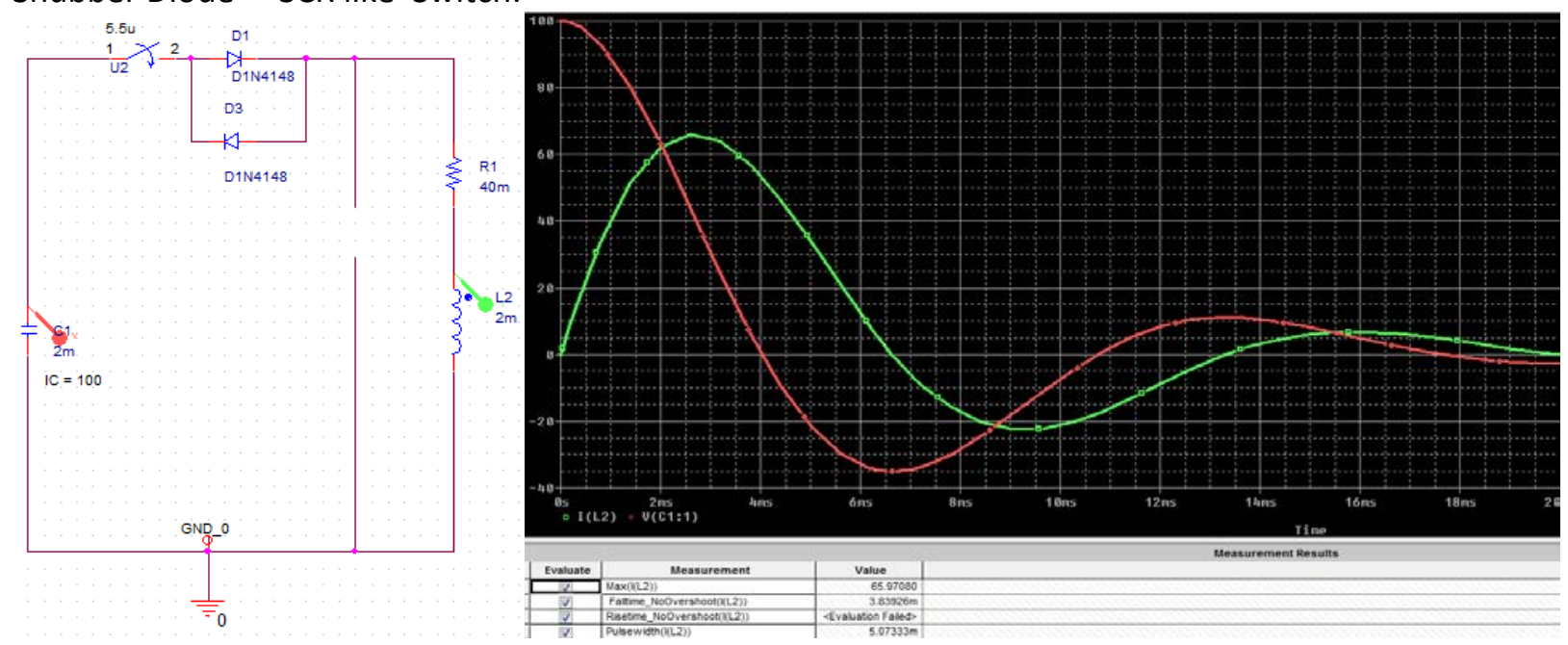

Snubber and Flywheel Diode - 'SCR like' Switch:

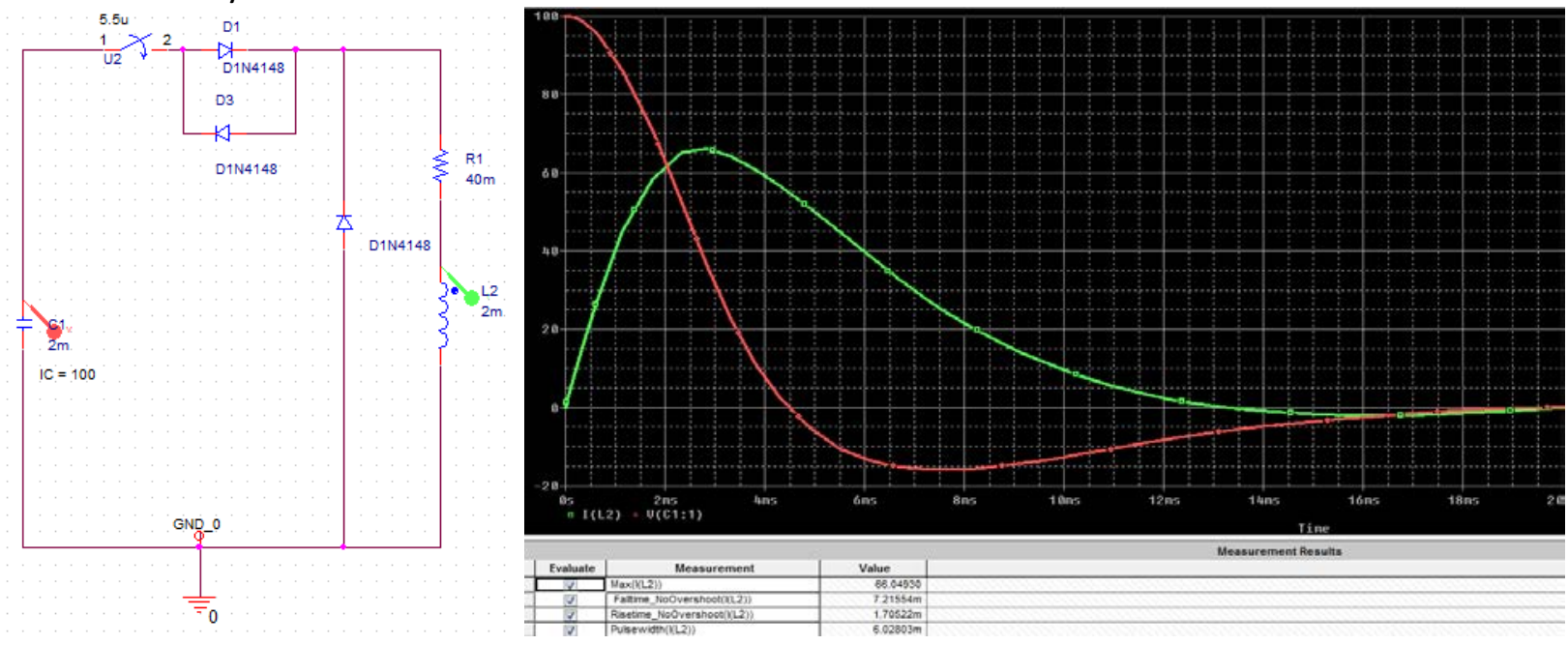




\subsection{SIMPLE RLC CIRCUIT}

Under damped:
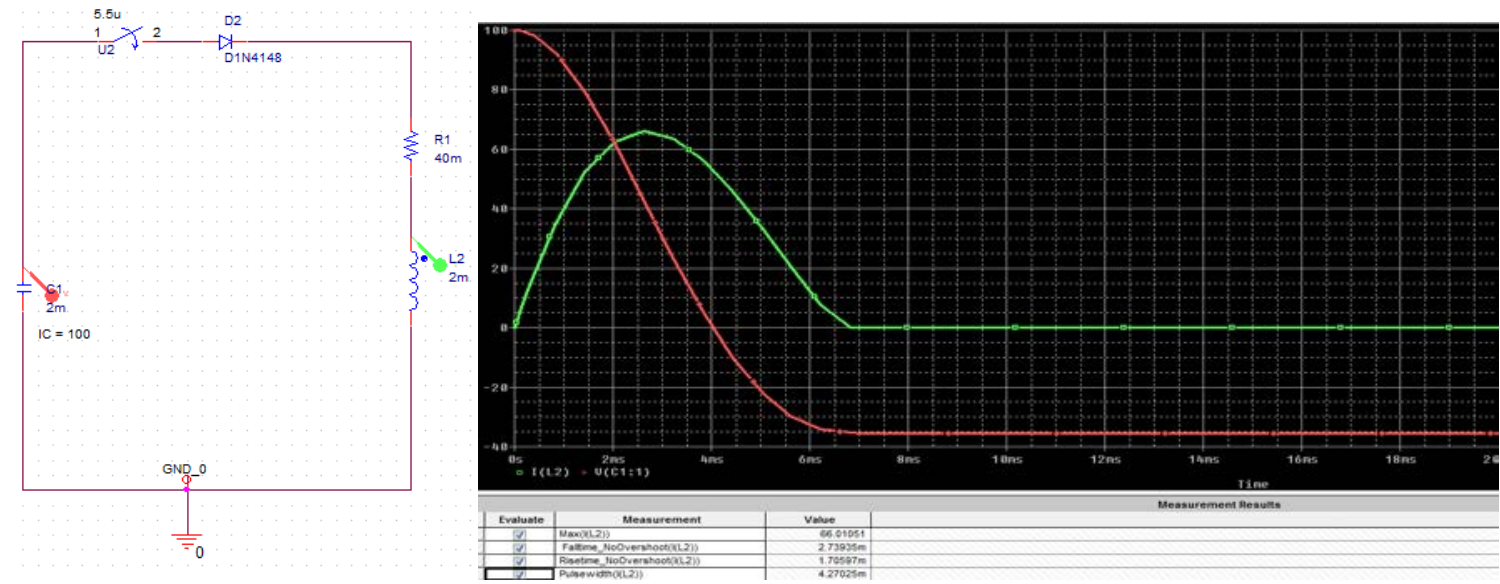

Critically Damped:
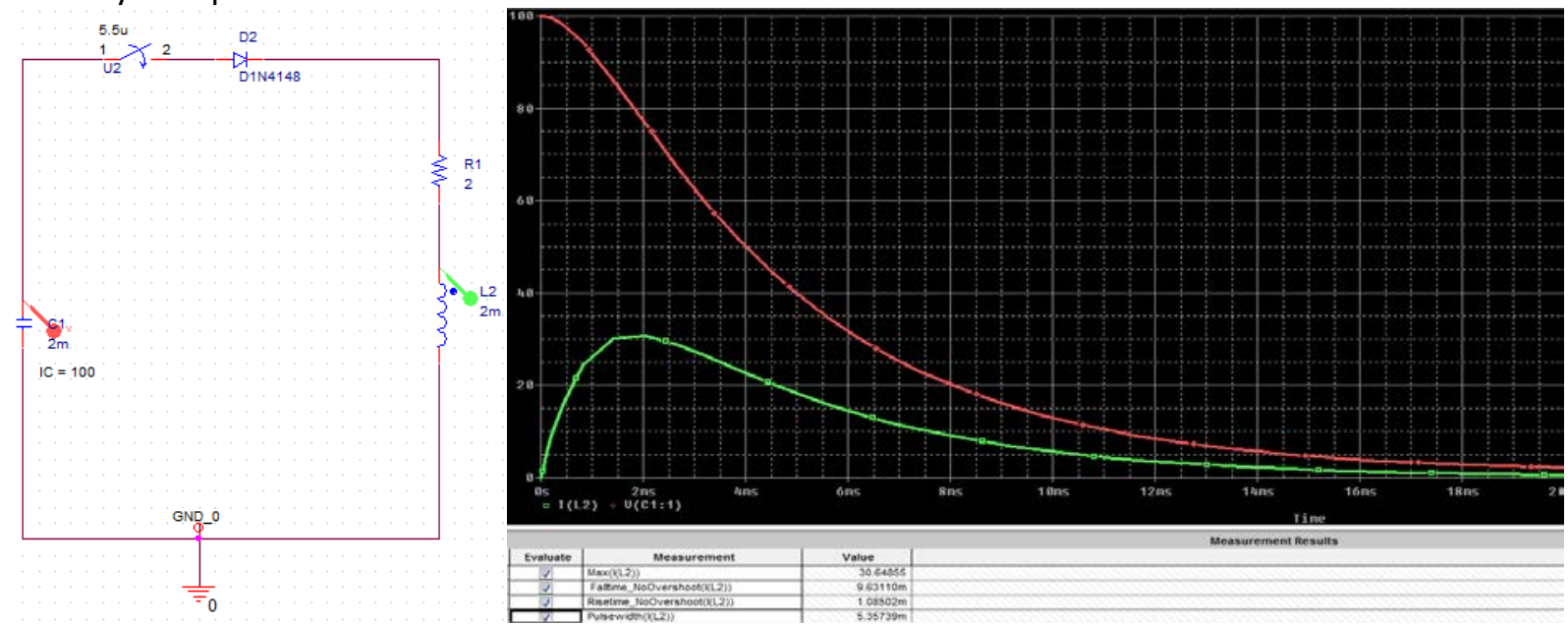

Over damped:
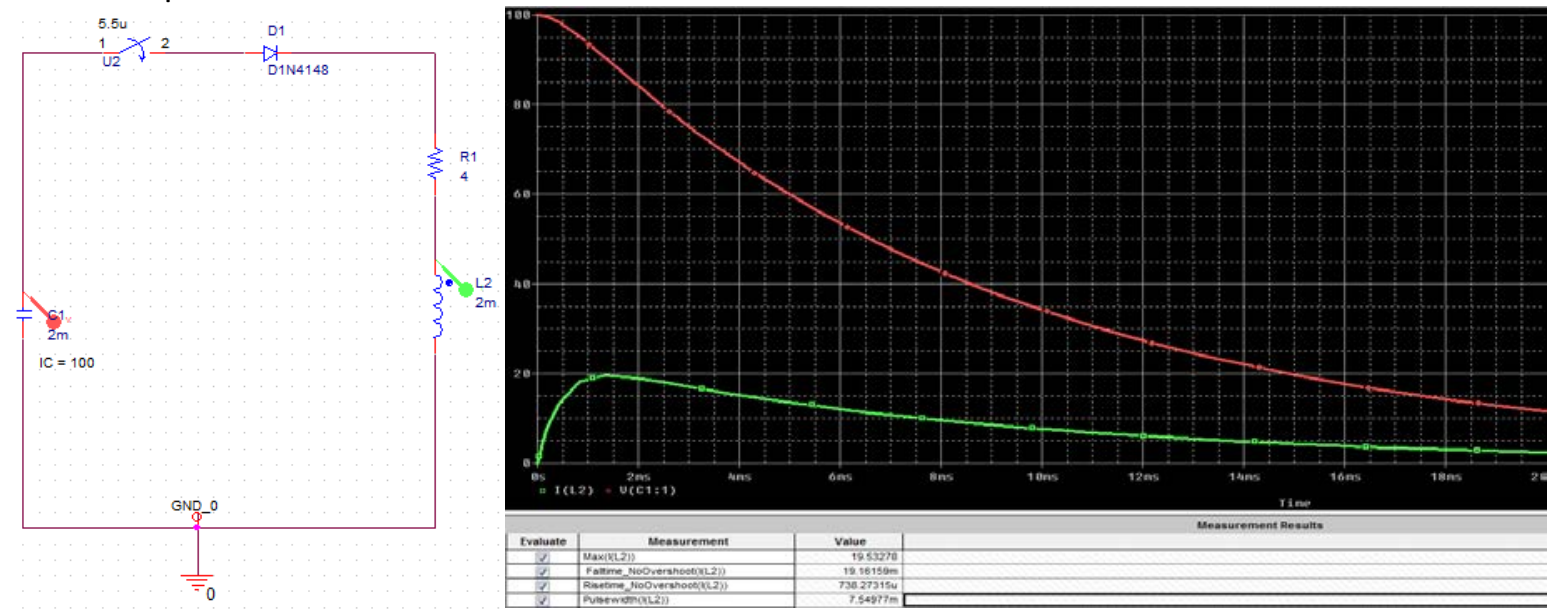
9.7 SIMPLE RLC CIRCUIT WITH CROWBARING Simple RLC:
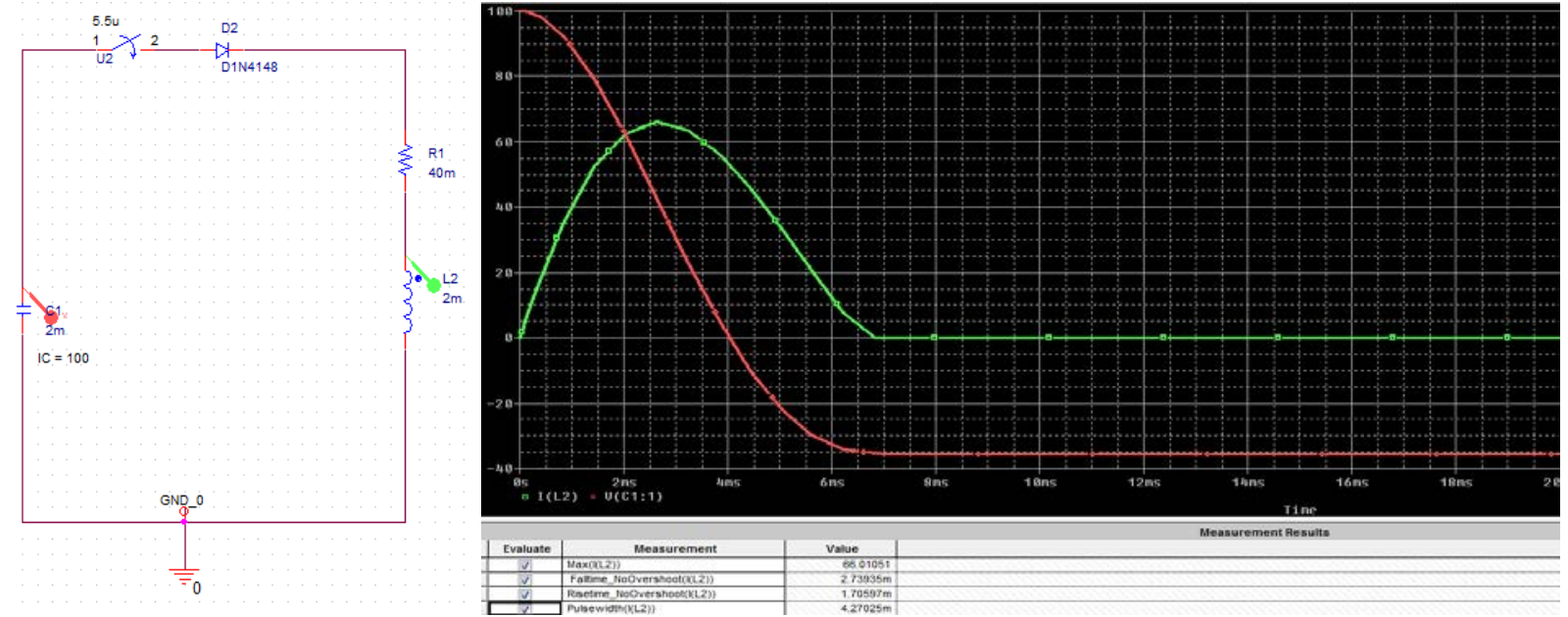

Simple RLC with Crowbar:
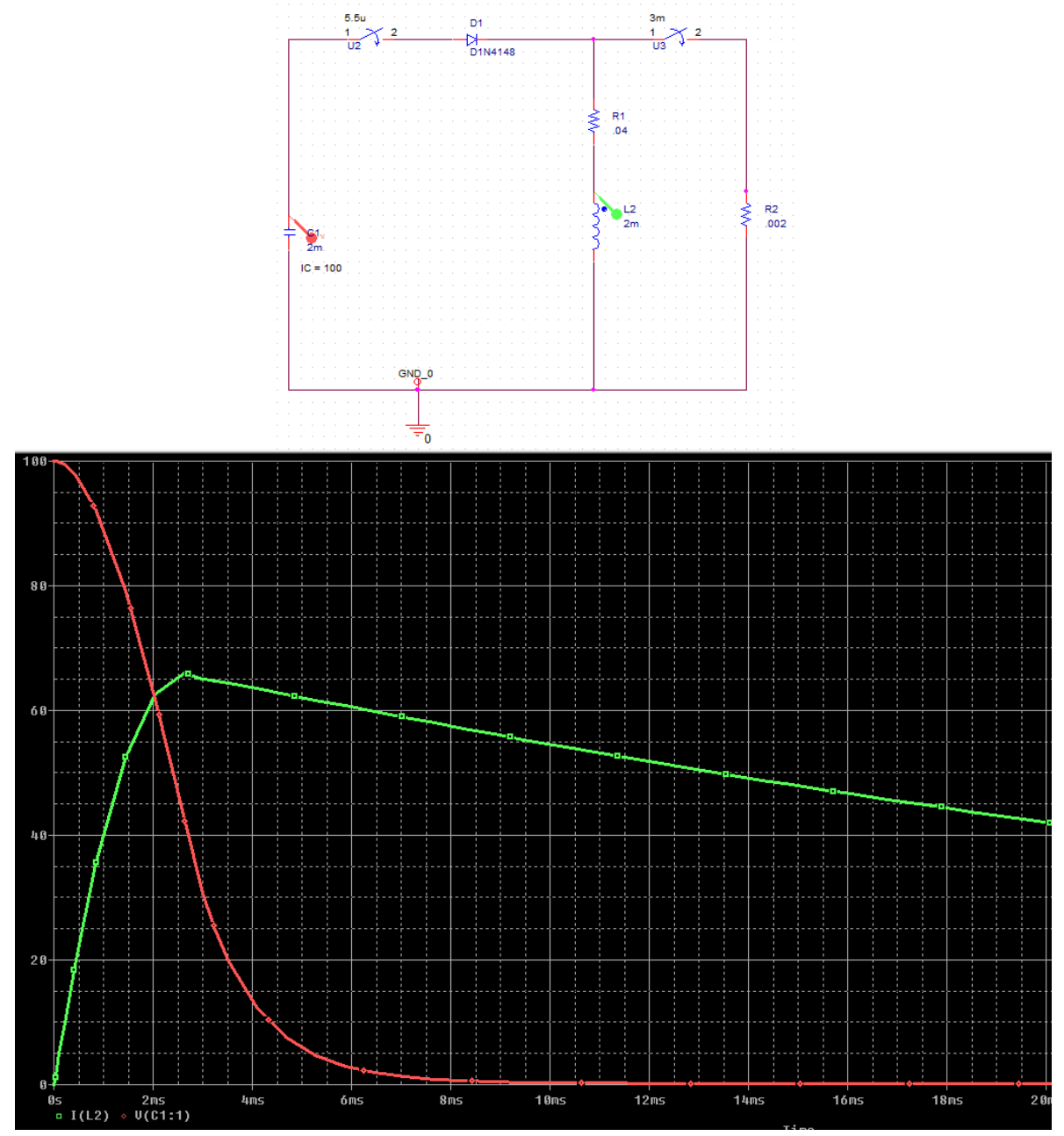
9.8 SIMPLE RLC CIRCUIT WITH FILTER CAP Simple RLC:
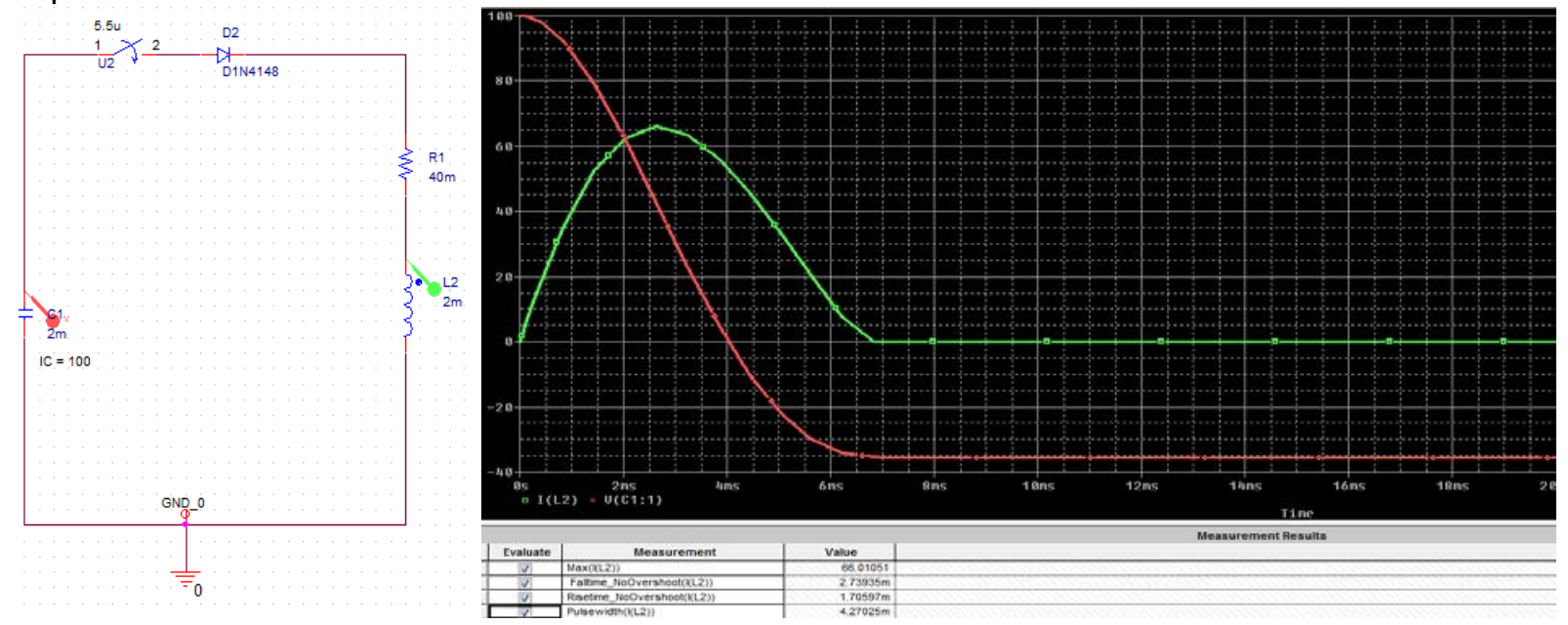

Simple RLC with Filter Cap:

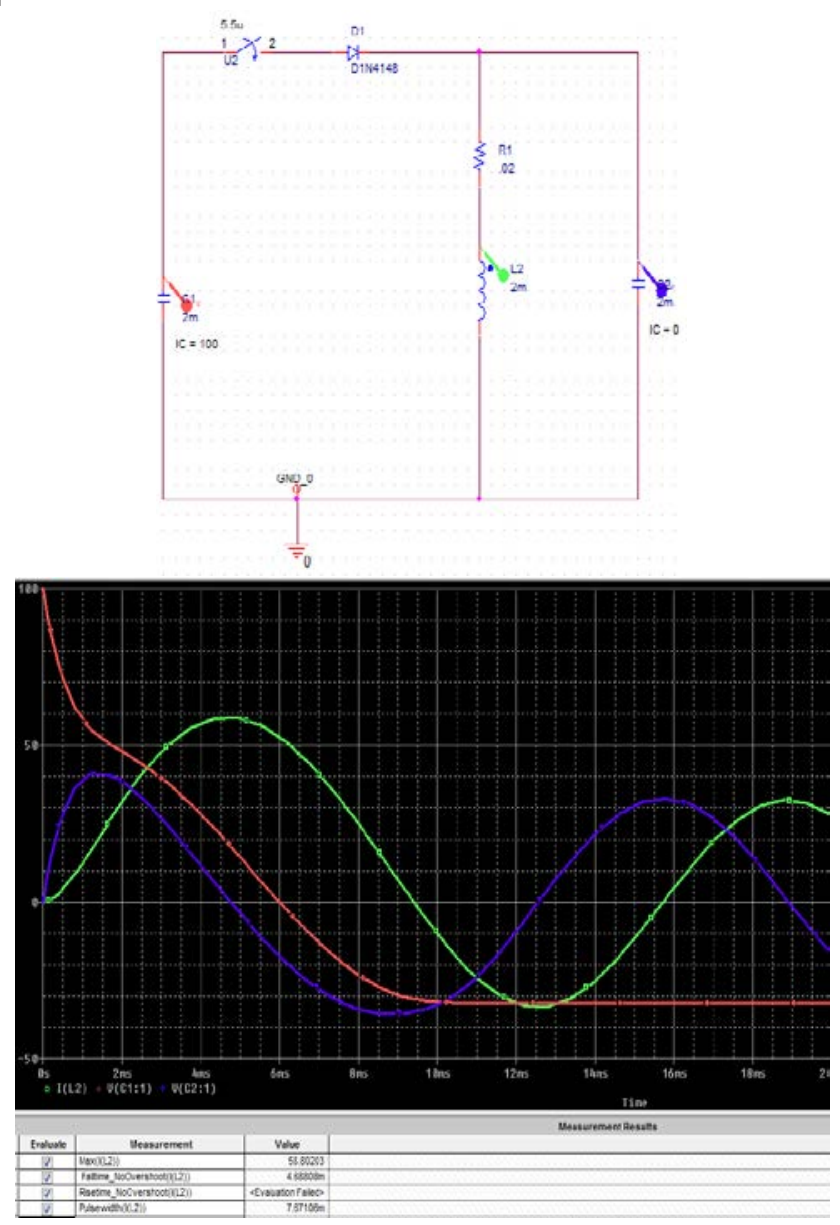


9.9 SIMPLE RLC CIRCUIT WITH RETROPULSING Simple RLC:
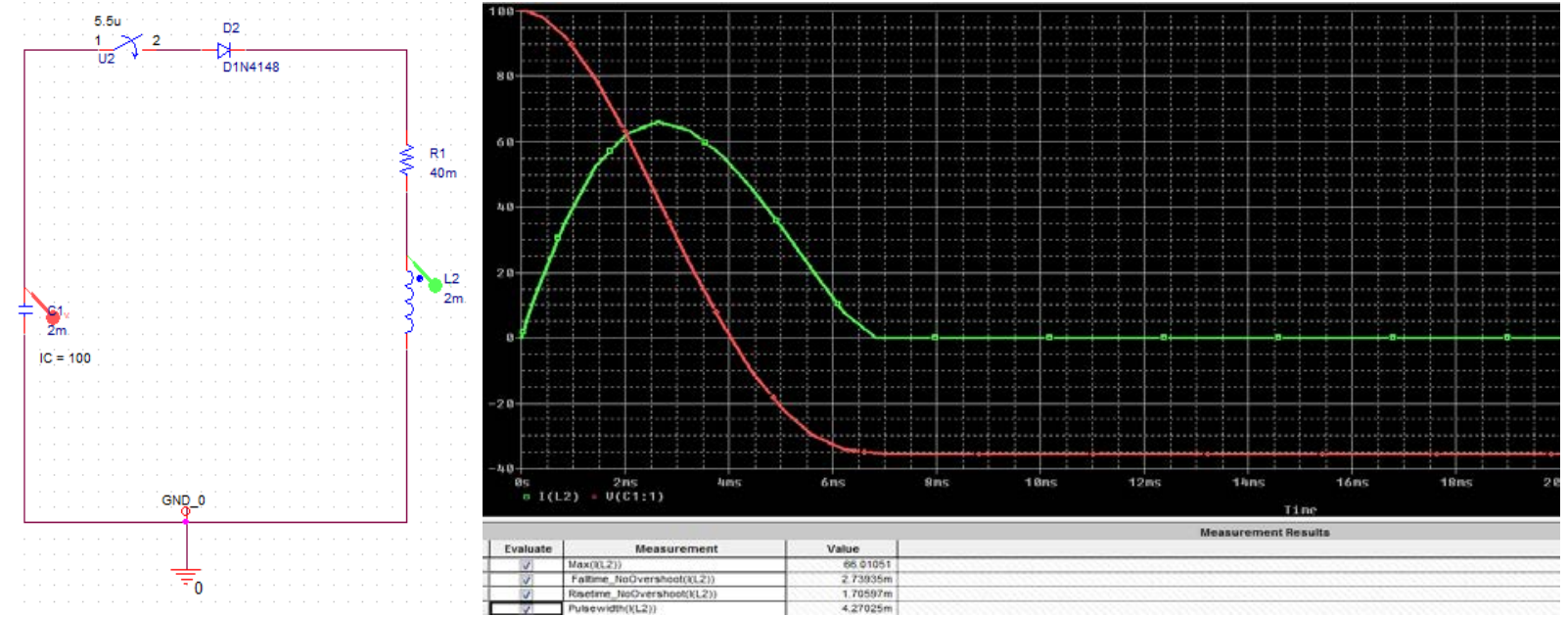

Simple RLC with Retropulsing:

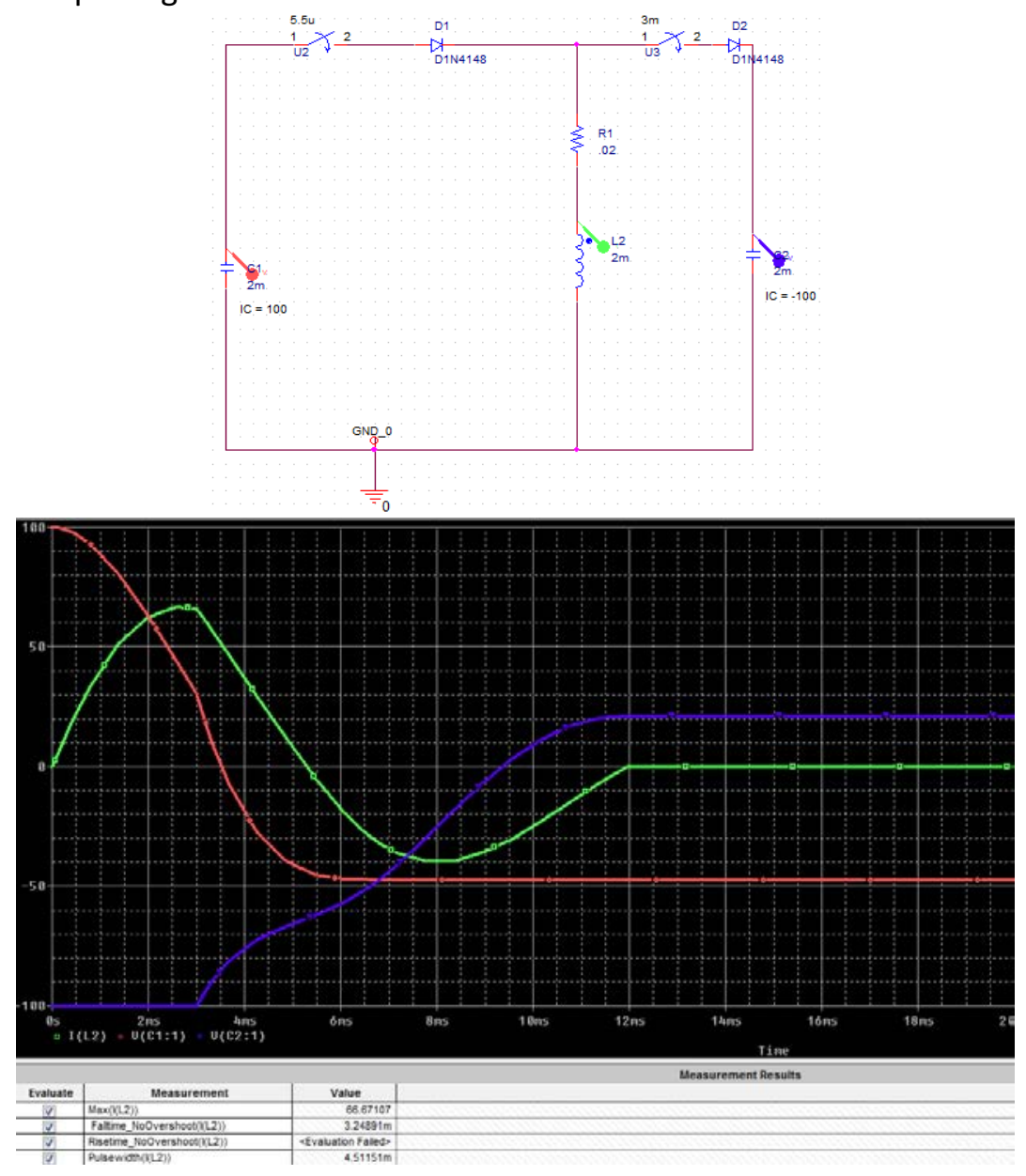


9.10 SIMPLE RLC CIRCUIT WITH RETROPULSING FOR SAWTOOTH Simple RLC:
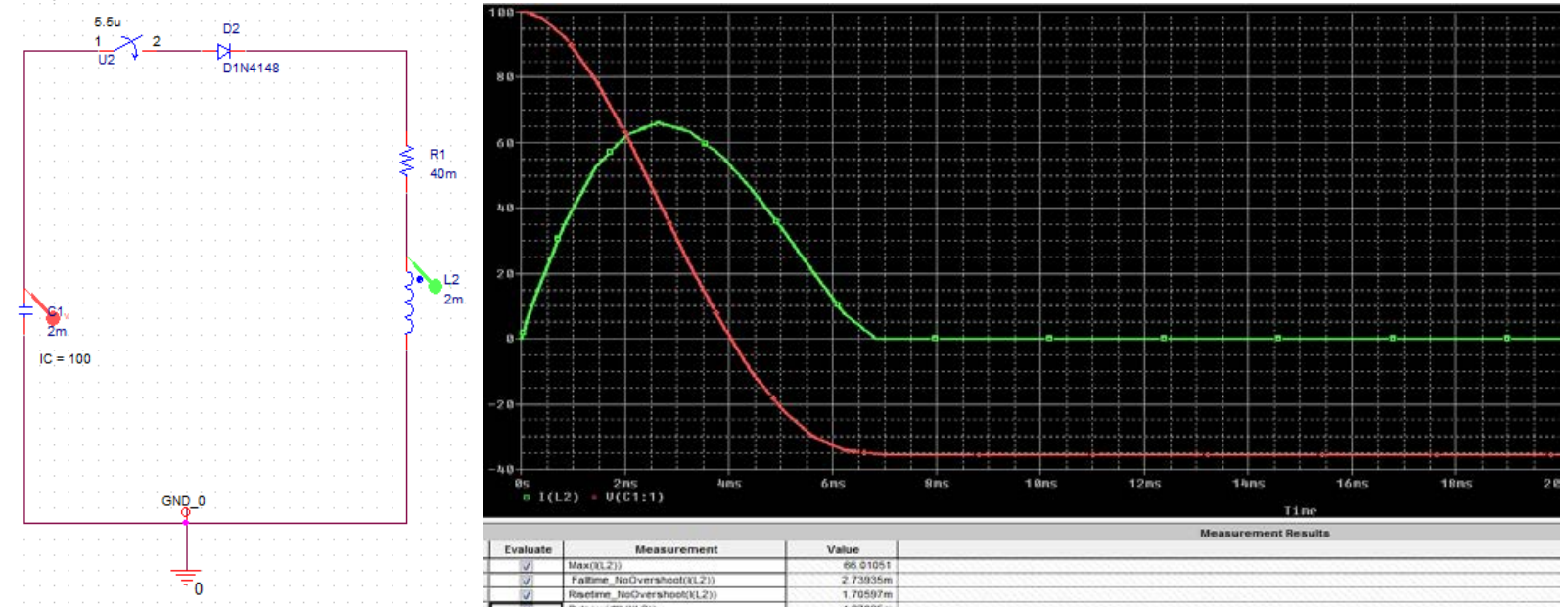

Simple RLC with Extreme Retropulsing:
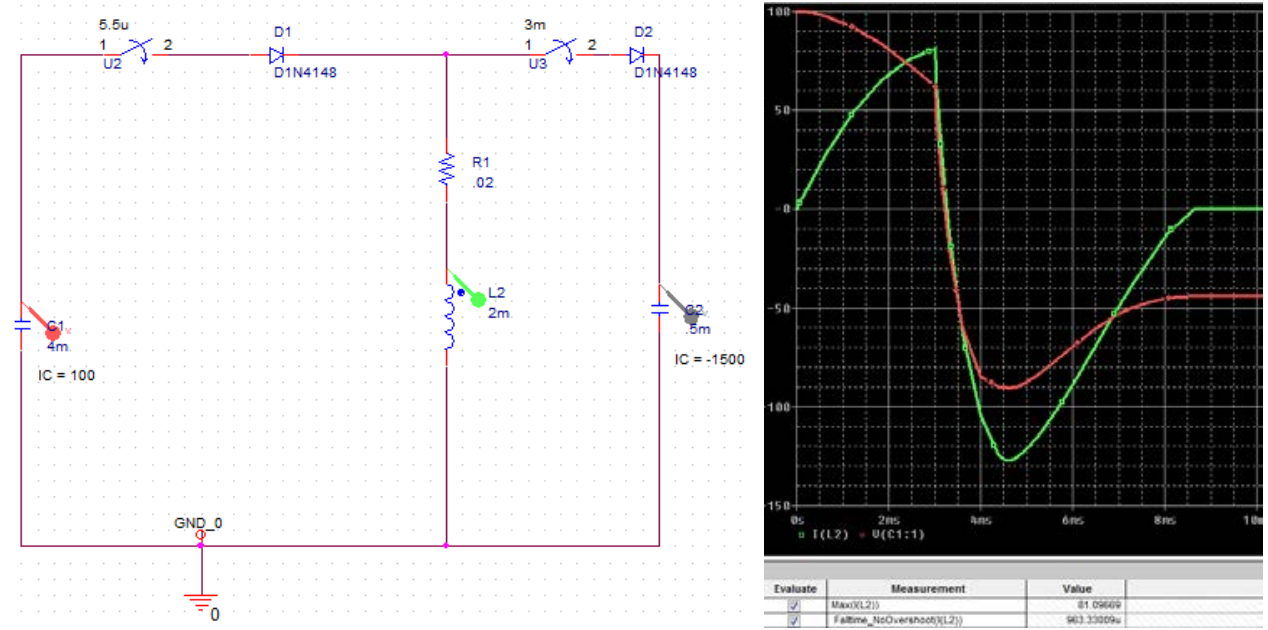

Simple RLC with Retropulsing and Crowbar:
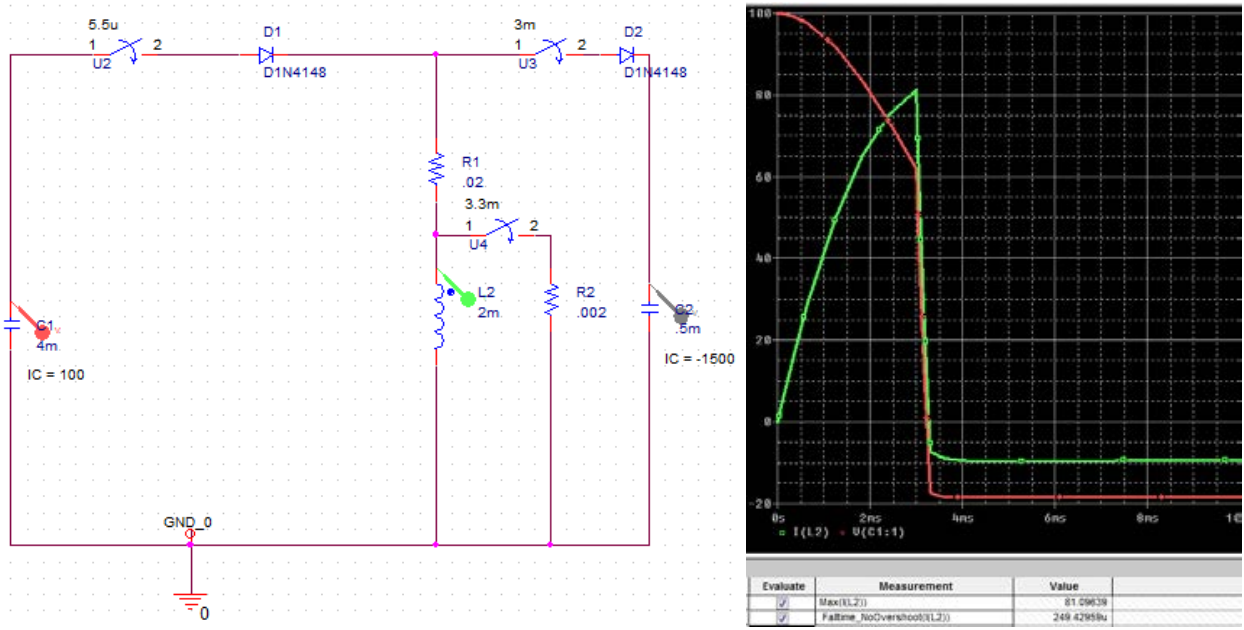
9.11 SIMPLE RLC CIRCUIT WITH RETROPULSING FOR TRIANGLE Simple RLC:

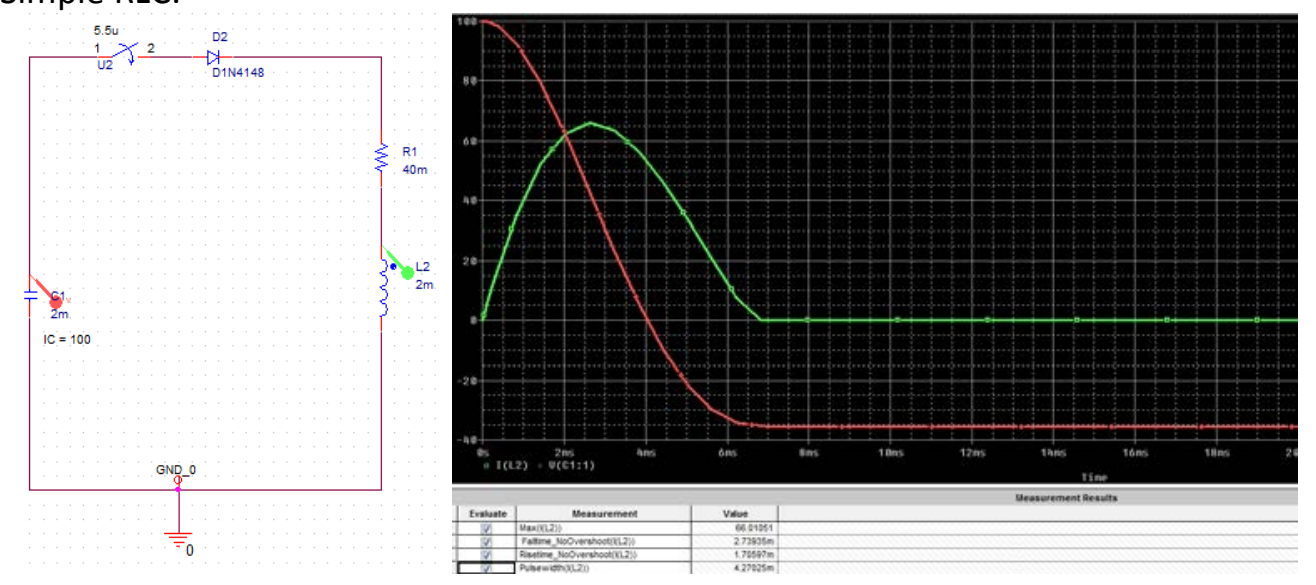

Simple RLC with Retropulsing:
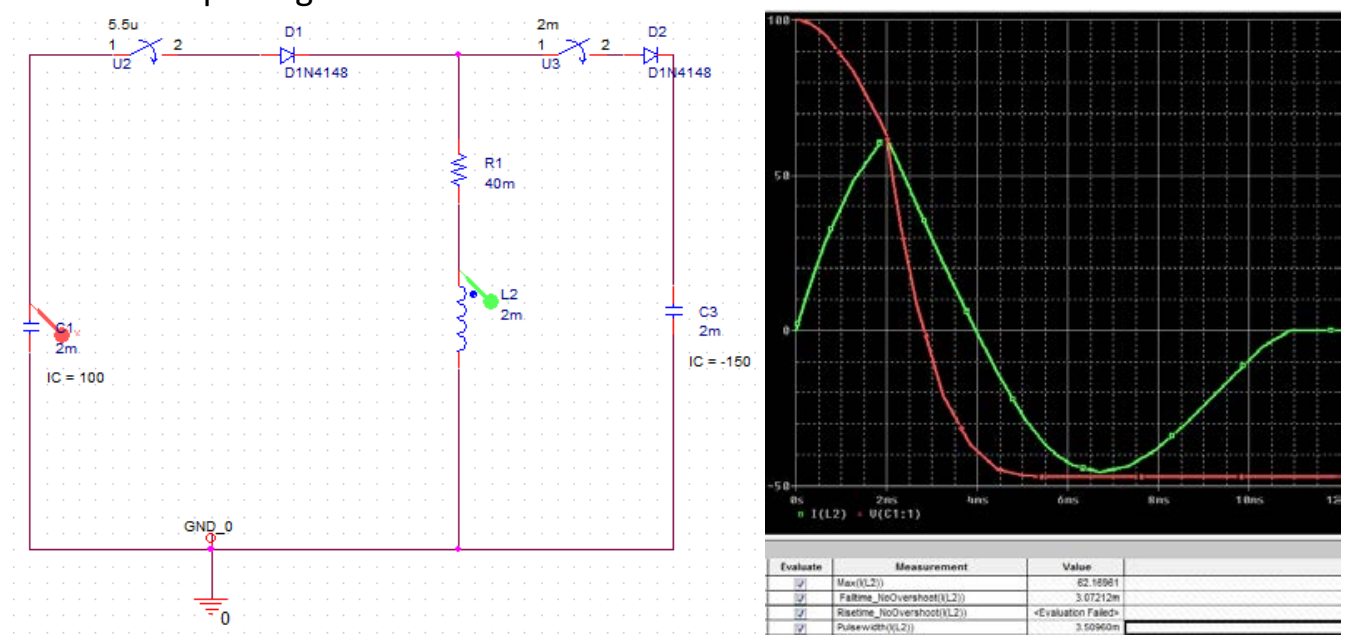

Simple RLC with Retropulsing and Crowbar:
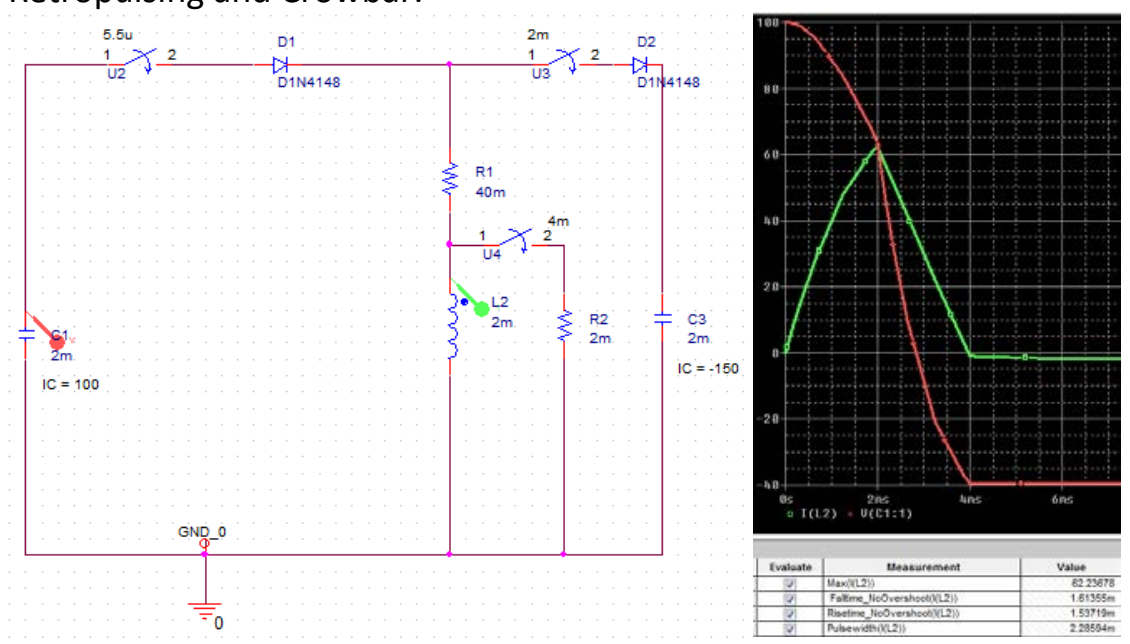


\subsection{CIRCUIT BOARD PICTURES AND SCHEMATICS}

HVDB BOARD

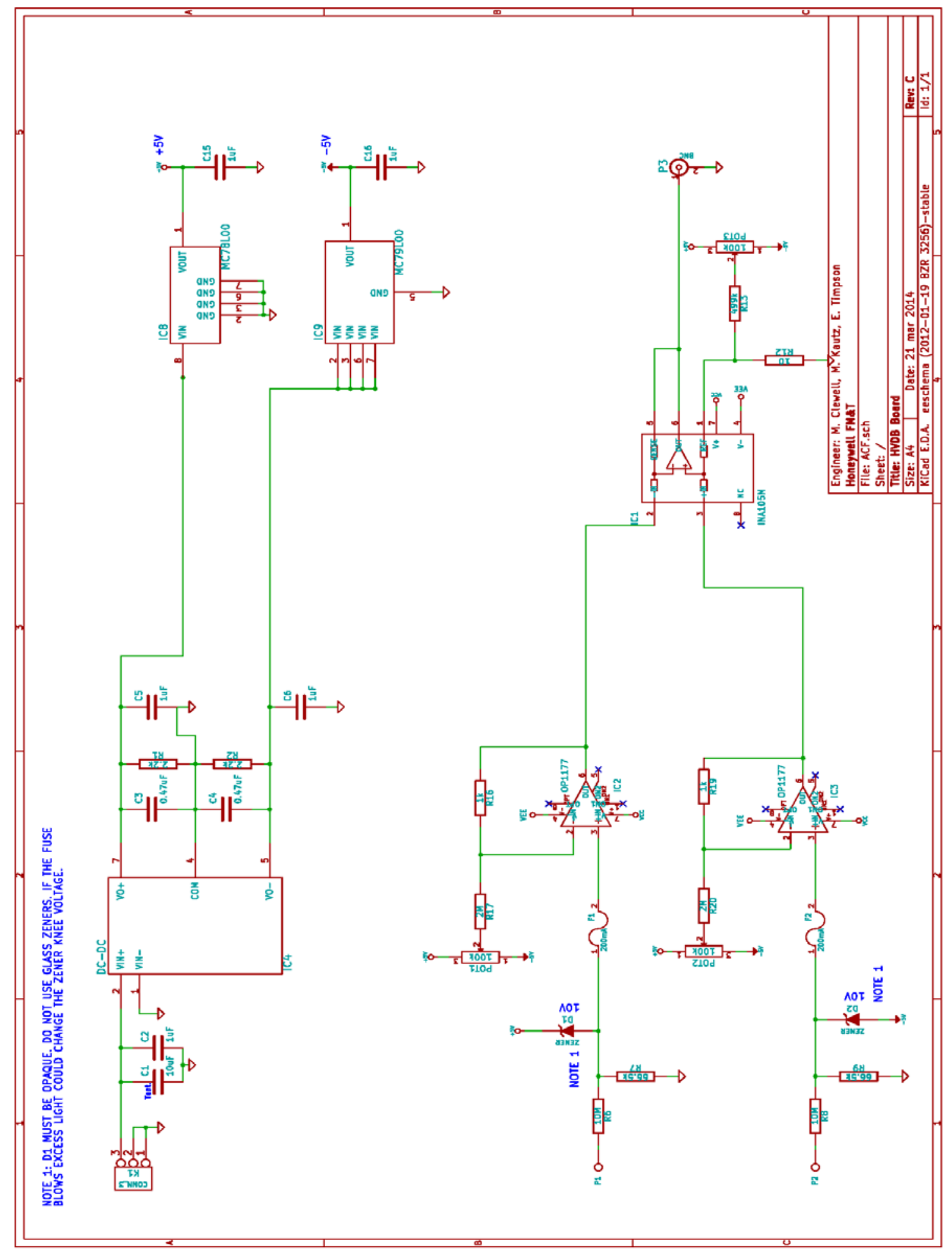



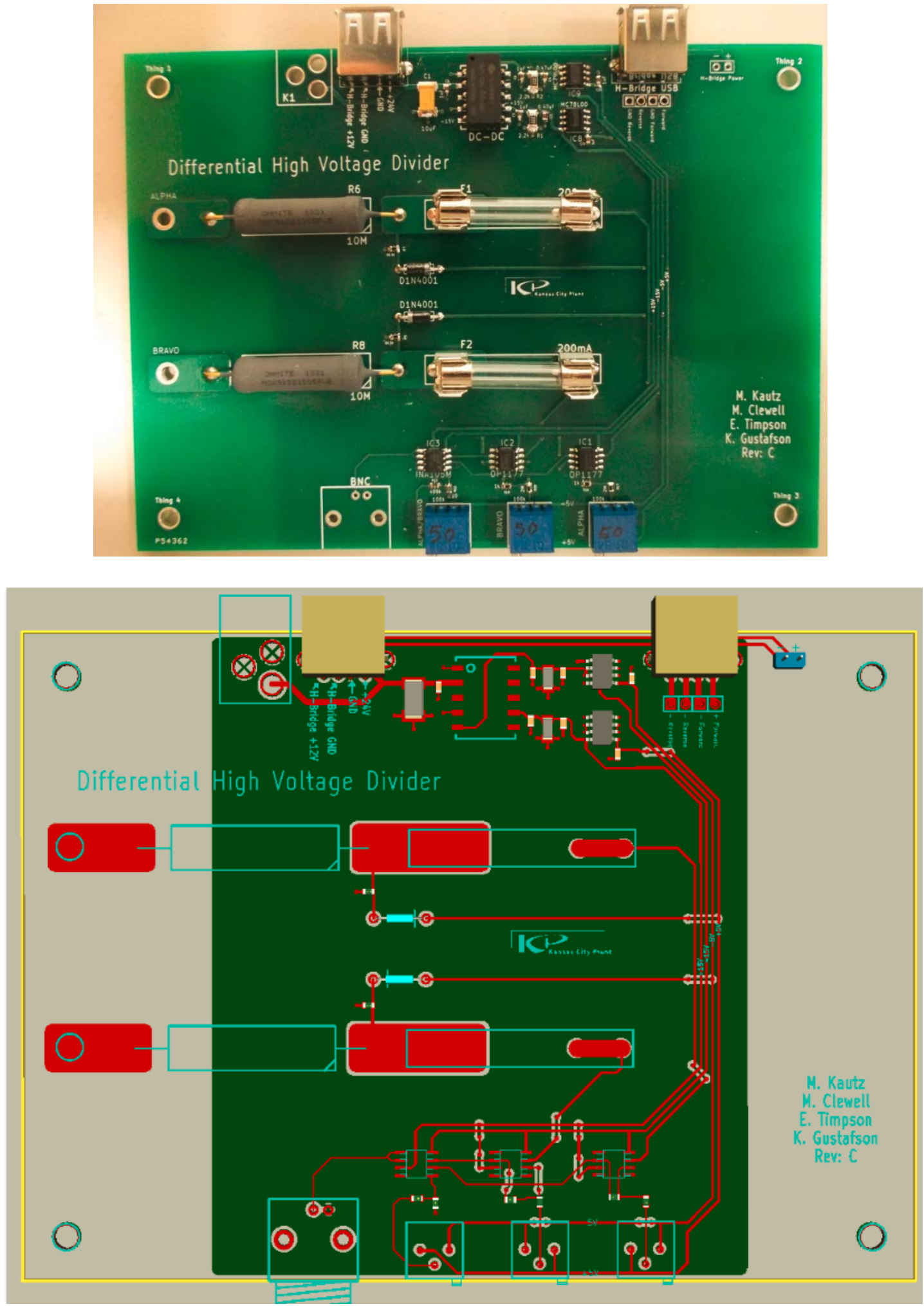
CHARGE DISCONNECT BOARD

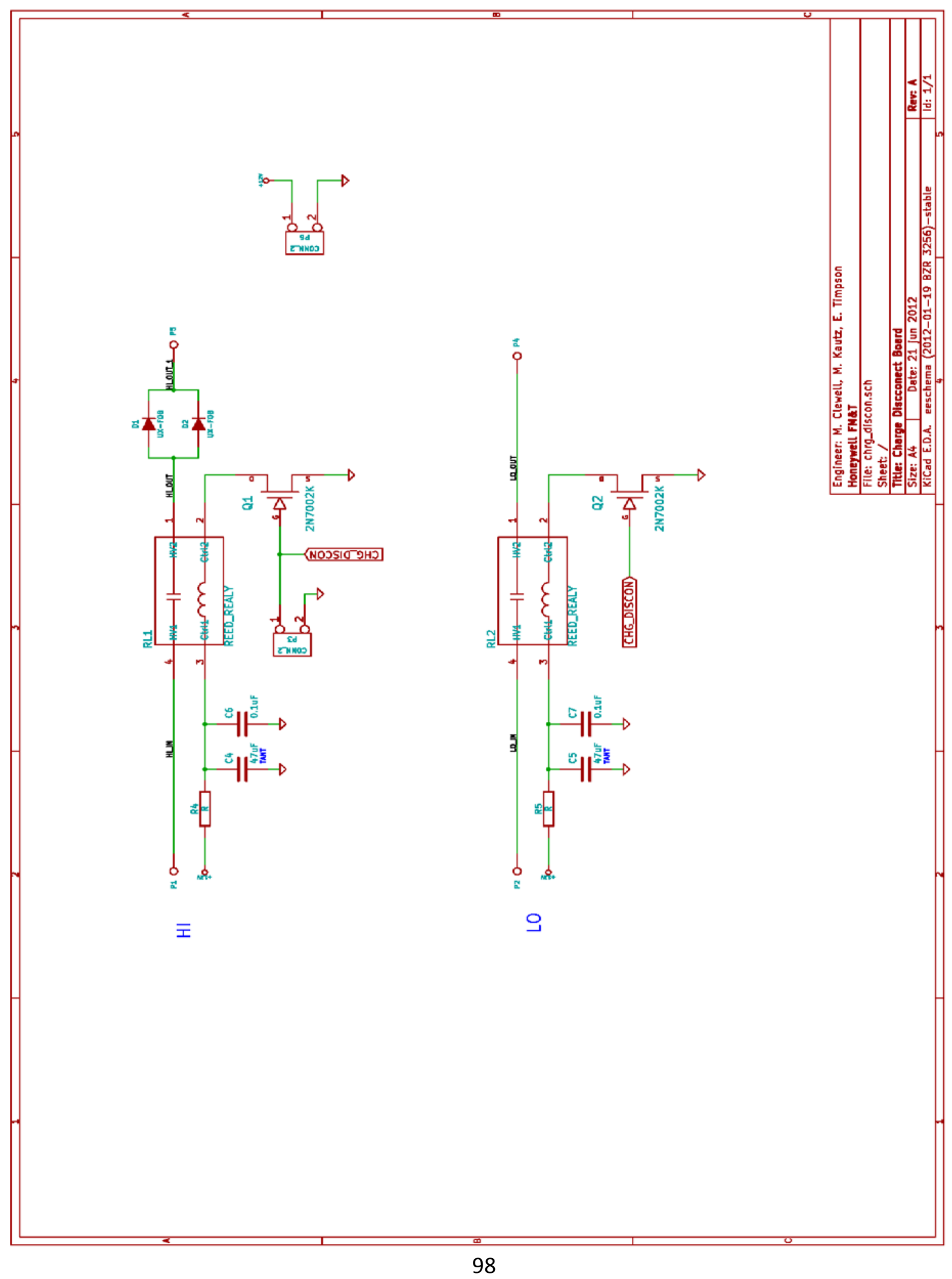


0
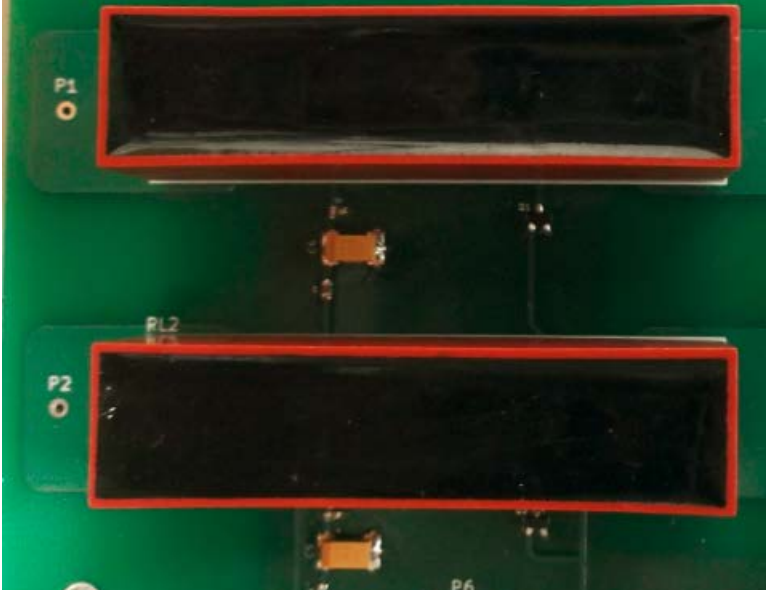

○

Q Charge Disconnect

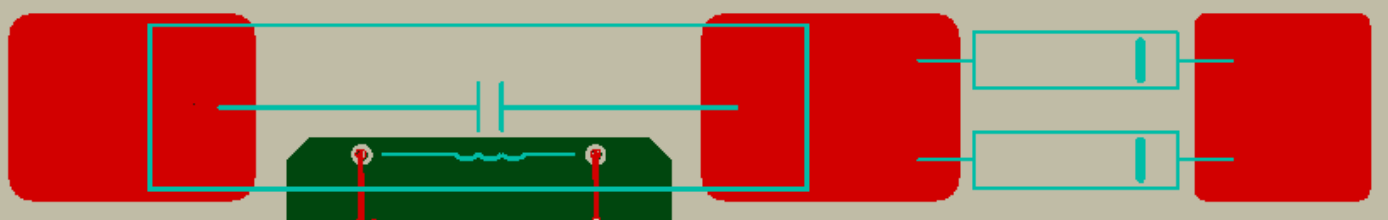

0

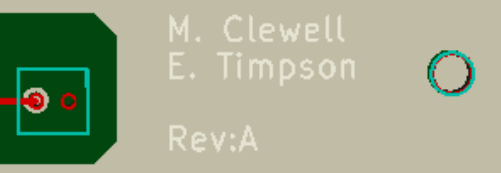




\section{H-BRIDGE BOARD}

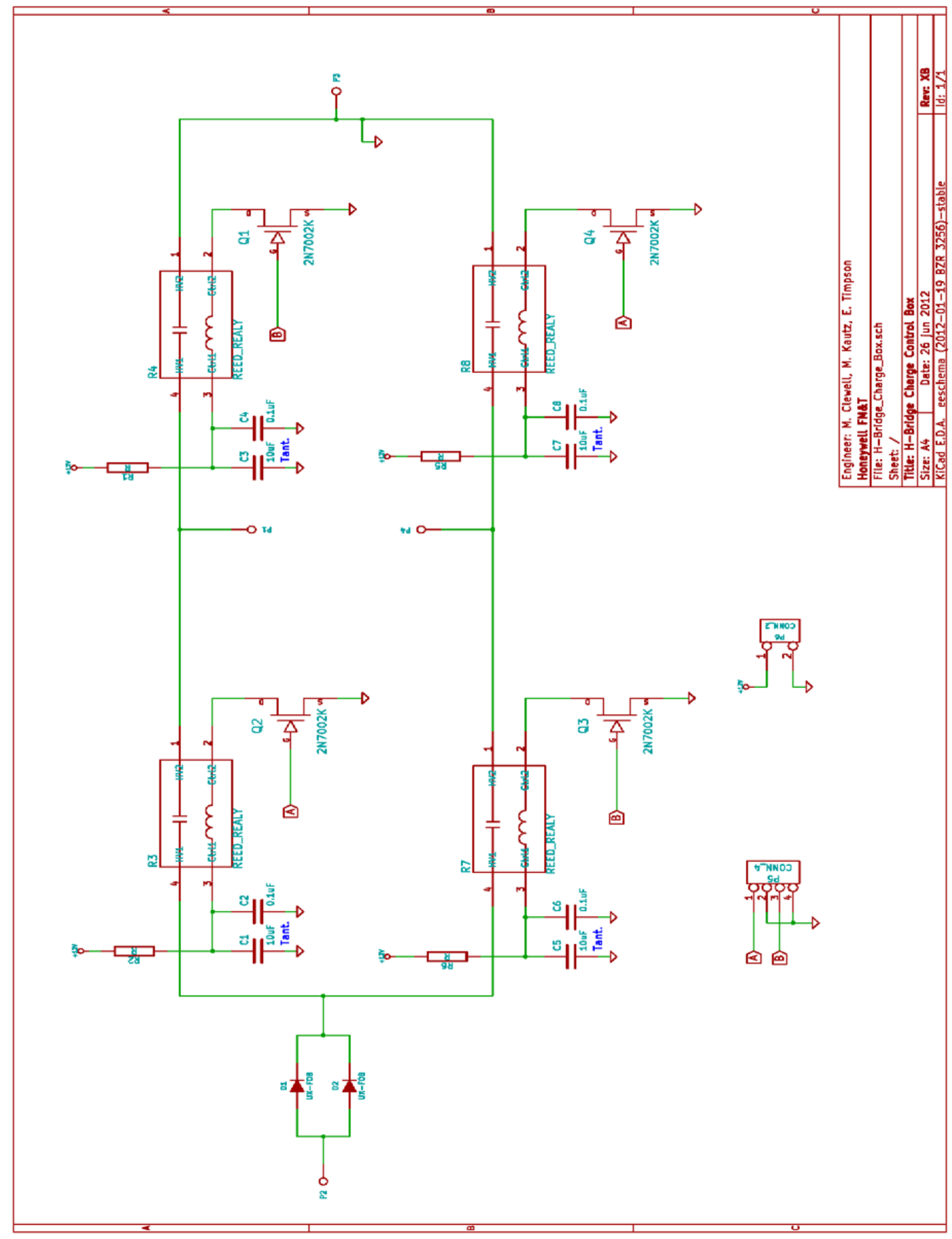




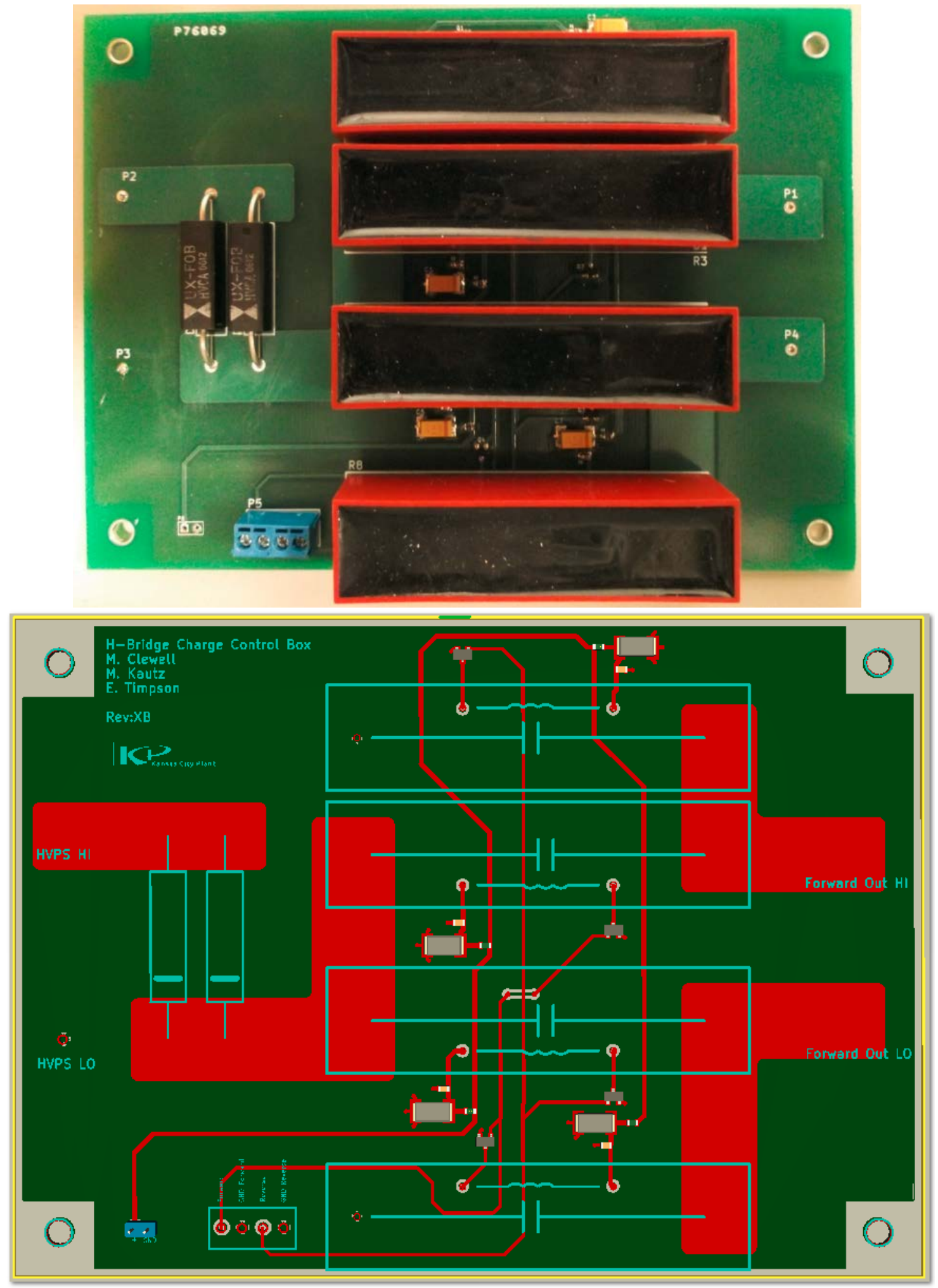


DMM SELECT BOARD

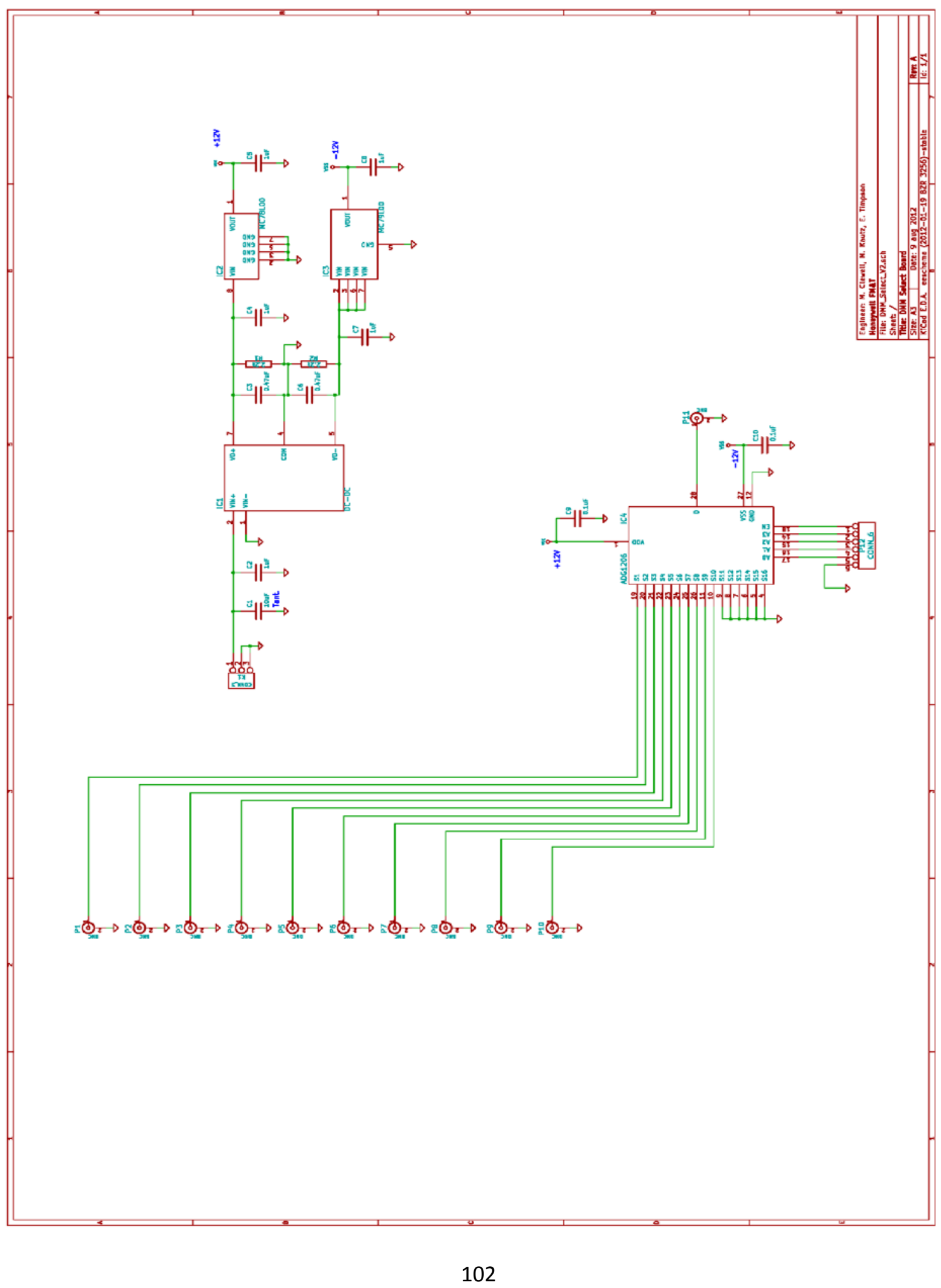




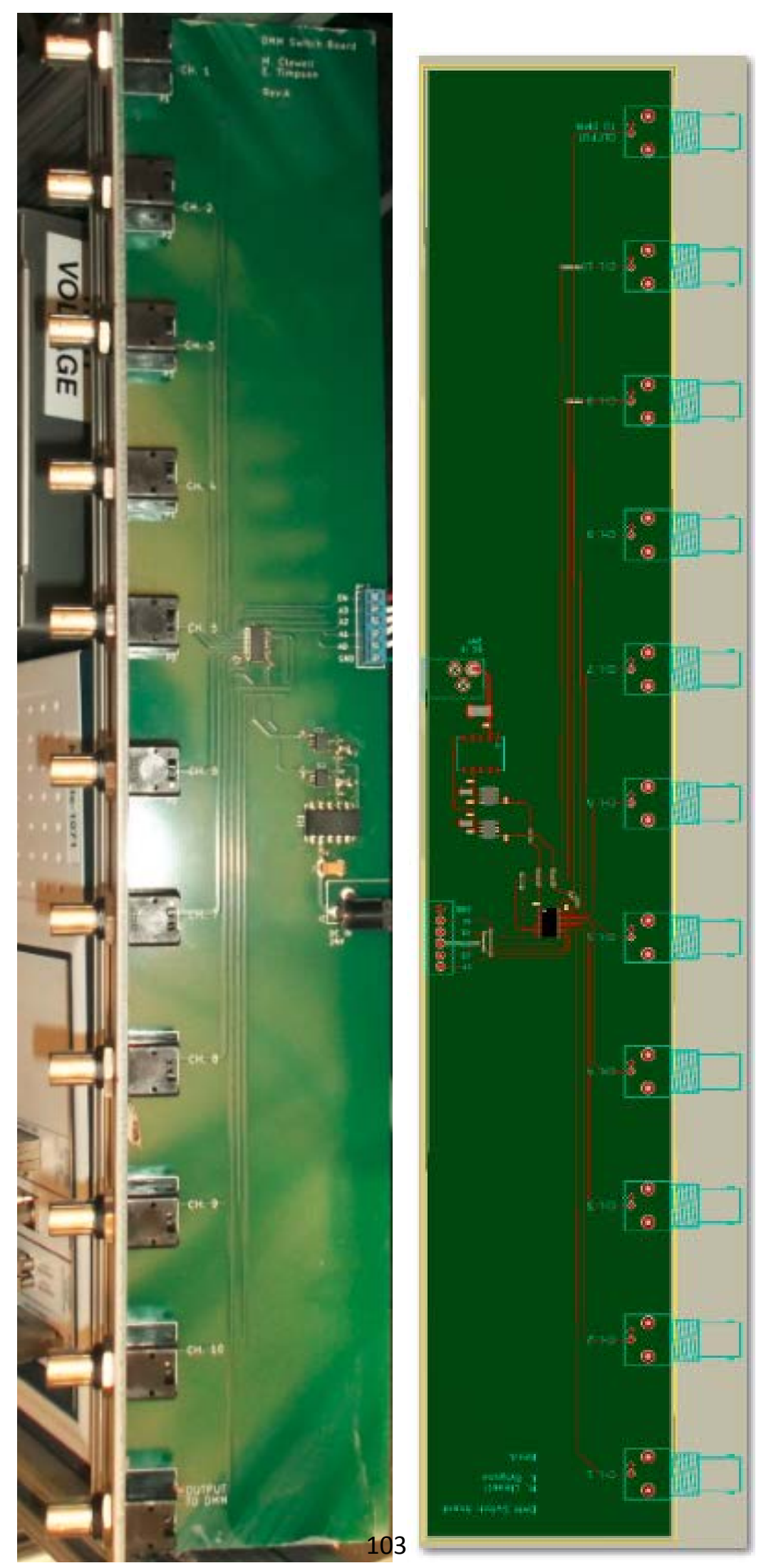


FIRE CONTROL BOARD

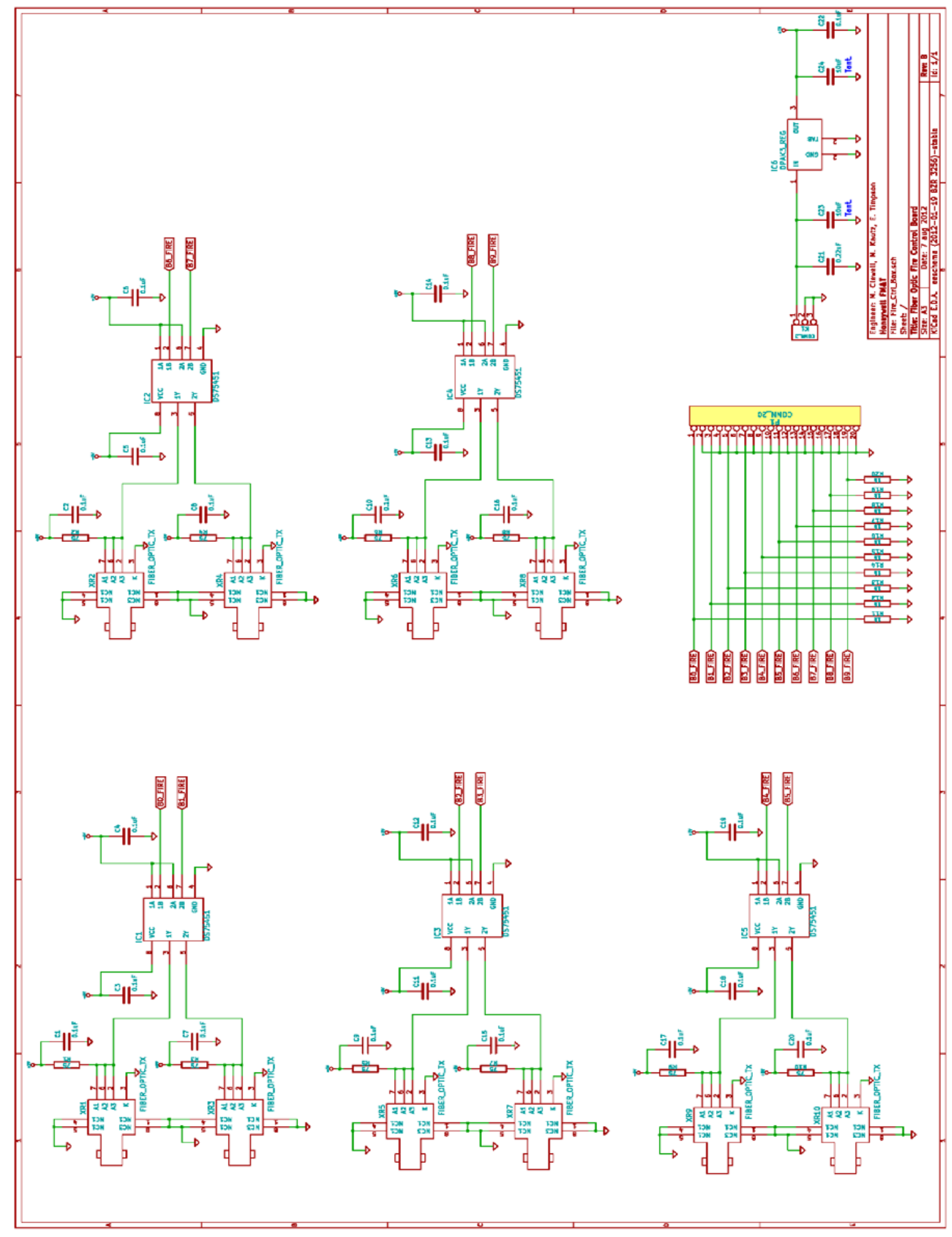



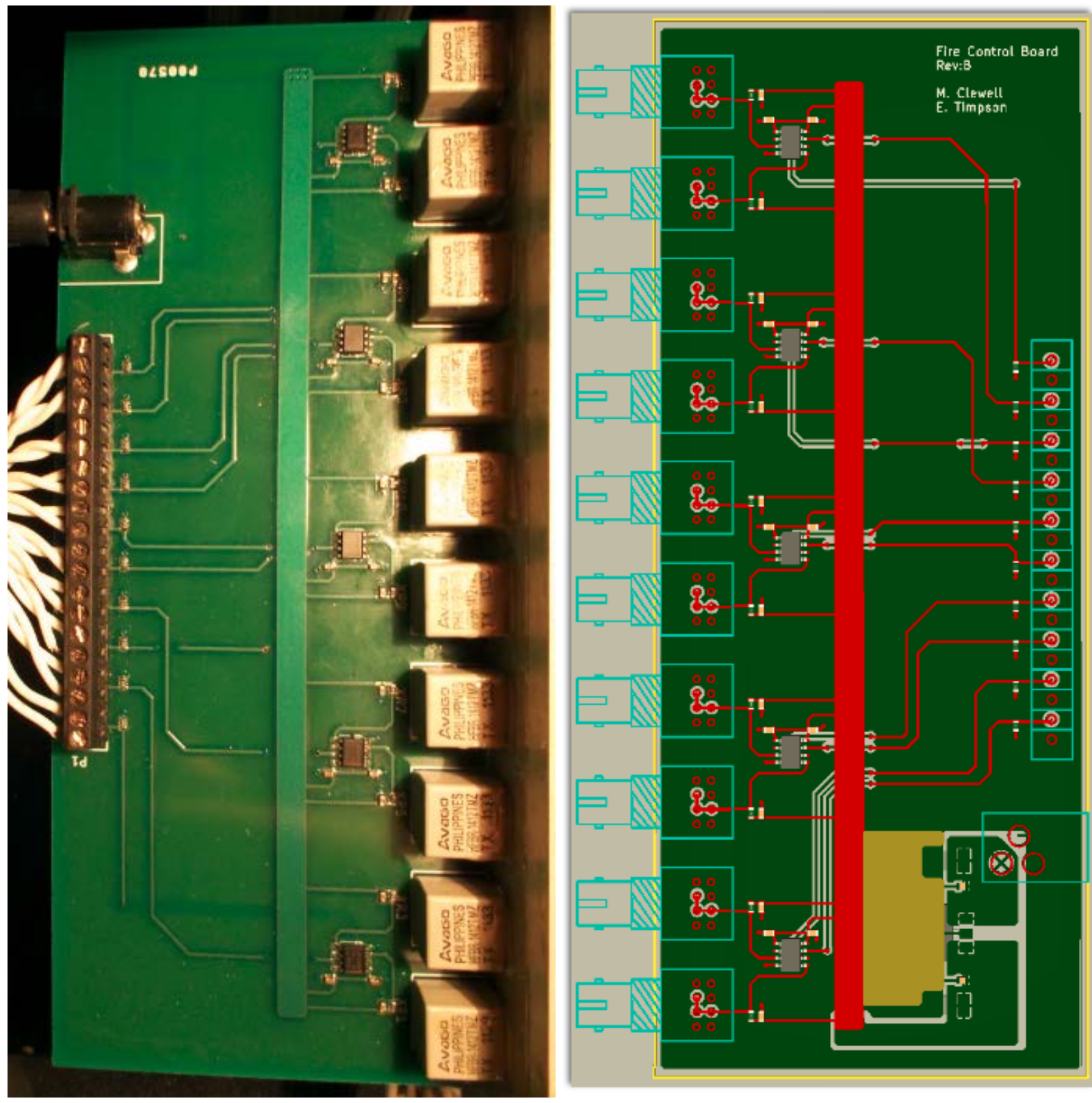
SCR DUAL BOARD

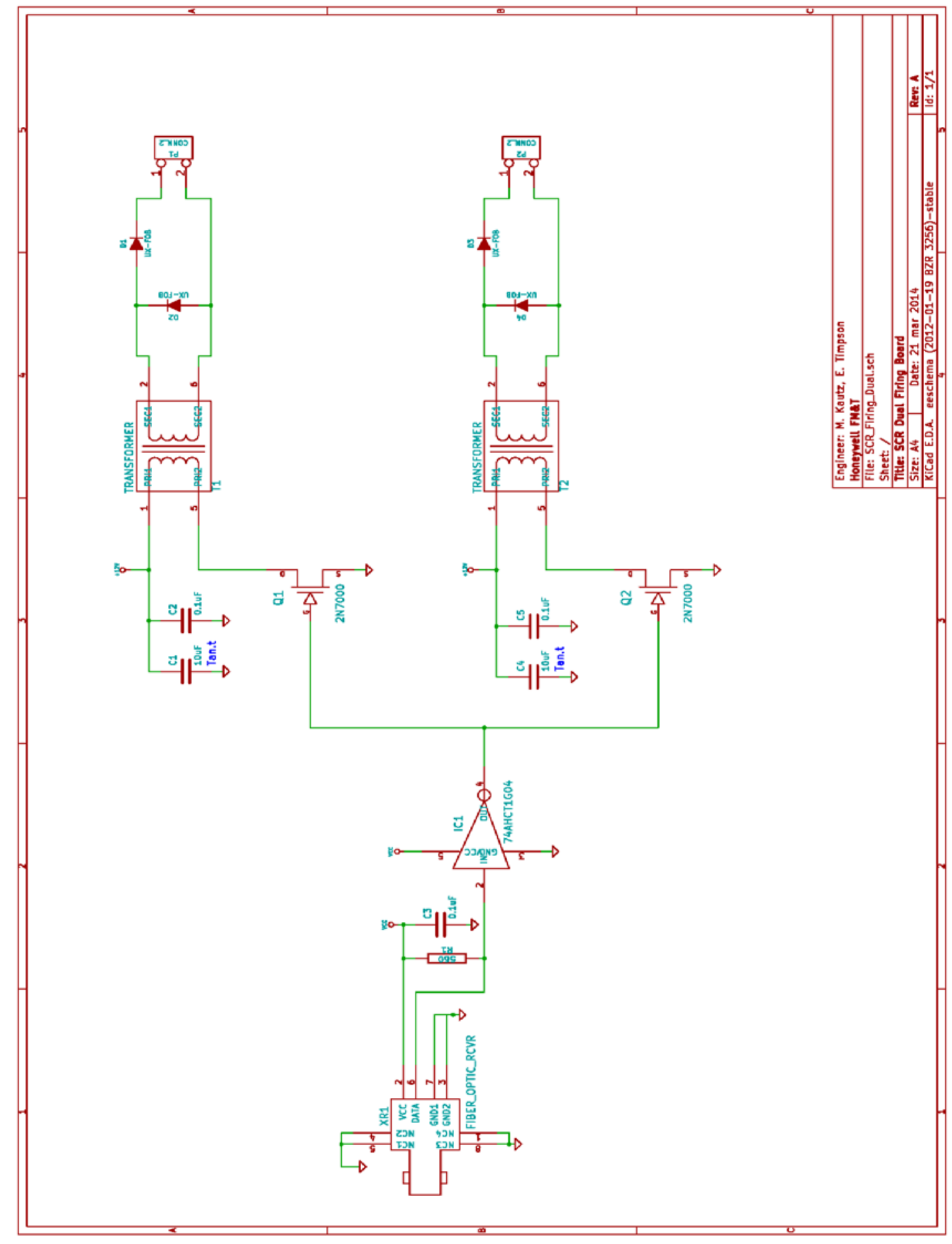



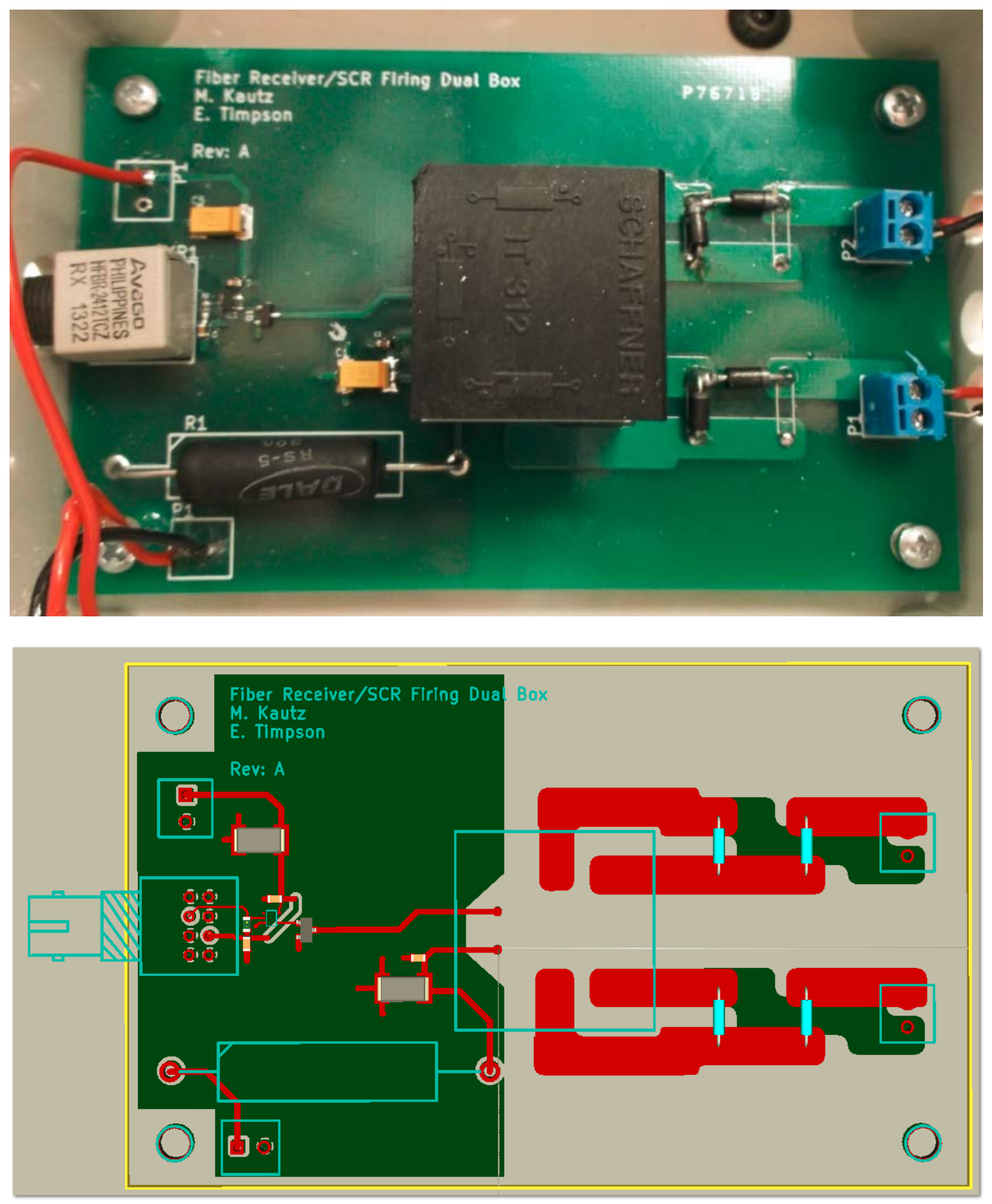
SCR BOARD

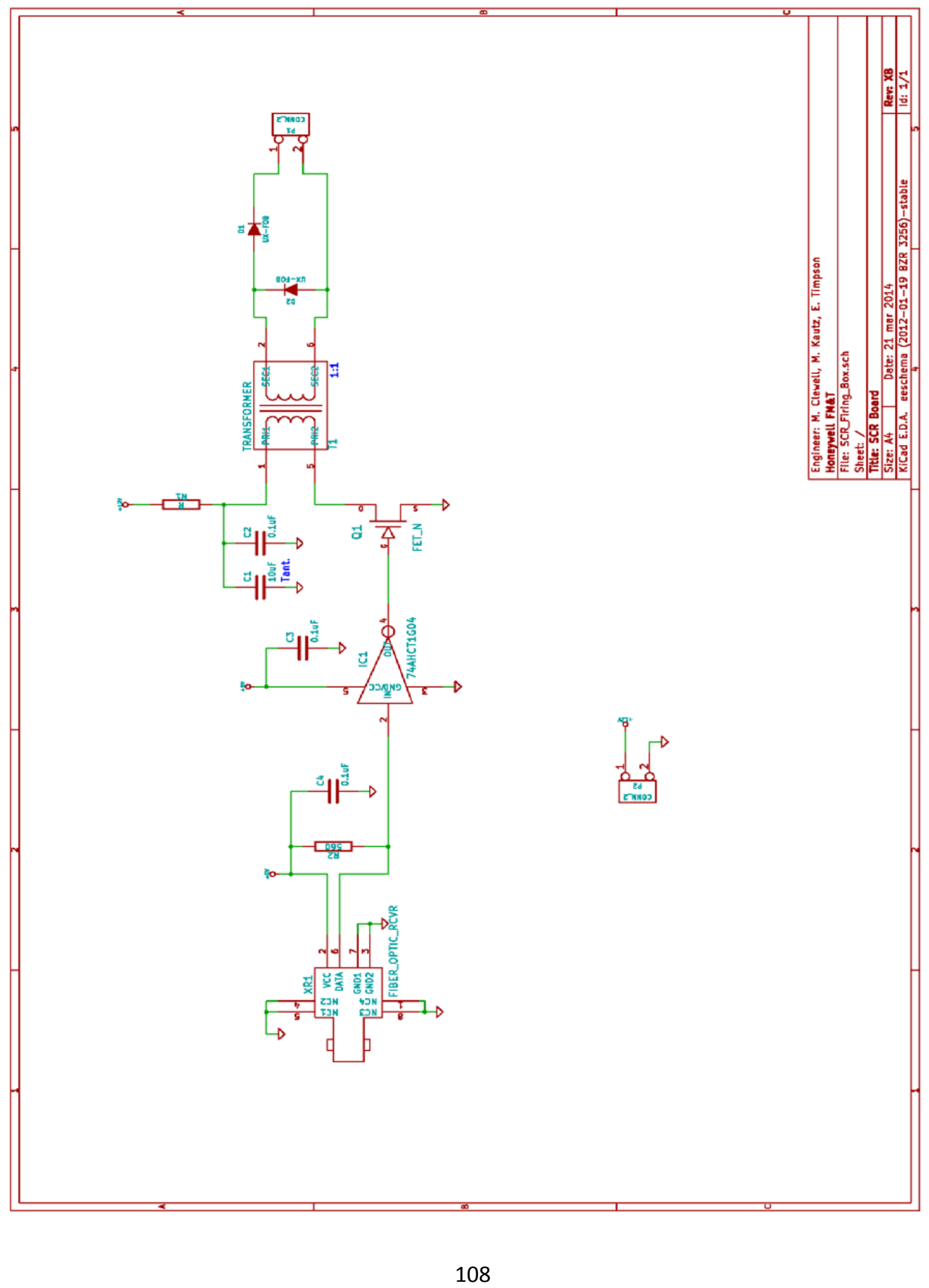



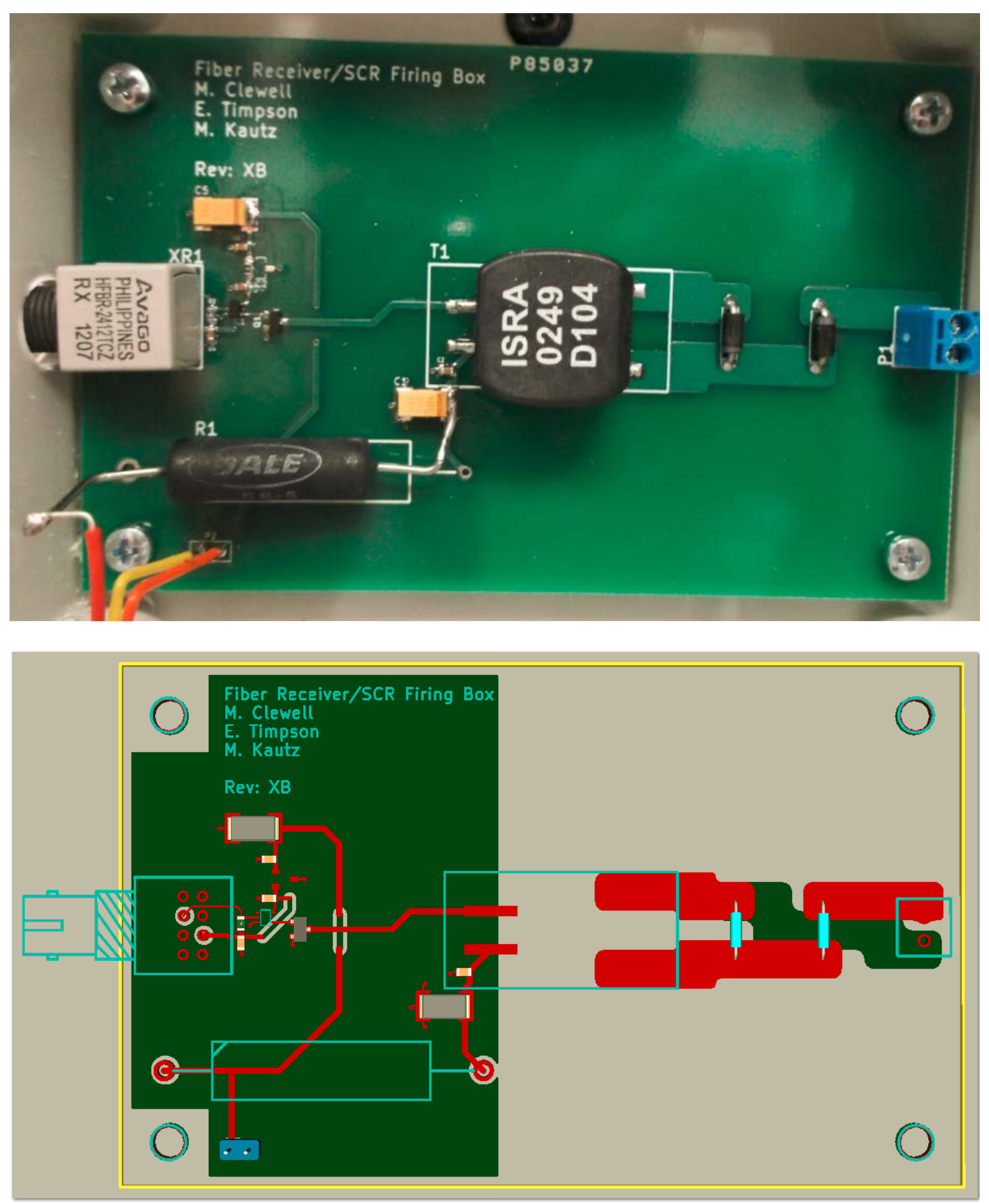
USB BOARD

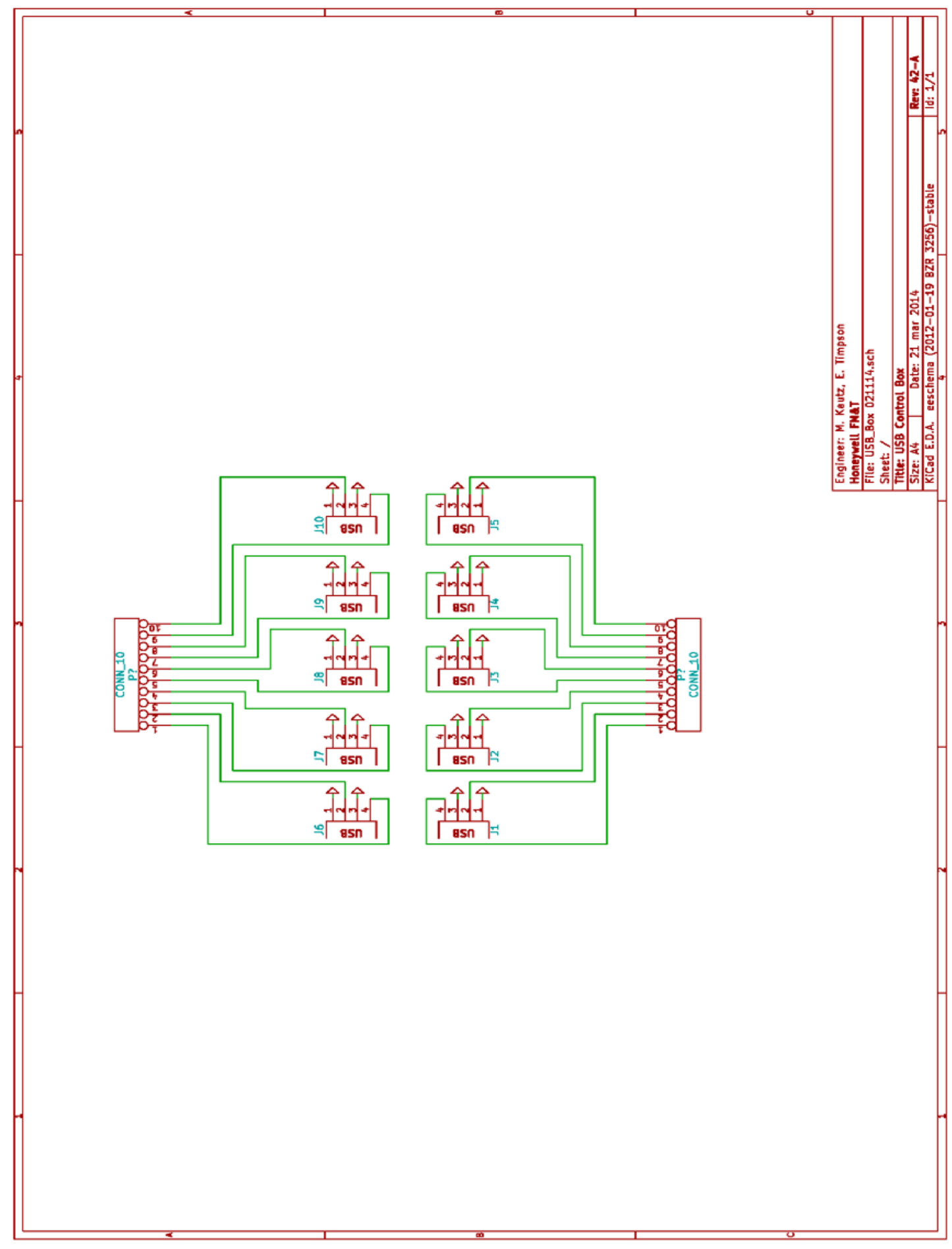



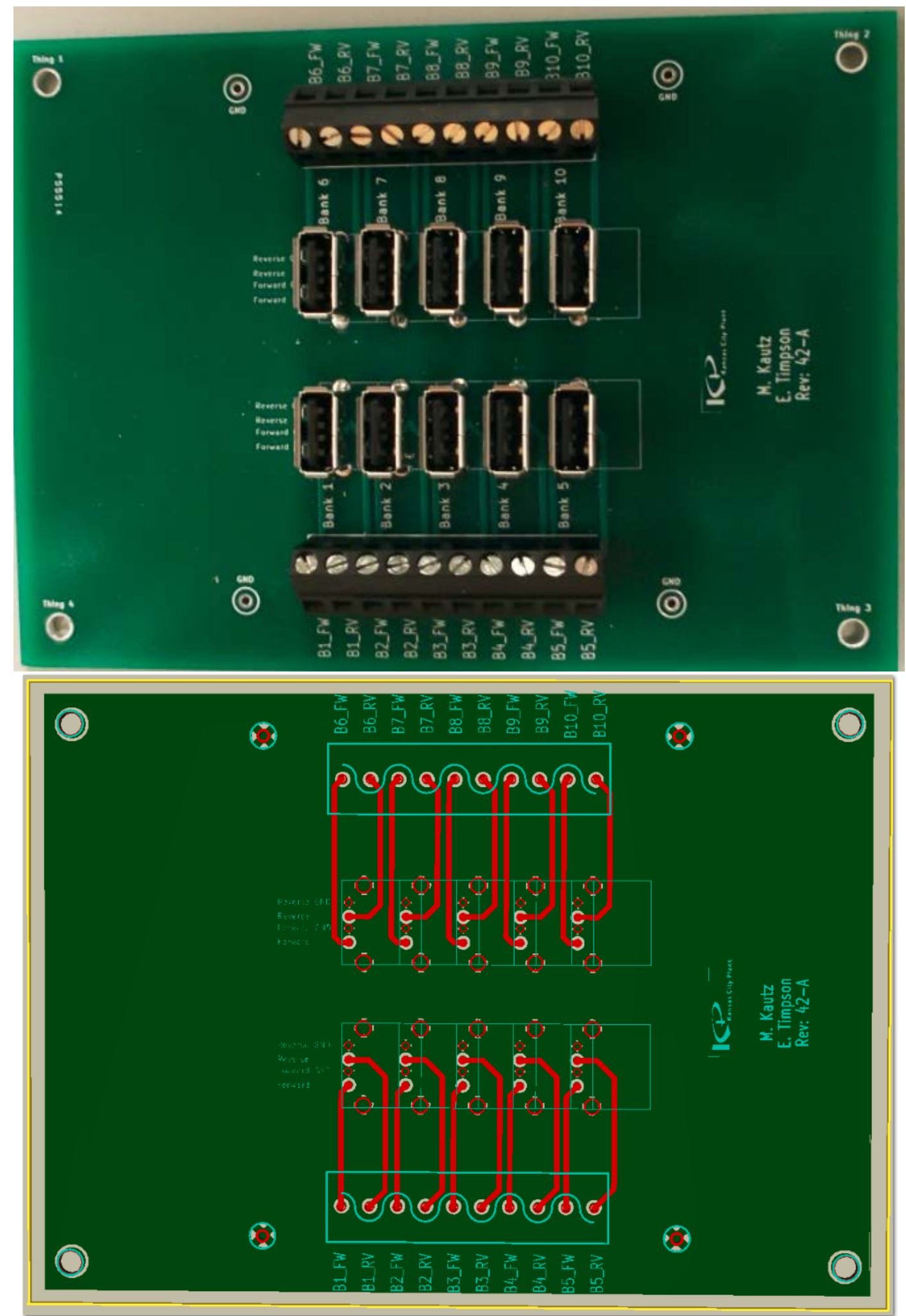


\subsection{SOFTWARE}

\section{LABVIEW}
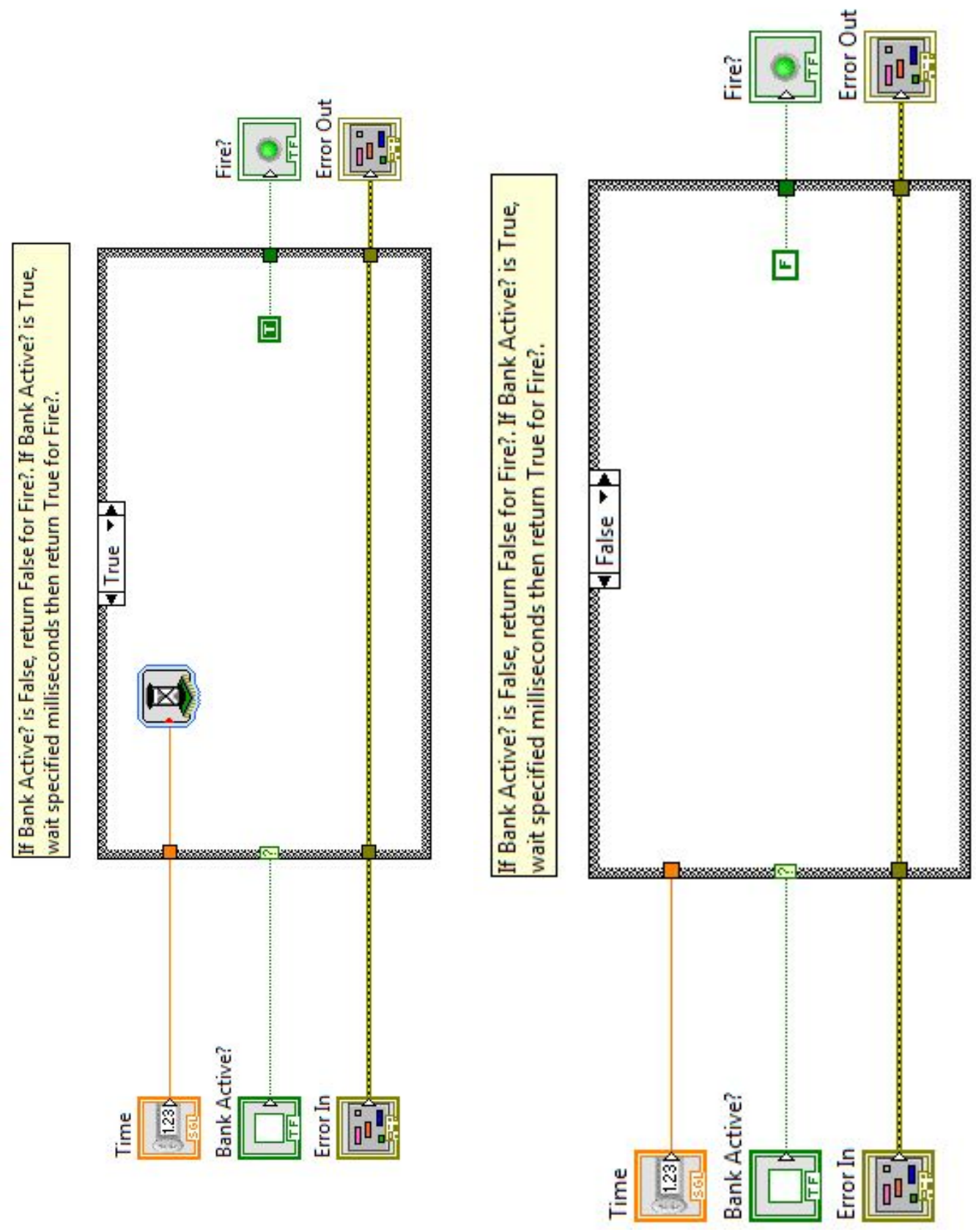


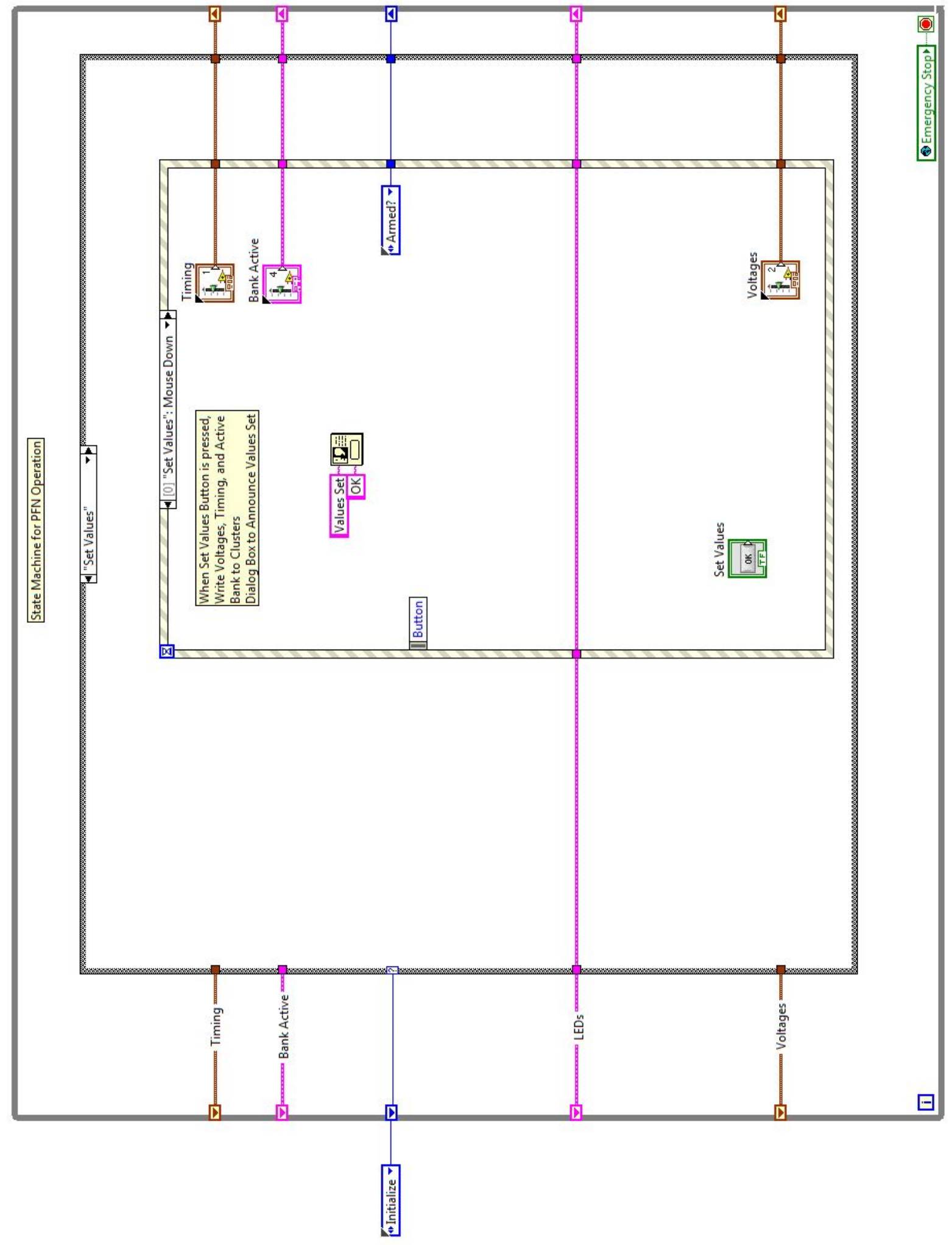



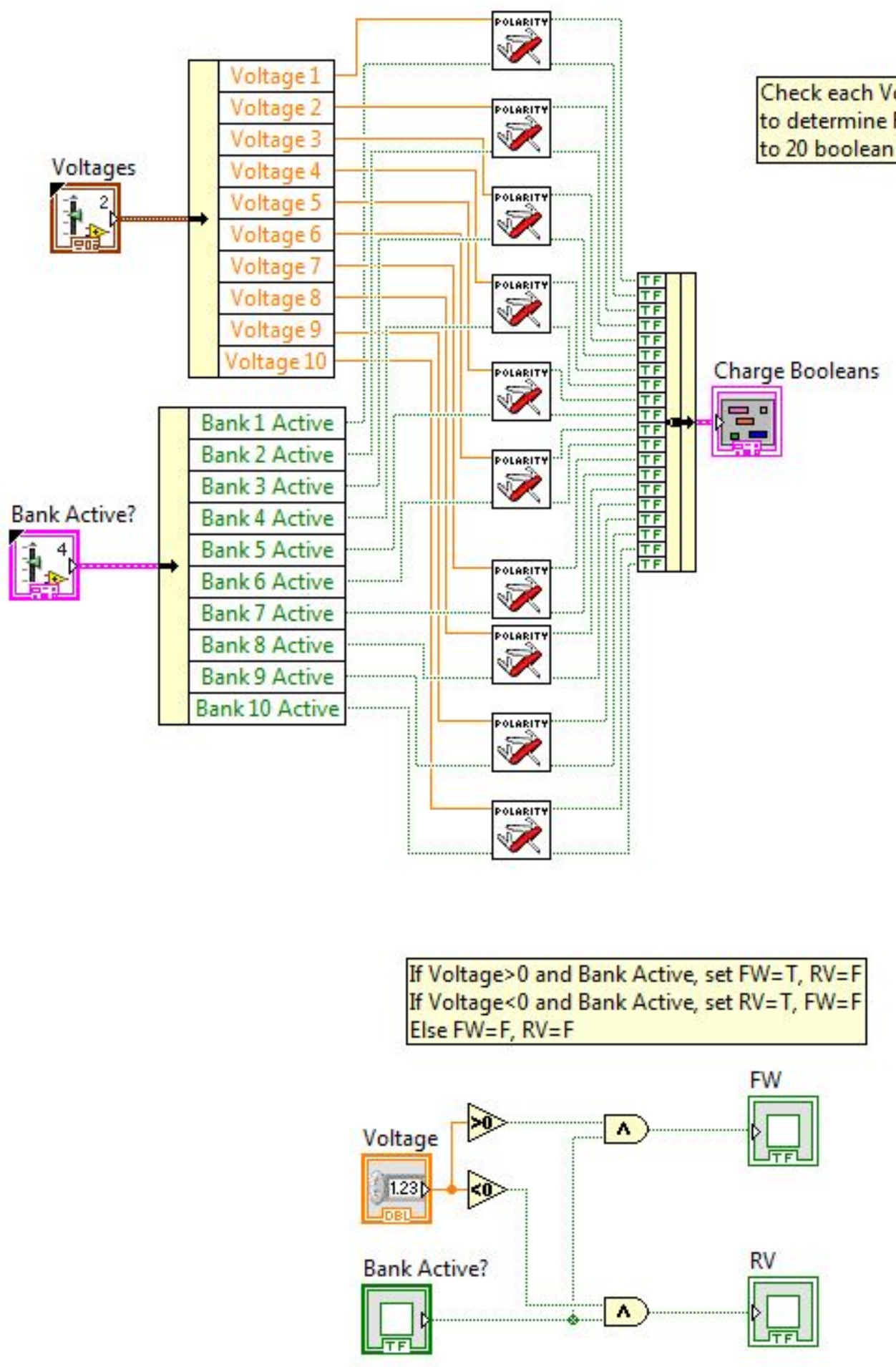

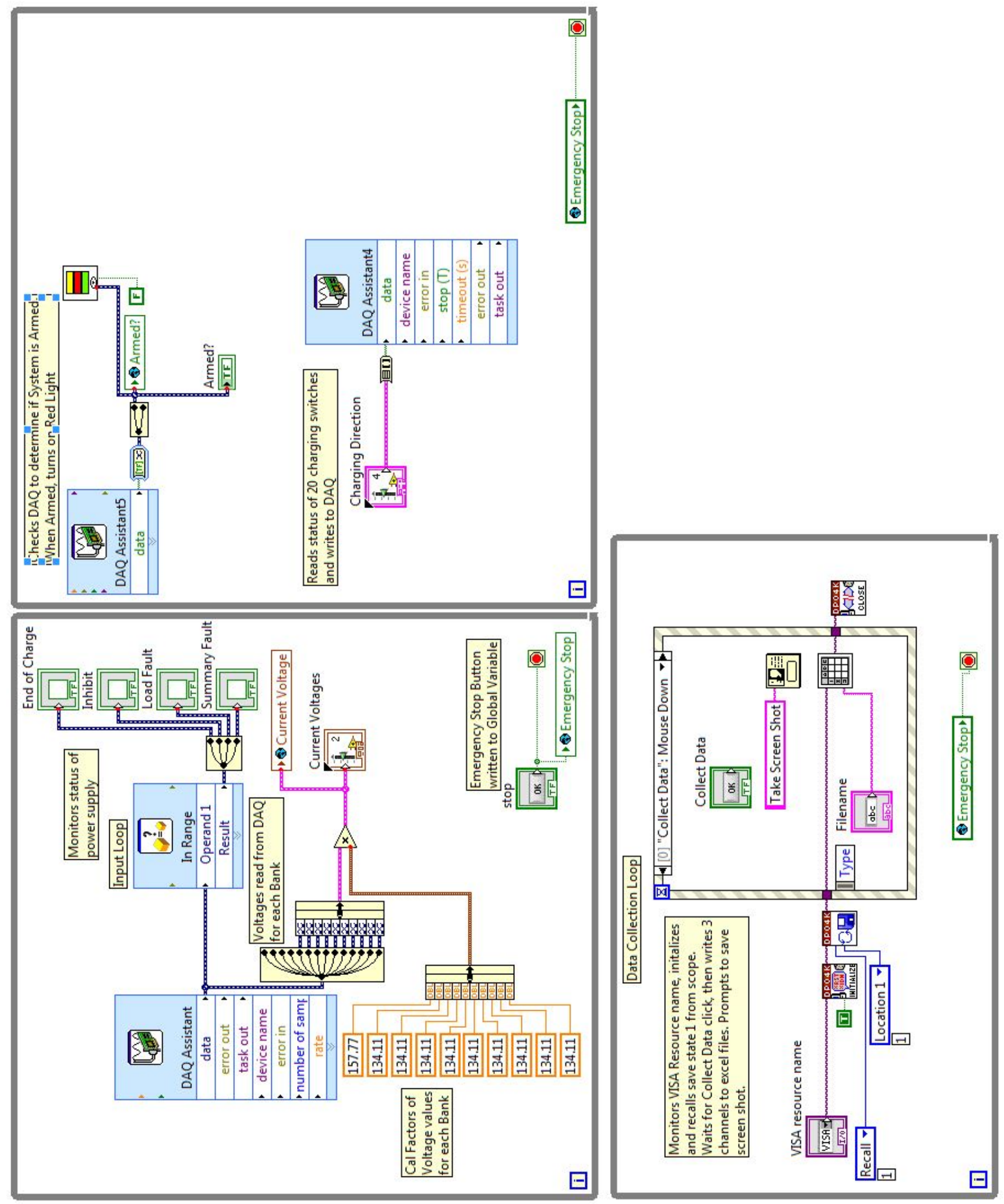


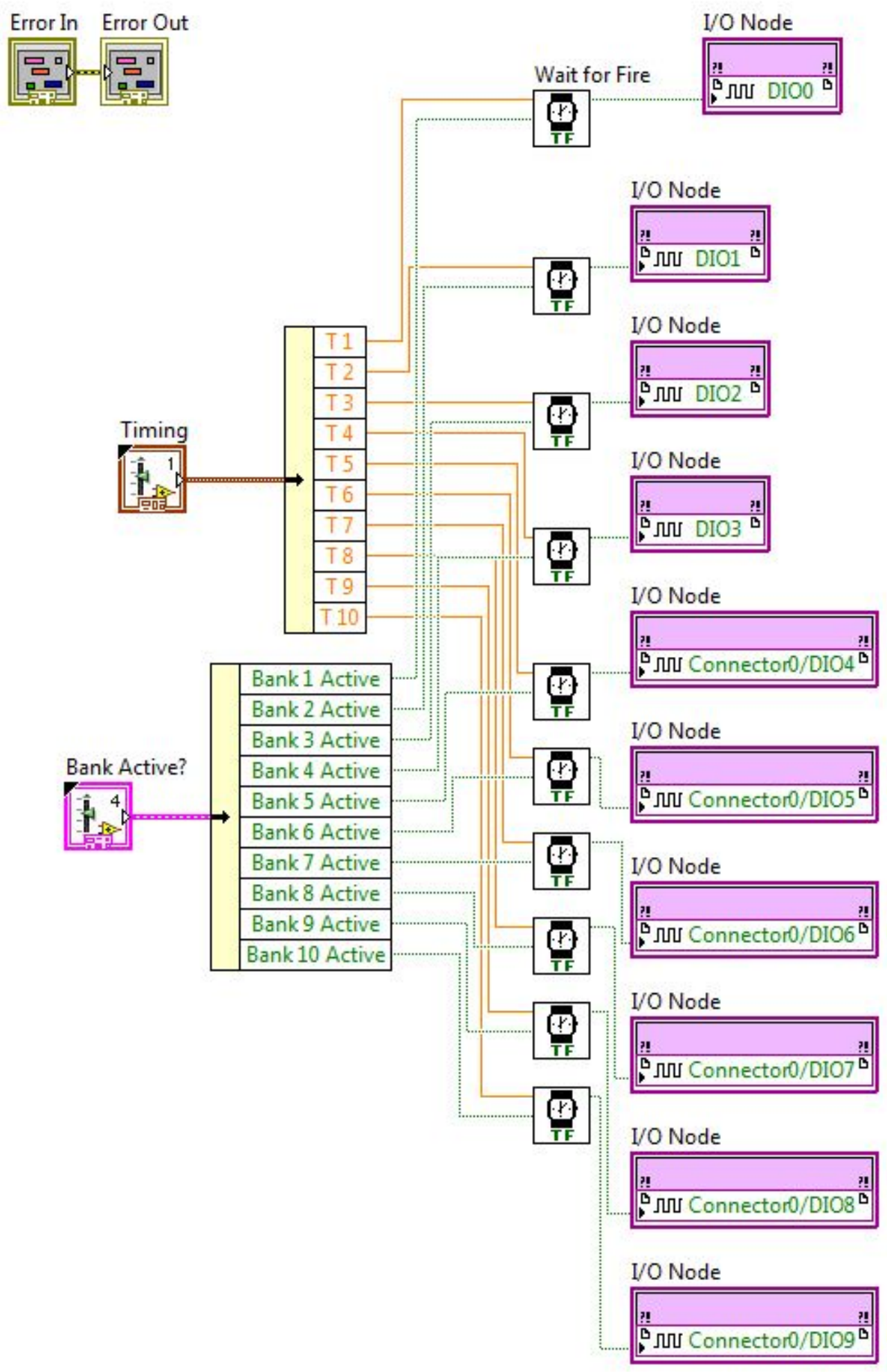


Determines the Maximum absolute Voltage set for all the Banks
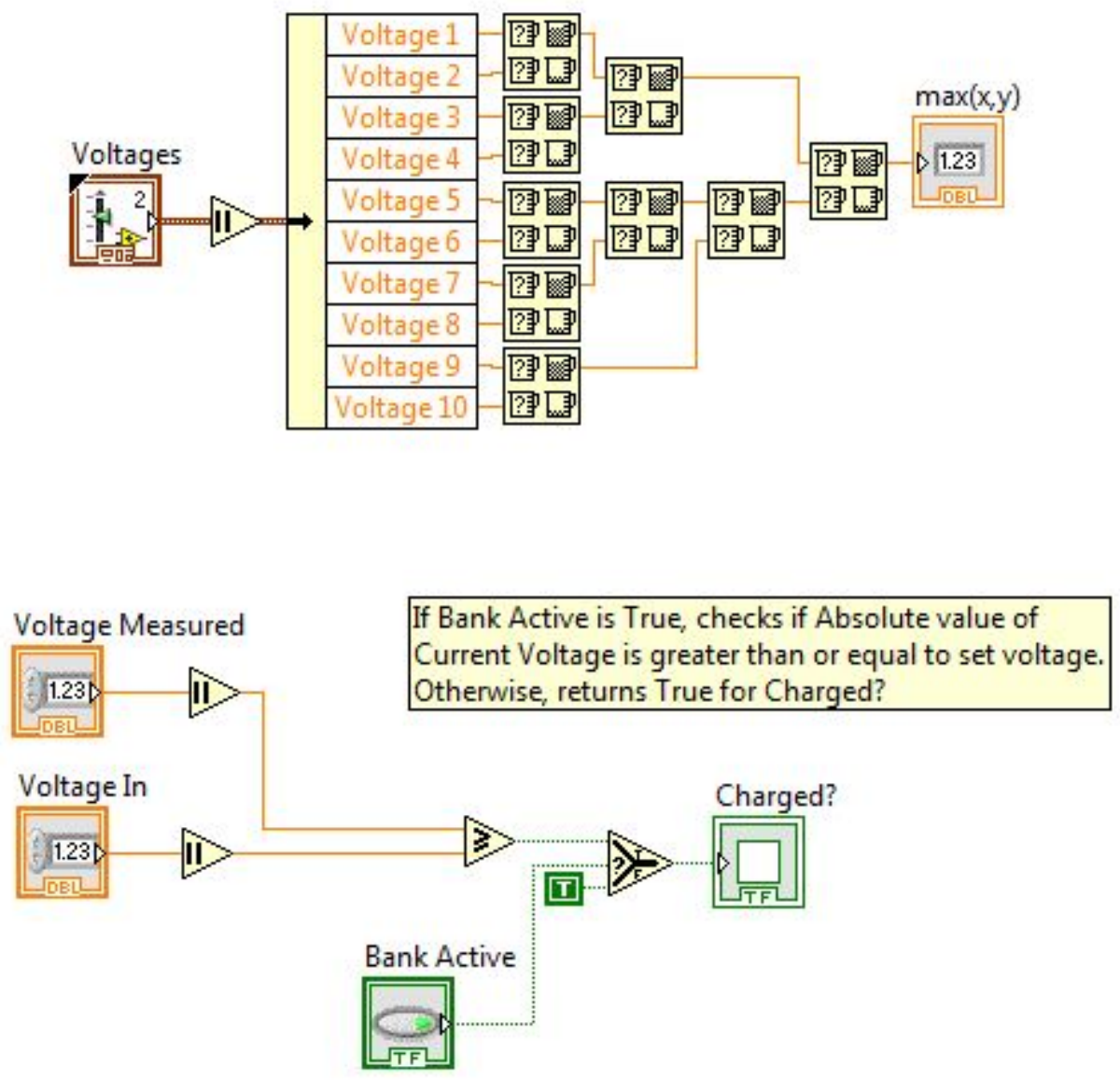

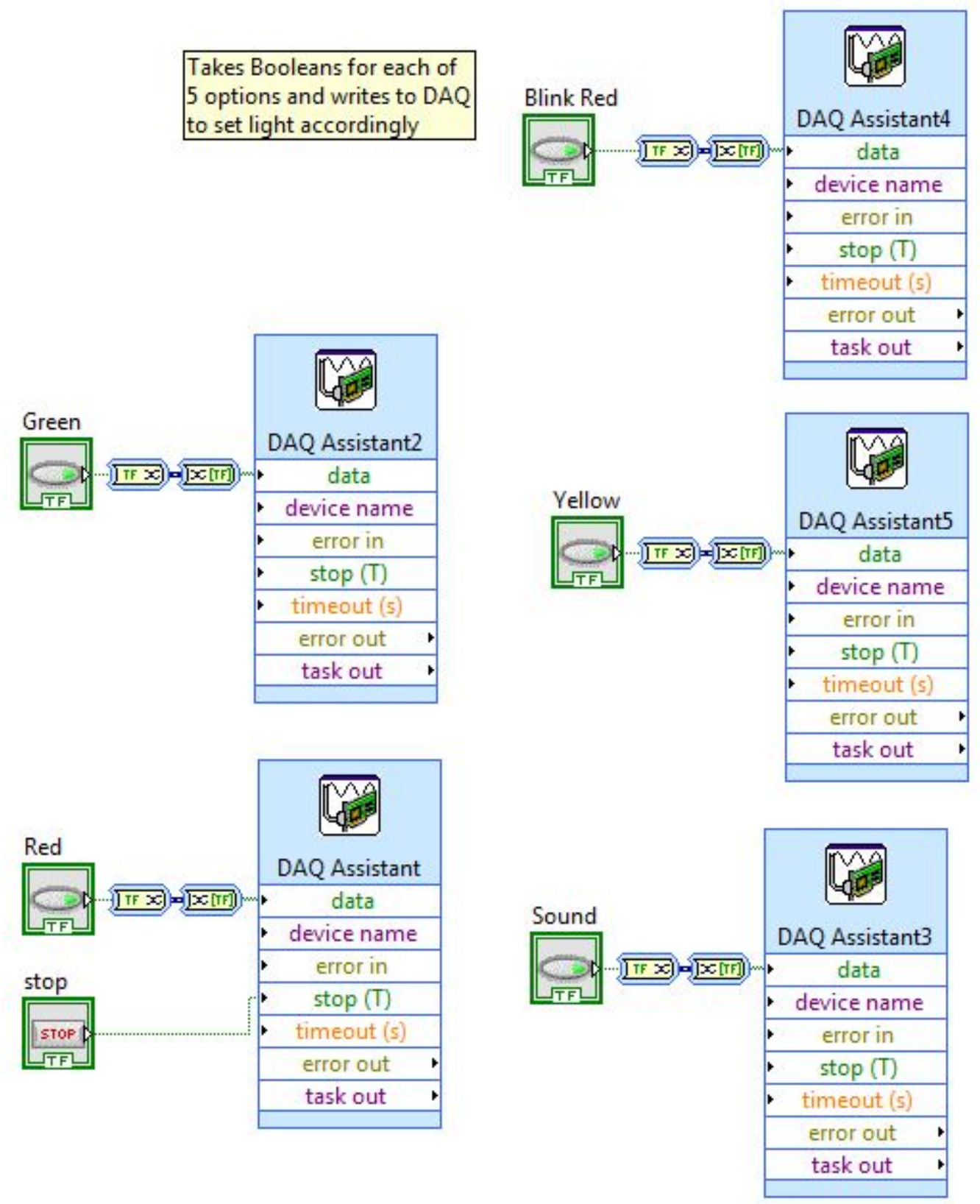


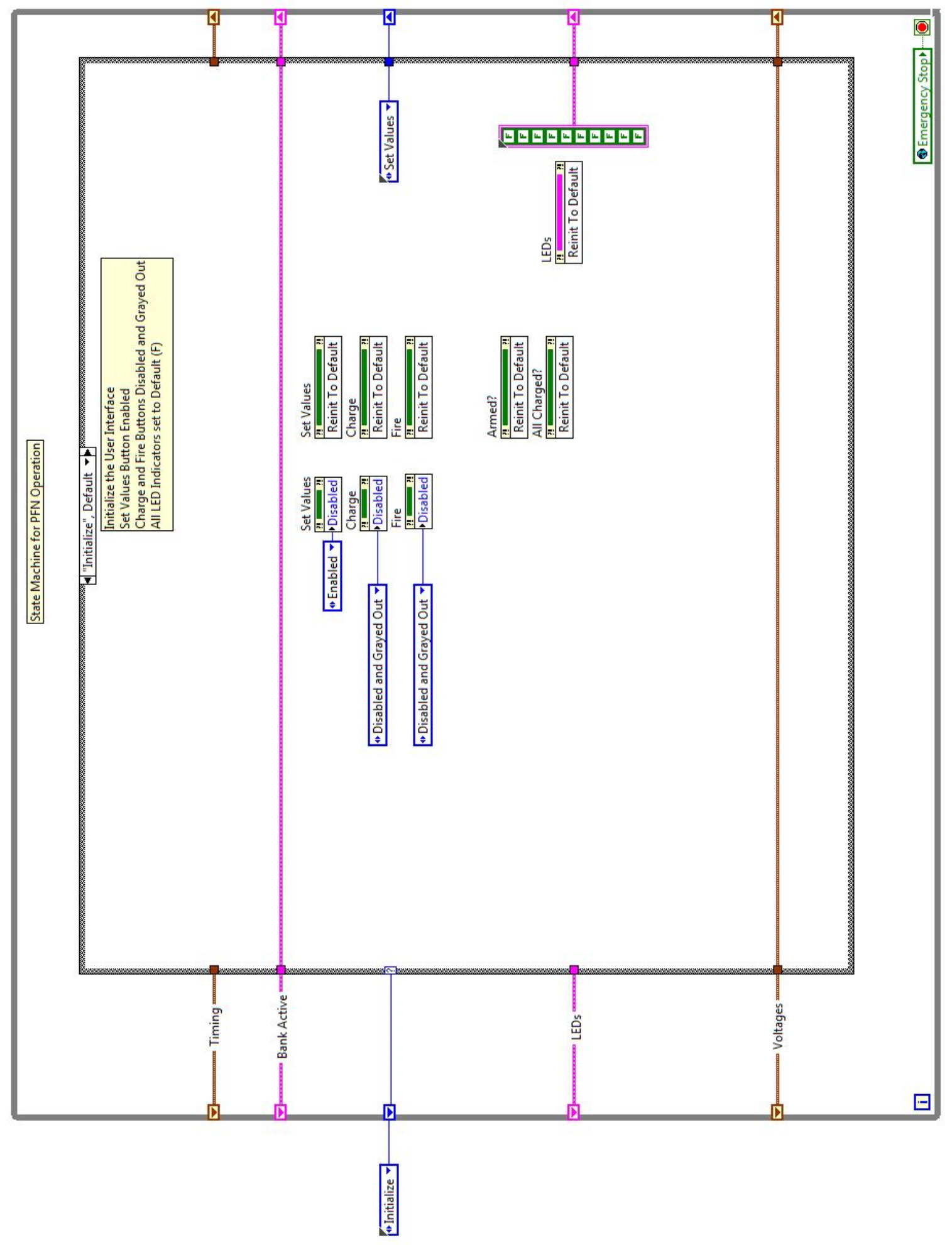




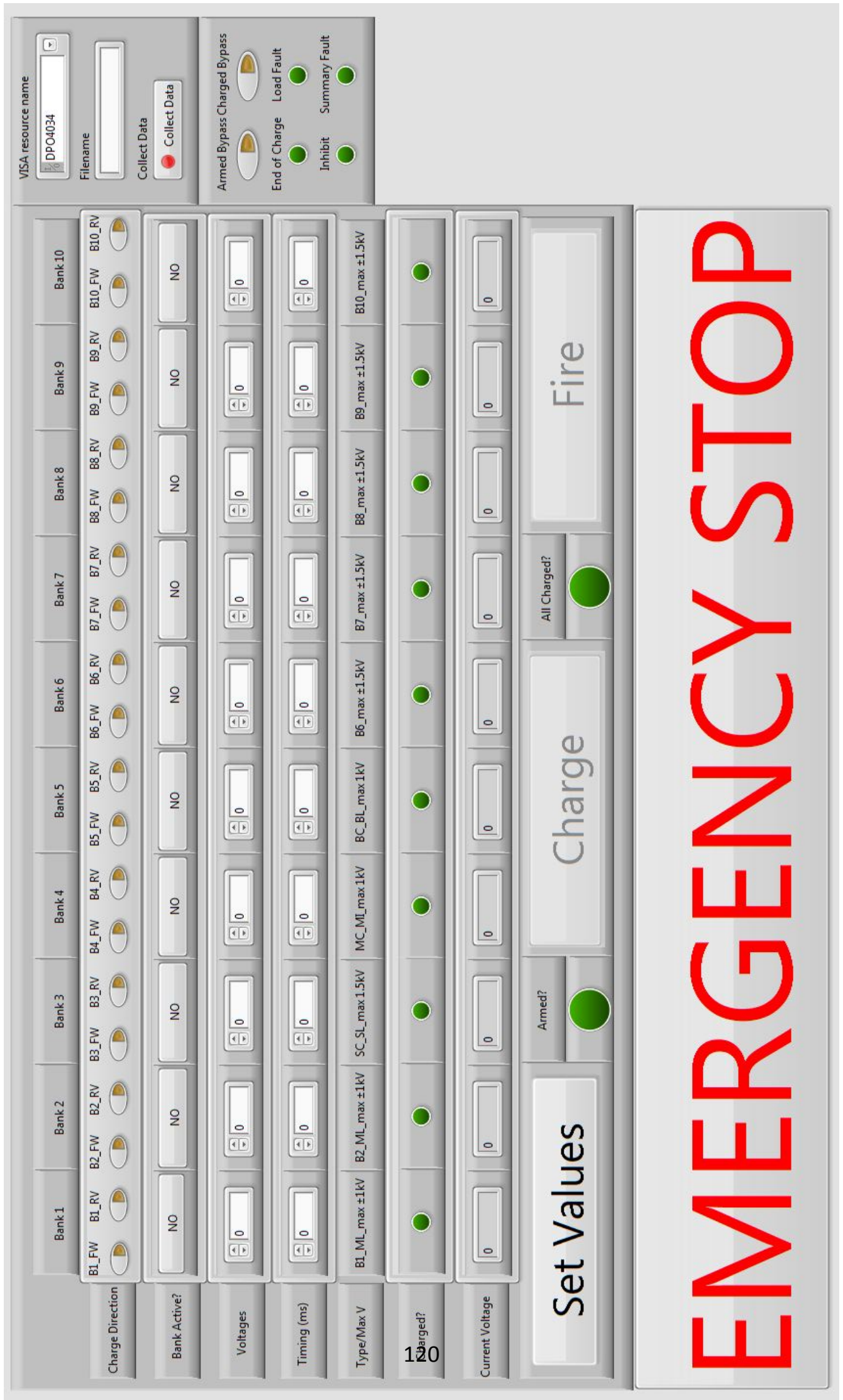




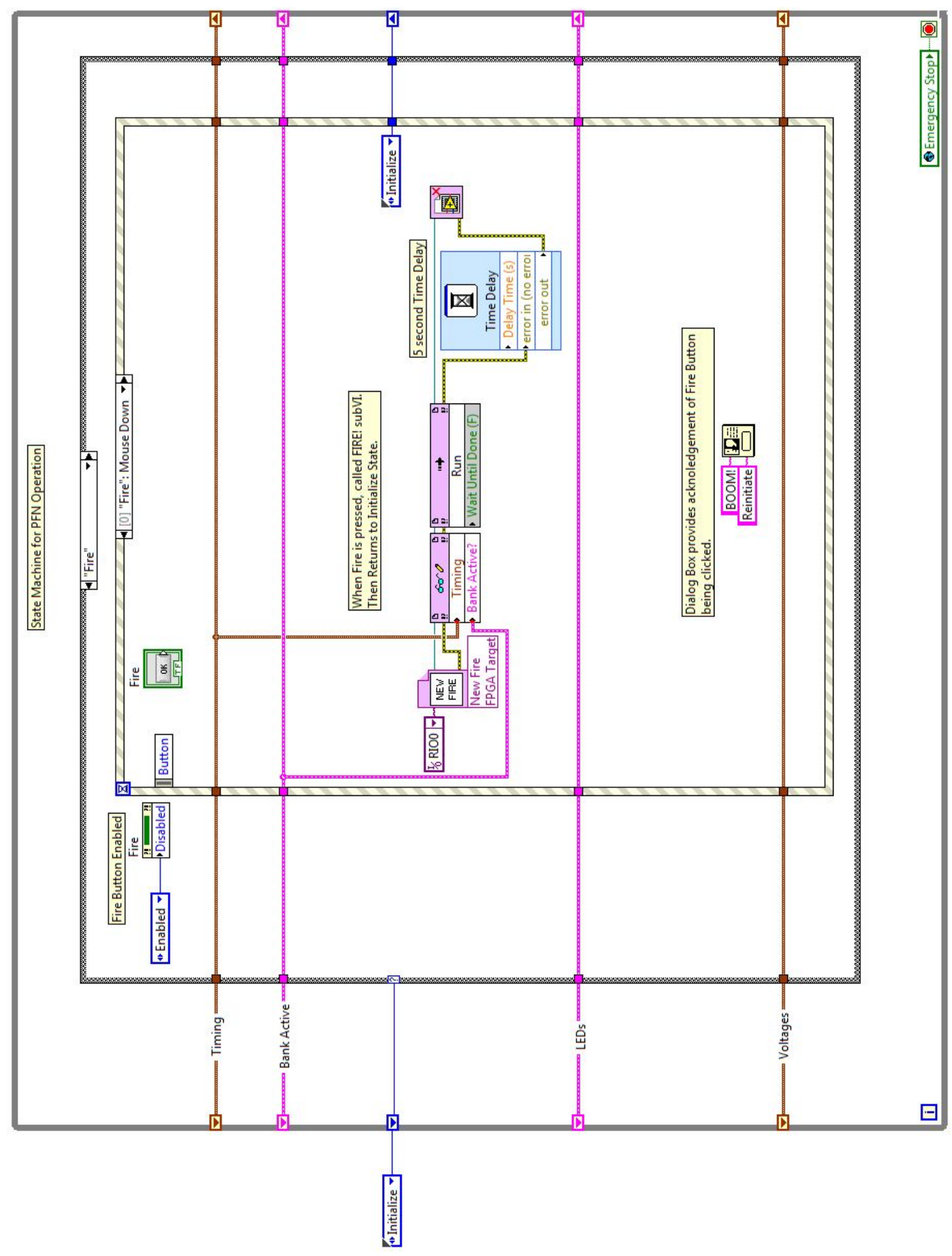




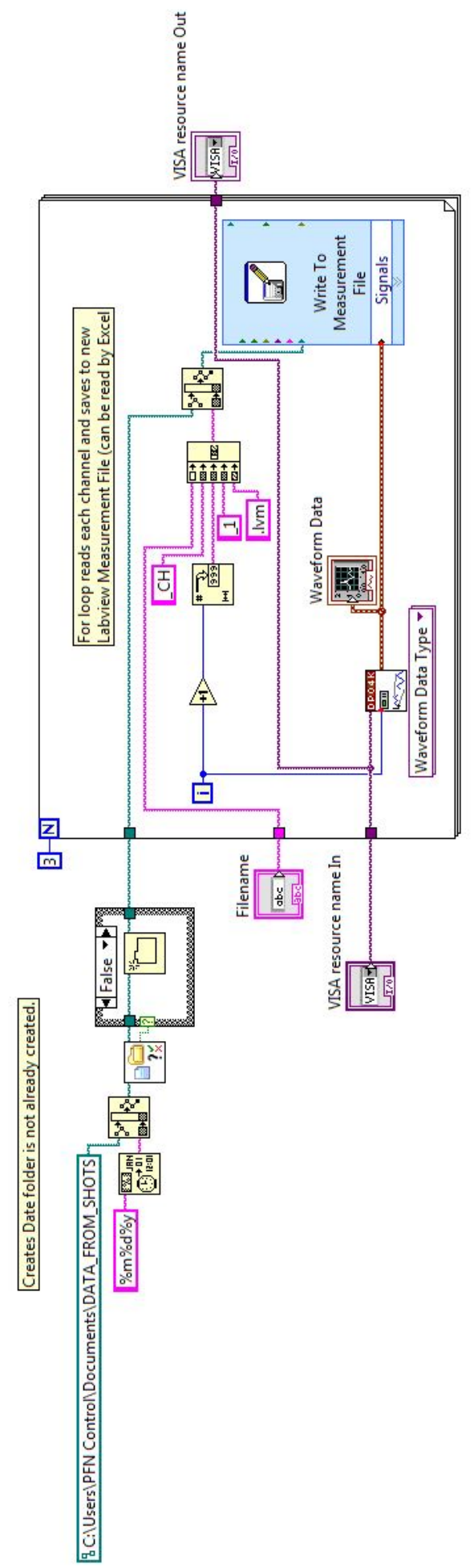




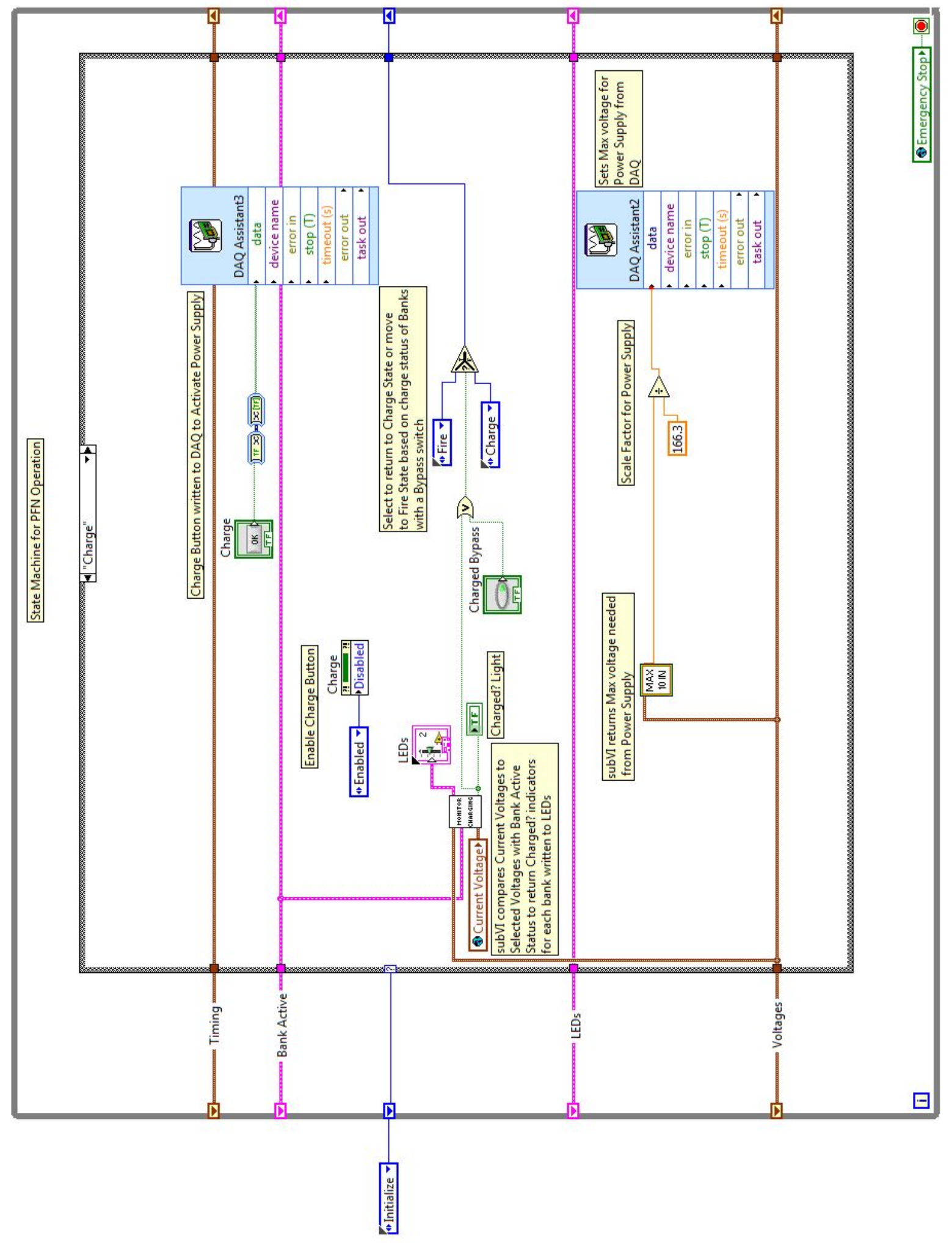




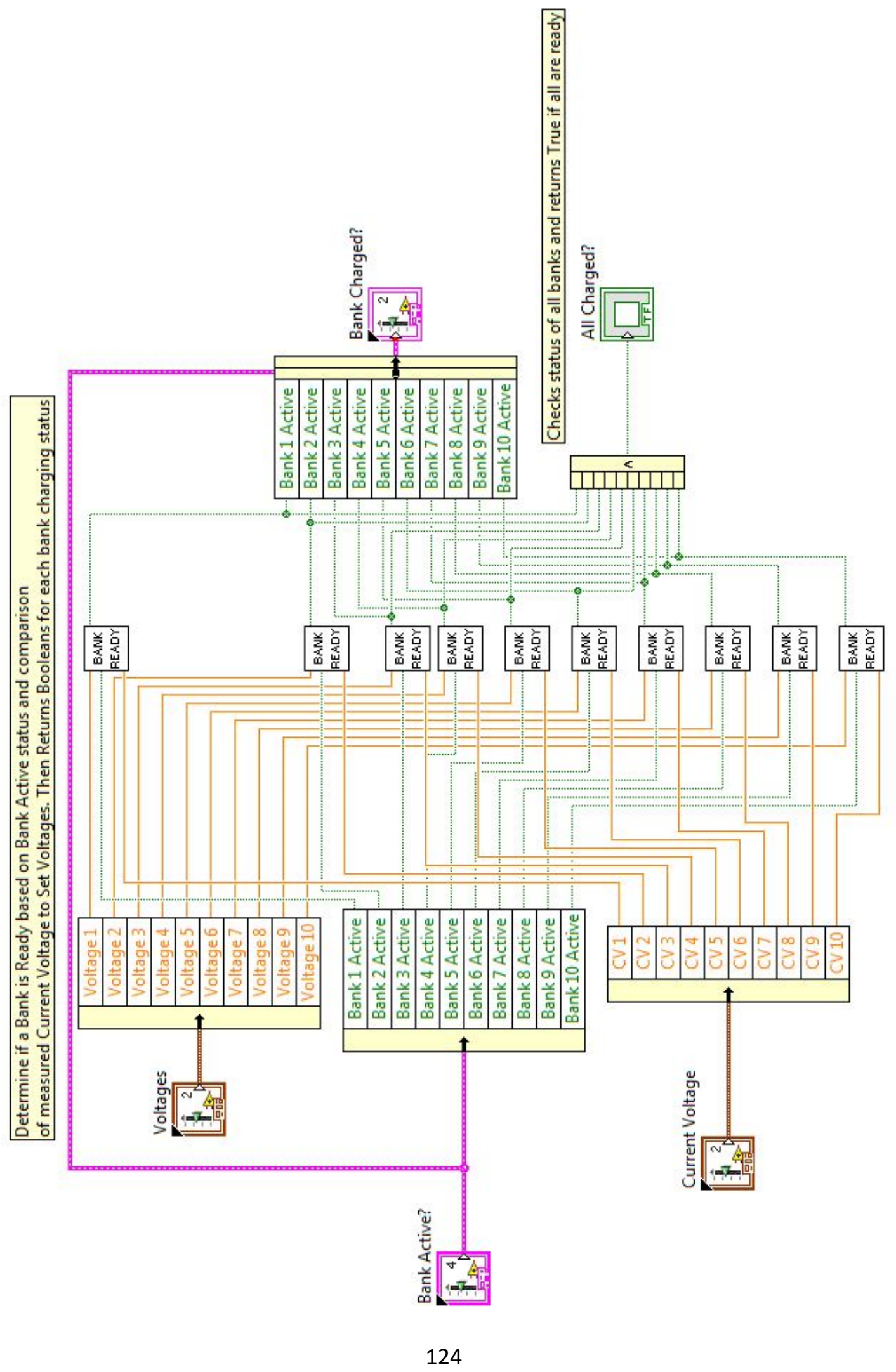




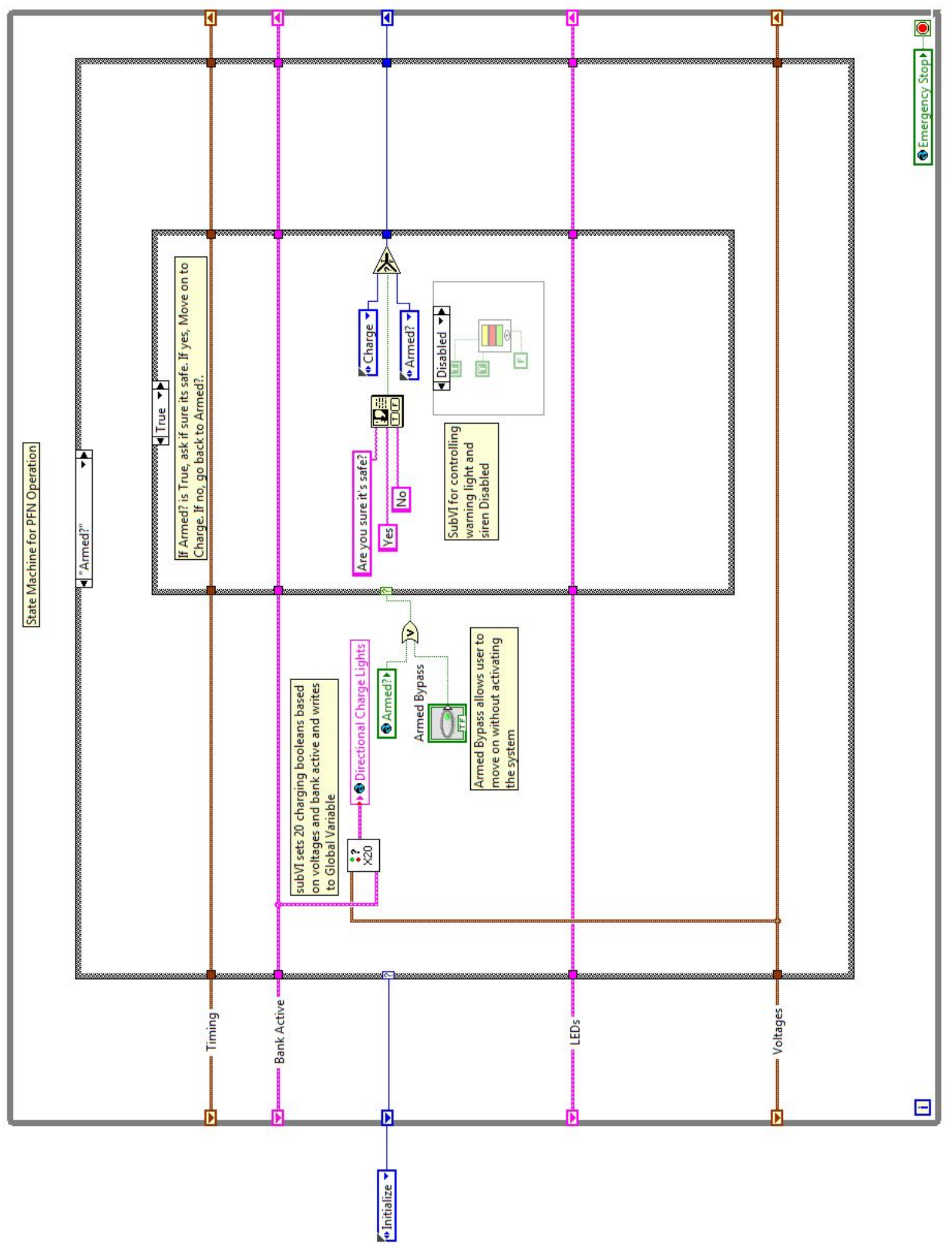




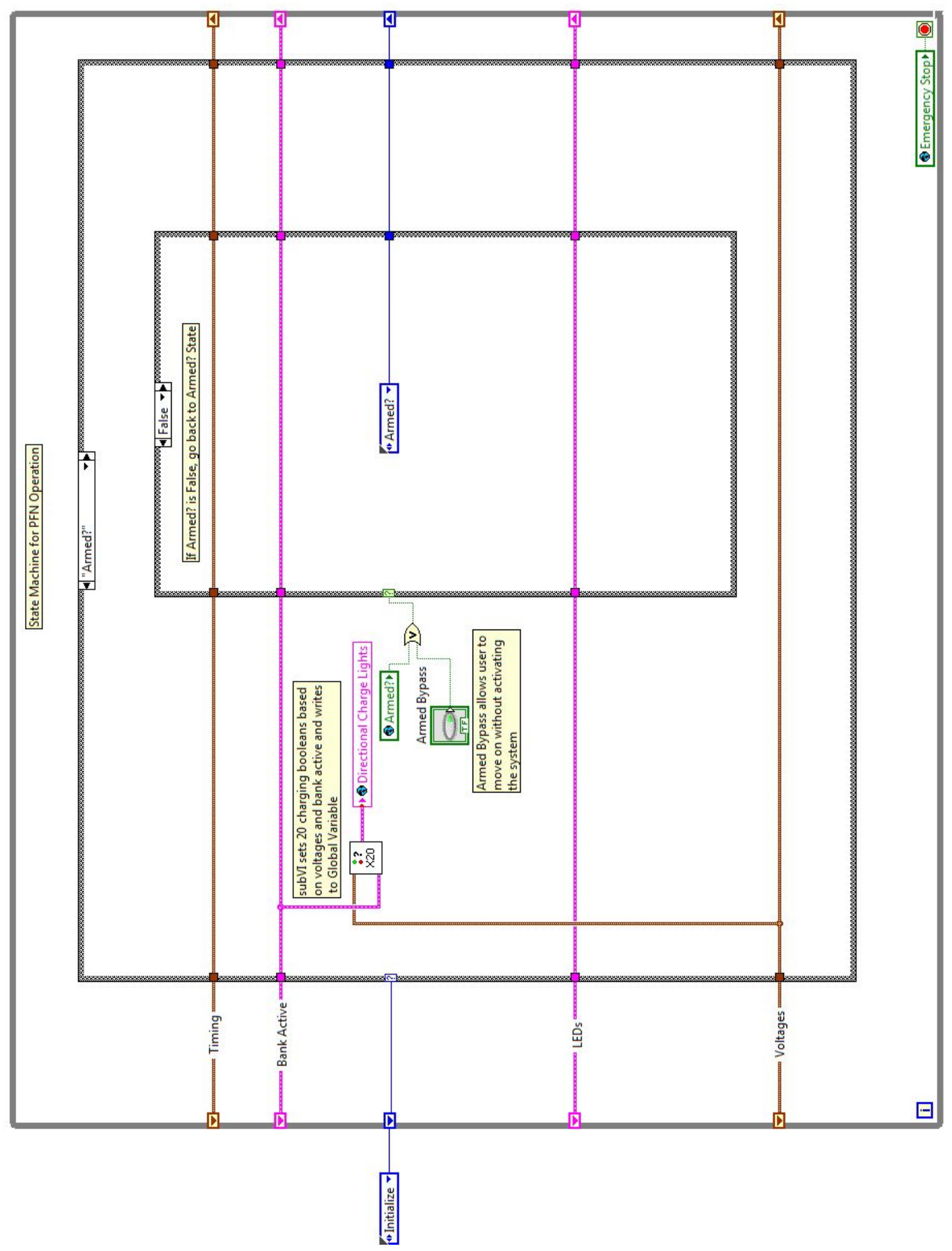




\subsection{PICTURES OF PULSES}
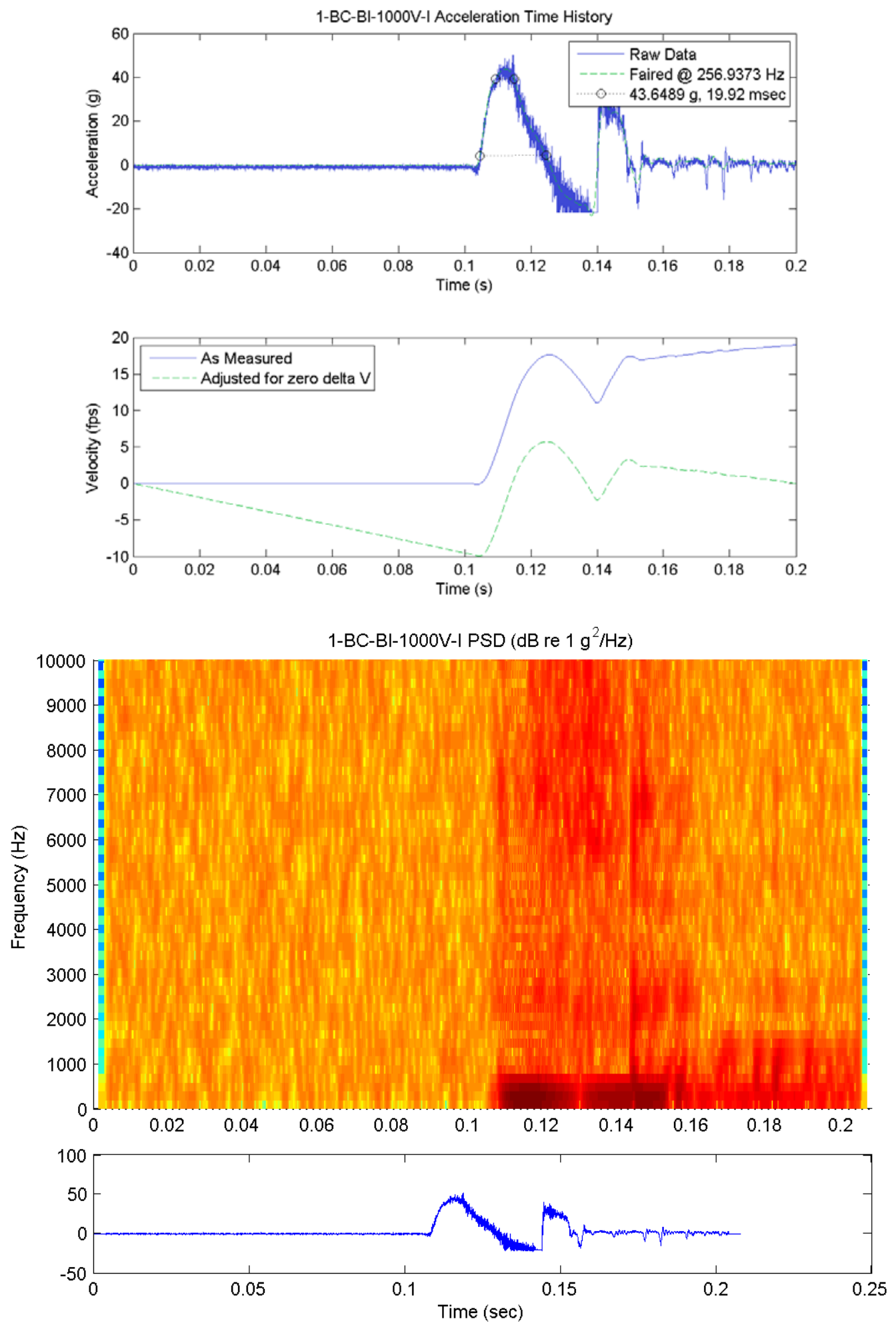

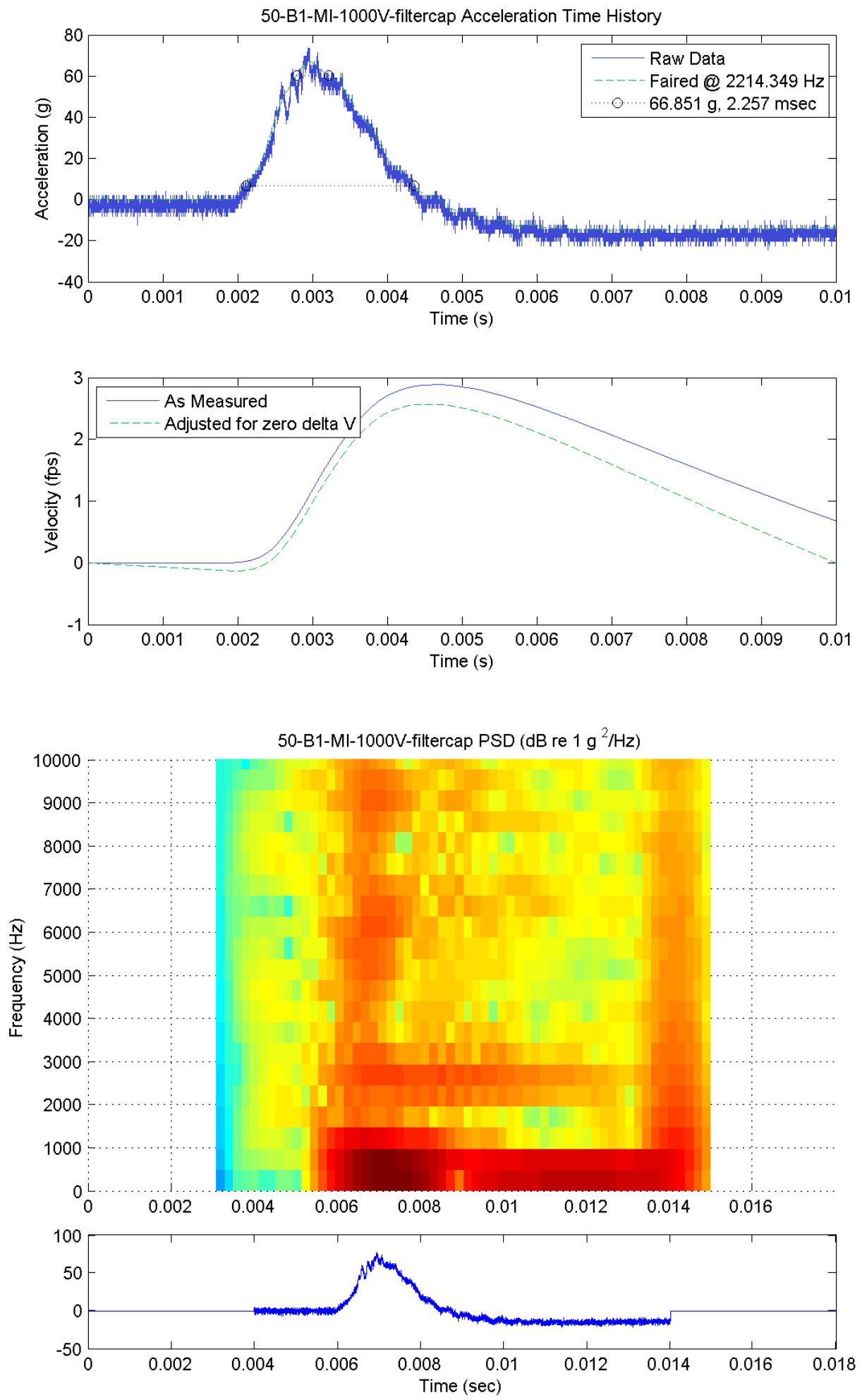

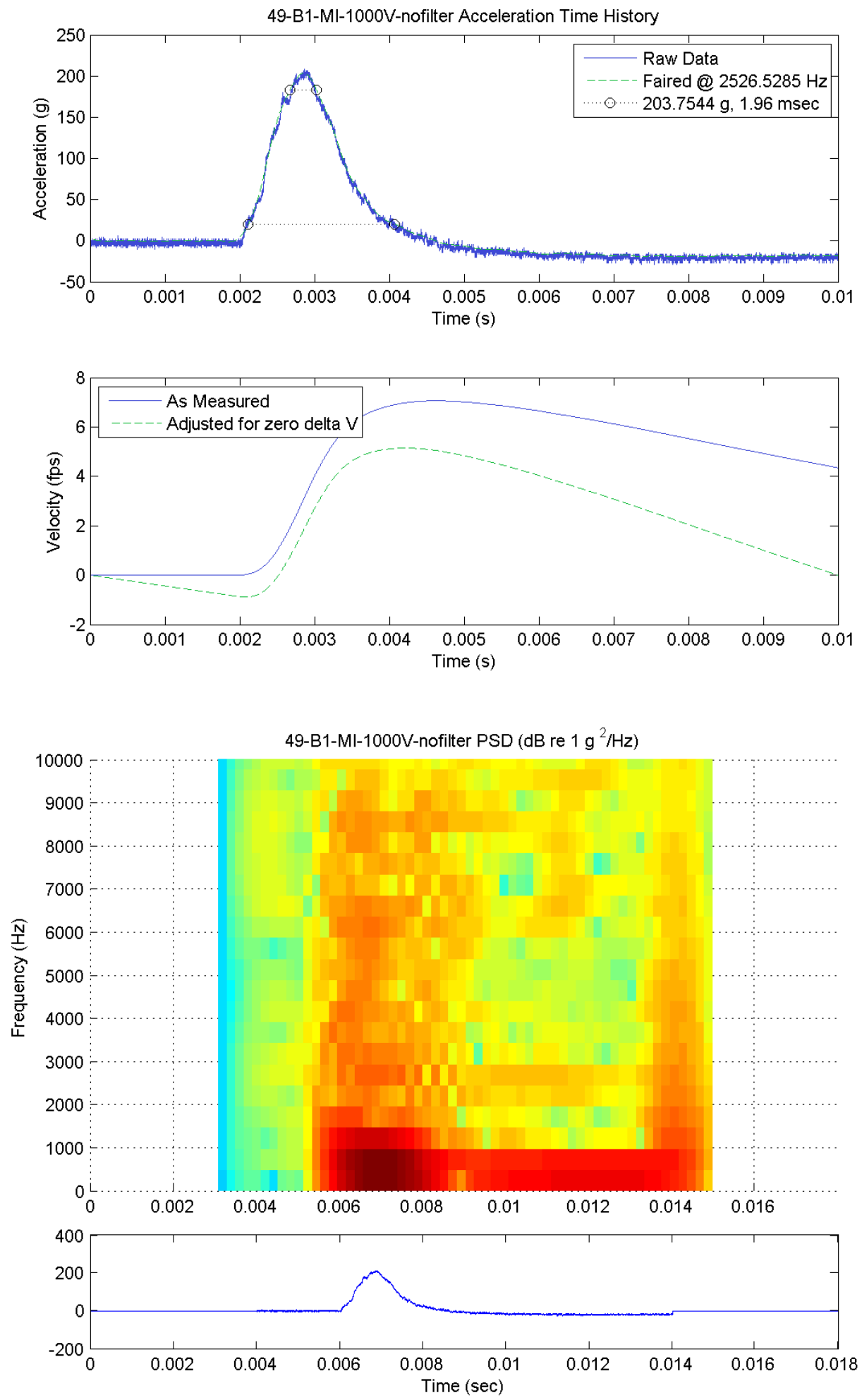

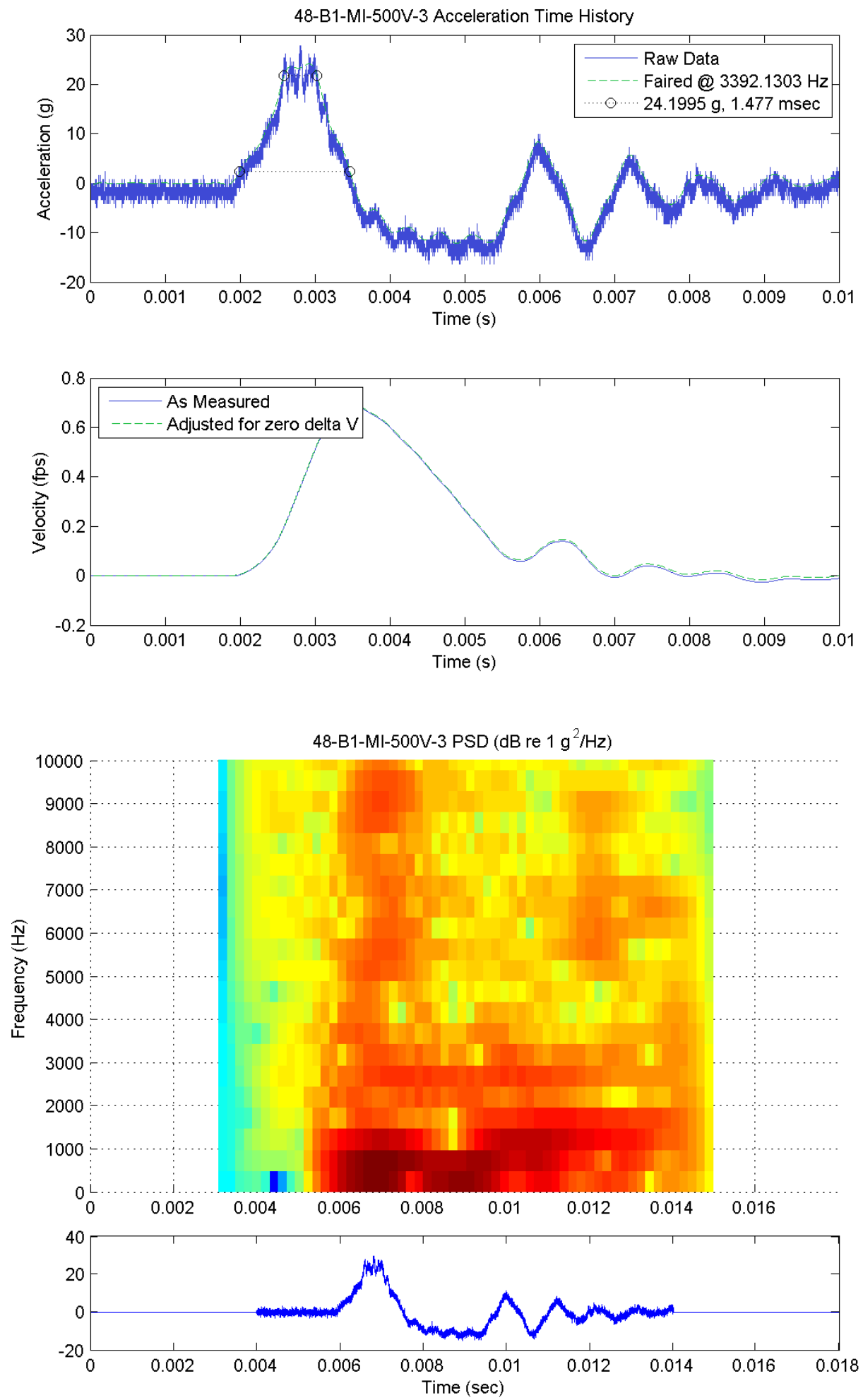

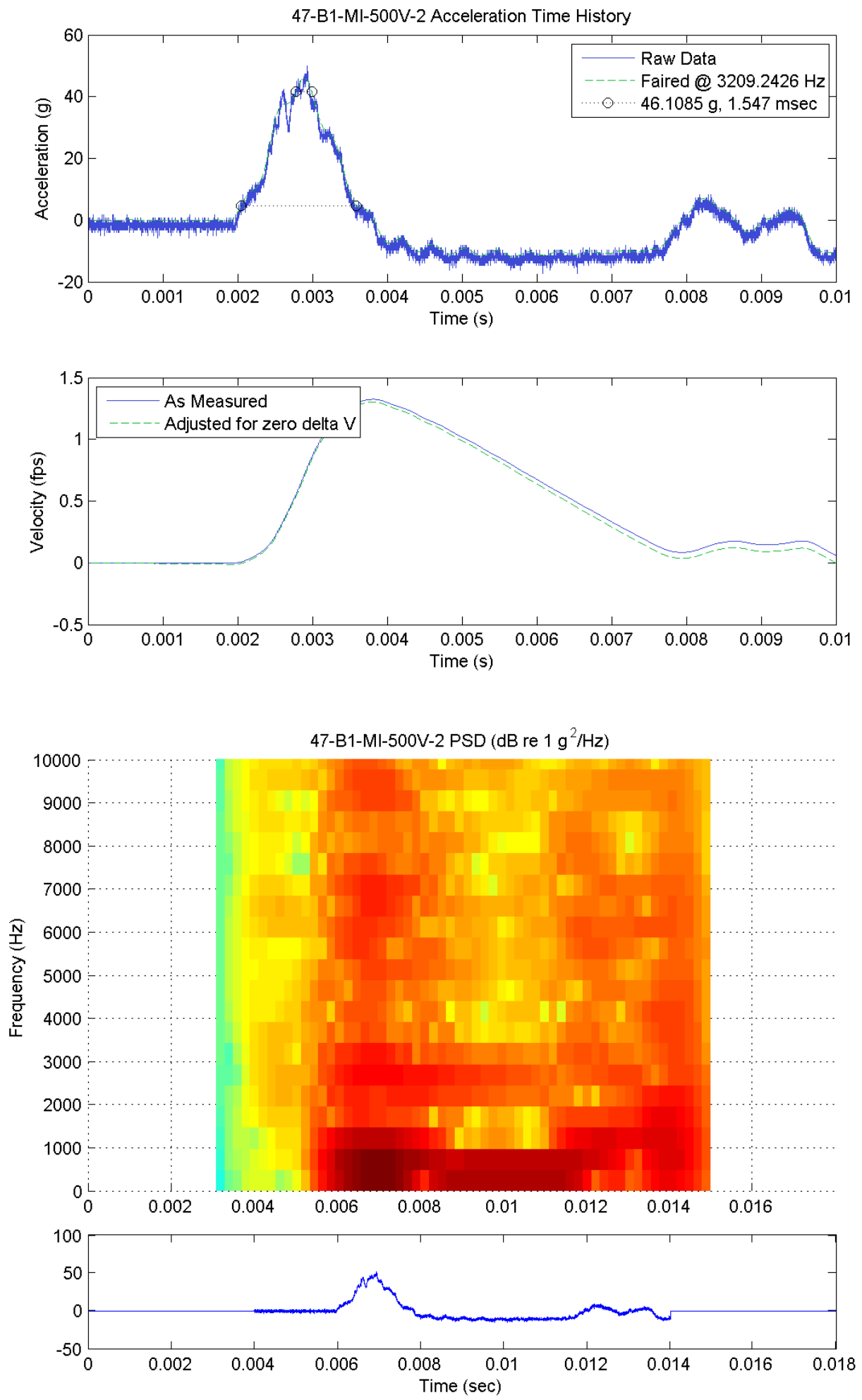

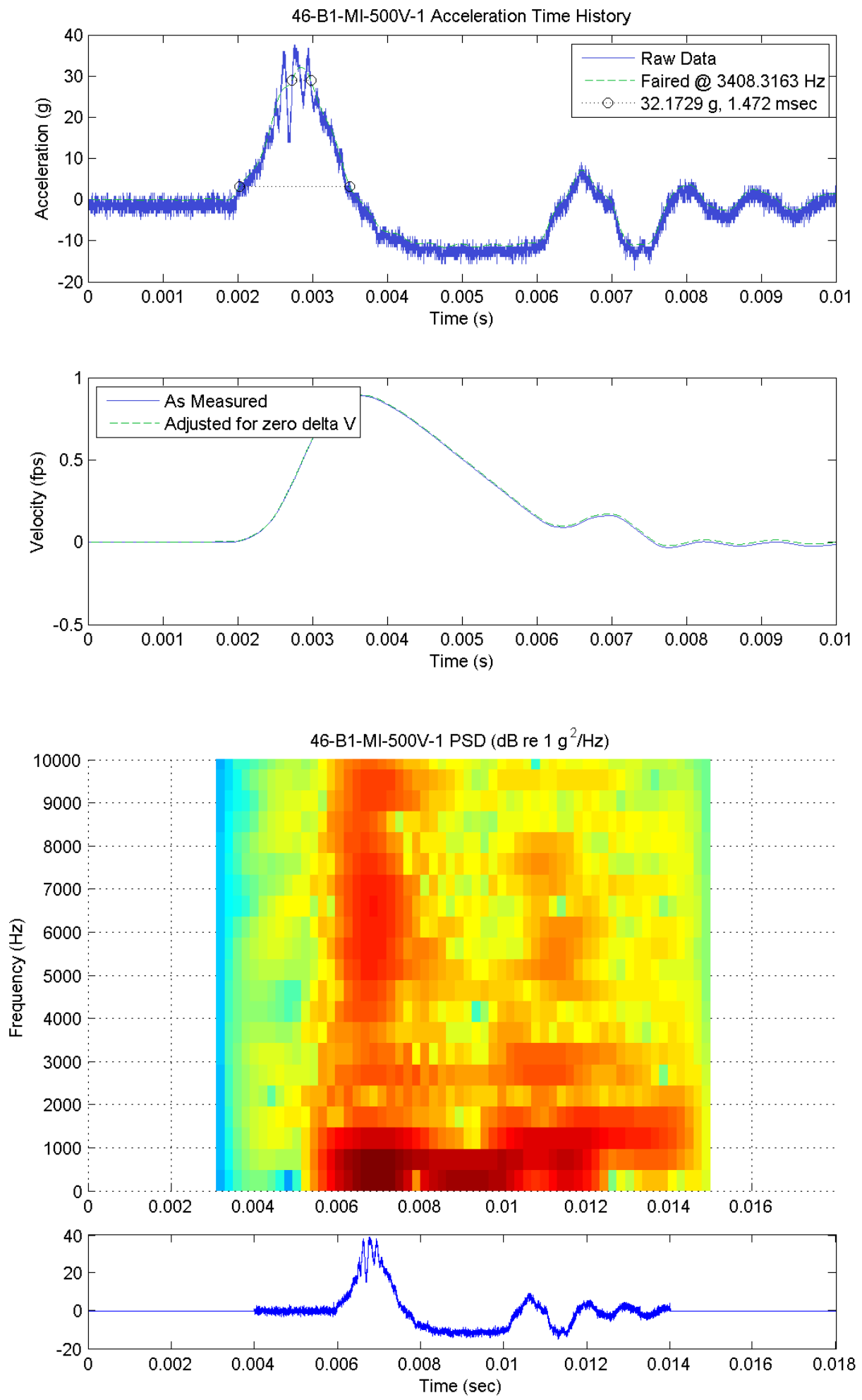

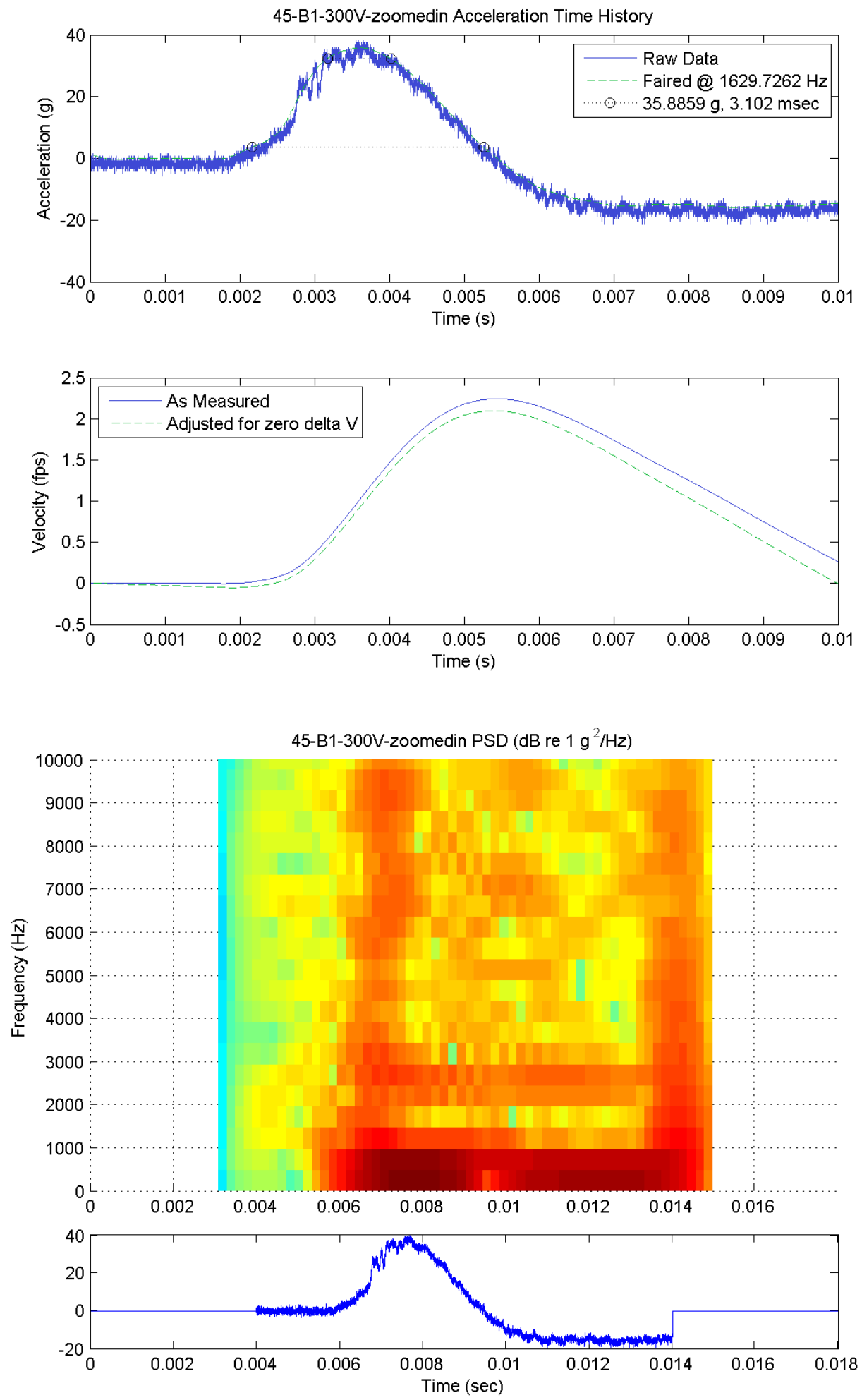

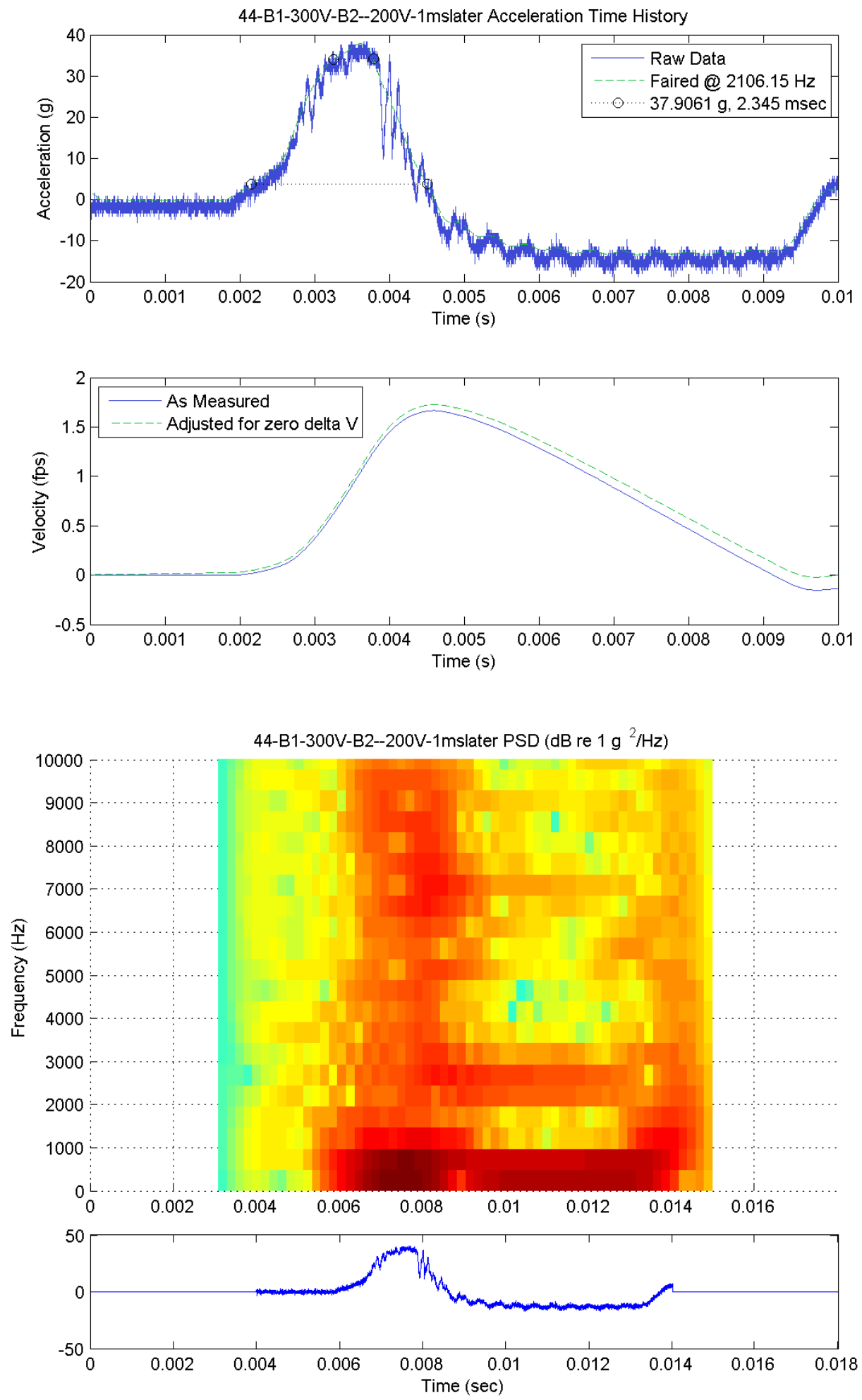

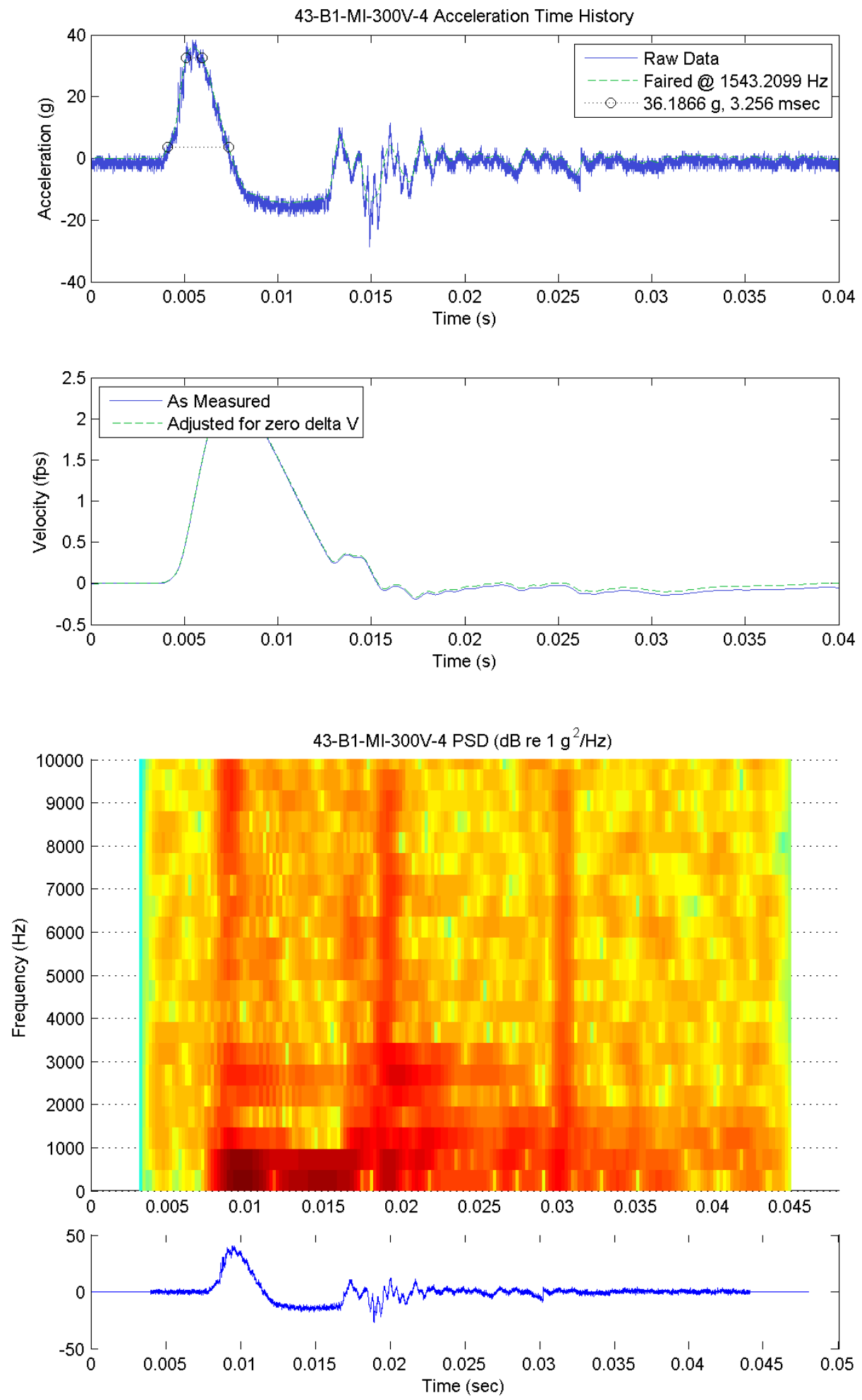

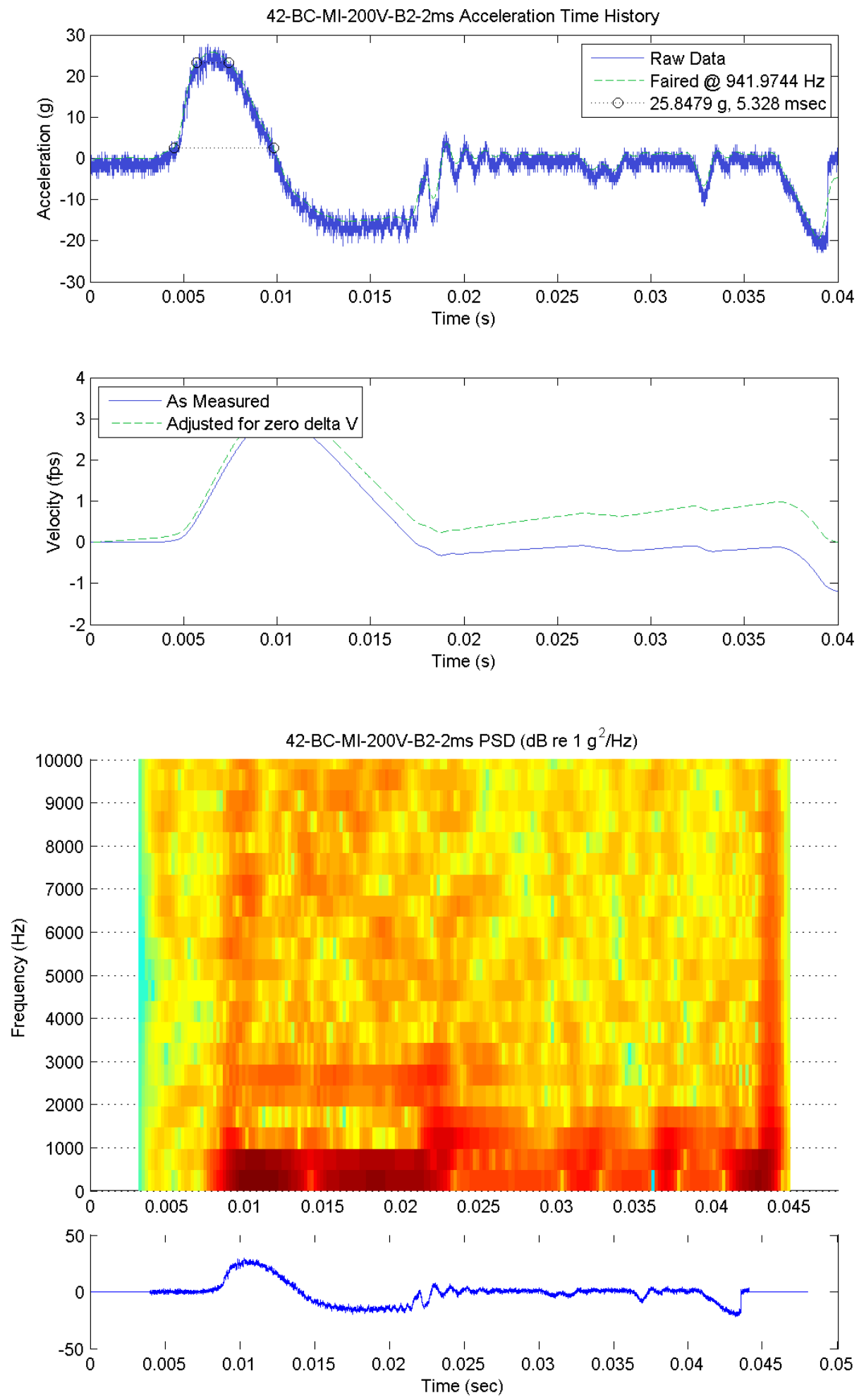

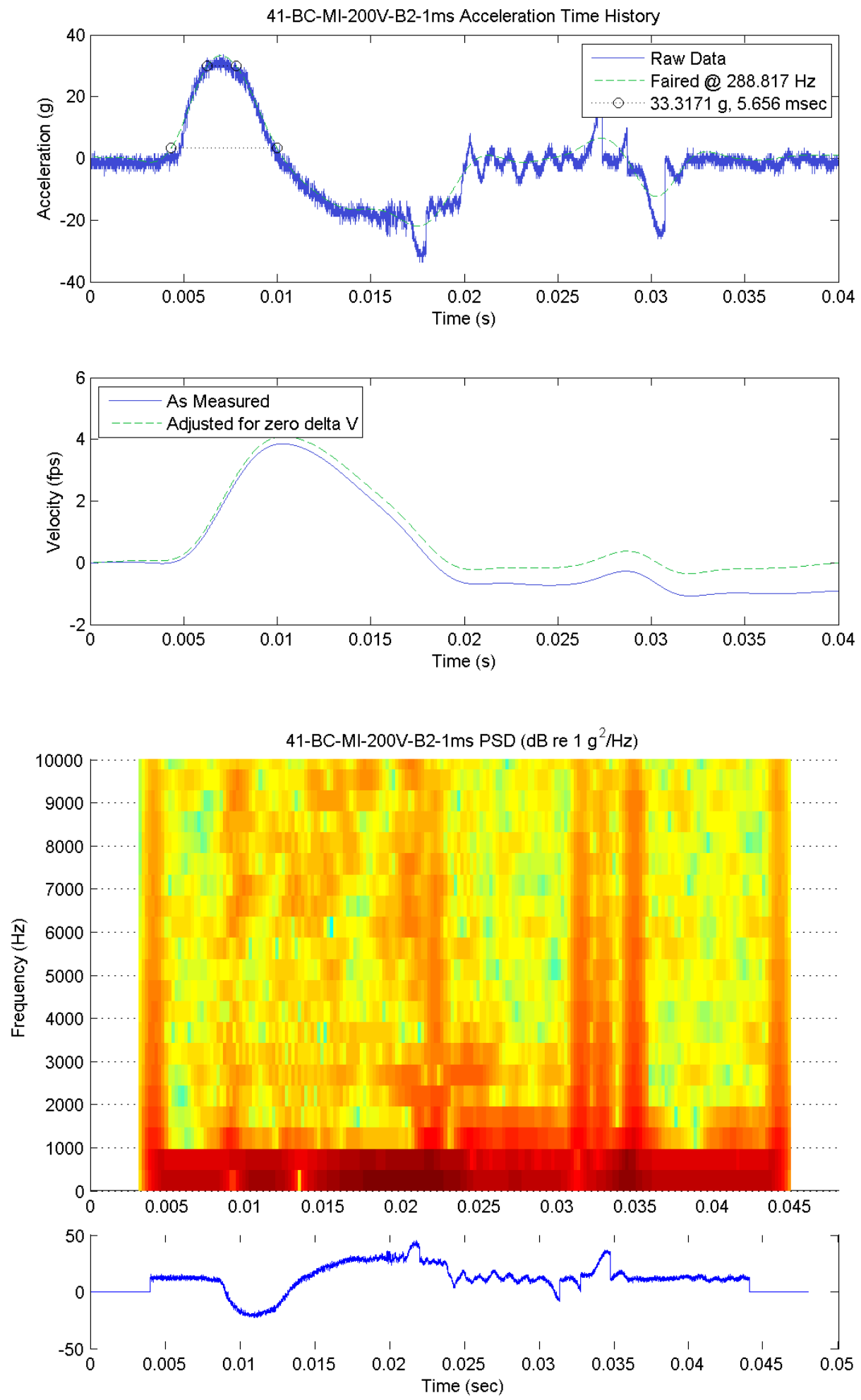

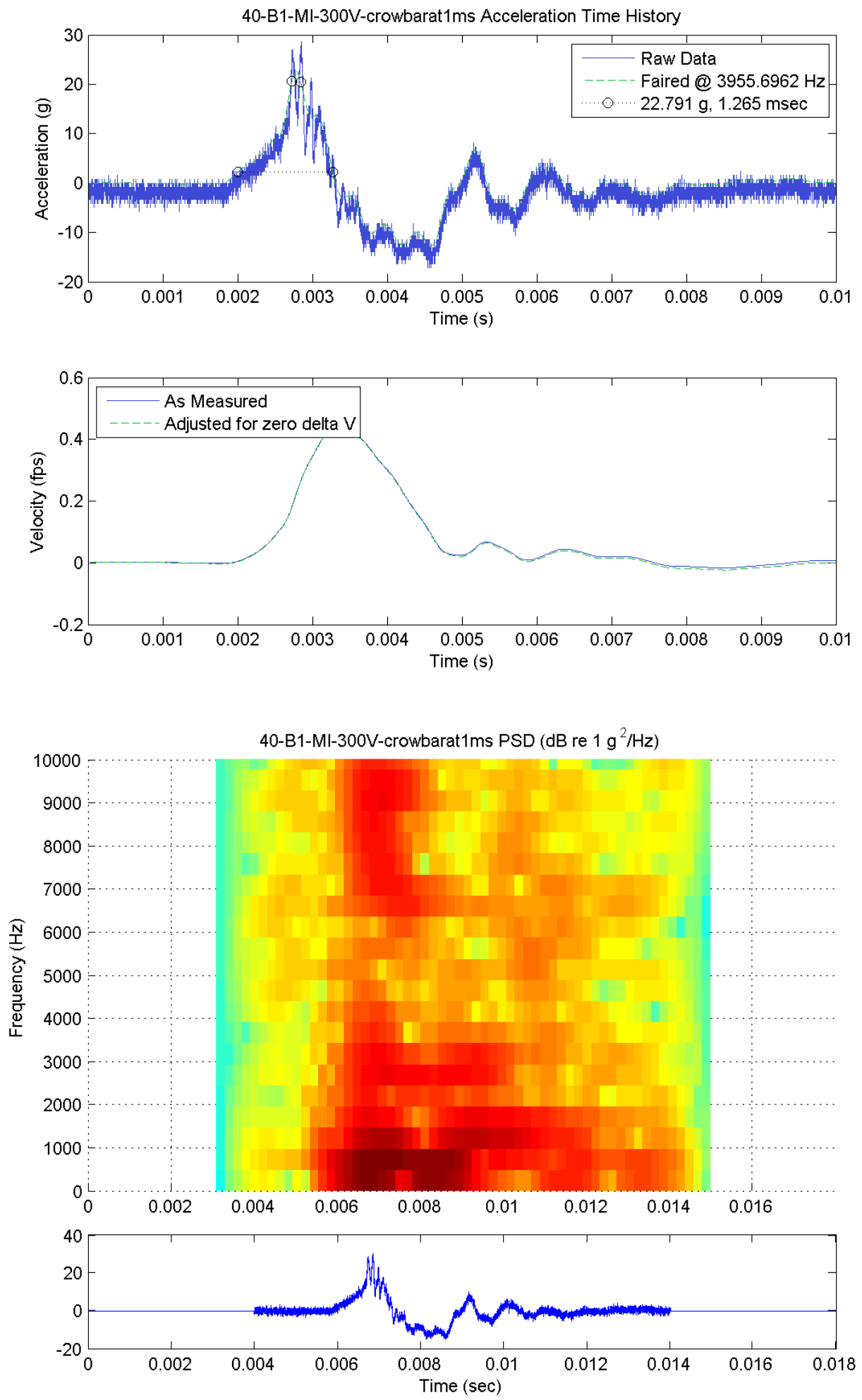

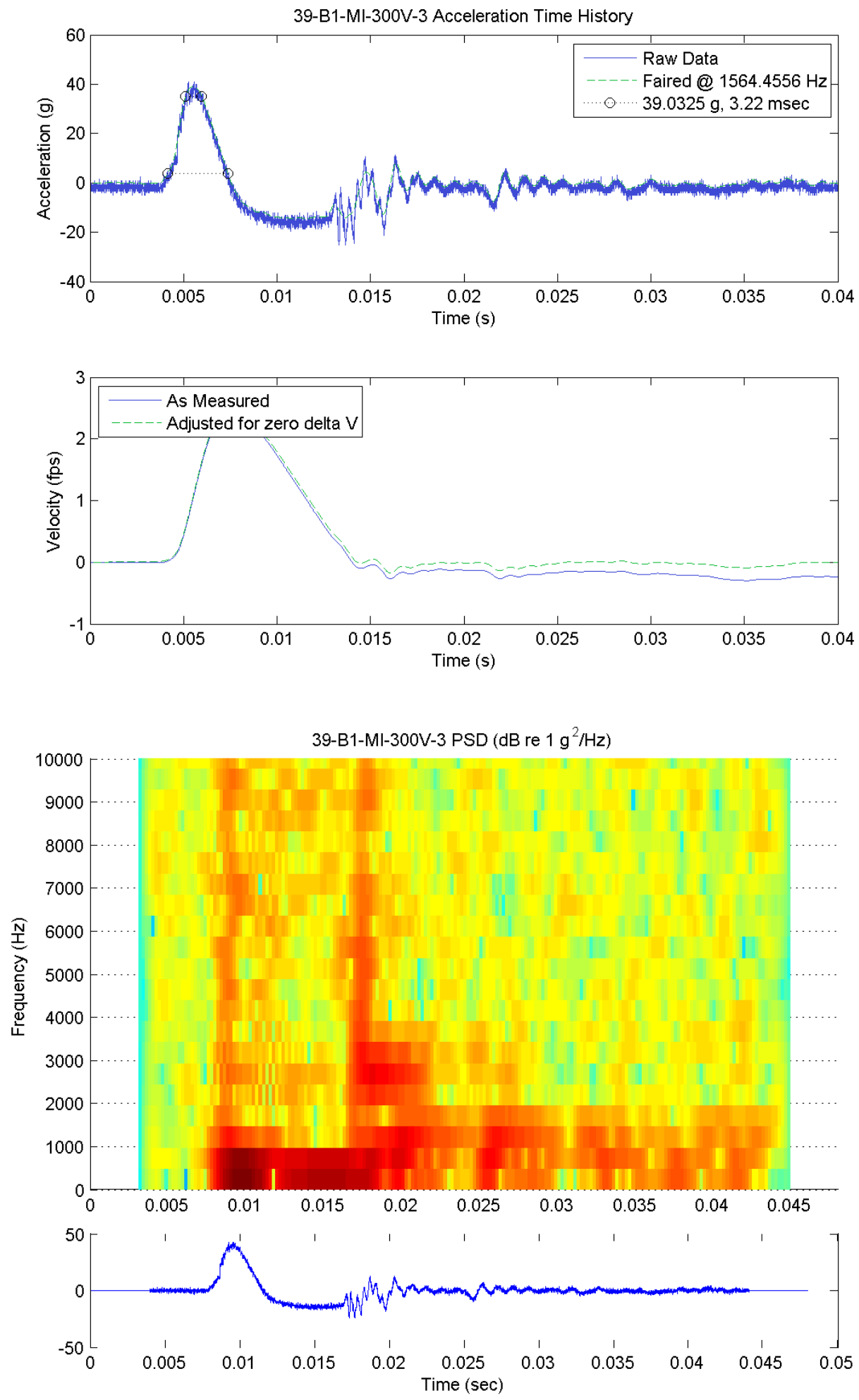

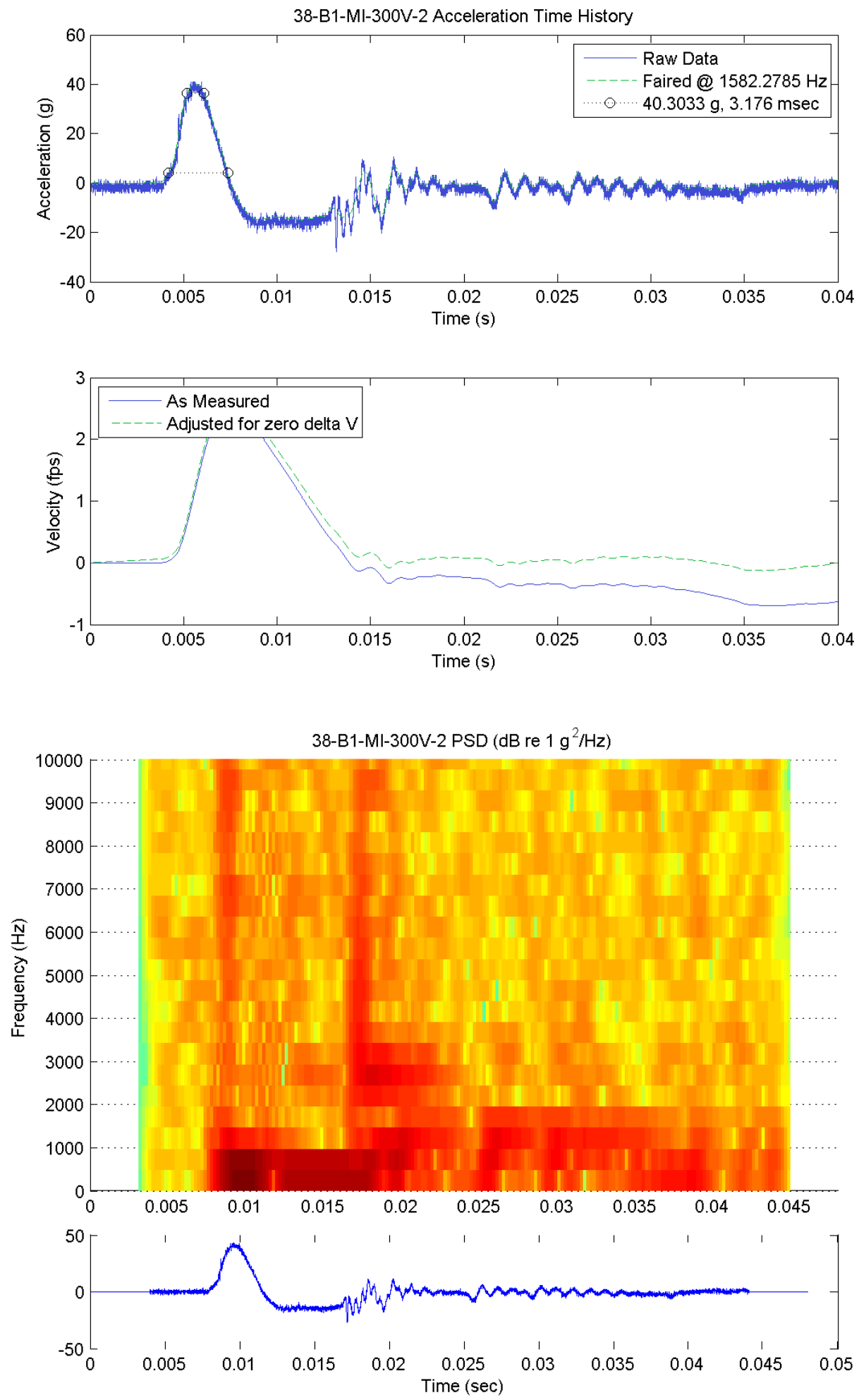

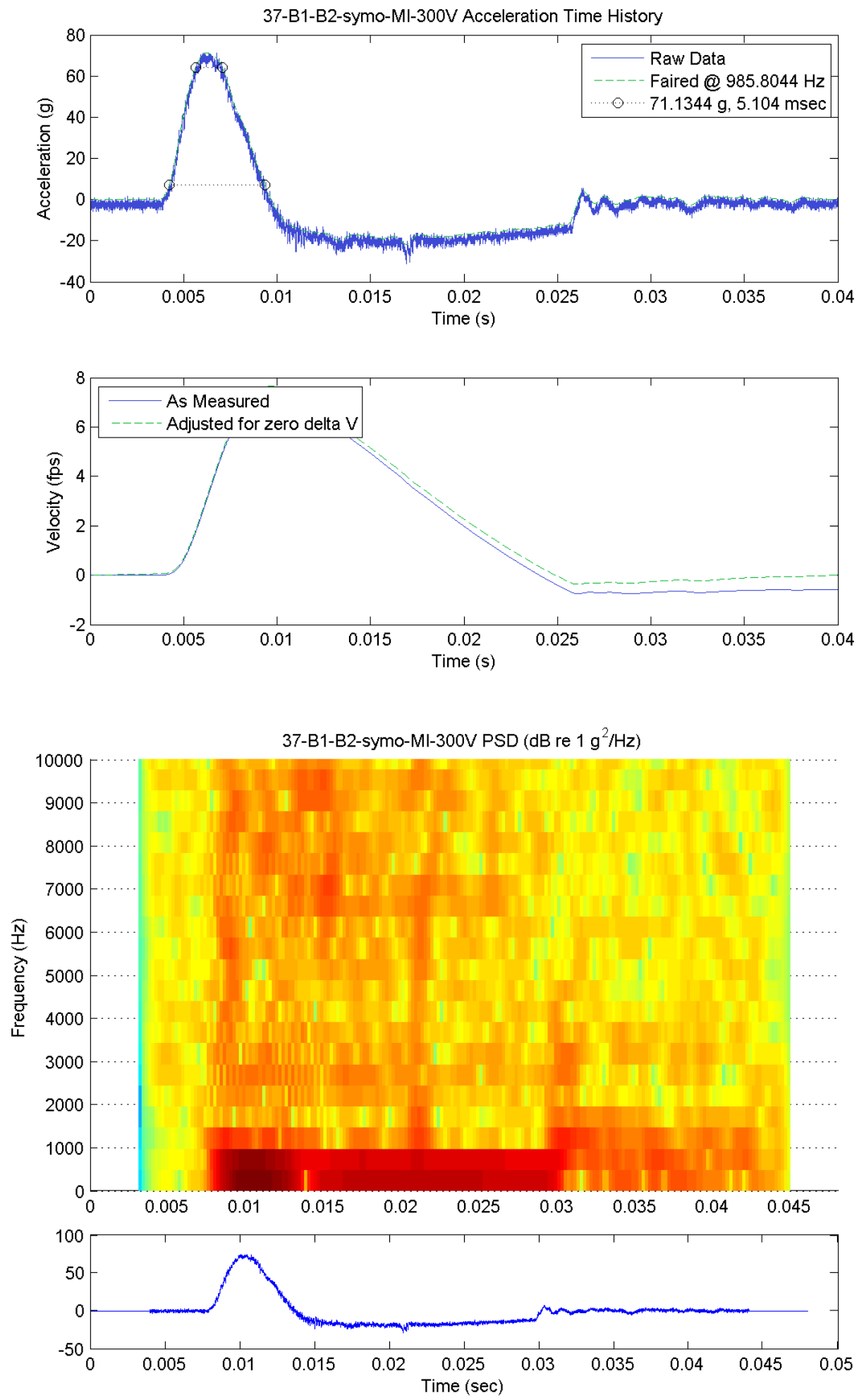

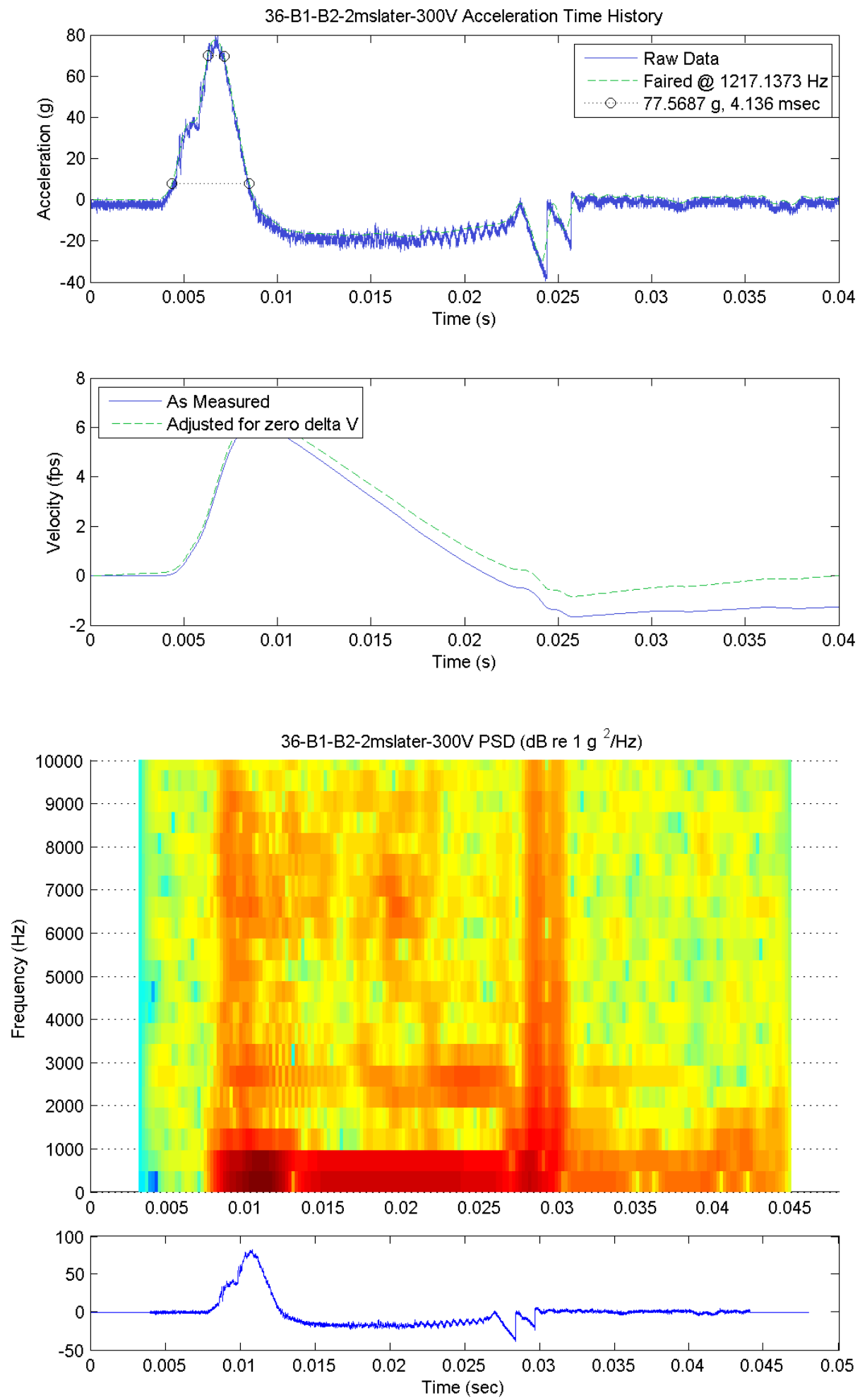

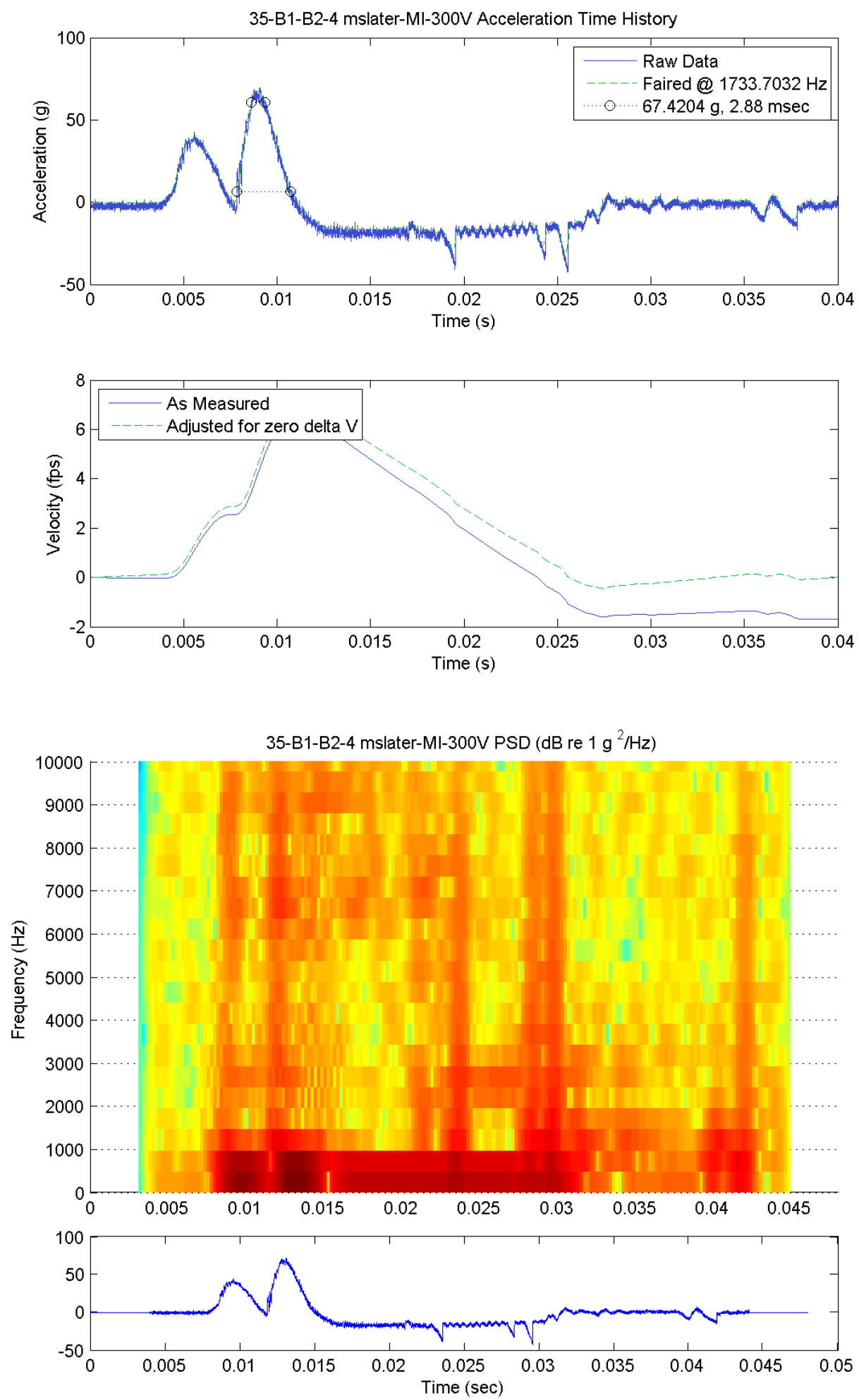

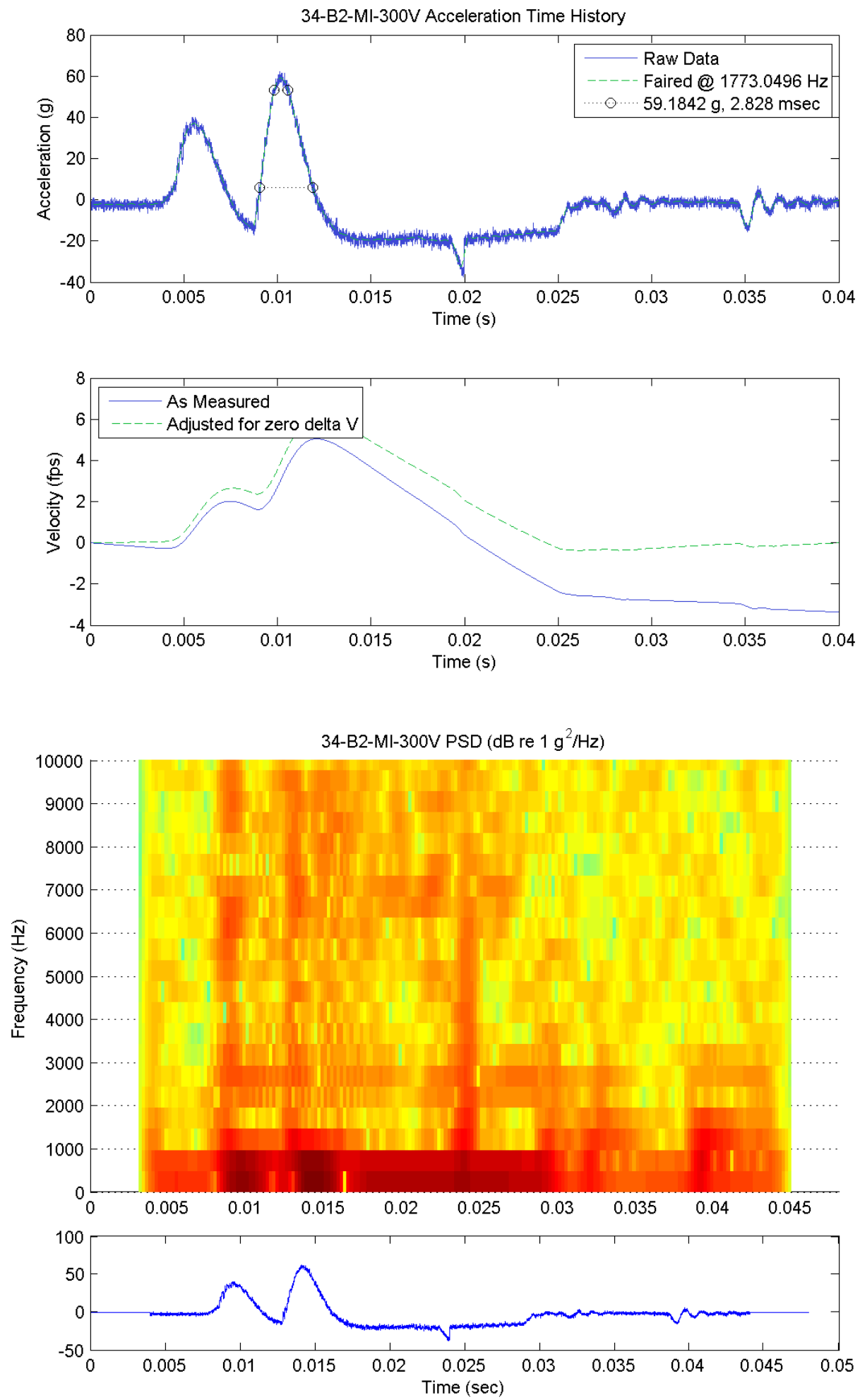

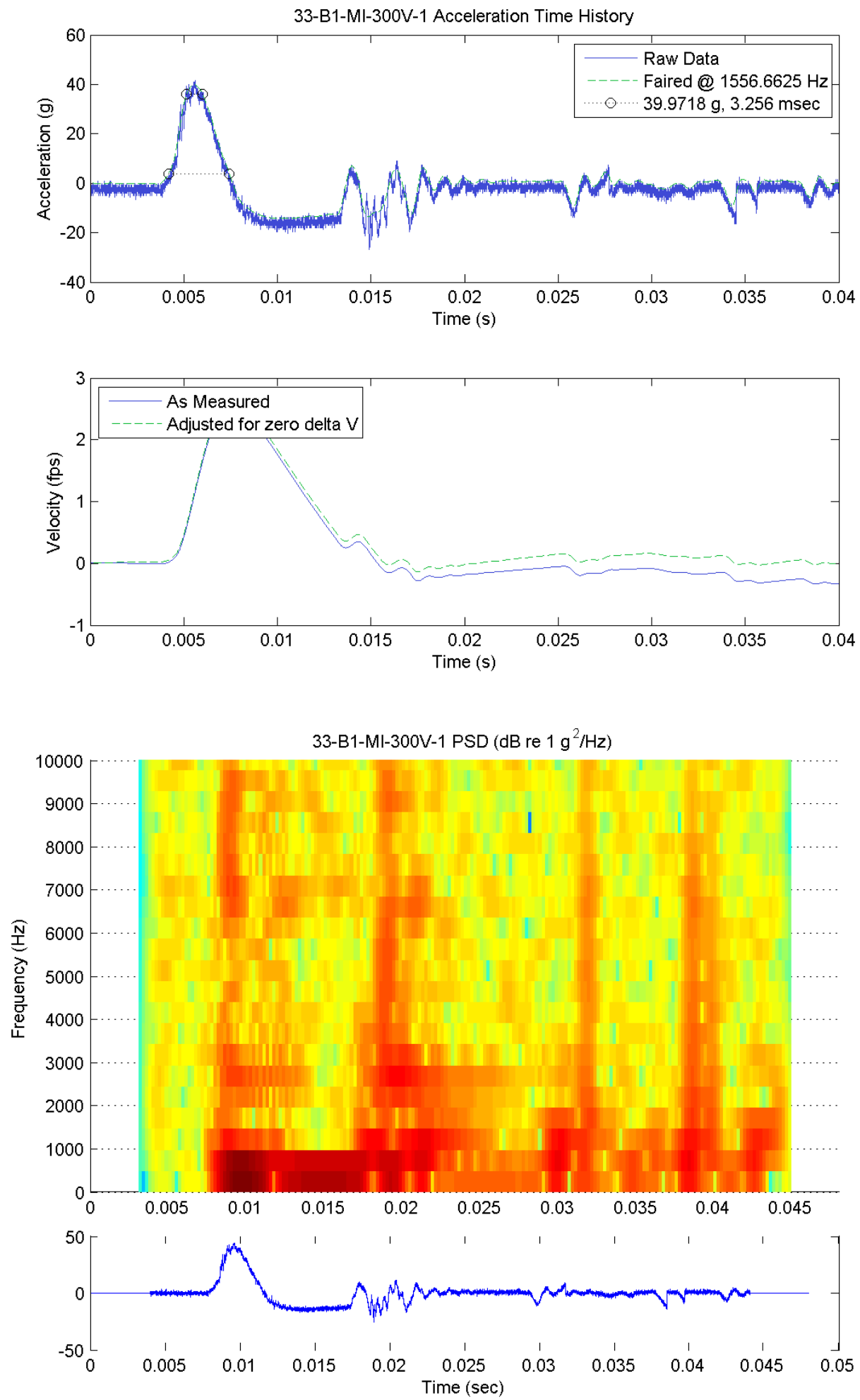

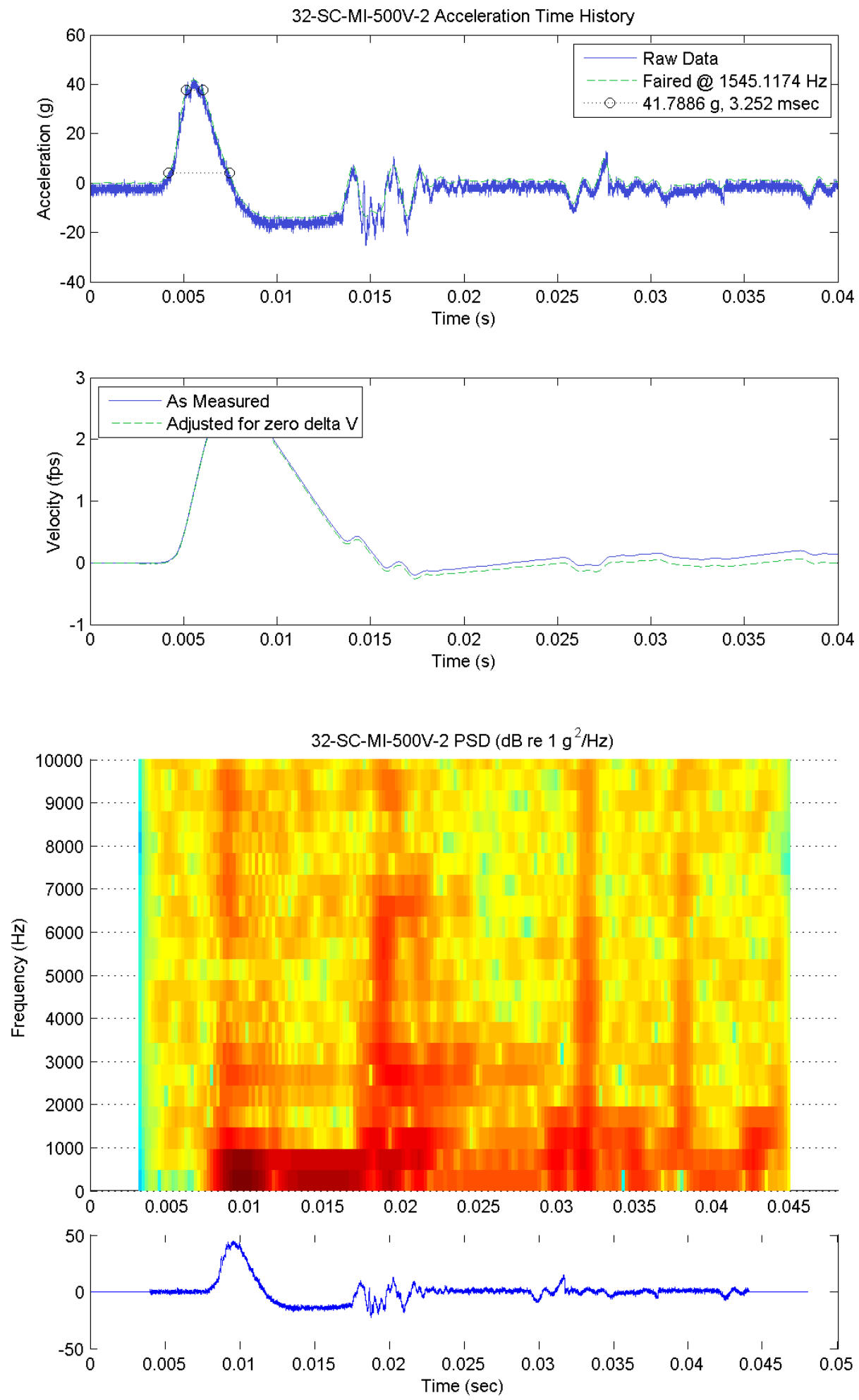

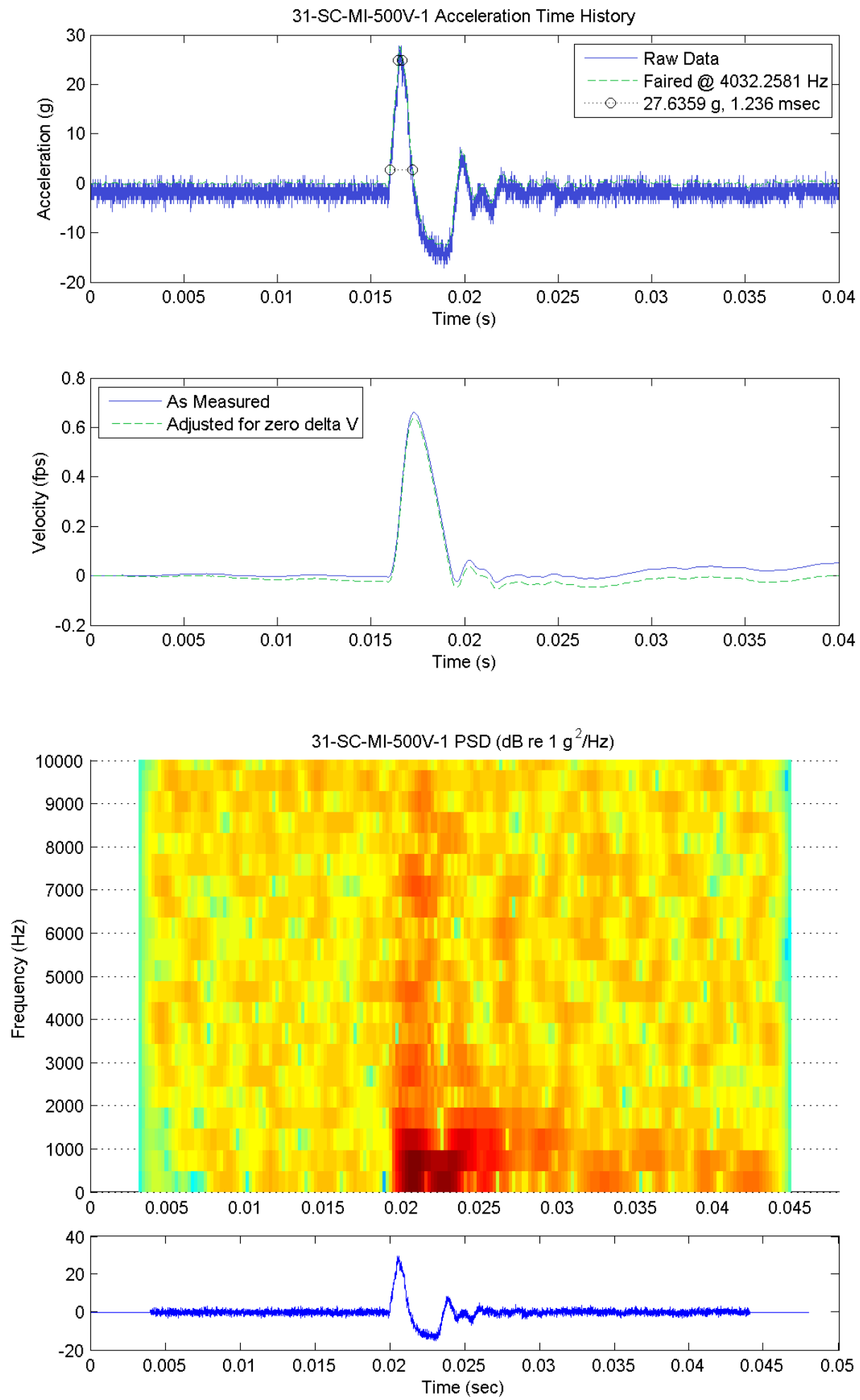

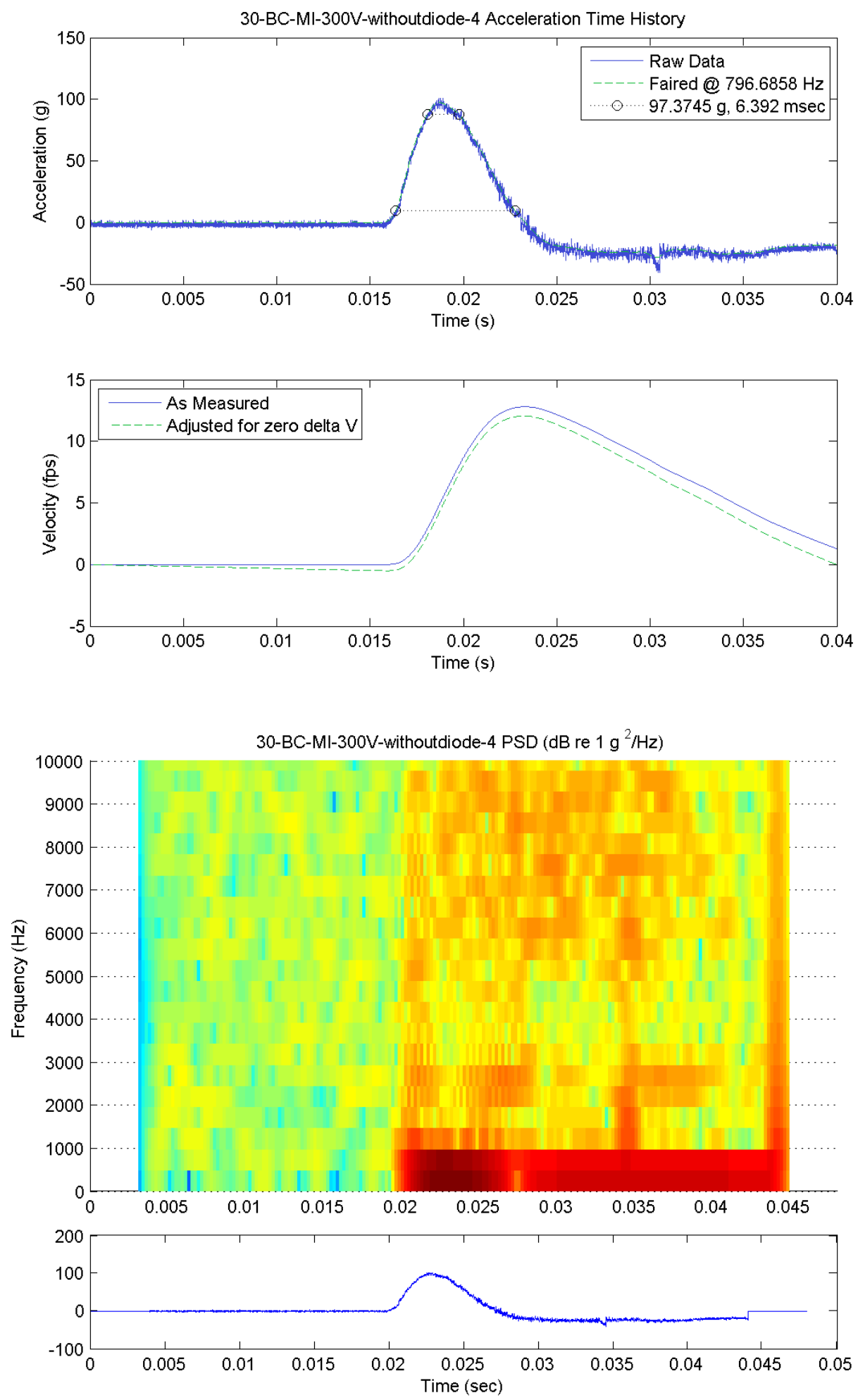

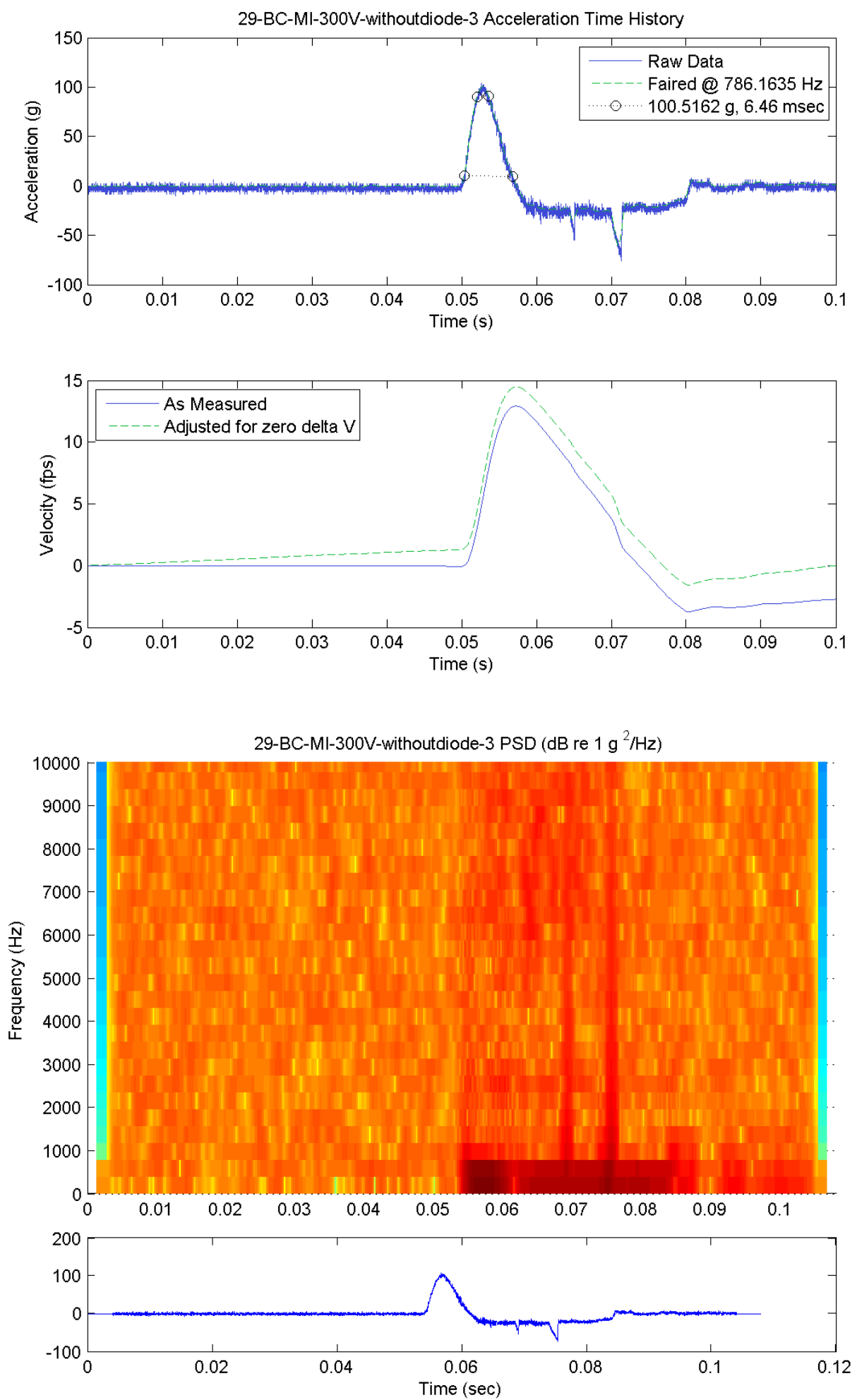

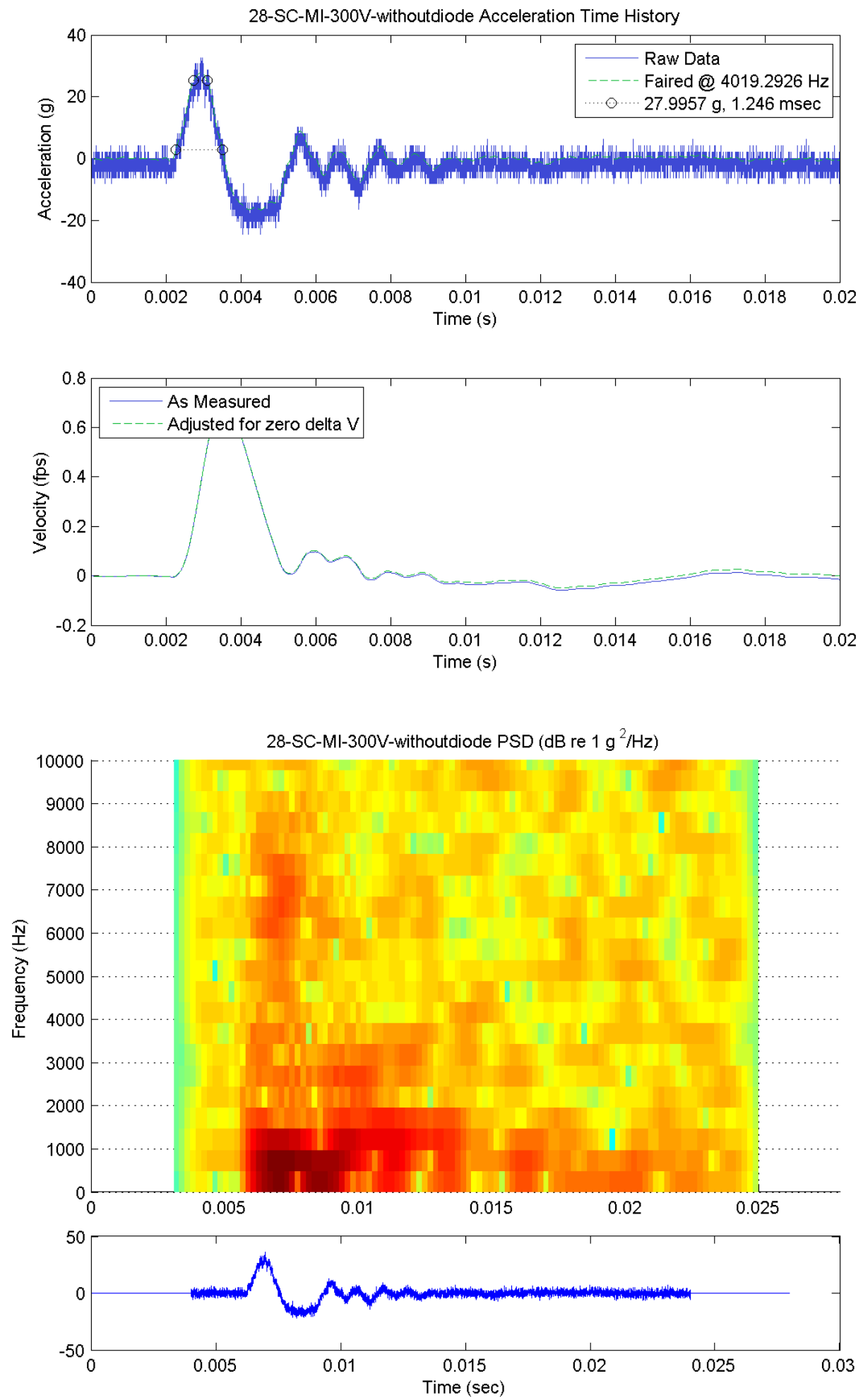

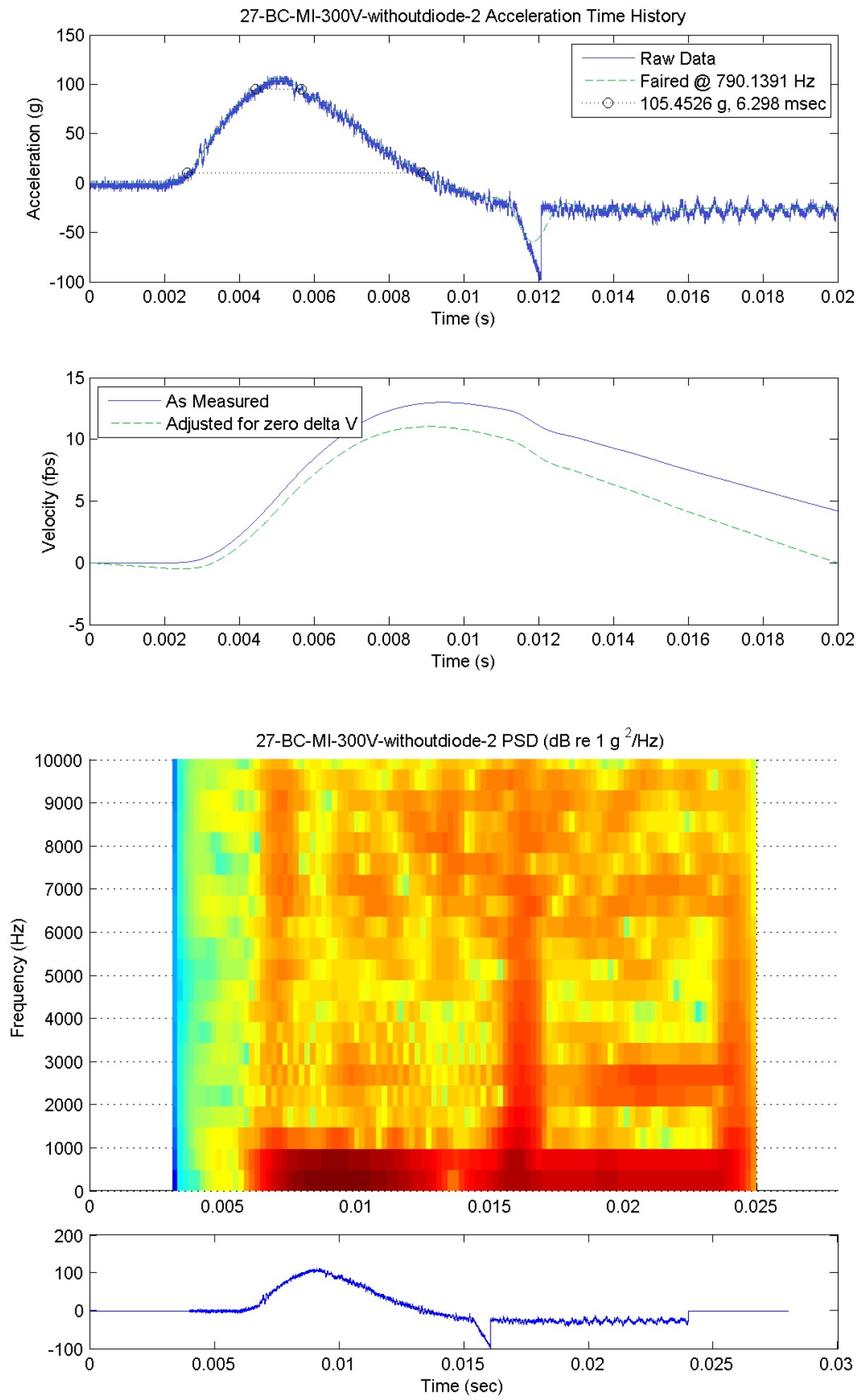

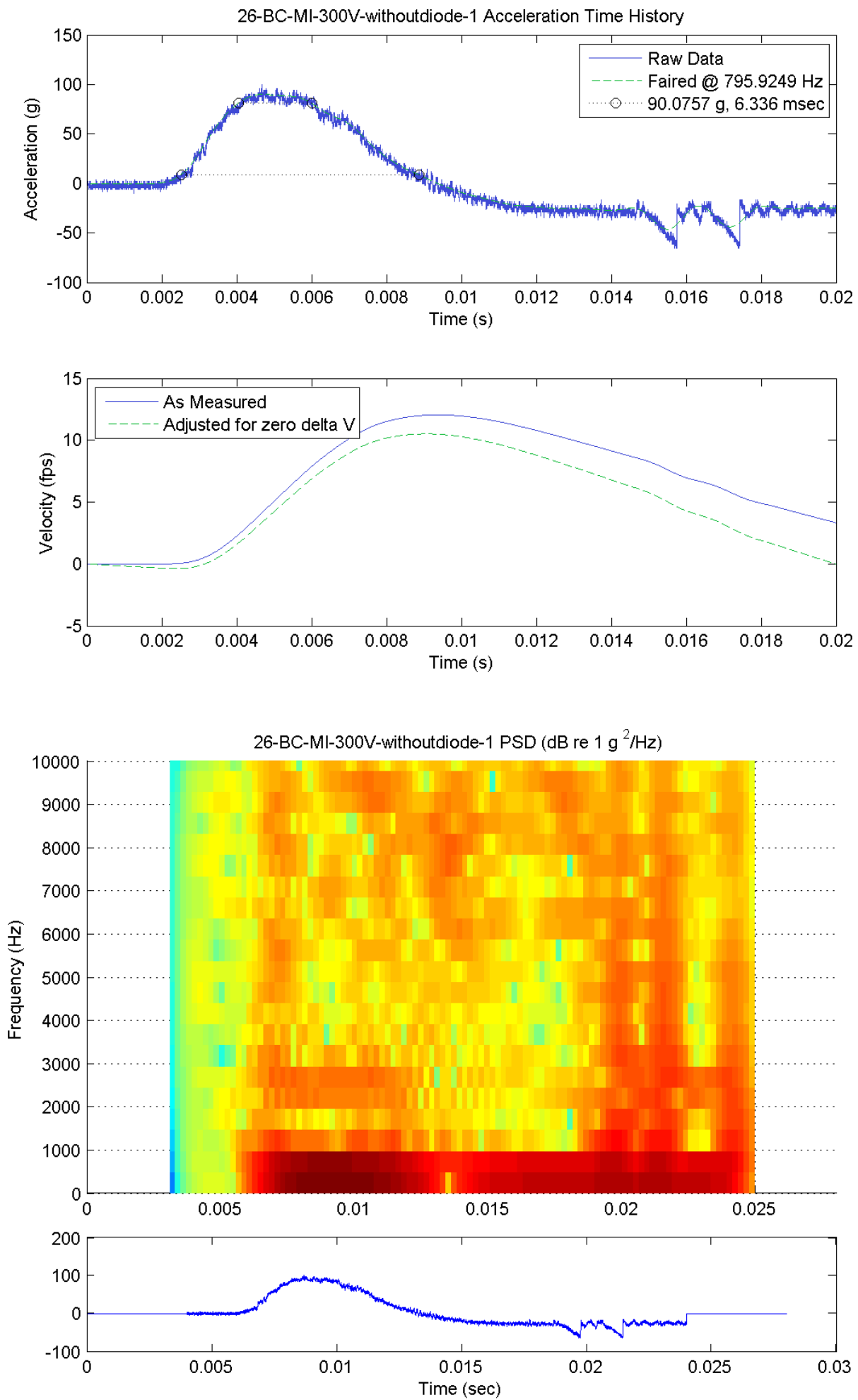

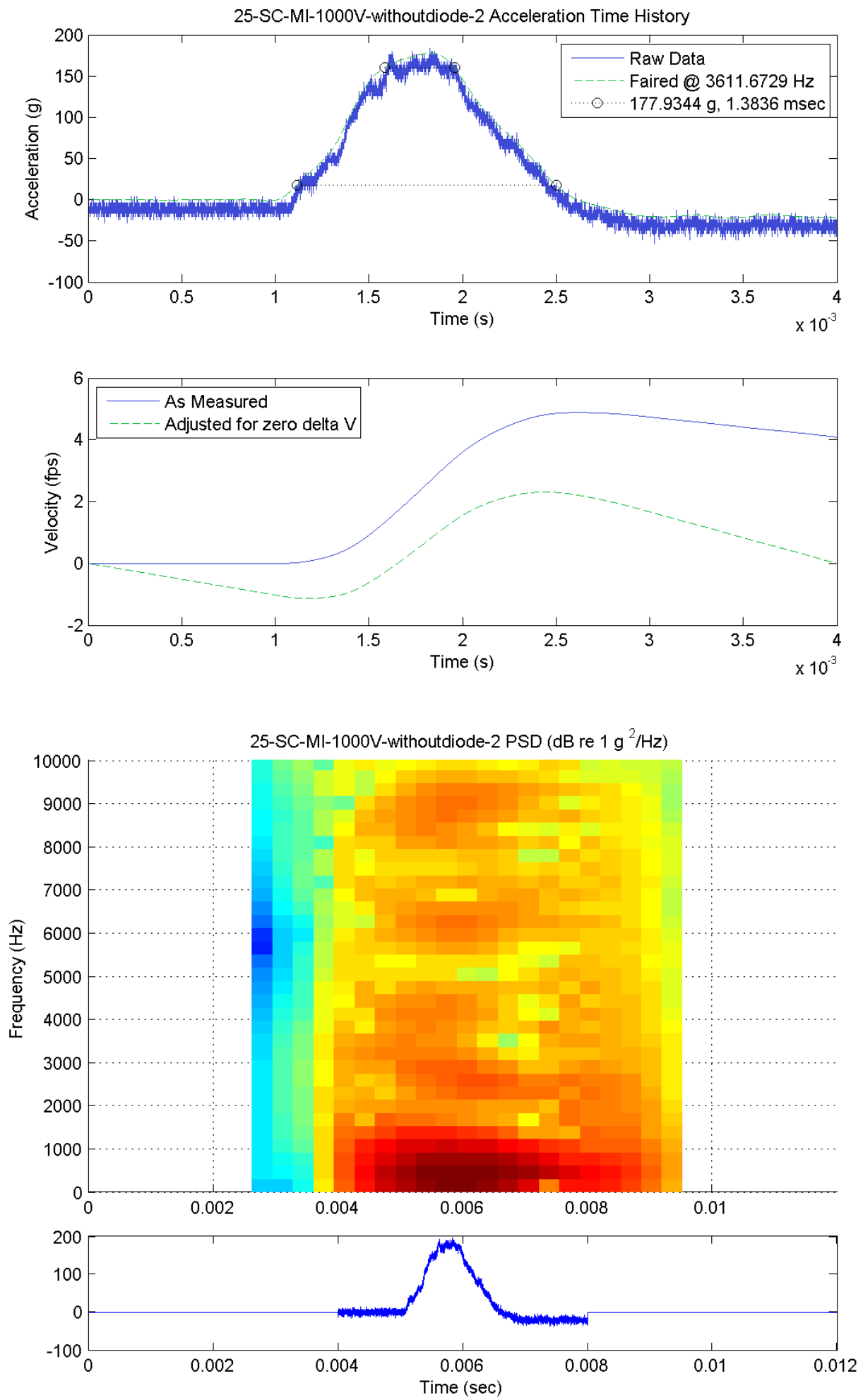

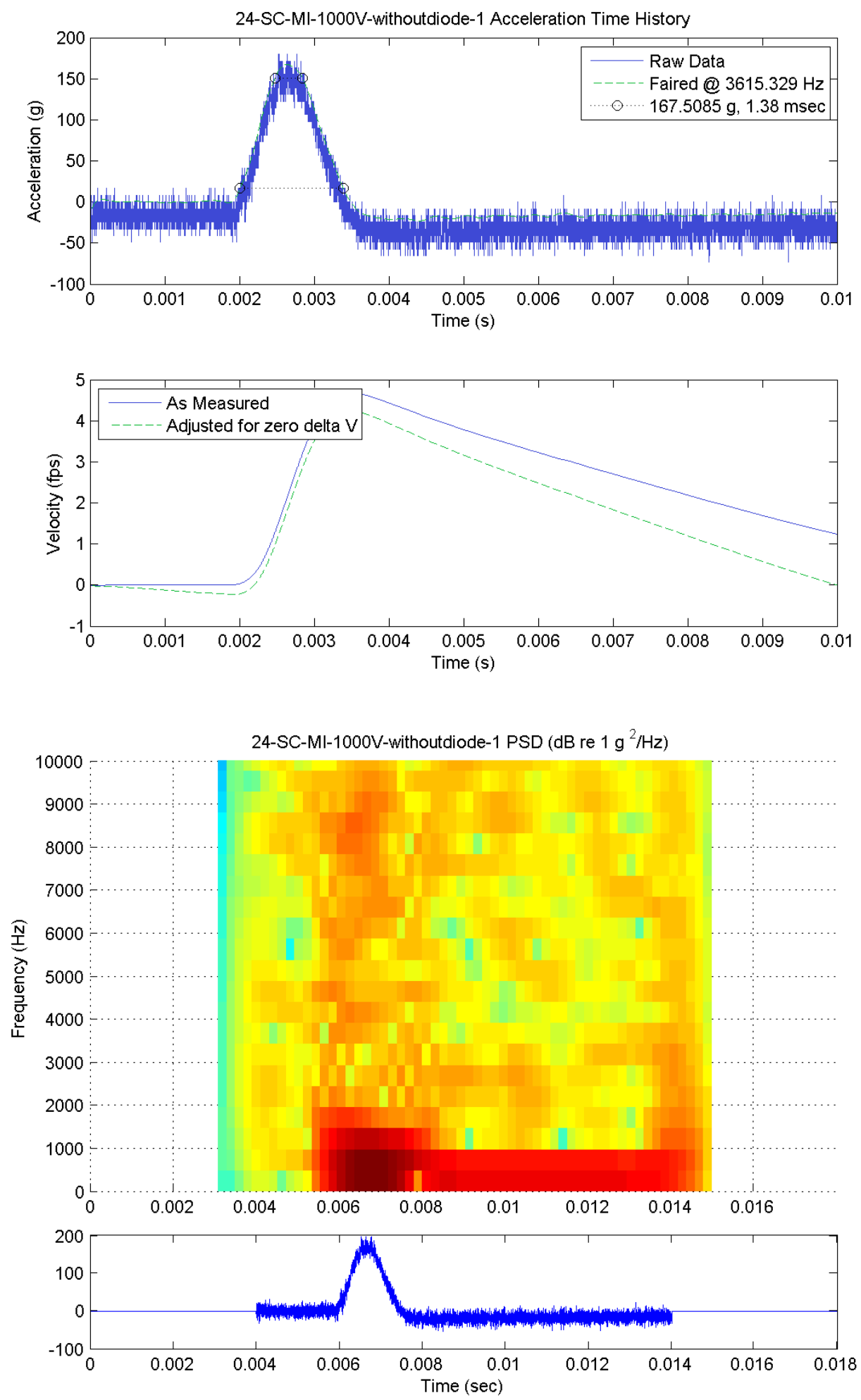

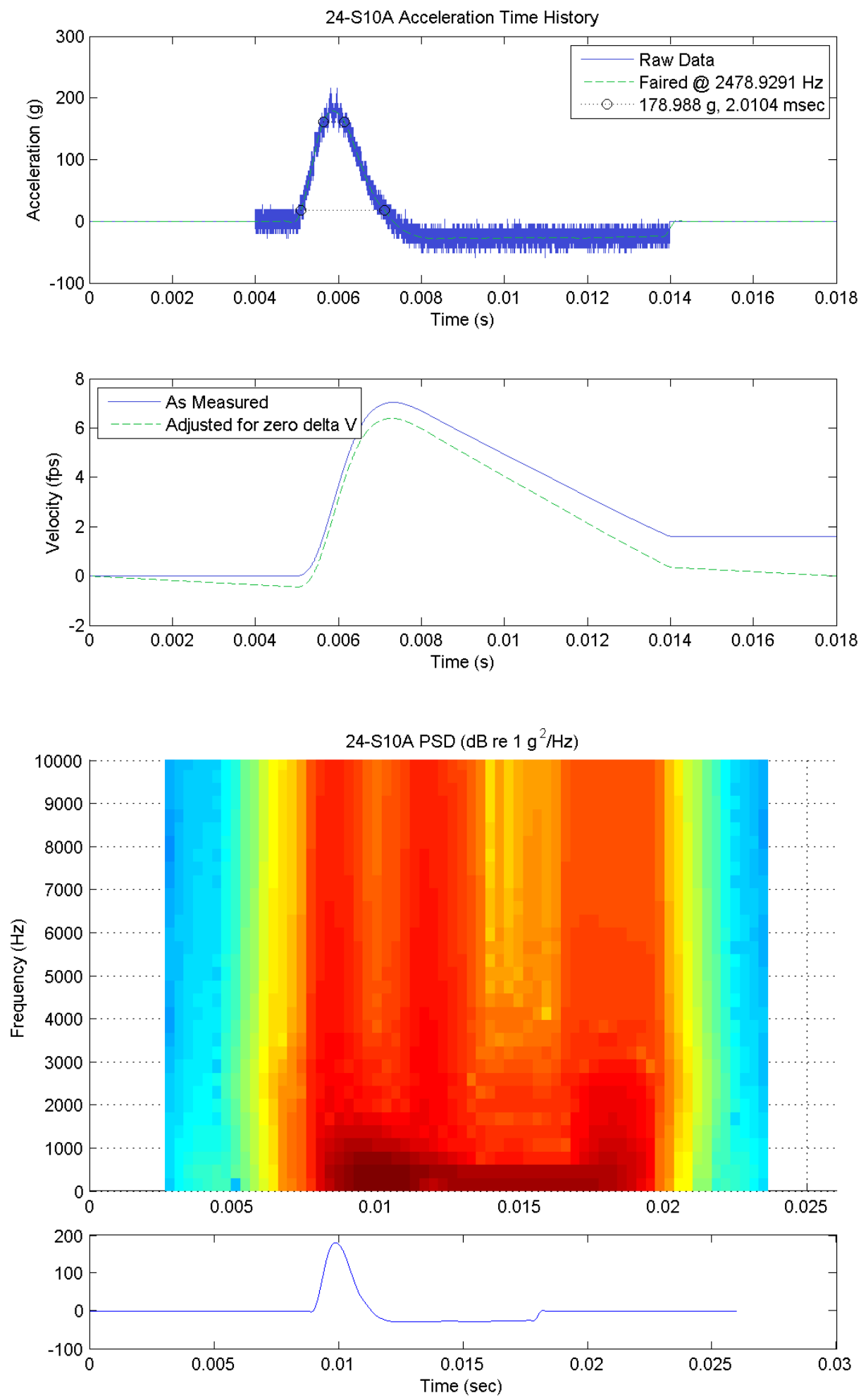

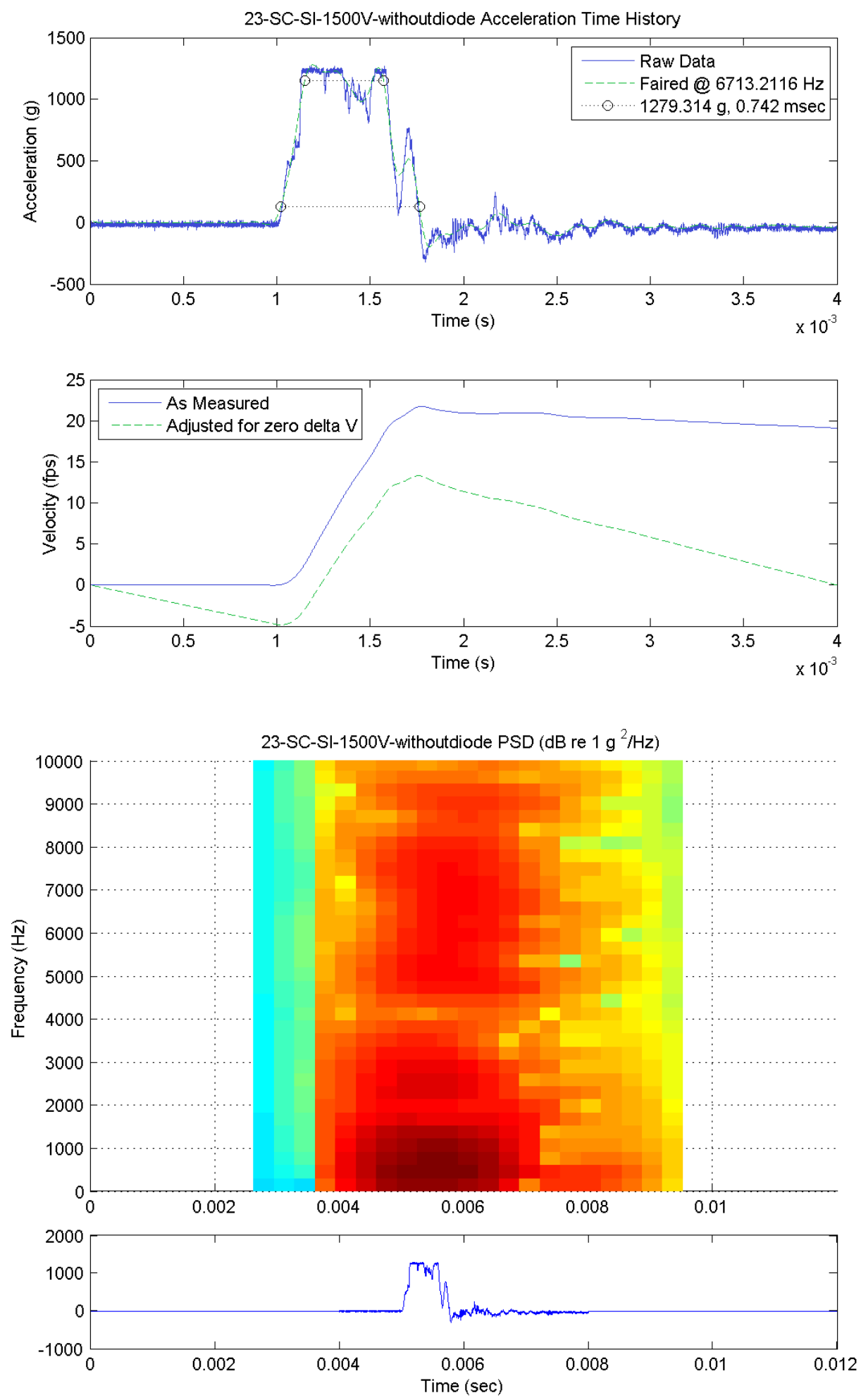

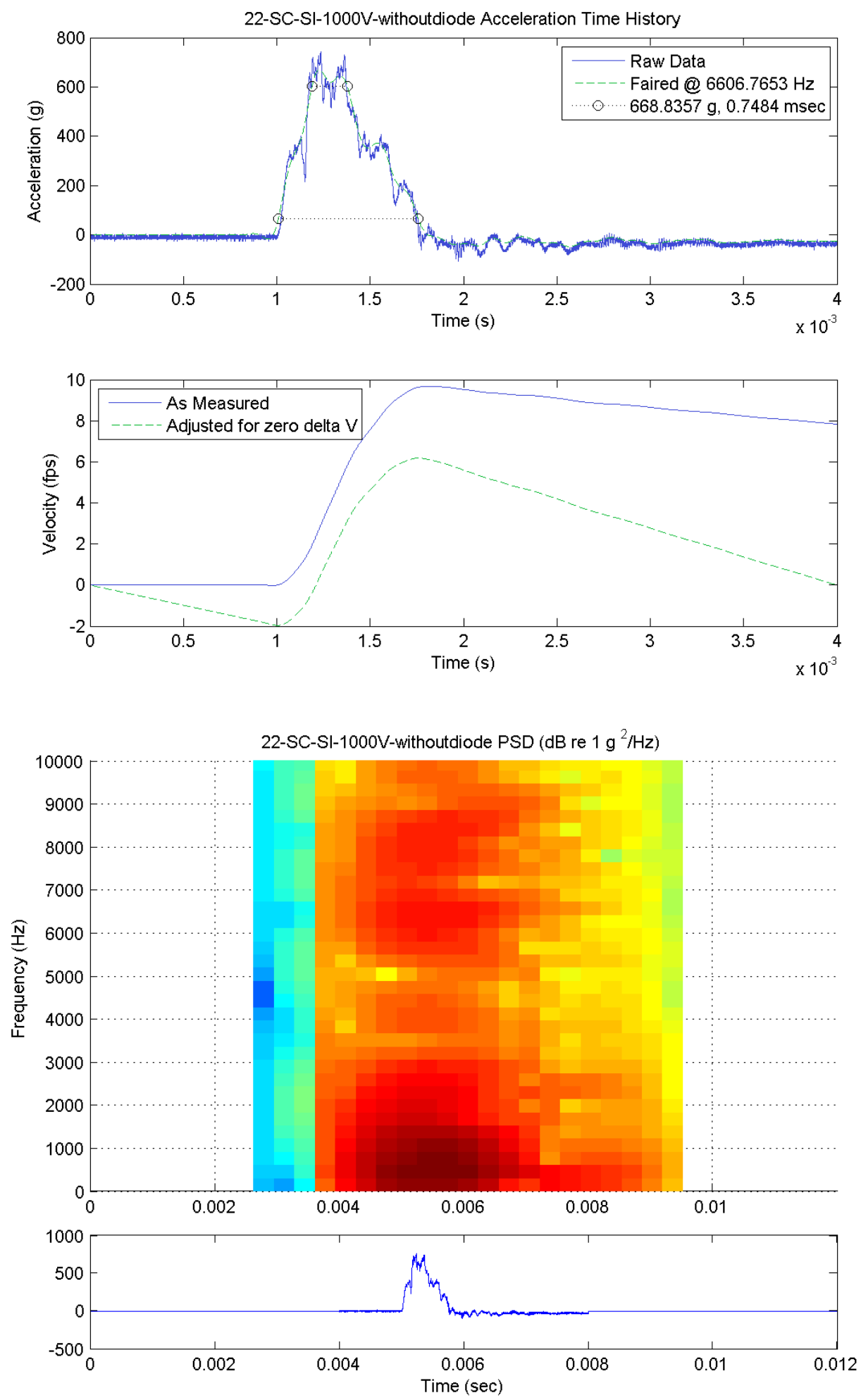

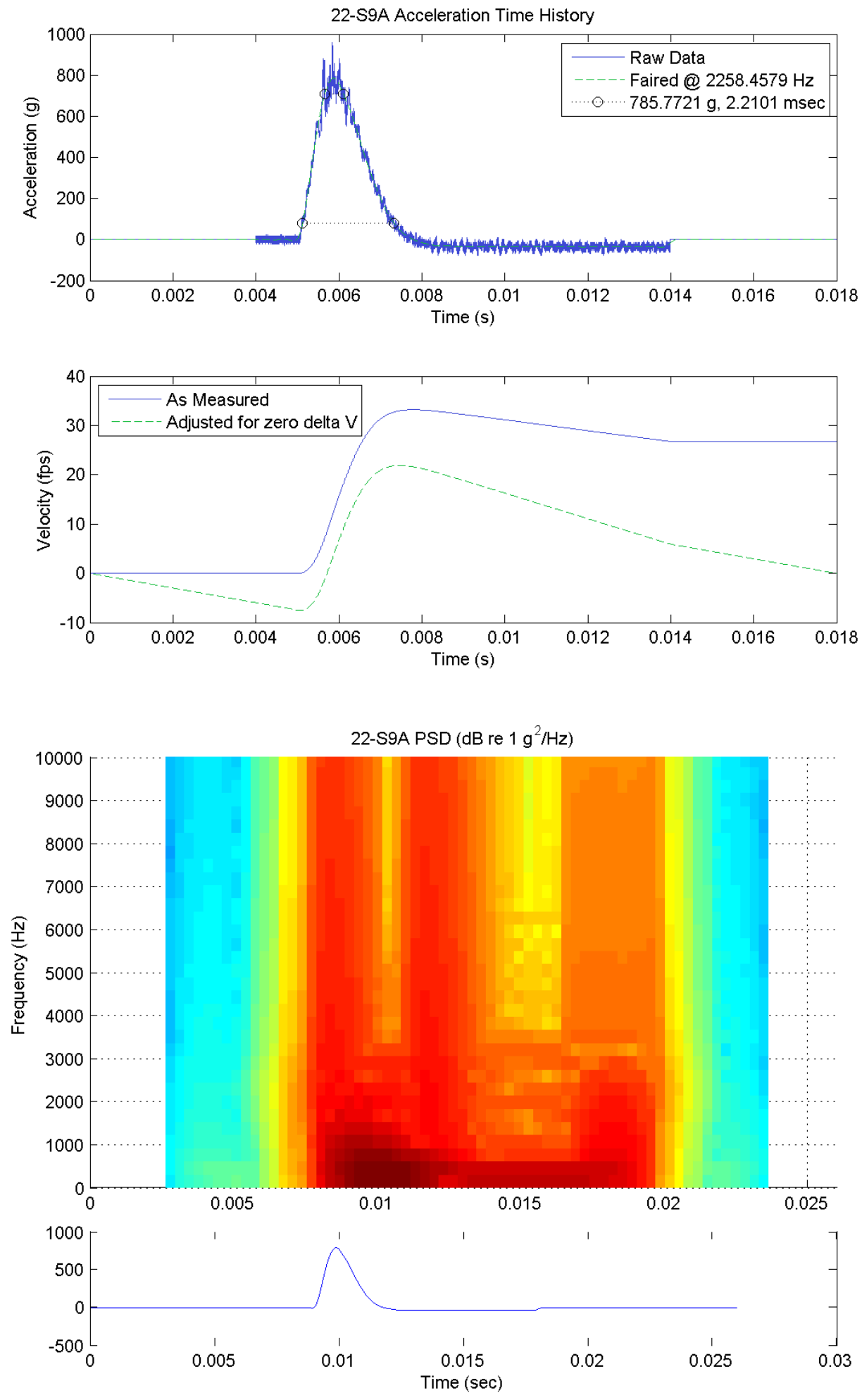

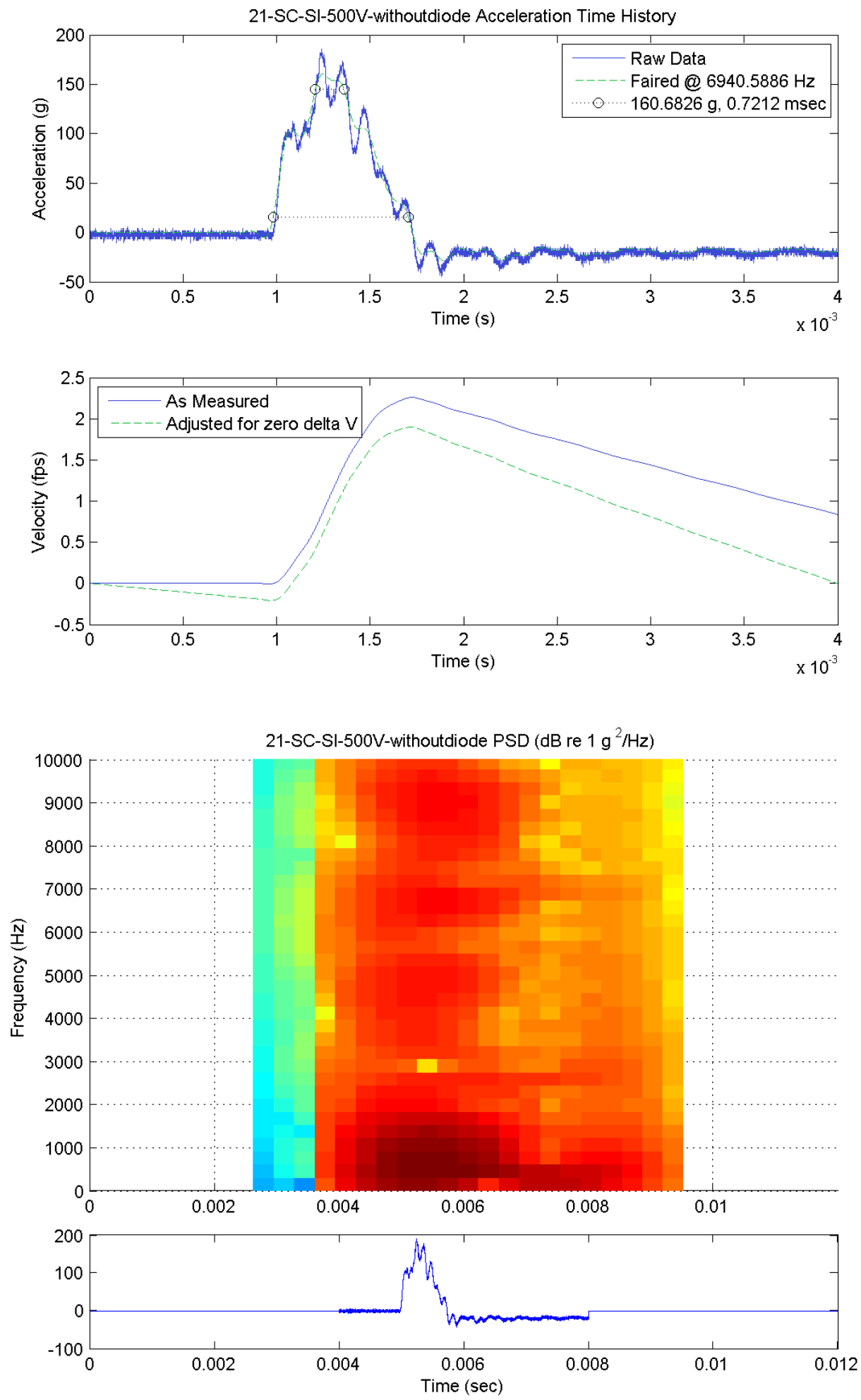

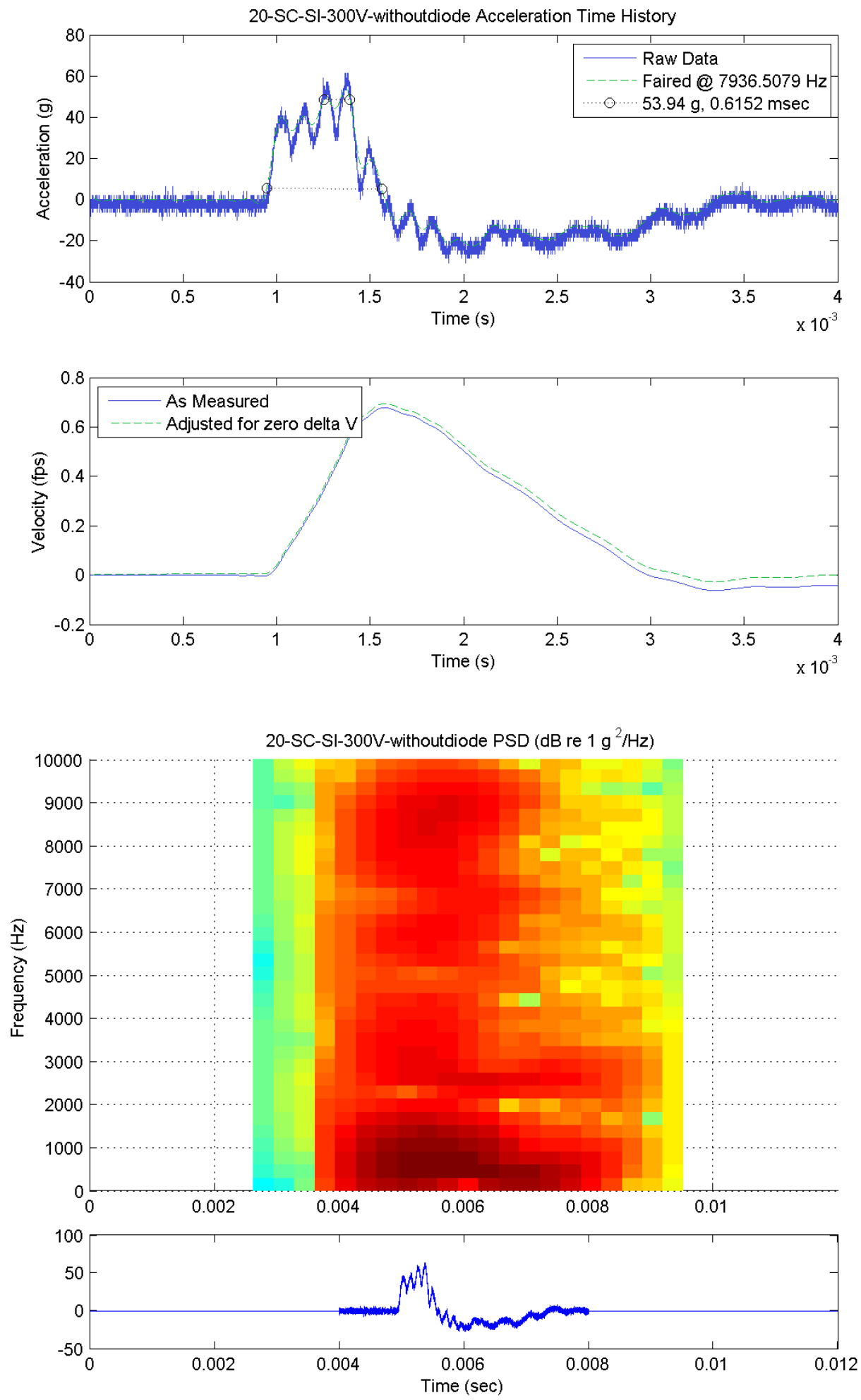

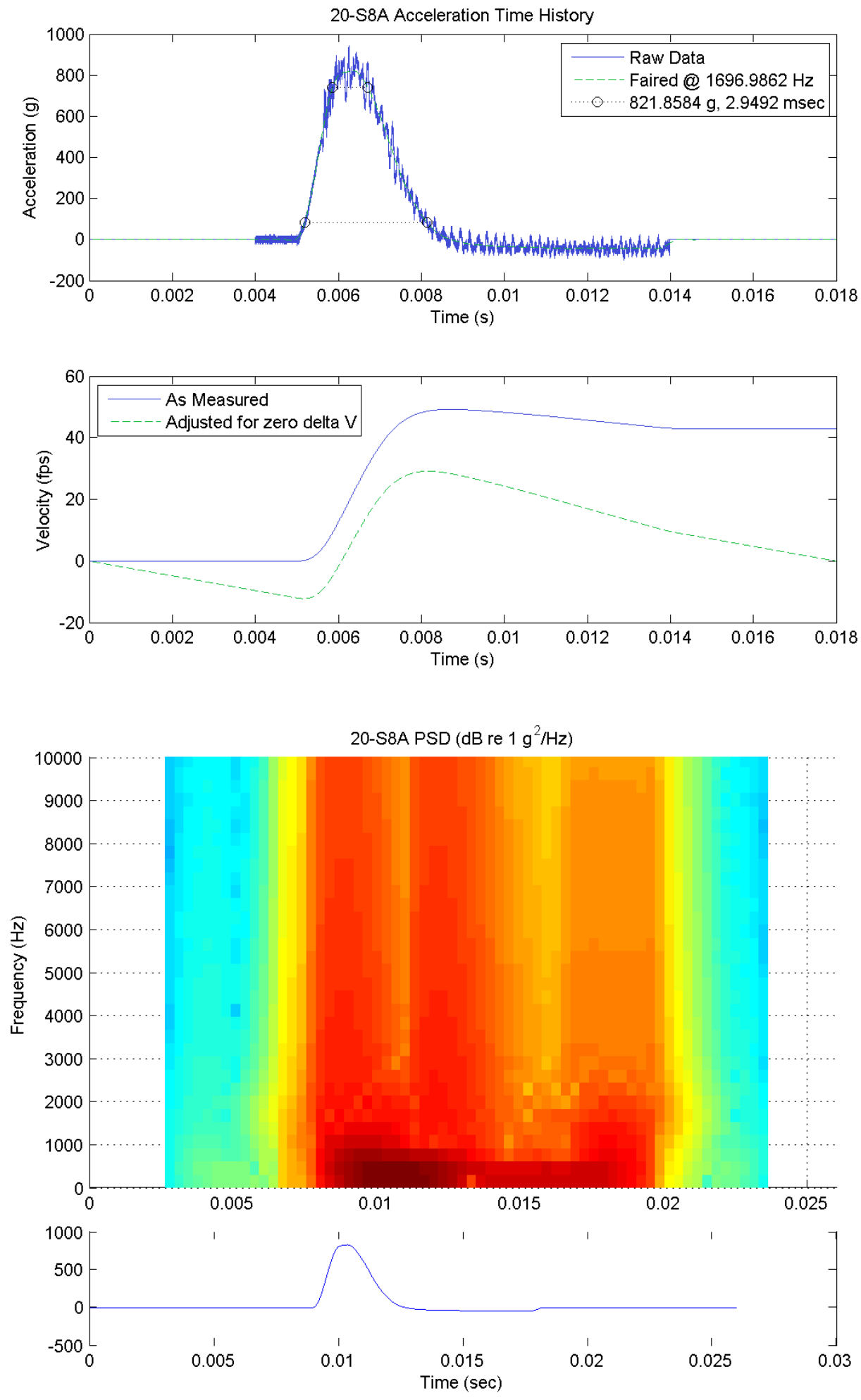

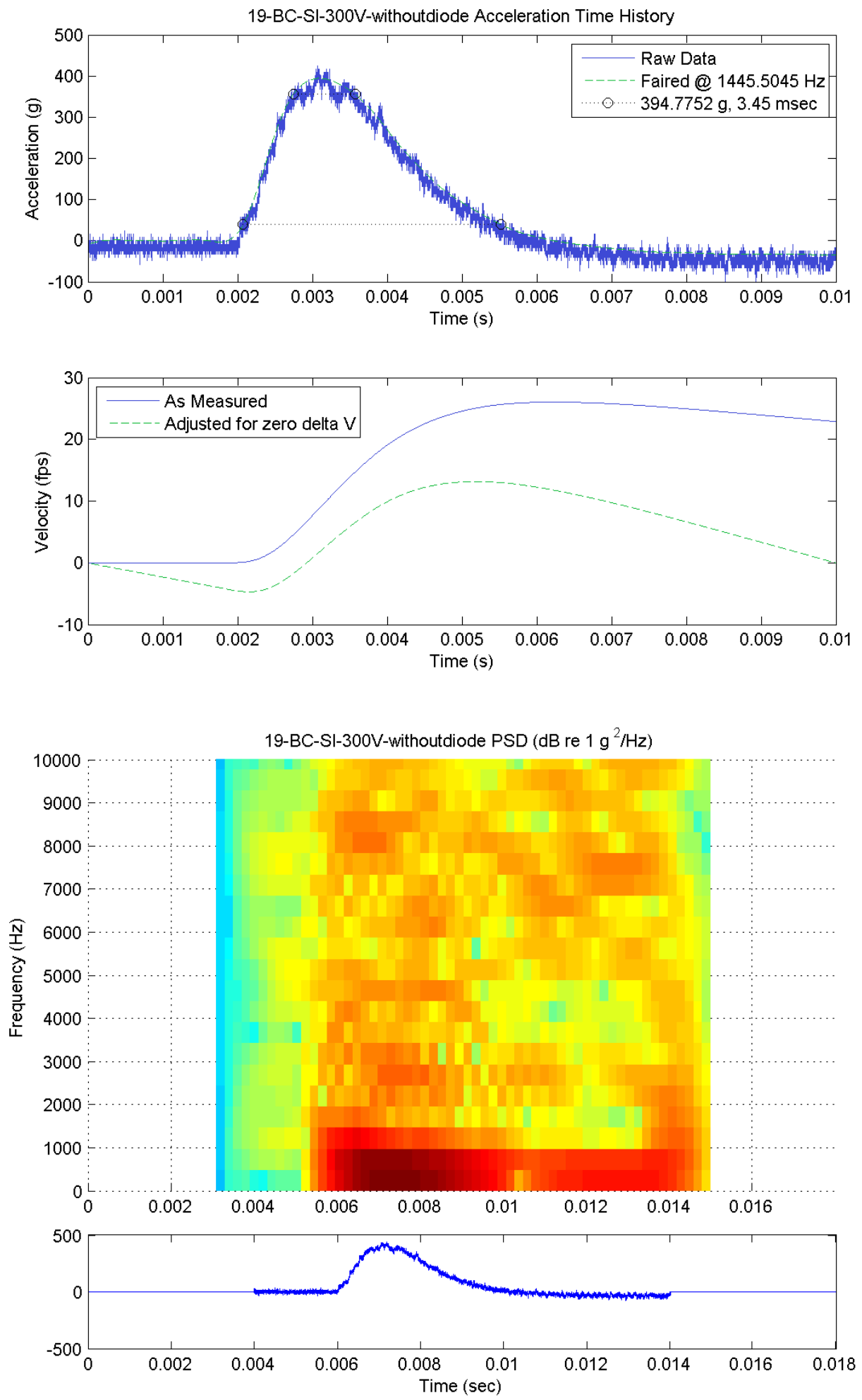

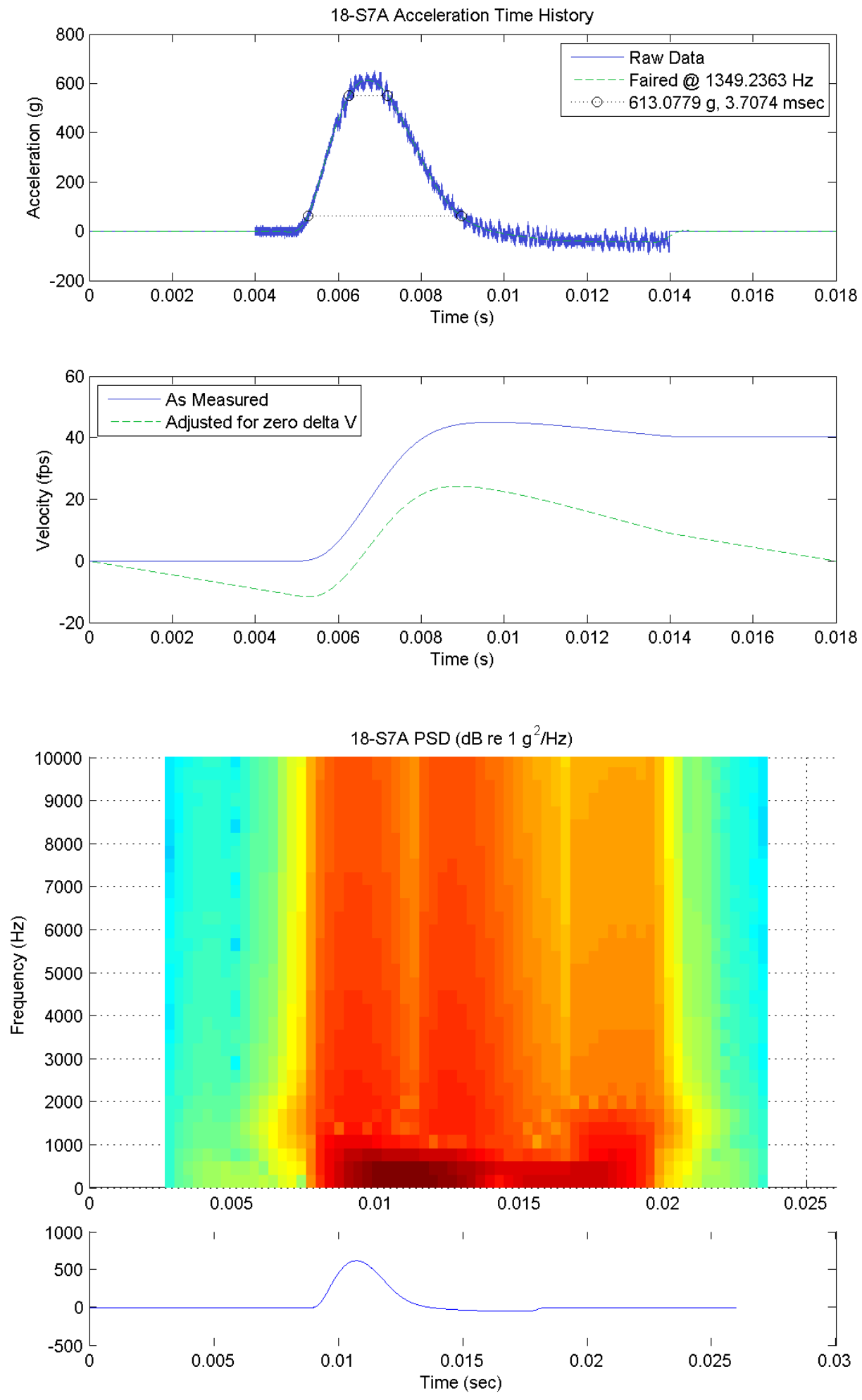

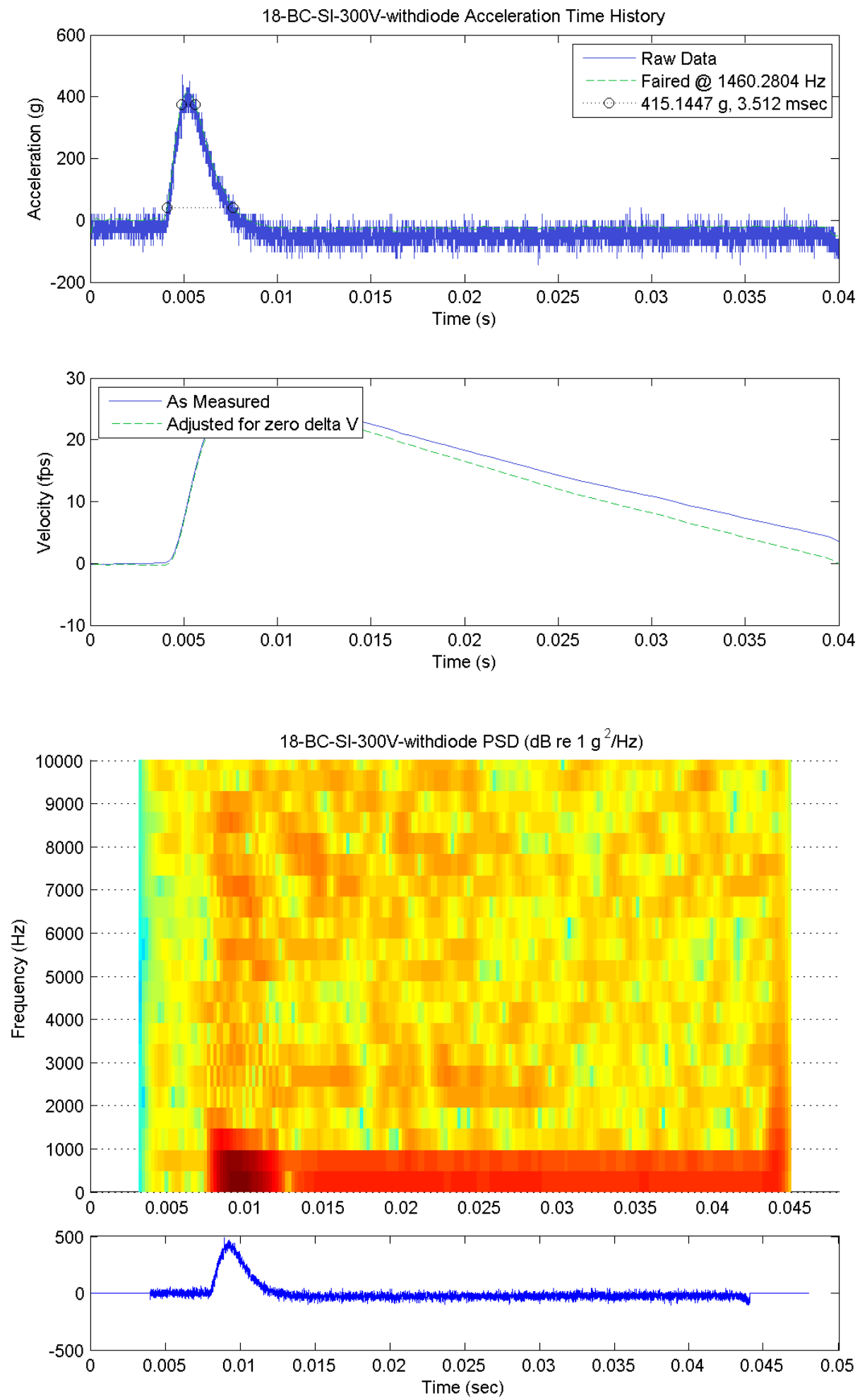

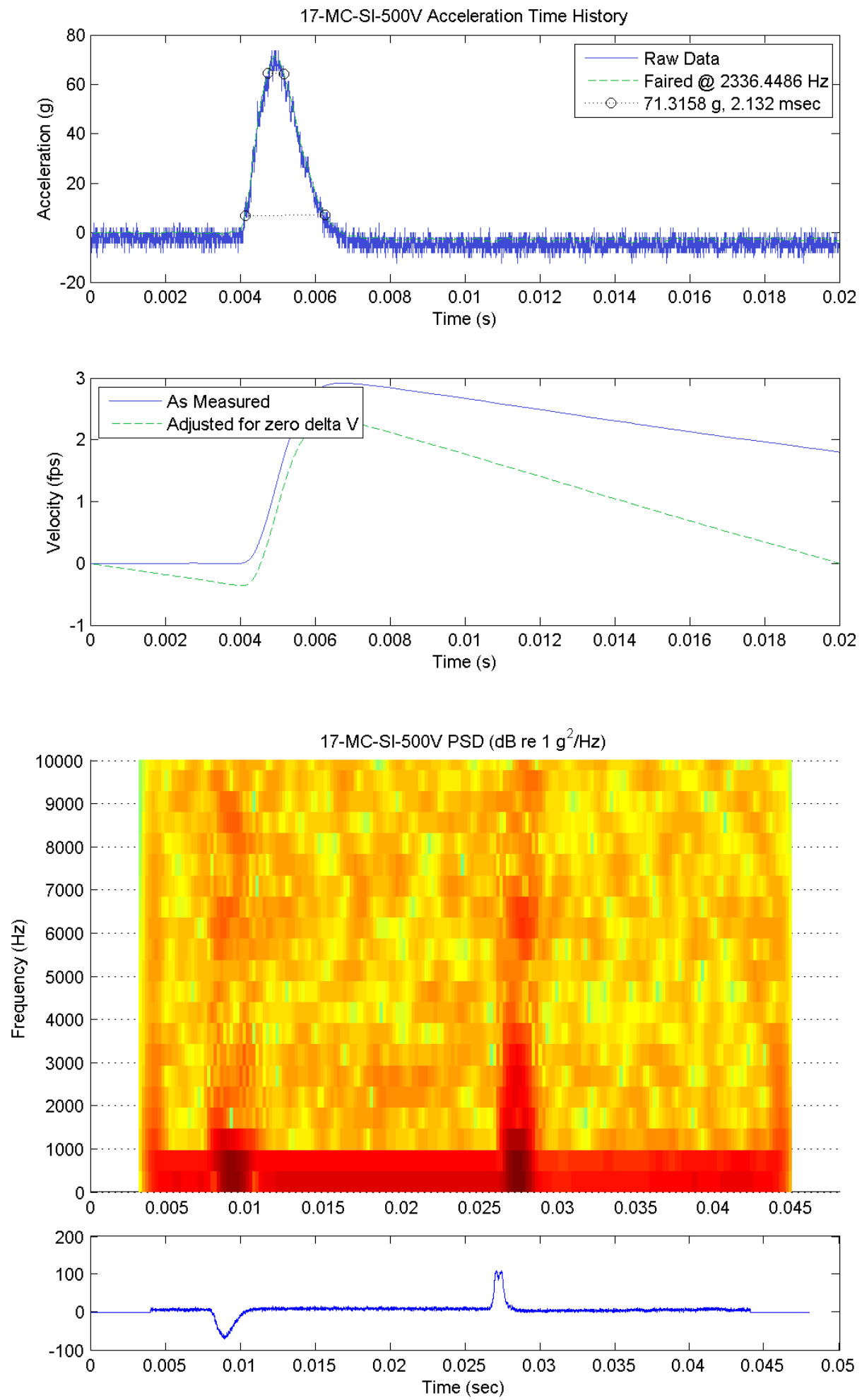

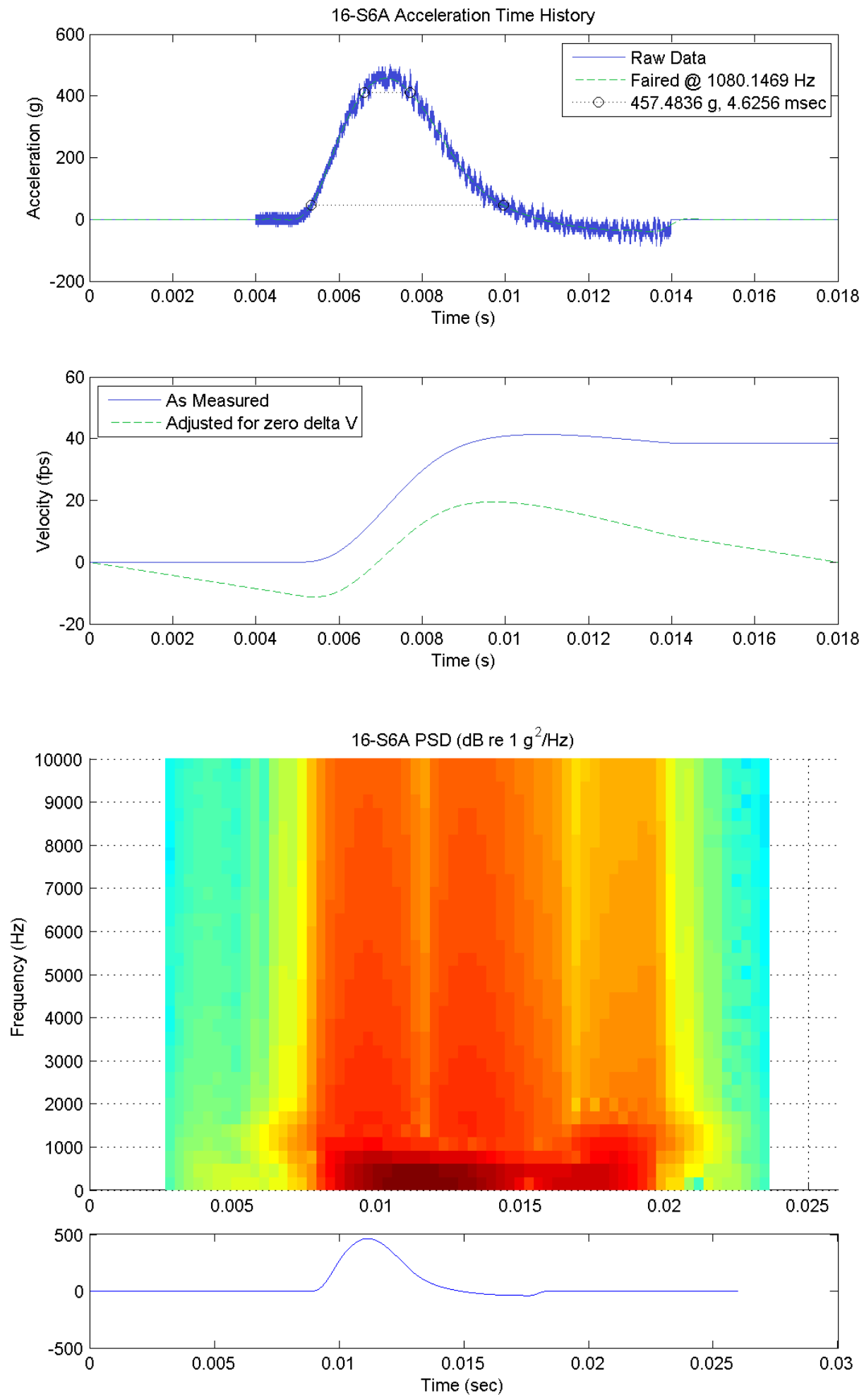

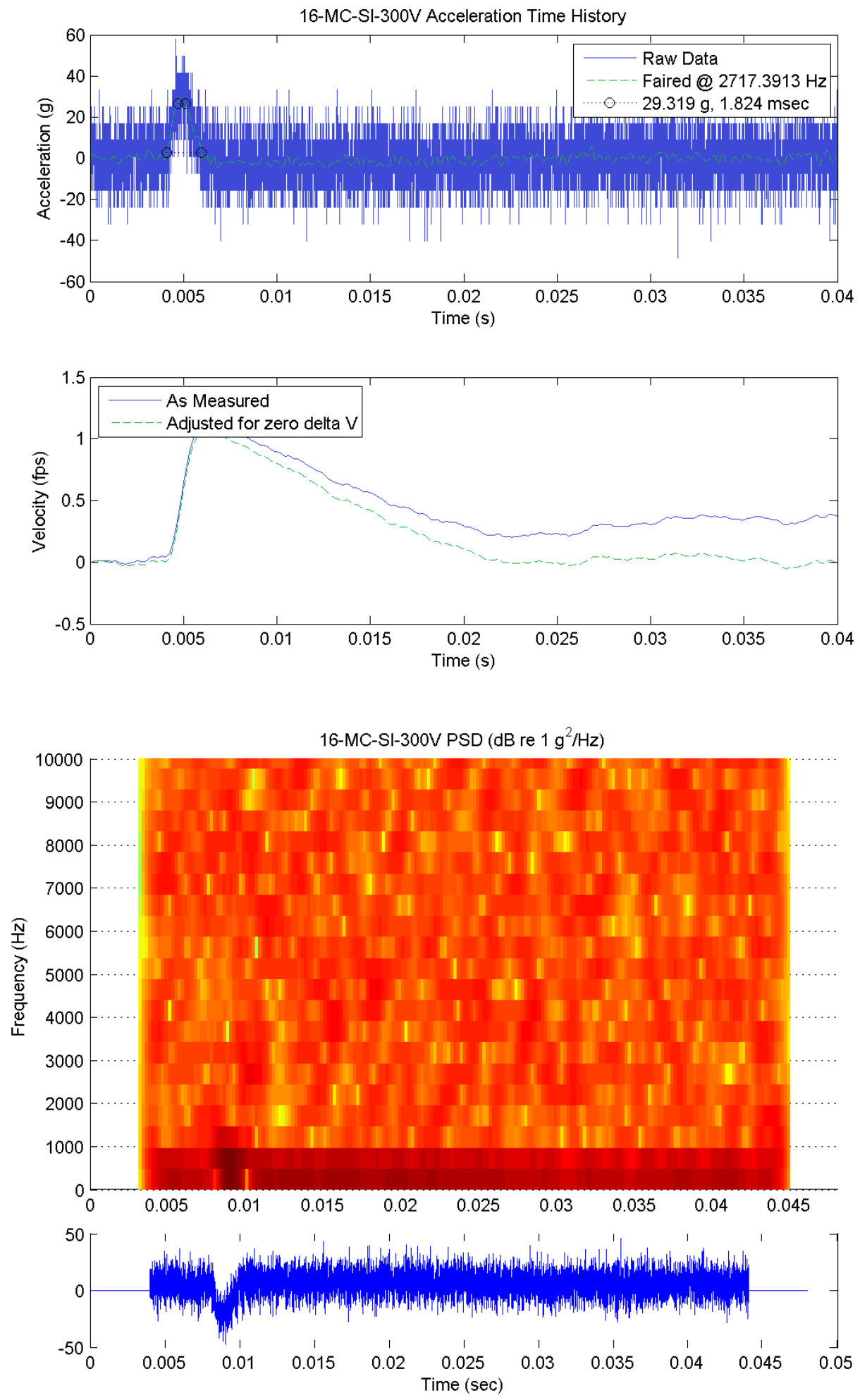

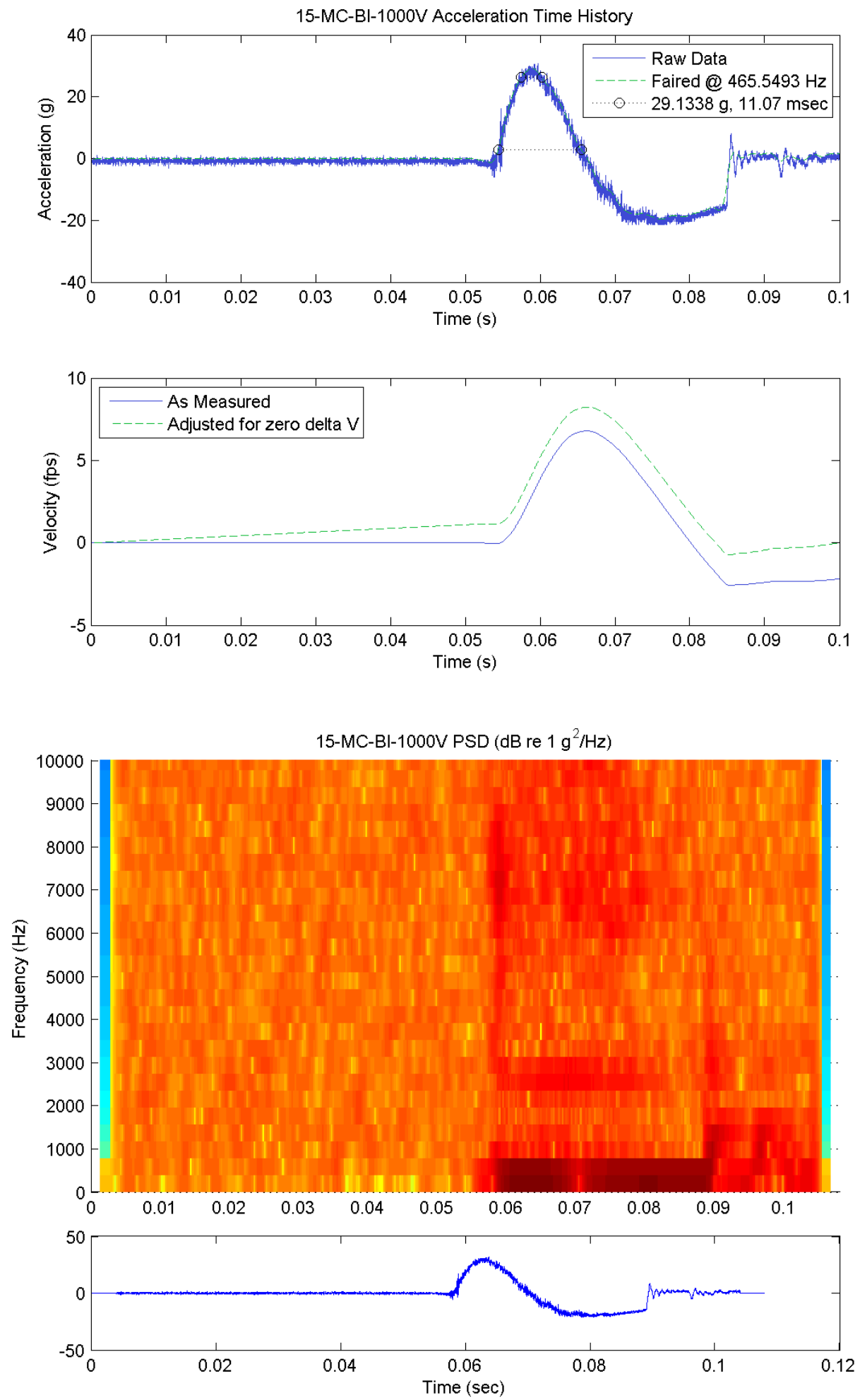

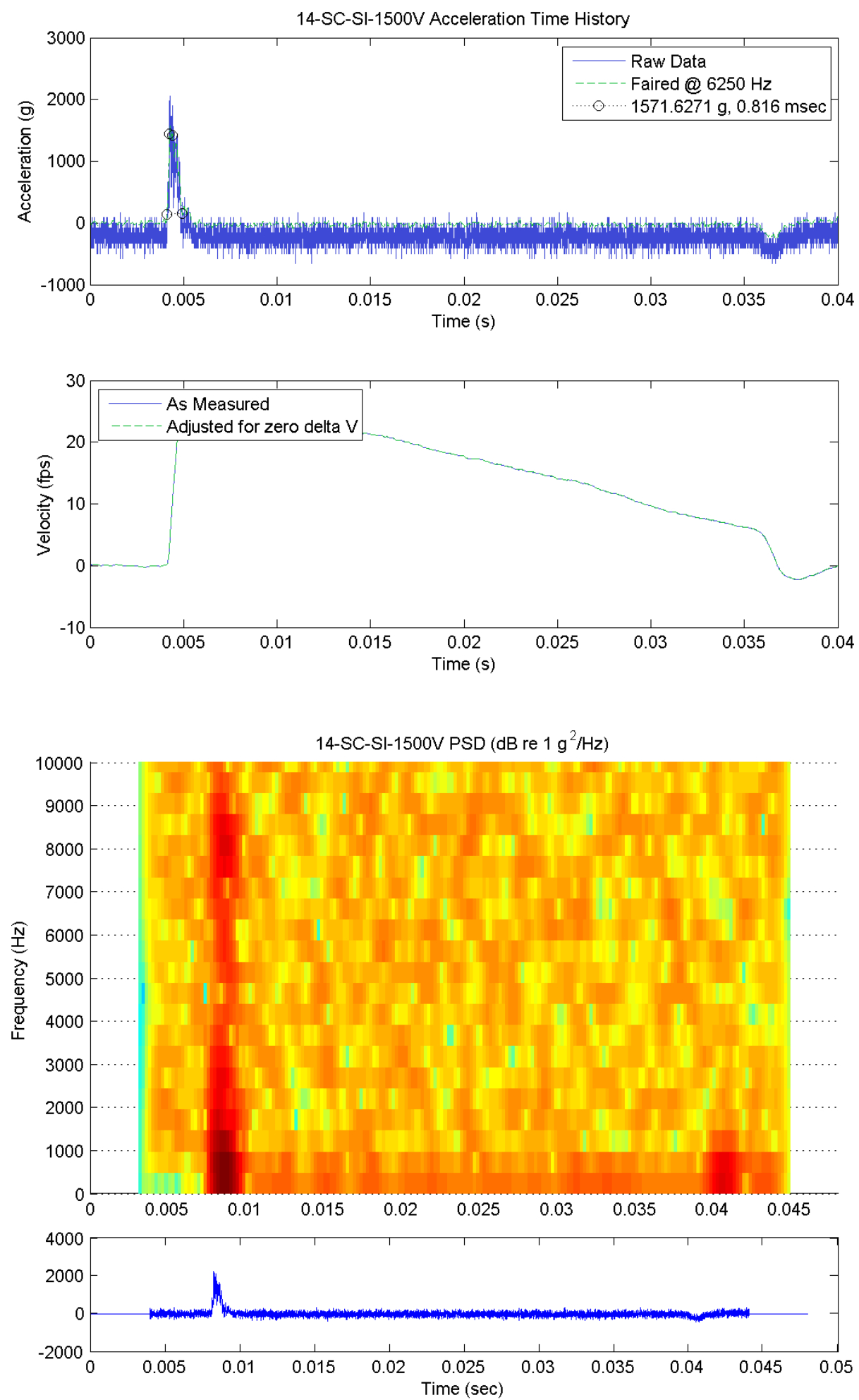

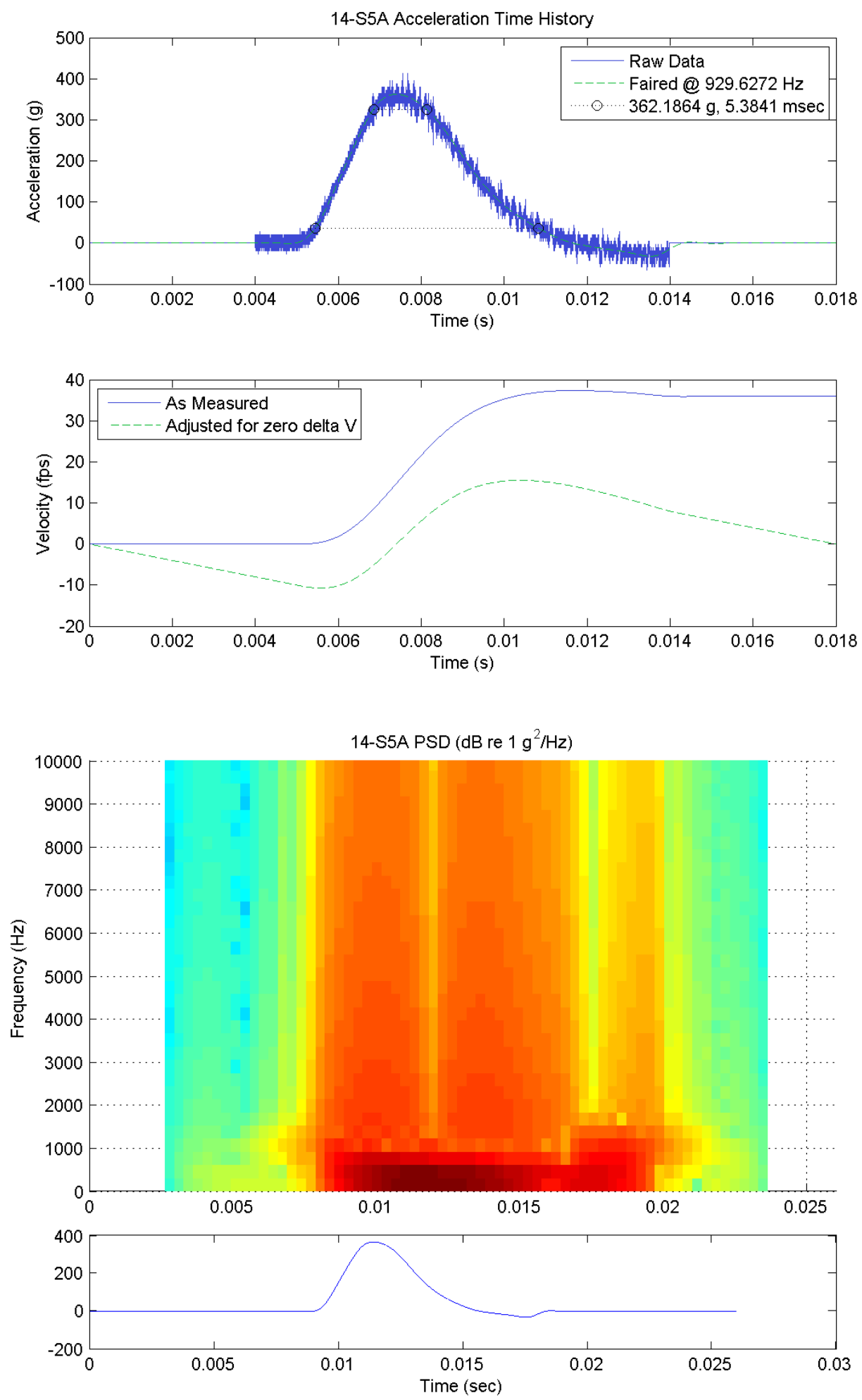

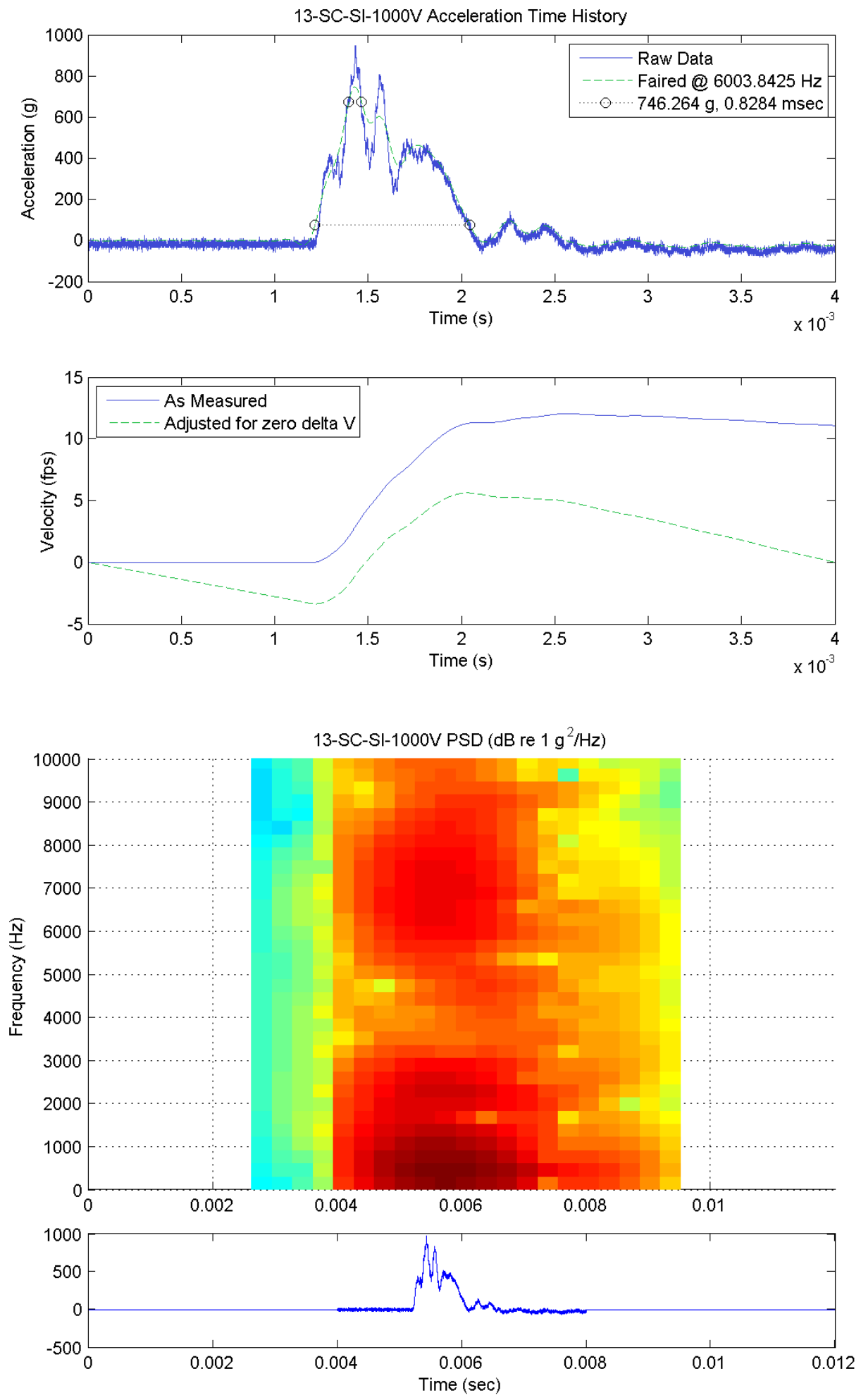

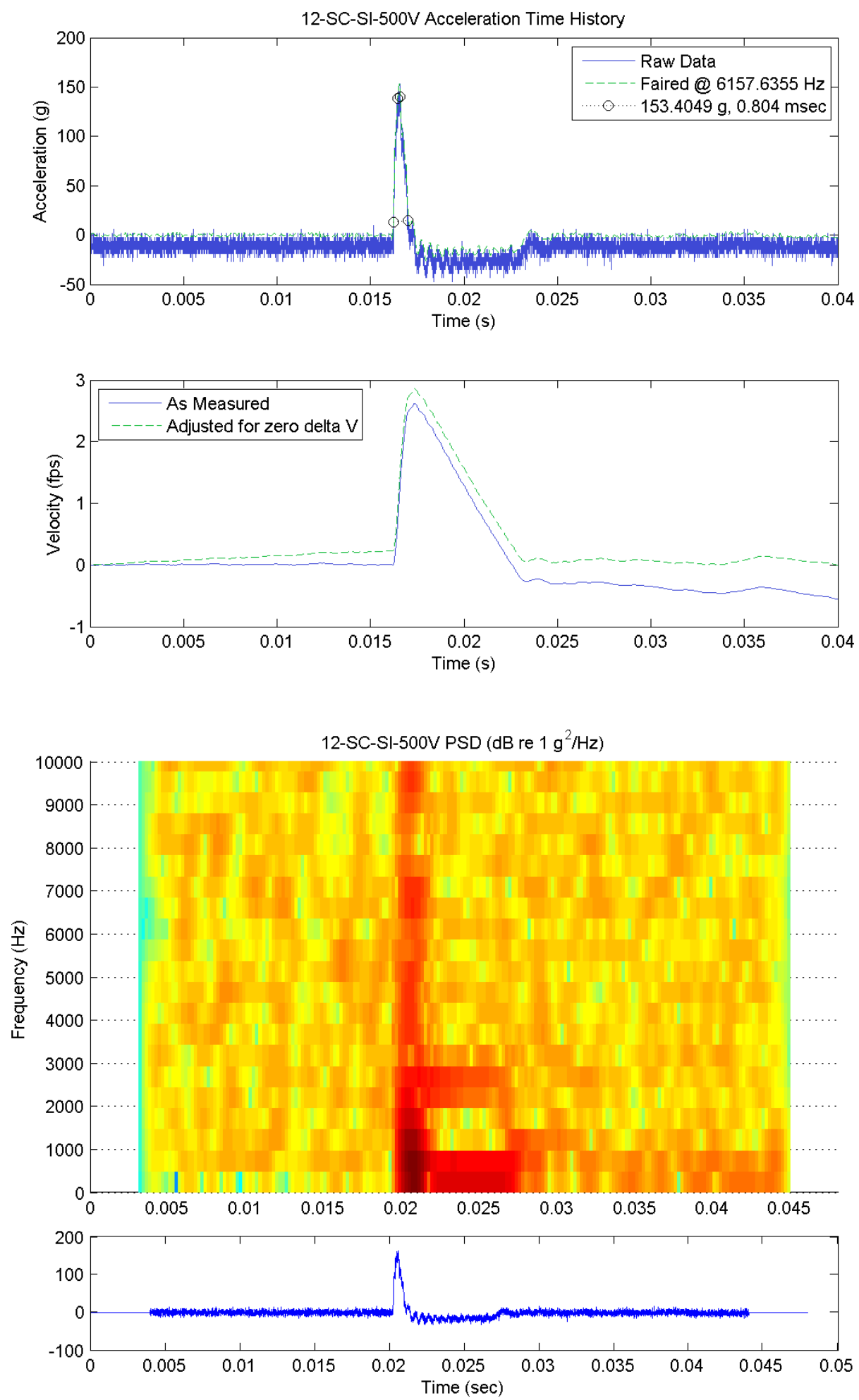

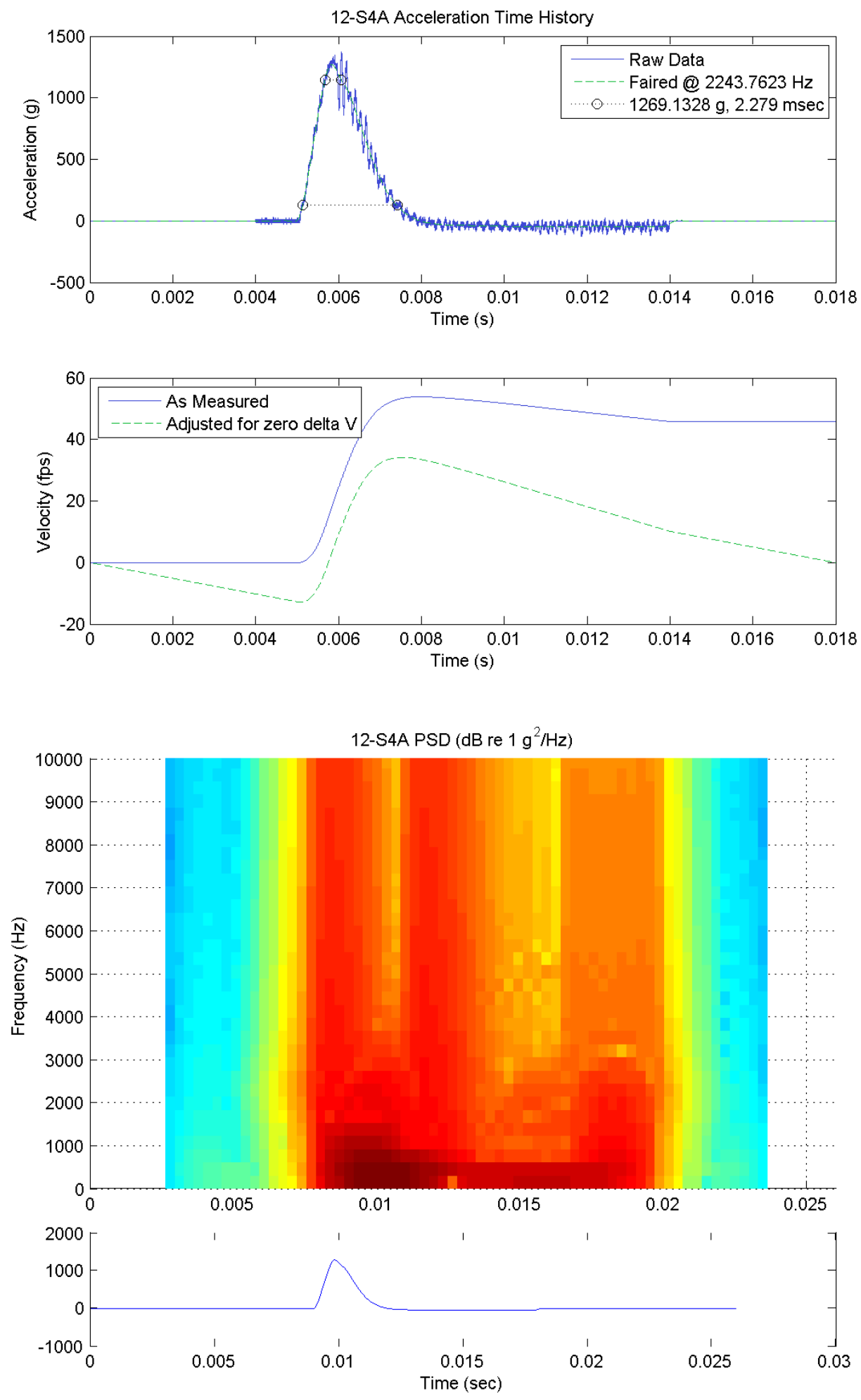

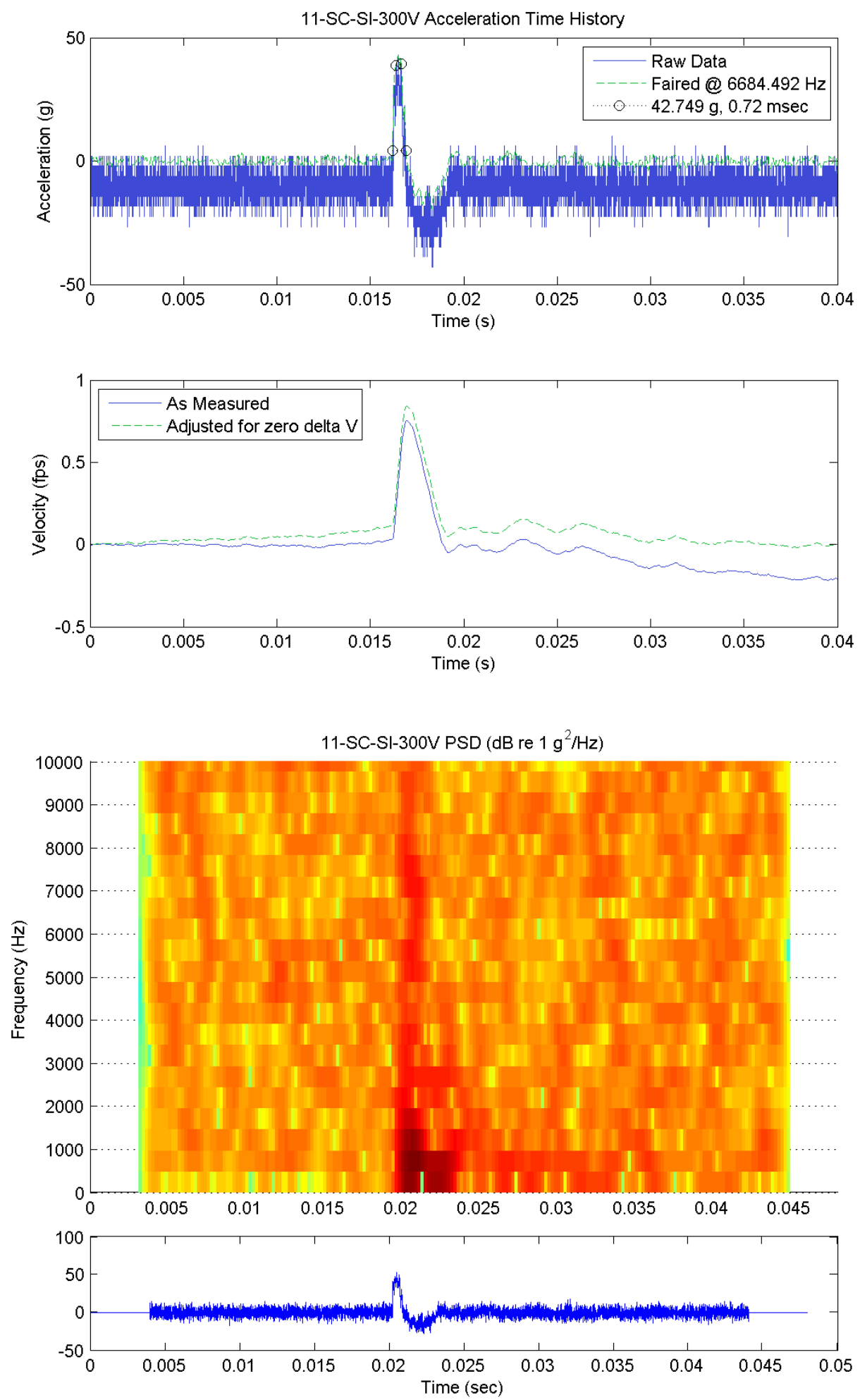

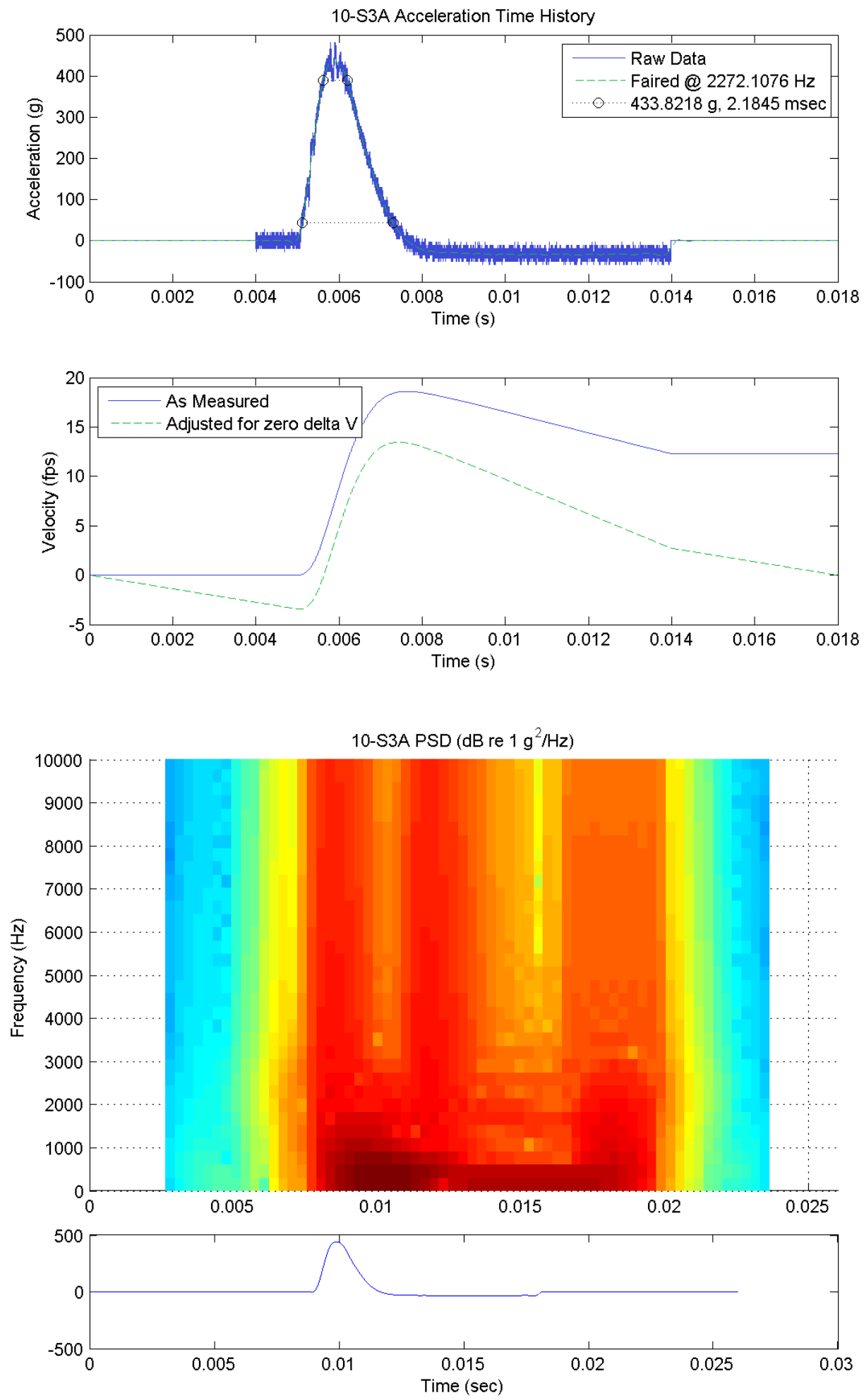

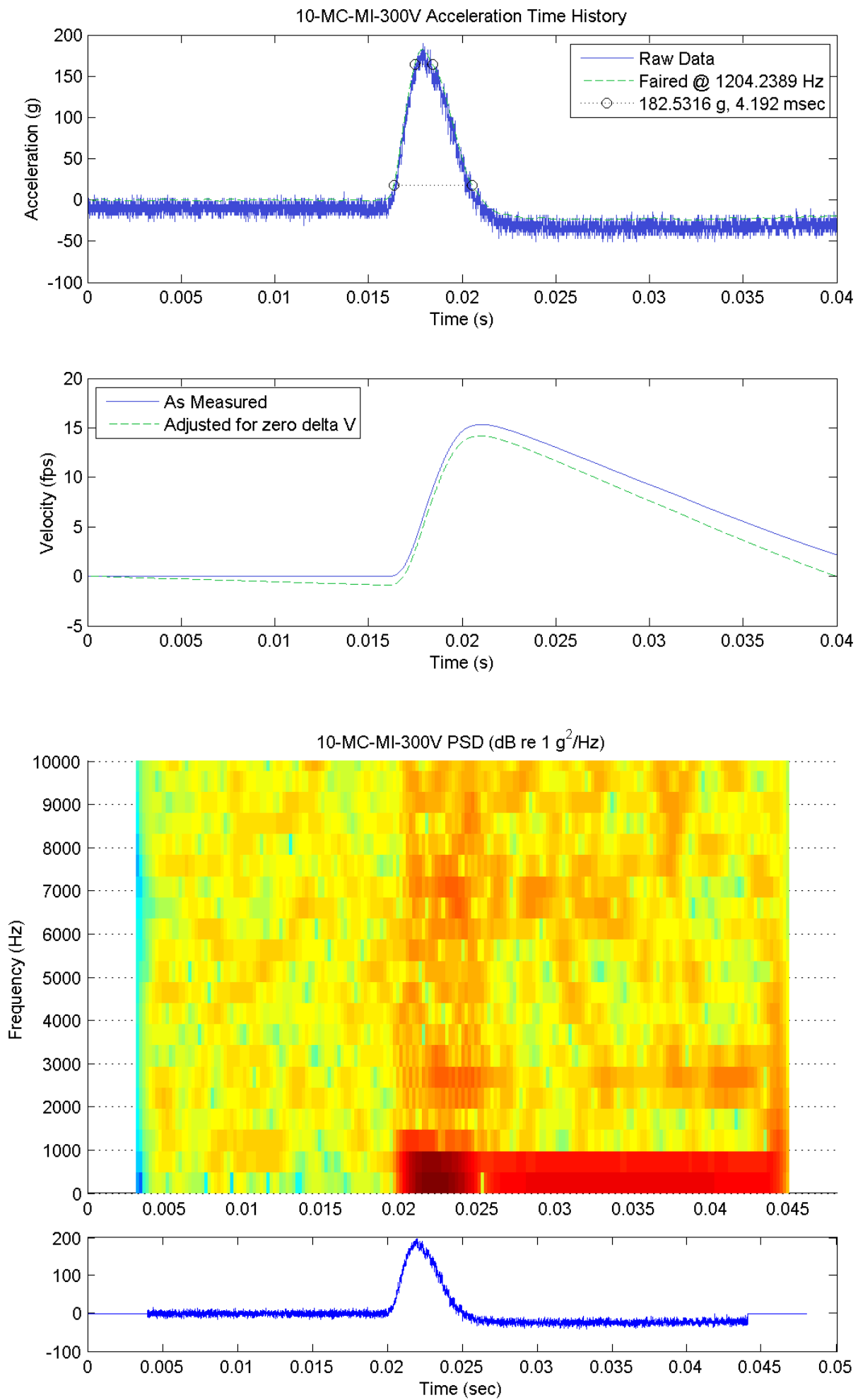

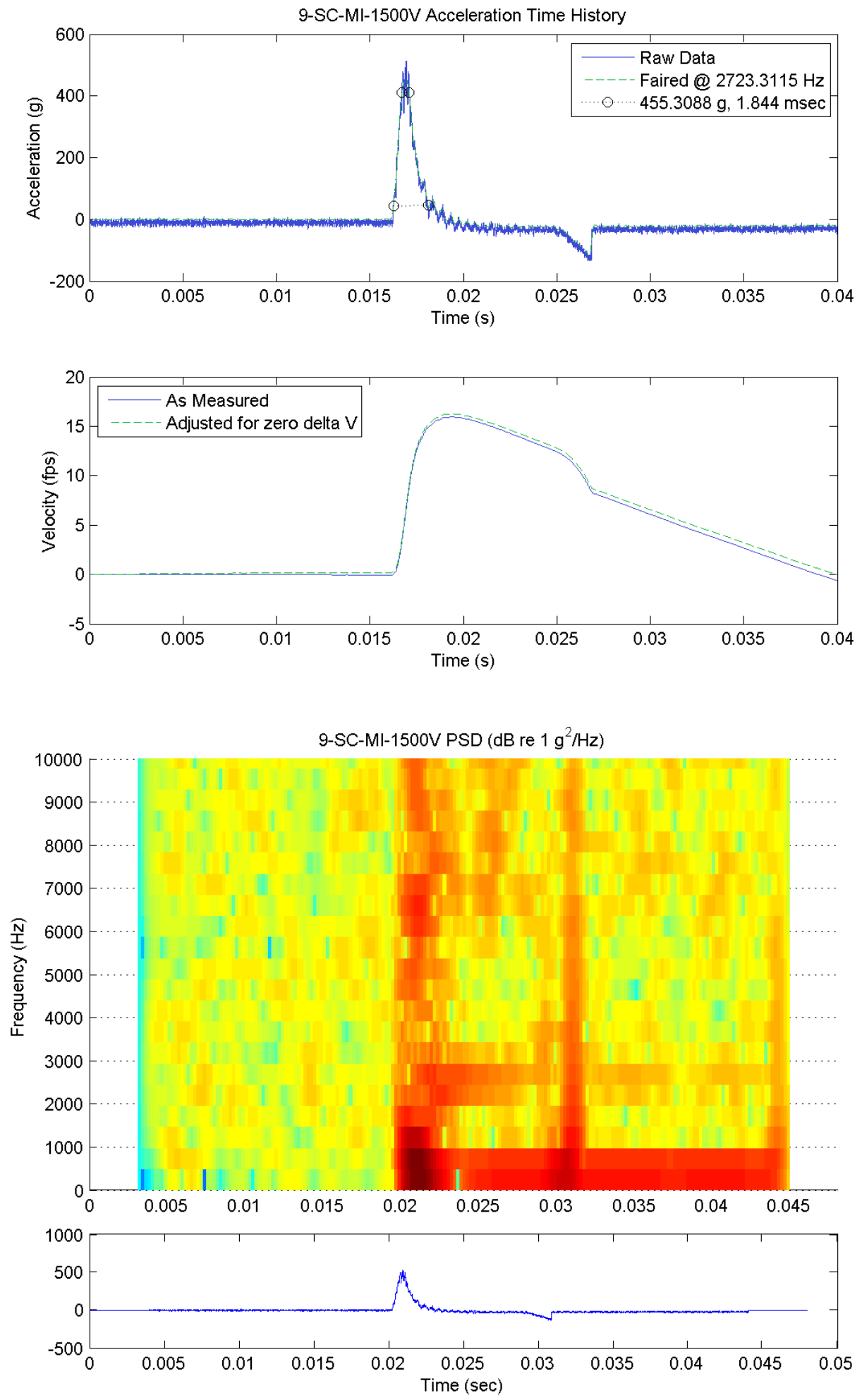

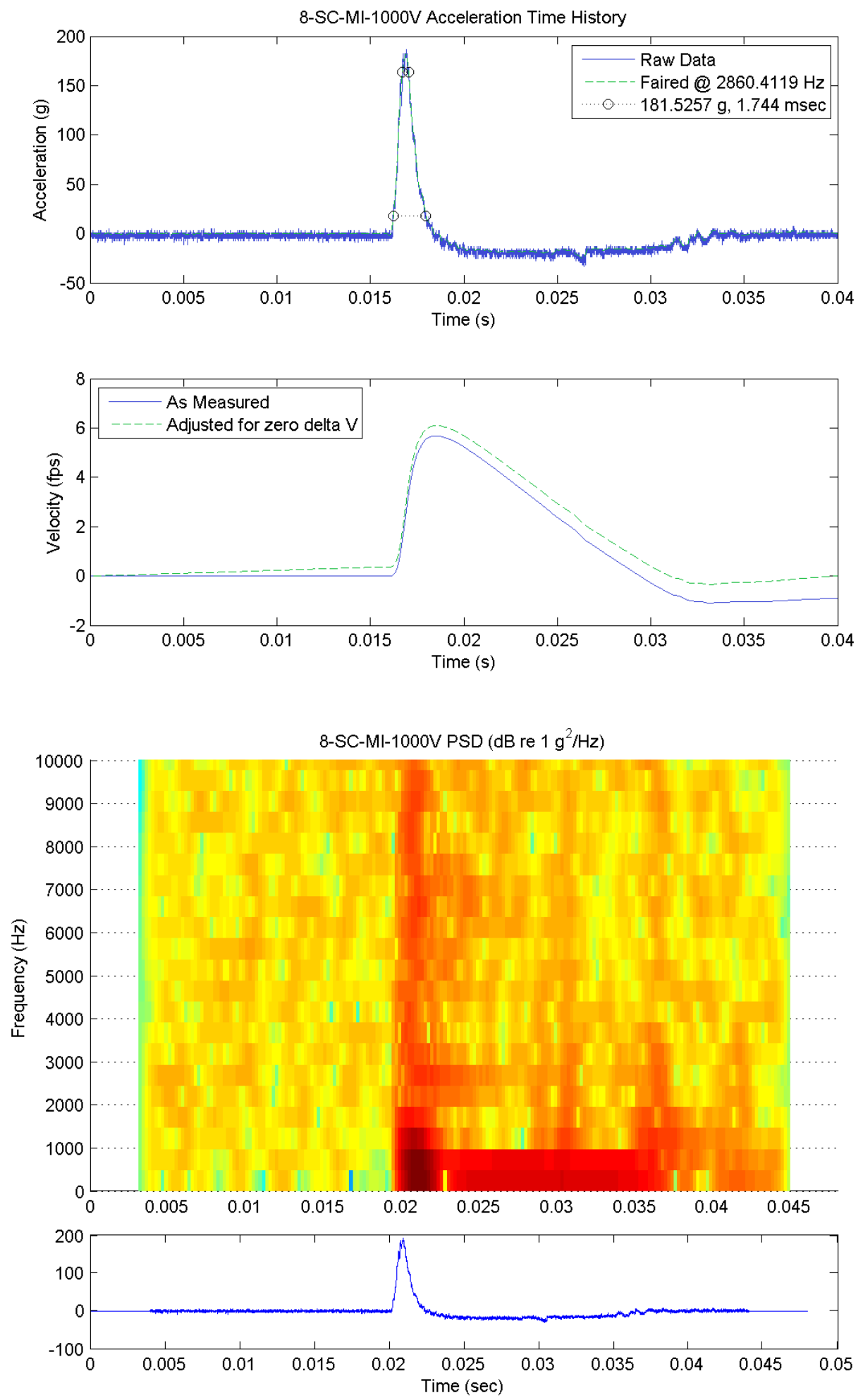

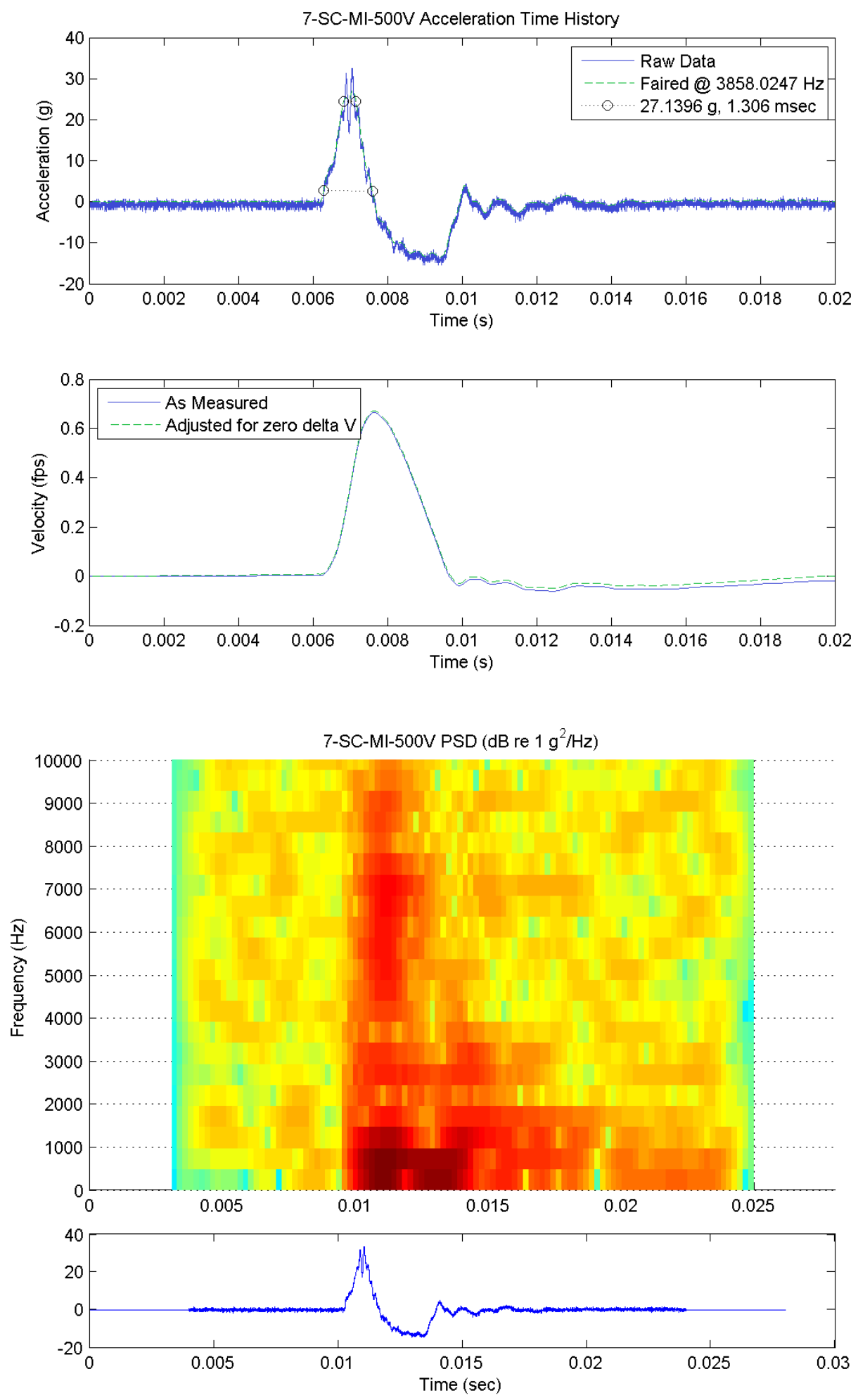

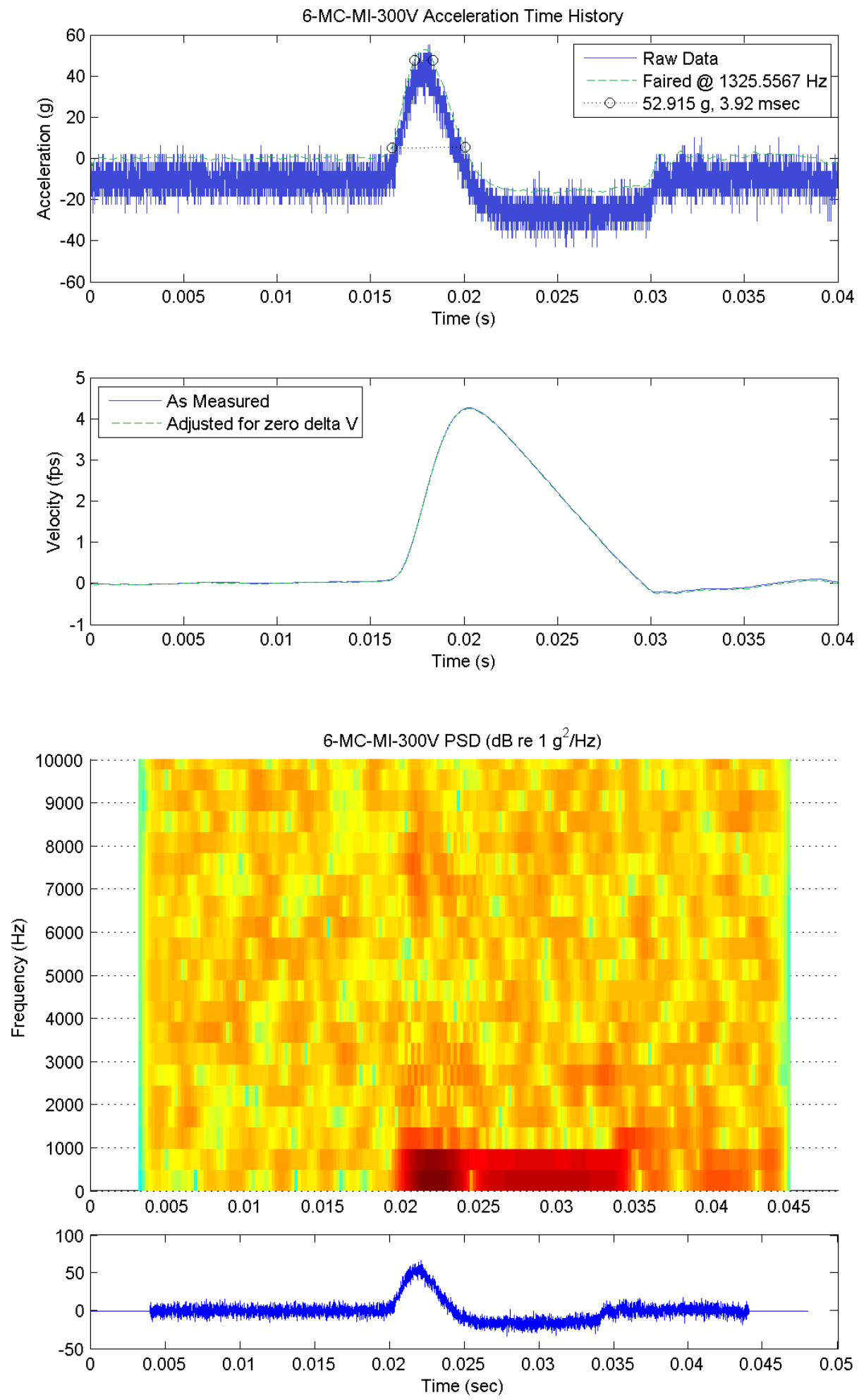

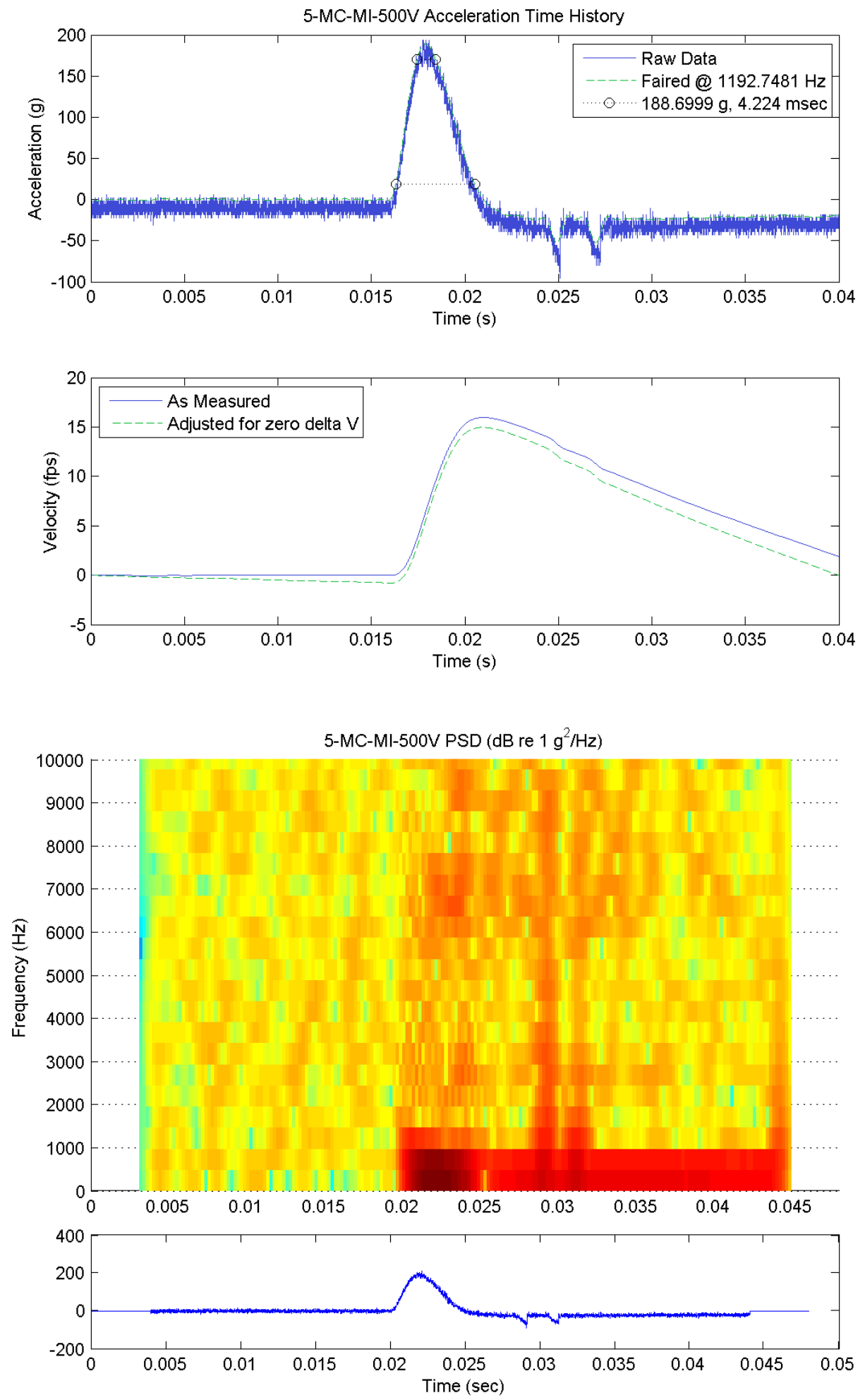

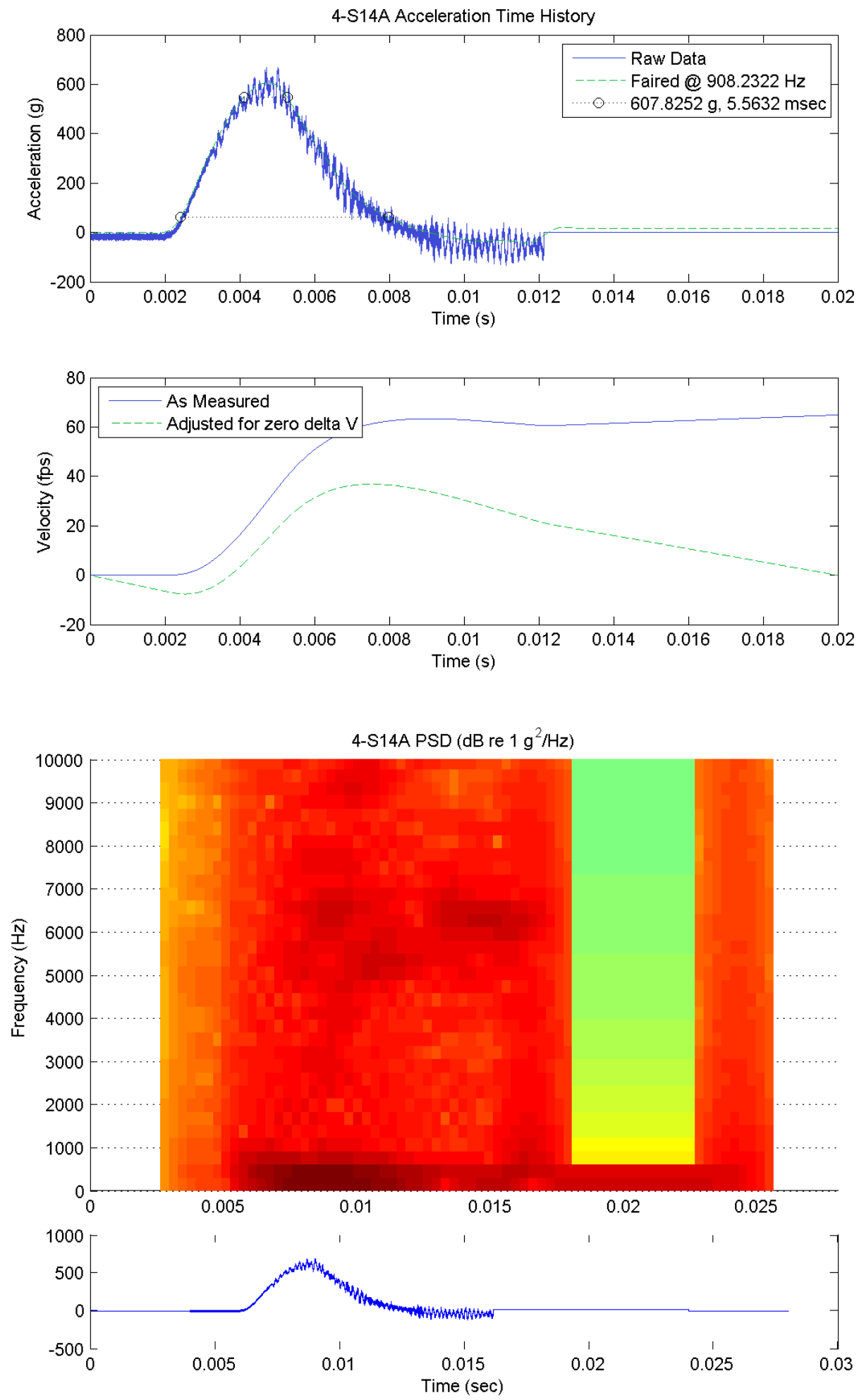

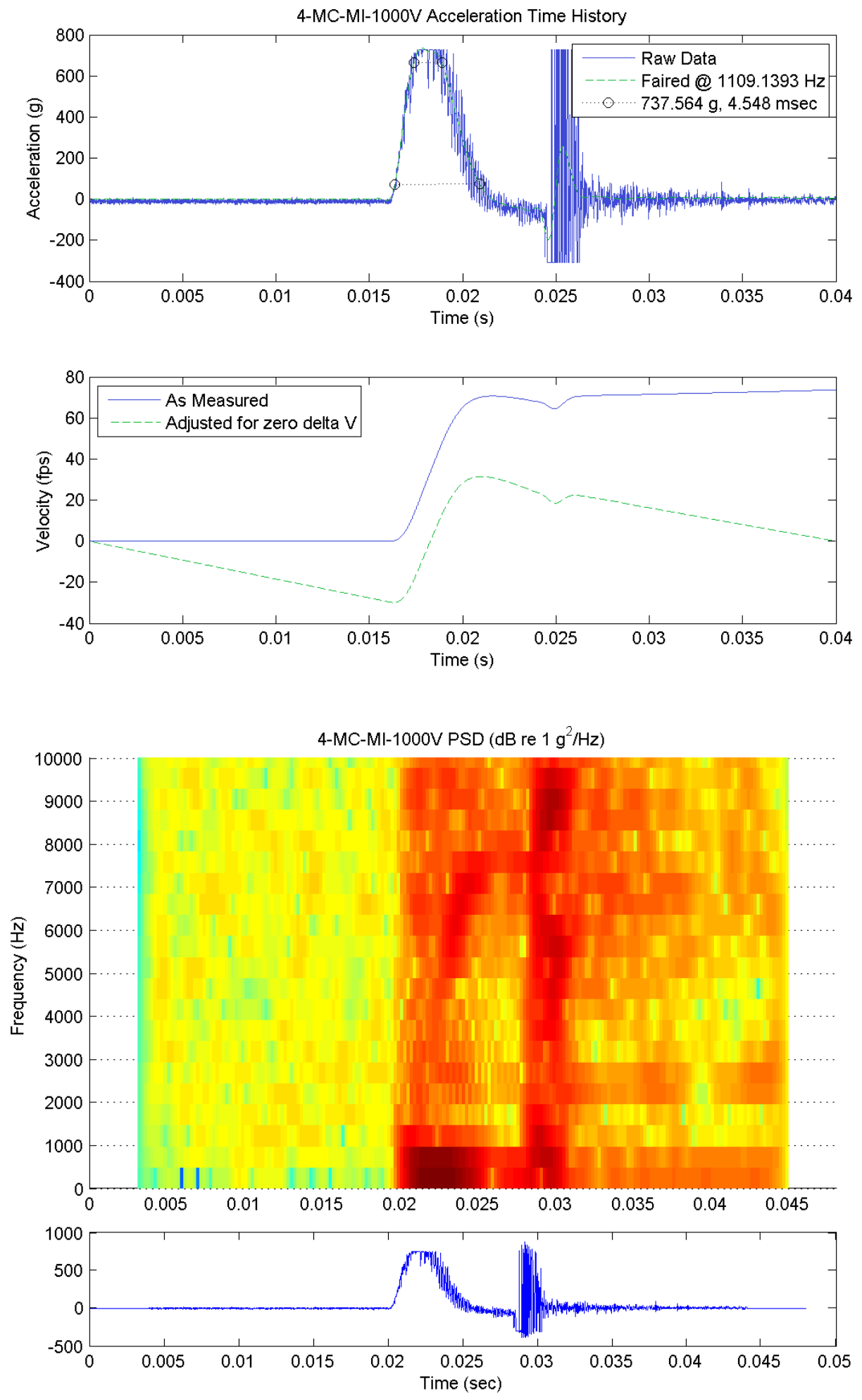

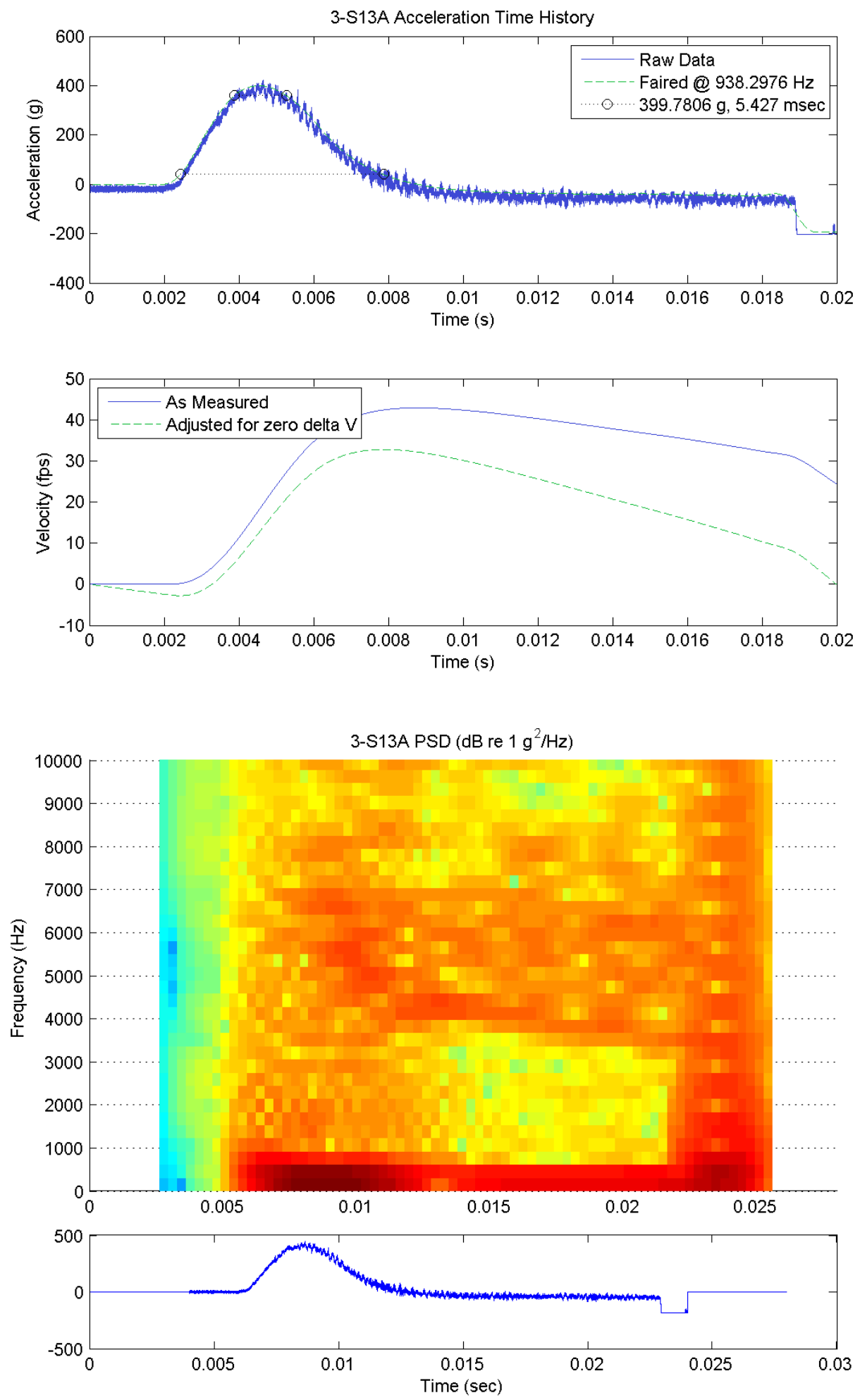

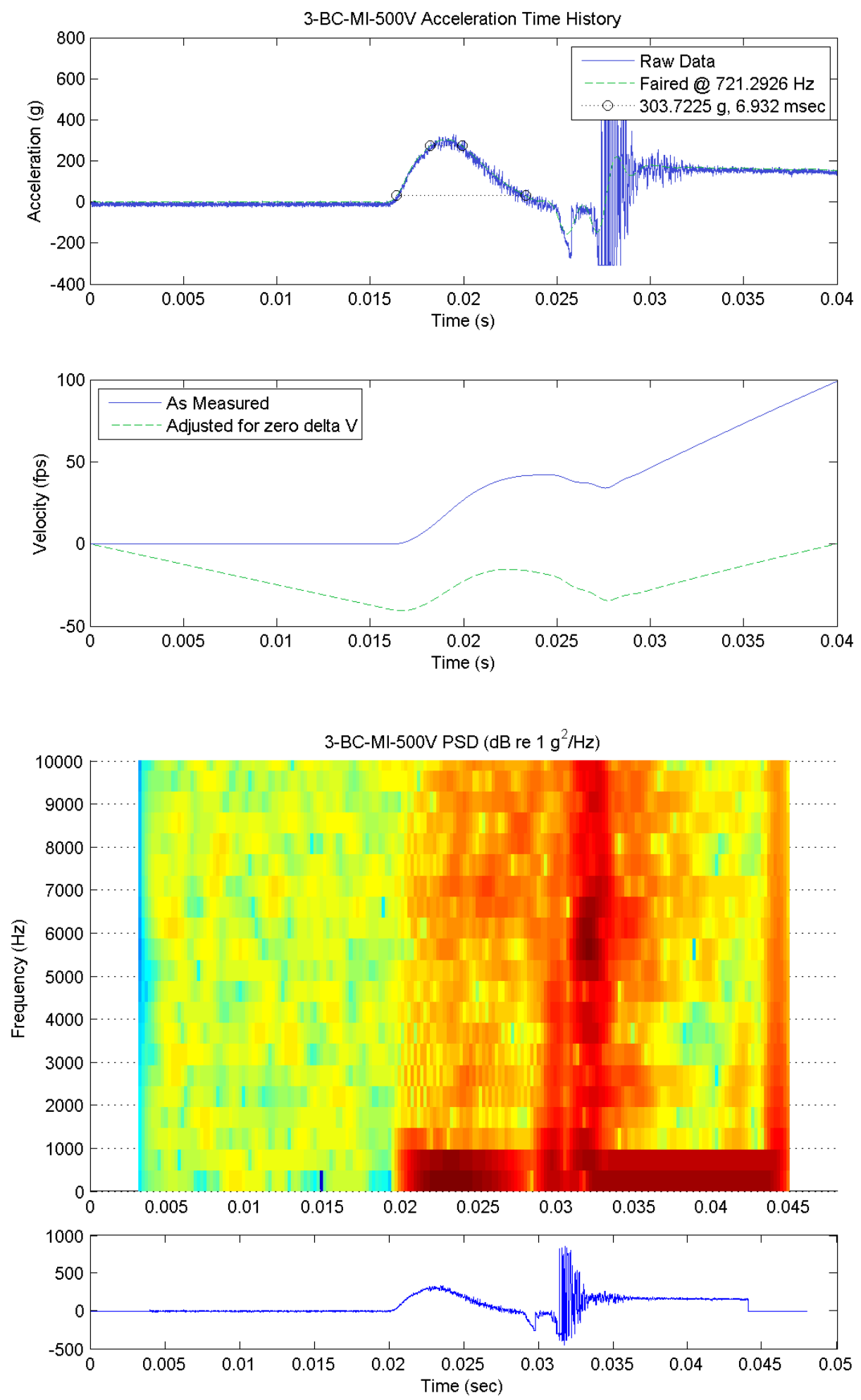

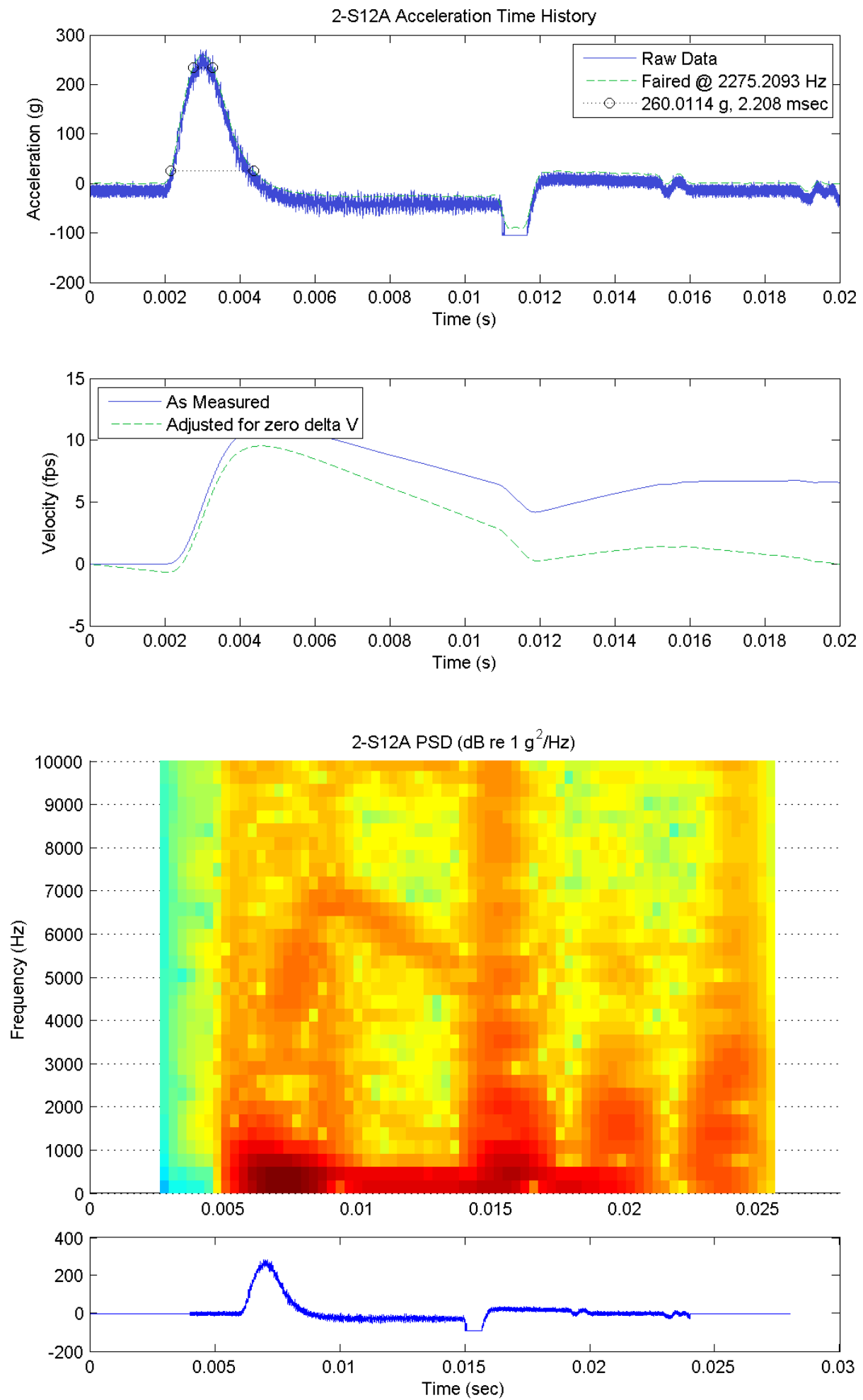

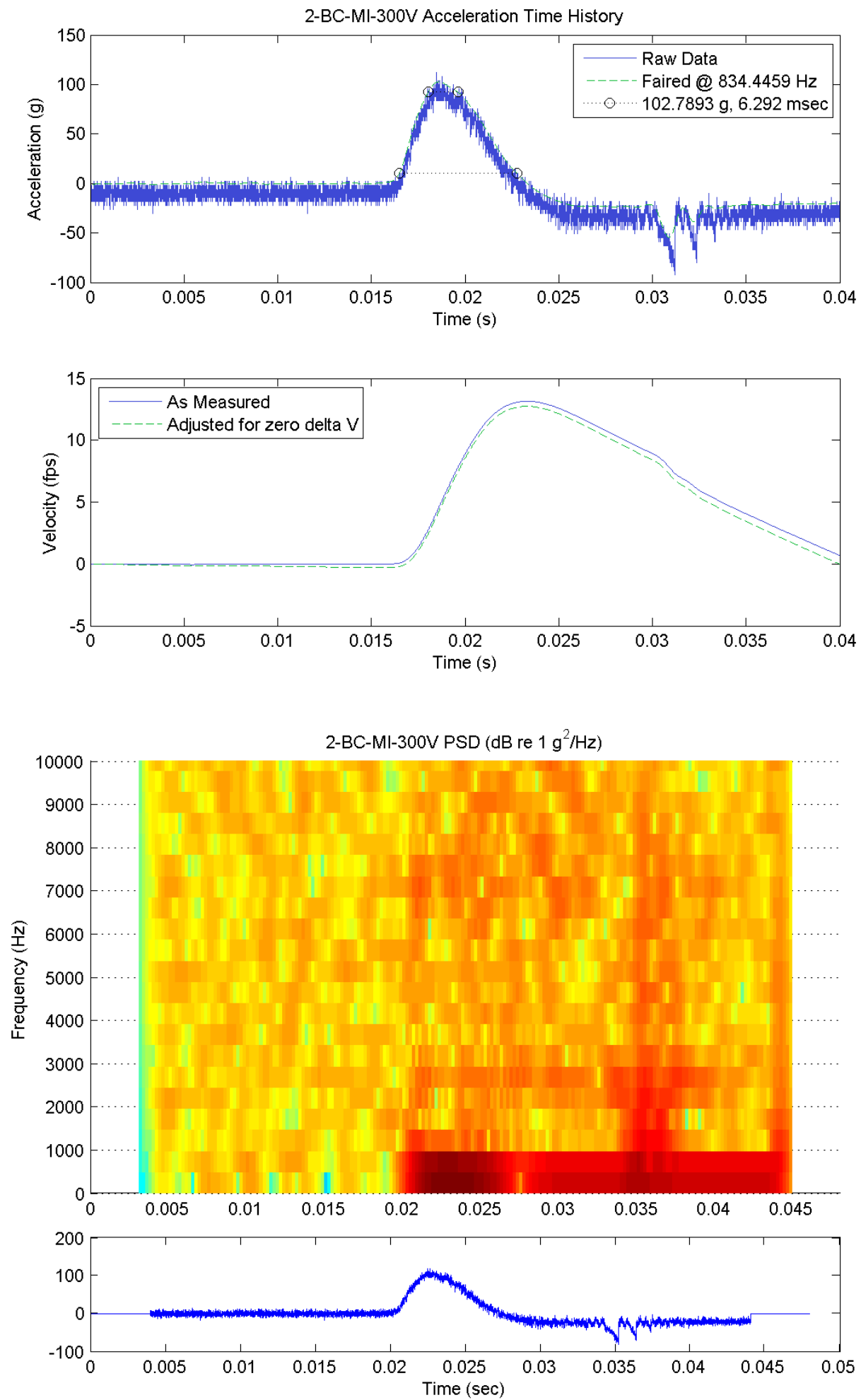

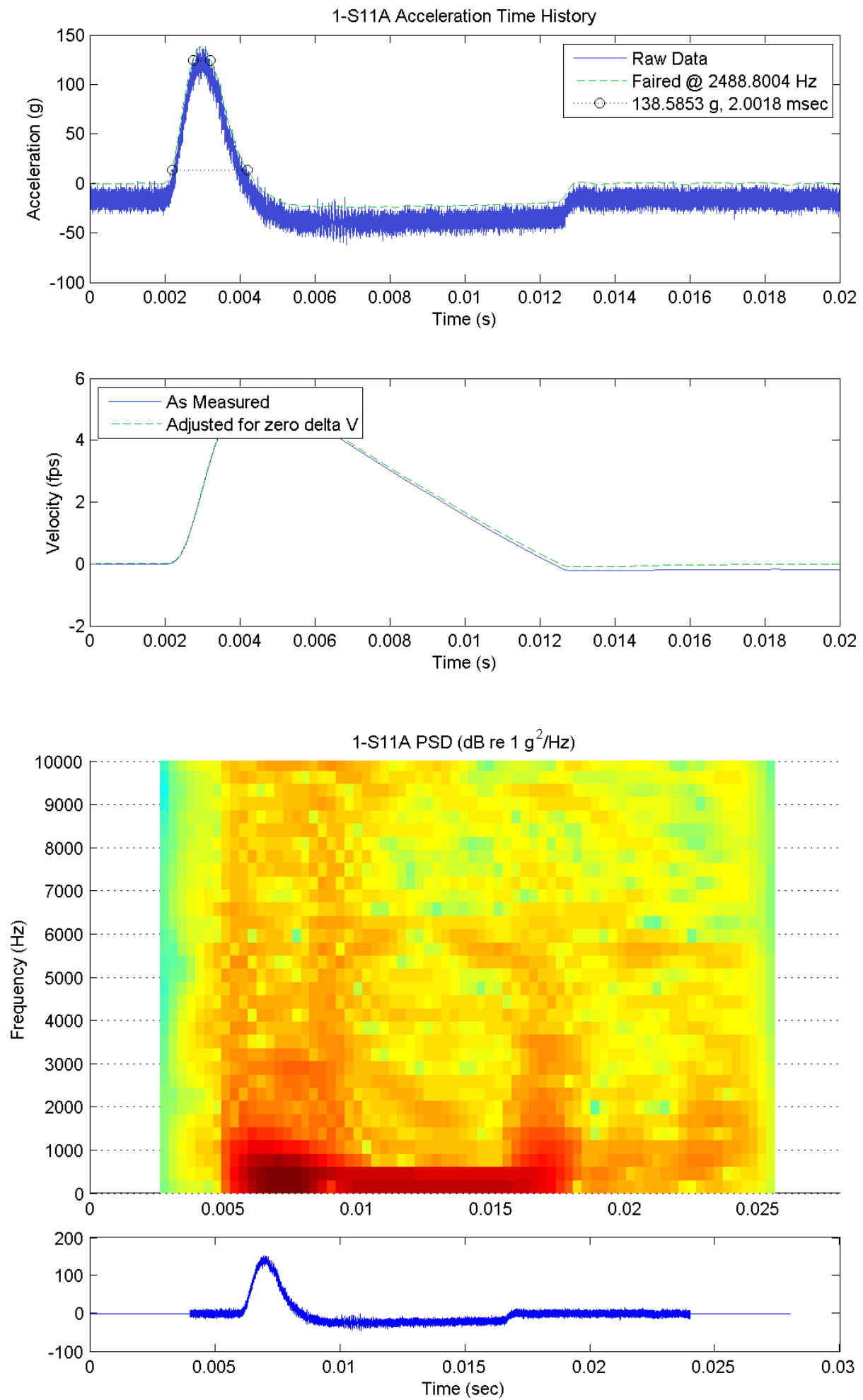


\subsection{THE PFN COMPARED TO PIANO AND OTHER INSTRUMENTS}

Below are the 'notes' the pulse forming network played. Red signifies meeting shape criteria.

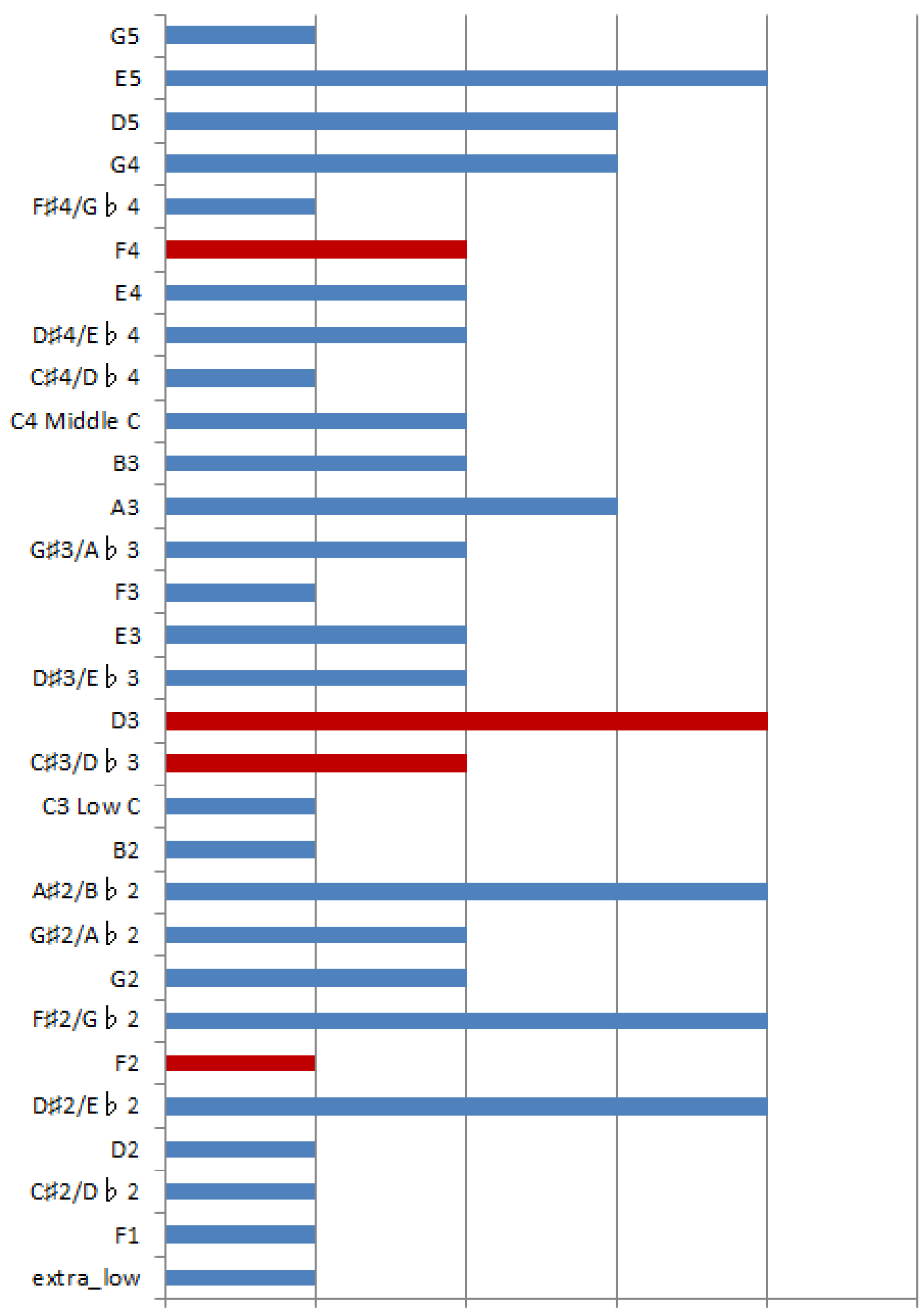


The same notes from p. 189 in comparison to other instruments [58].
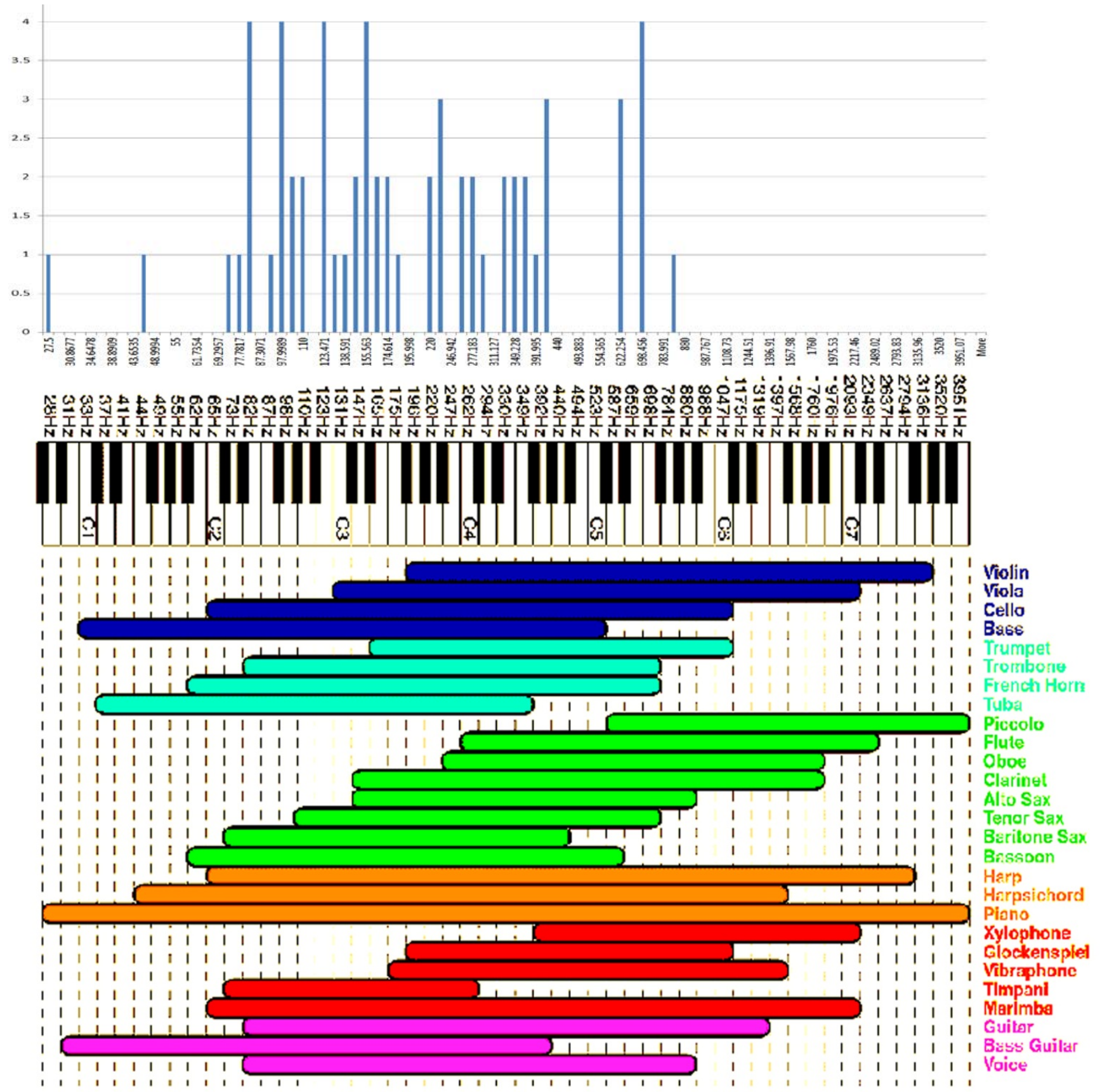


\subsection{UNITED STATES GOVERNMENT CLAIM}

This work has been funded by Honeywell Federal Manufacturing \& Technologies under Contract No. DE-NA0000622 with the U.S. Department of Energy. The United States Government retains and the publisher, by accepting the article for publication, acknowledges that the United Stated Government retains a nonexclusive, paid-up, irrevocable, world-wide license to publish or reproduce the published form of this manuscript, or allow others to do so, for United Stated Government purposes. 


\section{REFERENCES}

[1] UN report - ITU World Telecommunication /ICT Indicators database

[2] http://www.lansmont.com/techtalk/bak/techtalk_vits_bak.htm - with permission

[3] Environ Data sheet - www.envirotronics.com - with permission

[4] http://www.lansmont.com/shocktest/default.htm - with permission

[5] Hartwig, T., Hower, B., and Seaholm, A., " Adjustable Shock Test Sled for Haversine Pulses

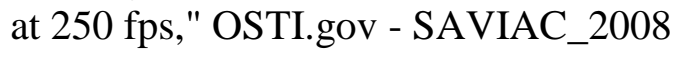

[6] Hartwig, T., Hower, B., and Seaholm, A., " Using ABAQUS and Customized Simulation Advisor to Model High Impact Test Sled," Proceedings, 2004 Abaqus Users Conference. ABAQUS Users Conference, June 2004, pp 303-317.

[7] Clarence W. de Silva, “Vibration Monitoring, Testing, and Instrumentation,” CRC Press, Boca Raton, FL 2007

[8] Clarence W. de Silva, "Vibration and Shock Handbook,” CRC Press, Boca Raton, FL 2005

[9] http://www.millitech.com/News.htm - with permissions

[10] http://www.thermotron.com - with permissions

[11] Plummer, A.R., "Modal control for a class of multi-axis vibration table," UKACC Control 2004 Mini Symposia , vol., no., pp.111,115, 8-8 Sept. 2004

[12] http://www.spectrum-technologies.com/0606multi-axis.asp.htm - with permissions

[13] Underwood, Marcos A. ; “The Adaptive Control of Multi Exciters using a Frequency Domain Approach,” Ph.D. Dissertation, U.C.L.A. School of Engineering and Applied Sciences. 1993

[14] Meagher T. F., “A High-Energy Shock Facility Using Electromagnetic Energy,” Sandia Corp Reprint. http://www.ece.unm.edu/summa/notes/FPN/FPN\%201.pdf

[15] Meagher, T.F., “THE CONVERSION OF ELECTROMAGNETIC ENERGY INTO SHOCK PULSES”, 5/1/1963, OSTI ID: 4687267; TID-18816; SCDC-2046; http://www.osti.gov/energycitations/product.biblio.jsp?osti_id=4687267 
[16] Timpson, E.J.; Engel, T. G., "Calibrating accelerometers using an Electromagnetic Launcher," Instrumentation and Measurement Technology Conference (I2MTC), 2012 IEEE International , vol., no., pp.1027,1032, 13-16 May 2012 doi: 10.1109/I2MTC.2012.6229531

[17] Timpson, E. J., Engel, T.G., "Experimental Evaluation of Helical Electromagnetic Launchers for Electronically Programmable Shock Pulses," The $83^{\text {rd }}$ SAVE, 2012

[18] Stephen J. Chapman, Electric Machinery Fundamentals, McGraw-Hill, 1221 Avenue of the Americas, New York, NY 10020, (C) 2005, ISBN 0-07-246523-9, p. 324

[19] David Brown, E.P. Hamilton III, Electromechanical Energy Conversion, (C) 1984, Macmillan publishing company, ISBN 0-02-315590-6, p. 66

[20] Syed A. Nasar, Electric Machines and Power systems, volume 1 electric machines, McGraw-Hill, Inc. C) 1995, ISBN 0-07-045958-4,

[21] Austin Hughes, Bill drury, Electric Motors and Drives Fundamentals, Types, and Applciations, (C) 2013, Published by Elsevier Ltd. ISBN 978-0-08-098332-5, p. 96

[22] Scanlon, J.J., III; Batteh, J.H.; Chryssomallis, G.; , "Tactical applications for electromagnetic launchers," Magnetics, IEEE Transactions on , vol.31, no.1, pp.552-557, Jan 1995 doi: 10.1109/20.364634

[23] McNab, I.R.; , "Launch to space with an electromagnetic railgun," Magnetics, IEEE Transactions on , vol.39, no.1, pp. 295- 304, Jan 2003 doi: 10.1109/TMAG.2002.805923

[24] Wang Ying, Richard A Marshall, Cheng Shukang, Physics of Electric Launch, EML Book 1, Science Press, 16 Donghuangchenggen North Street, Beijing 100717, China, 2004, ISBN 7-03-012821-4

[25] Richard A Marshall, Wang Ying, Railguns: their Science and Technology, EML Book 2, China Machine Press, 22 Baiwanzhuang Rd., Beijing 100037, China, 2004, ISBN 7-11114013-3

[26] Engel, T.G.; Nunnally, W.C.; Gahl, J.M.; , "Efficiency and Scaling in DC Electromagnetic Launchers," Pulsed Power Conference, 2005 IEEE , vol., no., pp.249-252, 13-17 June 2005 doi: 10.1109/PPC.2005.300589

[27] Engel, T.G.; Neri, J.M.; Nunnally, W.C.; , "A Same-Scale Comparison of Electromagnetic Launchers," Power Modulator Symposium, 2006. Conference Record of the 2006 TwentySeventh International , vol., no., pp.405-410, 14-18 May 2006 doi: 10.1109/MODSYM.2006.365270 
[28] Engel, T.G.; Veracka, M.J.; Neri, J.M.; , "The Specific-Force Performance Parameter for Electromagnetic Launchers," Plasma Science, IEEE Transactions on , vol.38, no.2, pp.194198, Feb. 2010 doi: 10.1109/TPS.2009.2036260

[29] Engel, T.G.; Neri, J.M.; Veracka, M.J.; , "Solid-Projectile Helical Electromagnetic Launcher," Plasma Science, IEEE Transactions on , vol.37, no.4, pp.603-607, April 2009 doi: 10.1109/TPS.2009.2012714

[30] Engel, T.G.; Veracka, M.J.; , "Solid-Projectile Helical Electromagnetic Launcher With Variable Gradient Stator and Magnetically Levitated Armature," Plasma Science, IEEE Transactions on , vol.39, no.12, pp.3371-3377, $\quad$ Dec. 2011 doi: 10.1109/TPS.2011.2168570

[31] Glasoe G.N. and Lebacoz J. V., “Pulse Generators,” McGraw-Hill Book Company, INC., New York \& London, Printed in the USA, 1948 Chapter 6, p. 175.

[32] Louis Weinberg, “Network Analysis and Synthesis,” McGraw-Hill Book Company, Inc. New York, 1969

[33] Bouche, R.R., "Calibration of Shock and Vibration Measuring Transducers," Navel Research Laboratory, 1979, pp. 12 \& 144-151, 1979

[34] Bateman, V.I.; Leisher, W.B.; Brown, F.A.; Davie, N.T., "Calibration of a Hopkinson bar with a transfer standard," Presented at the $62{ }^{\text {nd }}$ Shock and Vibration Symposium, Springfield, VA, Oct. 1991

[35] Bateman, V.I.; Brown F.A.; Davie N.T., "Use of a Beryllium Hopkinson Bar To Characterize a Piezoresistive Accelerometer In Shock Environments,” Journal of the Institute of Environmental Sciences, vol. 39, no. Nov. 1996

[36] M. W. Frazier, “An Introduction to Wavelets through linear algebra,” Springer (C) 1999 Springer-Verlag New York, ISBN 0-387-98639-1

[37] Paul W. Smith, Transient Electronics Pulse Circuit Fundamentals, (C) 2002 John wiley \& Sons Ld. ISBN 0-471-97773-X

[38] Polytechnic Institute of Brooklyn, "Proceedings of the Symposium on Modern Network Synthesis,” Polytechnic Institute of Brooklyn, 1952, New York, NY

[39] Myril B. Reed, “Electric Network Synthesis, Image Parameter Method” Prentice-Hall, Inc. Englewood Cliffs, N.J. 1955 
[40] E. Folke Bolinder, “An Evaluation of an Important Advance in Network Synthesis Theory,” Office of Aerospace Research, Bedford, Massachusetts, 1965

[41] Norman Balabanian, “ Network Synthesis,” Englewood Cliffs, N.J. Prentice-Hall, Inc. 1958

[42] David F. Tuttle, Jr.,’Network Synthesis,” John Wiley \& Sons, Inc., New York 1958 (Standford)

[43] Kendall L. Su, “Active Network Synthesis,” McGraw-Hill Book Company, St. Louis, 1965 (Georgia Tech.)

[44] Norman Balabanian, “Linear Network Theory,” Matrix Publishers, Inc. Beaverton, Oregon 1981

[45] H. Baher, “Synthesis of Electrical Networks,” John Wiley and Sons, Chichester, 1984

[46] Ewell, G.W.; McCune, E.; Wallace, T.V., "Protection of medium-power pulse klystrons," Power Modulator Symposium, 1990., IEEE Conference Record of the 1990 Nineteenth , vol., no., pp.44,51, 26-28 Jun 1990 doi: 10.1109/MODSYM.1990.201029

[47] Kekez, M.M., "A compact square wave 15 kJ generator: <15 ns rise-time; 7.5 ohms load impedance; and, pulse width 100-500 ns," Pulsed Power Plasma Science, 2001. IEEE Conference Record - Abstracts , vol., no., pp.277,, 17-22 June 2001

doi: 10.1109/PPPS.2001.960922

[48] Kaesler, W., "20-MW-long-pulse solidstate-klystron modulator," Pulsed Power Plasma Science, 2001. IEEE Conference Record - Abstracts , vol., no., pp.335,, 17-22 June 2001 doi: 10.1109/PPPS.2001.961019

[49] Huenefeldt, Shawn Ma, “A 750 KJ sequentially-fired pulse forming network for a helical coil electromagnetic launcher,” Masters Thesis, University of Missouri - Columbia, 2006

[50] Kontras, Evan A., "Projectile vibration analysis of an electromagnetic launcher,” Masters Thesis, University of Missouri - Columbia, 2013

[51] C.M. Harris, C. E. Crede, “The Shock and Vibration Handbook,” McGraw-Hill Book Company, INC., New York, 1961

[52] Evaluation of measurement data - Guide to the expression of uncertainty in measurement, JCGM 100:2008

[53] Kuyatt, C.E.; Taylor, B.N., "Guide for Evaluating and Expressing the uncertainty of NIST Measuremet Results” NIST Technical Note 1297, 1994 
[54] Engel T. G., Veracka, M.J., Timpson E. "Development of a Reversible Helical Electromagnetic Launcher,” To be published in $17^{\text {th }}$ EML symposium, July 2014

[55] Engel T. G., "Voltage and Current Scaling Relationships for Electromagnetic Launchers," To be published in $17^{\text {th }}$ EML symposium, July 2014

[56] Timpson, E., Knotras, E., Miniature HEMLs for implantable sensor. Internal Report.

[57] http://phys.org/news/2011-09-world-smallest-electric-motor-molecule.html

[58] http://en.audiofanzine.com/dossiers_v3/making_a_studio/part2/piano_frequency_chart.jpg with permission. 


\section{VITA}

This Vita will recapitulate and cover the time from the last Vita, in the last pages of the thesis titled, “Experimental Evaluation of Intravascular Flow Meter and Miniature RFID Antennas Using MEMS Pressure Sensors and Flexible PCD Techniques,” published January 17, 2012. Erik Joseph Timpson was born in Salt Lake City, Utah. He received an Associate’s degree in Engineering at Longview Community College and a Bachelor's Degree in Electrical Engineering magna cum laude with Honors and minors in Math, Physics and Biology from University of Missouri-Rolla. He received a Master’s Degree from UMKC in 2011.

Academically, Erik had a number of leadership roles. Fueled by an intrinsic desire to help people, he tutored and taught many subjects including Calculus, Physics, and Computer Engineering. Driven by curiosity, he has researched many areas including Plasma Physics, Mycology, Sensors, MEMS, Antennas, Biocompatibility, Pulse Power and Electromagnetic Launchers. He considers experimentation, instrumentation, measurements and the uncertainty calculations therein to be paramount to the progression of man-kind.

Professionally, Erik is established. He worked for Sprint, the telecommunications company, from 2001 to 2008. In 2008, he left Sprint to work for Honeywell Federal Manufacturing and Technology (FM\&T) as a Metrology Engineer. In 2009, he became a Professional Engineer. In 2011, he was selected for a Technology Fellowship to pursue a PhD.

He documented in his master's thesis that his greatest inspiration is Emery Gold and now he considers Anabella Marie to be just as inspirational. Lord only knows if more inspirations are to come. 